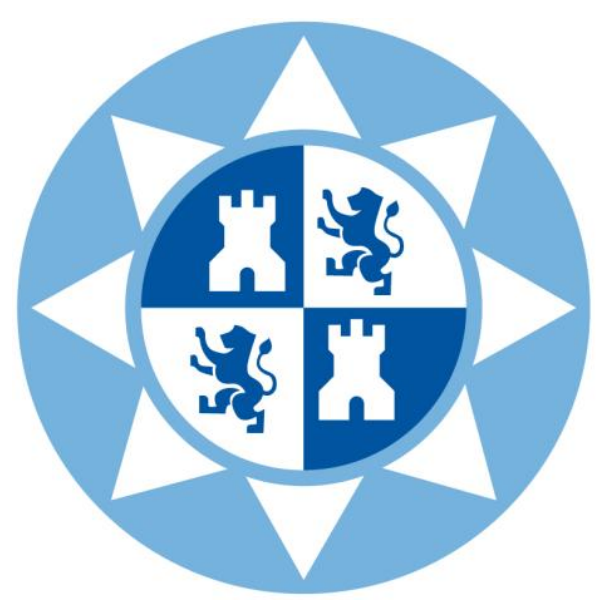

Universidad Politécnica de Cartagena

Departamento de Producción Vegetal

\title{
Biosolarización de invernaderos para cultivos de pimiento: manejo de patógenos y fatiga del suelo.
}

\author{
María del Mar Guerre ro Díaz
}

\author{
Director
}

Dr. Alfredo Lacasa Plasencia 



\section{AGRADECIMIENTOS}

Cualquiera que lea este trabajo con detenimiento y atención se dará cuenta que detrás no está solo mi esfuerzo y trabajo, sino el de muchísima gente.

Lo importante de esta tesis no es que los trabajos que aquí se presentan sirvan para que haya un nuevo doctor, en este caso doctora. Lo importante es que han contribuido a solucionar importantes problemas reales de gente que, a pesar de todo sigue viviendo de este difícil oficio o mejor llamado, Ciencia, que es la Agricultura. Por lo tanto gracias a todos los agricultores que han cedido lo más valioso que tienen con absoluta confianza en nosotros.

A todas y todos mis compañeros del departamento de Biotecnología y Protección de cultivos, y de otros departamentos del IMIDA. Obviamente éste también es vuestro trabajo.

A Santiago y Mireia por facilitarme el requisito imprescindible, y muchas más cosas.

Al Dr. Julio C. Tello Marquina también una parte importante de esta tesis se debe a sus años de trabajo.

A mi tutora en la UPCT, que además es mi amiga.

A los que la leerán con interés y a los que ya no podrán leerla. Gracias.

Y por supuesto,

A Alfredo Lacasa Plasencia, por hacerme entender que la fitopatología no solo se aprende detrás de un microscopio o de una lupa y que el campo no solo son plantas. Por seguir confiando en mí, por continuar enseñándome, y por hacer que ir a trabajar cada día sea un placer. GRACIAS.

A mis padres, por seguir pensando, a pesar de todo, que con esfuerzo y honradez se consiguen los deseos.

A todos los que embellecéis mi vida, y este grupo afortunadamente es muy grande. 



\section{RESUMEN}

El cultivo de pimiento supone una parte importante de la economía agrícola de la Región de Murcia, en particular en la comarca del Campo de Cartagena donde ha llegado a ocupar unas 2000 ha de invernaderos. Las prácticas agrícolas de monocultivo han provocado una fuerte especificidad de importantes patógenos como Phytophthora spp., productora de la "tristeza del pimiento" y Meloidogyne incognita, que llegan a ser factores limitantes para este cultivo, por la importancia de las pérdidas que ocasionan.

La prohibición del bromuro de metilo por su efecto nocivo en el medio ambiente, utilizado todos los años para desinfectar los suelos de los invernaderos del cultivo de pimiento, ha provocado una búsqueda incesante de alternativas que fueran sostenibles y duraderas. Para eso eran necesarios estudios actualizados de los patógenos principales y de las circunstancias actuales del cultivo, en particular sobre el causante de la muerte de plantas, sobre las características de la fatiga del suelo y sobre la biosolarización (biofumigación con solarización) como método de desinfección de los suelos.

-Se ha realizado la caracterización del patógeno causante de la "marchitez o tristeza del pimiento" como paso previo al establecimiento de estrategias de control por medios no químicos, comprobando una evolución de especies a lo largo del tiempo, que había pasado inadvertida. Se han utilizado aislados obtenidos de plantas enfermas de pimiento en varios invernaderos y en distintas anualidades entre 1997 y 2006. Los estudios morfológicos, fisiológicos y de patogeneicidad han permitido poner de manifiesto que la especie predominante de Phytophthora en los invernaderos del Campo de Cartagena es $P$. parasitica, lo que contrasta con estudios precedentes en los que $P$. capsici era la especie mayoritariamente encontrada. Las variaciones observadas hacen plantearse preguntas sobre las causas que han originado o facilitado los cambios, que parecen consolidados.

-En condiciones controladas y estudiando suelos de invernaderos con diferentes antecedentes de antigüedad del monocultivo y forma de desinfección, se ha caracterizado la fatiga del suelo, que provoca grandes pérdidas debido al monocultivo de la zona, utilizando como indicadores el pimiento, el apio y la lechuga. Se ha encontrando una importante especificidad para el pimiento debida a la componente microbiológica seleccionada a lo largo del ciclo de cultivo o de permanencia de las plantas en el invernadero.

-Desde la prohibición del bromuro de metilo en 2005 se han venido evaluando distintas enmiendas para utilizar como biofumigantes intentando encontrar las más adecuadas para el control de patógenos, sin tener que alterar el ciclo habitual del cultivo de pimiento en las zonas del sur de Alicante y Campo de Cartagena, así como evaluar su eficacia desinfectante para el control de los dos principales patógenos en el tiempo. La biosolarización con estiércoles frescos iniciada en agosto proporciona resultados satisfactorios para el limitar la incidencia de la "tristeza del pimiento", e inciertos para el control de Meloidogyne incognita. Algunas enmiendas mejoran los efectos de la biosolarización con estiércoles, cuando se inicia la desinfección en octubre coincidiendo con el final del ciclo habitual del cultivo, si bien los niveles de control de Phytophthora spp. y Meloidogyne incognita son insuficientes en algunos invernaderos y años. 



\begin{abstract}
Sweet pepper crops represent an important part of the agricultural economy of the province of Murcia. This is particularly true in the Campo de Cartagena region, where its cultivation occupies 2000 ha of greenhouses. However, the monoculture of sweet pepper has led to the presence of specific pathogens such as Phytophthora spp., the cause of an important disease and Meloidogyne incognita, which have become limiting factors for the crop and the cause of serious economic losses.
\end{abstract}

The prohibition of methyl bromide because of its harmful effect on the environment following years of use to disinfect the soils in which pepper has been cultivated, has led to the search for alternatives that are both sustainable and lasting. For this reason it is so important to update our knowledge of the main pathogens involved and cultivation techniques used, particularly those causing plant death, the characteristics of soil fatigue and on the biosolarization (biofumigation plus solarization) as a methodology for disinfecting the soils.

We characterized the pathogen causing pepper disease as a prior step to establishing non-chemical strategies for its control, observing in the process that there had been an evolution in the species involved that had passed unnoticed. Isolates obtained from diseased pepper plants from several greenhouses during the years 1997 to 2006 were used. Morphological, physiological and pathogenicity studies revealed the predominant species of Phytophthora in the greenhouses of Campo de Cartagena to be $P$. parasitica, which contrasts with previous studies in which $P$. capsici was seen to be the main species, a situation that had not been noticed until our study. The variations observed pose questions regarding the causes giving rise to or facilitating such changes which, moreover, seem to be permanent.

In controlled conditions we studied the soils of greenhouses supporting a different number of years of monoculture and the form of disinfection used in order to characterize soil fatigue, the cause of large losses, using as indicators pepper, celery and lettuce. A high degree of specificity for pepper was found due to the microbiological component selected during the crop cycle or length of time the plants had been in the greenhouse.

Since methyl bromide was banned in 2005, we have evaluated different amendments for use as biofumigation elements in order to control the pathogens while not affecting the normal crop cycle in the area south of Alicante and the Campo de Cartagena, evaluating their ability to control the two main pathogens at the same time. Biosolarization with fresh manure beginning in August provided satisfactory results as regards limiting the incidence of Phytophthora sp. wilt but not such good results for controlling Meloidogyne. Some amendments improved the effects of biosolarization with manure, when example beginning in October coinciding with the end of the normal crop cycle, although the level of control of Phytophthora spp. and Meloidogyne incognita remained insufficient in some greenhouses and in some years. 



\section{ÍNDICE}

1 ANTECEDENTES __ 1

1.1 BIBLIOGRAFÍA_ 3

2 INTRODUCCIÓN ___ 7

2.1 CARACTERÍSTICAS DEL CULTIVO DEL PIMIENTO EN LOS INVERNADEROS DE LA REGIÓN DE MURCIA

2.1.1 El pimiento en el contexto de la horticultura regional ___ 7

2.1.2 La tecnología del cultivo en los invernaderos __ 8

2.1.3 El ciclo de cultivo ___ 9

2.1.4 Las labores culturales__ 11

2.1.5 Los tipos de pimientos cultivados en los invernaderos___ 15

2.2 PROBLEMAS FITOSANITARIOS 16

2.2.1 La "seca" o "tristeza" producida por Phytophthora spp. ___ 16

2.2.2 Phytophthora spp. 17

2.2.3 La "tristeza" o "seca" 19

2.2.4 Los nematodos noduladores o agalladores_ 20

2.2.5 Meloidogyne incognita, el problema re-emergente en los invernaderos

del Campo de Cartagena ___ 21

2.2.6 La fatiga delos suelos por monocultivos reiterados _ 23

2.3 CONTROL DE LAS ENFERMEDADES DEL SUELO EN CULTIVOS DE PIMIENTO EN INVERNADERO__ 23

2.3.1 La desinfección del suelo _ 24

2.3.2 Control de los patógenos sin desinfección _ 31

2.4 OBJETIVOS_ 35

2.4.1 Objetivo general 35

2.4.2 Objetivos específicos__ 36

2.5 BIBLIOGRAFÍA__ 37

3 CARACTERIZACIÓN DE LAS POBLACIONES DE PHYTOPHTHORA SP. DE LOS INVERNADEROS DE PIMIENTO DEL CAMPO DE CARTAGENA _ 53

3.1 INTRODUCCIÓN _ 53

3.2 OBJETIVOS_ 54

3.3 MATERIAL Y MÉTODOS

3.3.1 Origen de los aislados 55

3.3.2 Estudios morfológicos 57

3.3.3 Crecimiento miceliar a diferentes temperaturas _ 59

3.3.4 Patogeneicidad delos aislados __ 59

3.4 RESULTADOS Y DISCUSIÓN__ 61

3.4.1 Características de las colonias y del micelio _ 61

3.4.2 Características de los esporangios __ 62

3.4.3 Tipo de compatibilidad genética y dimensiones de órganos sexuales

63 Crecimiento miceliar a diferentes temperaturas 66

3.4.5 Patogeneicidad delos aislados frente a pimiento ___ 68

3.5 CONCLUSIONES__ 74

3.6 BIBLIOGRAFÍA ___ 75 
4 CARACTERÍSTICAS DE LA FATIGA DEL SUELO EN LOS INVERNADEROS DE PIMIENTO DEL CAMPO DE CARTAGENA 81

4.1 ANTECEDENTES 81

4.2 EL CONCEPTO DE FATIGA DEL SUELO

4.2.1 Etiología de la fatiga del suelo ___ 83

4.2.2 La fatiga y sus componentes_ 85

4.2.3 La componente biológica o microbiológica ___ 87

4.3 JUSTIFICACIÓN Y OBJETIVOS_ 88

4.4 MATERIAL Y MÉTODOS _ 88

4.4.1 Procedencia y antecedentes de los suelos estudiados ___ 89

4.4.2 Recogida de la tierra y procesado de las muestras __ 90

4.4.3 Planteamiento de los ensayos _ 90

4.4.4 Bioensayos de especificidad ___ 91

4.4.5 Procesado de los datos ___ 94

4.5 RESULTADOS Y DISCUSIÓN___ 96

4.5.1 Ajuste de la técnica utilizada __ 96

4.5.2 Selección de los parámetros para evaluar el desarrollo de las plantas 97

4.5.3 Evaluación de la fatiga en muestras de suelos de invernaderos

comerciales desinfectados por medios químicos o no químicos ___ 99

4.5.4 Evaluación de la especificidad dela fatiga del suelo ___ 103

4.5.5 Evaluación de la fatiga en muestras de suelos de invernaderos con ensayos de desinfección por medios no químicos

4.5.6 Evaluación de la fatiga y su relación con tratamientos de desinfección utilizando materia orgánica

4.5.7 Evaluación de la especificidad dela fatiga en suelos biosolarizados _ 114

4.6 CONCLUSIONES

120

4.7 BIBLIOGRAFÍA 121

5 BIOSOLARIZACIÓN PARA LA DESINFECCIÓN DE LOS SUELOS DE LOS INVERNADEROS DE PIMIENTO DEL CAMPO DE CARTAGENA___ 129

5.1 ANTECEDENTES E INTRODUCCIÓN _ 129

5.1.1 Biosolarización, biodesinfección 129

5.1.2 Biosolarización en invernaderos de pimiento del Campo de Cartagena. Ensayos preliminares

5.1.3 La metodología del proceso de biosolarización ___ 134

5.2 OBJETIVOS DEL CAPÍTULO _ 138

5.3 BIBLIOGRAFÍA___ 139

5.4 IMPLEMENTACIÓN DE LA BIOSOLARIZACIÓN EN PIMIENTO DE INVERNADERO. REITERACIÓN DE LA APLICACIÓN 7 AÑOS, CON REDUCCIÓN DE LA CANTIDAD DE ENMIENDA 145

5.5 ENMIENDAS PARA CULTIVOS ECOLÓGICOS_ 150

5.6 ENMIENDAS ESPECÍFICAS PARA BIOSOLARIZACIÓN DE INVERNADEROS ECOLÓGICOS 156

5.7 LA BIOSOLARIZACIÓN MÁS EFICAZ QUE LA BIOFUMIGACIÓN 
5.8 PELLETS DE Brassica carinata ENMIENDA DE BIOSOLARIZACIÓN PARA EL CONTROL DE PATÓGENOS 169

5.9 EVALUATION OF REPEATED BIODISINFESTATION USING BRASSICA CARINATA PELLETS TO CONTROL MELOIDOGYNE INCOGNITA IN PROTECTED PEPPER CROPS 178

5.10 CONCLUSIONES DE BIOSOLARIZACIÓN 194 CONCLUSIONES DE LA TESIS 199 



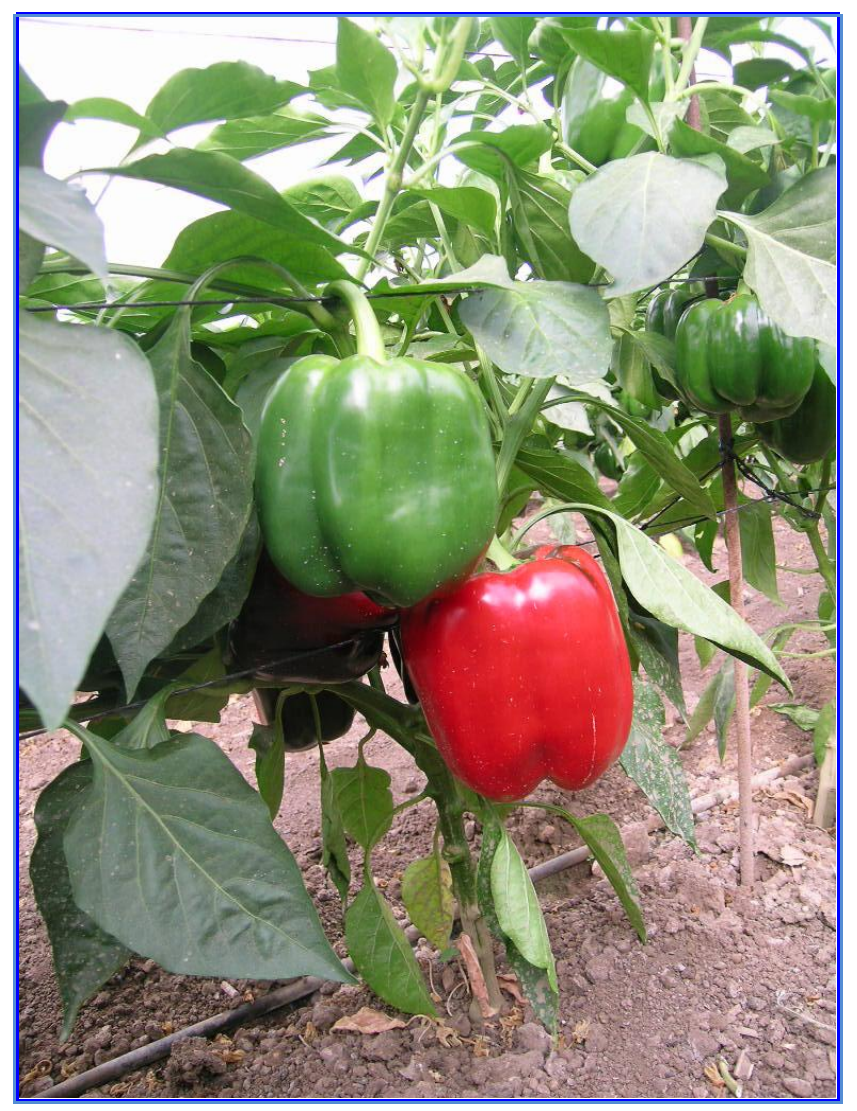

GAPÍTULO I

ANTECEDENTES 



\section{ANTECEDENTES}

En 1978, Tello et al. (1978) advertían de la importancia del diagnóstico en Patología Vegetal, dado que una vez conocido el agente patógeno causante de la enfermedad se podían establecer con claridad las relaciones de la interacción hospedante/patógeno y arbitrar los medios y estrategias para paliar o controlar los efectos de la enfermedad sobre los cultivos.

Los mencionados autores utilizaron como ejemplo el cultivo del pimiento de "bola" que venía siendo un cultivo sociale industrial en la Vega del río Segura y que, en esos años, emigraba de la huerta al campo como consecuencia de la incidencia de la "marchitez", "seca", "tristeza" o "fusario del pimiento" (de esta última forma denominaban los huertanos murcianos a la causa de la muerte de los pimentonares). Como indican Bartual et al. (1991), se había imputado a Fusarium oxysporum la muerte de los pimentonares, y se habían establecido estrategias de control para este hongo y no para el verdadero causante de la muerte de las plantas. Según Tello et al. (1978) Phytophthora capsici, el causante de la "tristeza" del pimiento en zonas productoras de pimiento del Valle del Ebro (Alfaro y Vegh, 1971), también lo era en Murcia.

Pero Tello y sus colaboradores asistieron, en los últimos años de la década de los setenta del pasado siglo, a la desaparición del cultivo del pimiento de bola en la Huerta de Murcia y de la Vega del río Segura. Los suelos es taban contaminados del hongo y éste permanecía en el suelo de un cultivo al siguiente. Las aguas de riego y las de escorrentías se encargaban de diseminar el hongo y la enfermedad por las tierras regadas. $P$. capsici era un factor limitante del cultivo pues no habían remedios, en aquel momento, para evitar las epidemias que se desencadenaban cada año o para paliar sus efectos.

García (1978) encontró P.capsici en pimentonares de la Vega del Guadalentín y del poniente del Campo de Cartagena a donde se había mudado el cultivo del pimiento para pimentón, donde el agua procedía de pozos y donde el pimiento rotaba a uno o dos años con los cereales o el melón. Cabe la sospecha que la contaminación de las nuevas parcelas se produjera con las plantas, que se seguían produciendo en almácigos de la Vega.

Tello (1984) señala a $P$. capsici como causante de la muerte de plantas en los invernaderos de< pimiento del Campo de Cartagena. Son numerosas las referencias analíticas y de diagnóstico que se encuentran en los Cuadernos de Laboratorio del Departamento de Protección Vegetal del actual IMIDA sobre consultas y prospecciones, llevadas a cabo en los invernaderos de esa comarca, que se refieren a $P$. capsici como el patógeno asociado a plantas con síntomas de marchitez. Legaz (1985) estudia aislados obtenidos de muestras recogidas en los invernaderos del Campo de Cartagena y los identifica como $P$. capsici, determinando su patogeneicidad frente a varias hortalizas, incluido el pimiento. Algunos de esos aislados fueron utilizados en los estudios de resistencia genética en pimiento a Phytophthora spp. llevados a cabo por Bartual et al. (1991).

Como indican Tello y Lacasa (1997 y 2004), en la década de los años ochenta del siglo pasado se llevaron a cabo ensayos de control de la enfermedad mediante desinfección del suelo con diferentes fumigantes, mediante el control del agua de riego, con aplicación de fungicidas en el agua de riego a lo largo del cultivo o indagando sobre las características de la resistencia genética. La desinfección del 
suelo con bromuro de metilo todos los años fue la solución práctica adoptada a partir del año 1988 en todos los invernaderos (Lacasa y Guirao, 1997).

Veinte años más tarde de que se acertara con el diagnóstico de la enfermedad, nos encontramos que la situación establecida y admitida de forma generalizada entre los cultivadores de la comarca delCampo de Cartagena, estaba abocada a cambiar, al habérsele puesto fecha de caducidad al uso de bromuro de metilo para la desinfección de los suelos de los invernaderos. Se tendría que experimentar con nuevos desinfectantes o nuevas estrategias de control a las mayoritariamente utilizadas.

La encuesta realizada por Lacasa y Guirao (1997) ponía de manifiesto que, pese a la desinfección con bromuro de metilo, más de un $20 \%$ de los invernaderos encuestados tenían pérdidas de plantas por "seca" o "tristeza", más del 32\% tenían contaminado el suelo con Phytophthora sp. y un buen número de los encuestados, no habían observado muerte de plantas pero desinfectaban todos los años pues si dejaban de hacerlo las plantas crecían menos y disminuía sensiblemente la producción, que interpretaban como "cansancio del suelo", ya que en más de1 $95 \%$ de los invernaderos el pimiento se repetía todos los años.

En la búsqueda de alternativas al bromuro de metilo se plantearon como aspectos relevantes:

a) Si la causa de la muerte de las plantas con síntomas de "tristeza" o "seca" seguía siendo la misma que en la década de los años ochenta, ya que en otras zonas se implicaba a Verticillium dahliae en la muerte de plantas de pimiento con síntomas próximos (Palazón, 1988).

b) Si los descensos de cosecha y reducción del desarrollo de las plantas, que los agricultores observaban al dejar de desinfectar con bromuro de metilo los invernaderos donde no se morían plantas, eran exclusivos del pimiento o se manifestaban en otros cultivos que pudieran alternarse.

c) Las soluciones por medios químicos, tanto para el control de los patógenos como para paliar los efectos del "cansancio" del suelo, no serían aplicables a cultivos con planteamientos de producción integrada, que en aquel momento se empezaban a implantar, ni de cultivos ecológicos, que en aquel momento se iniciaban.

El propósito de esta tesis es dar respuesta a las cuestiones antes planteadas. 


\subsection{BIBLIOGRAFÍA}

Alfaro A, Vegh Y. 1971. La "tristeza" o "seca" del pimiento producida por Phytophthora capsici Leonian. An INIA. Servicio de Protección Vegetal 1:9-42.

Bartual R, Marsal JI, Carbonell EA, Tello JC, Campos T. 1991. Genética de la resistencia a Phytophthora capsici Leonian en pimiento. Boletín de Sanidad Vegetal. Plagas 17: 3-124.

García J. 1978. Prospección de Phytophthora capsici Leonian en el pimiento "Ñora" de la región murciana. Trabajo Fin de Carrera. EUITA Orihuela. Universidad Politécnica de Valencia. 34 pp.

Lacasa A, Guirao P. 1997. Investigaciones actuales sobre alternativas al uso del bromuro de metilo en pimiento de invernadero. En: López A, Mora JA, eds. Publicaciones de la Consejería de Medio Ambiente, Agricultura y Agua. Jornadas 11: 47-50 pp.

Legaz C. 1985. Caracterización de cepas de Phytophthora capsici Leonian, aisladas del litoral mediterráneo, con vistas a su utilización en programas de introducción de resistencia en pimiento. Trabajo Fin de carrera. EUITA. Orihuela (Alicante). Universidad Politécnica Valencia, 197 pp.

Palazón C. 1988. Estudio de los posibles métodos de control de la "Tristeza" o "Seca" del pimiento. Tesis Doctoral, Universidad Politécnica de Valencia. Valencia, $231 \mathrm{pp}$.

Tello J, Costa J, Lacasa A, Campos T. 1978. La importancia del diagnóstico en el cóntrol de las enfermedades micológicas del pimiento. La Verdad, 19 de febrero: 30.

Tello JC. 1984. Enfermedades criptogámicas en hortalizas. Comunicaciones INIA. Serie Protección Vegetal, n²2, 342 pp.

Tello J, Lacasa A. 1997. Problemática fitosanitaria del suelo en el cultivo del pimiento en el campo de Cartagena. En: López A, Mora JA, eds. Publicaciones de la Consejería de Medio Ambiente, Agricultura y Agua. Jornadas 11:11-18.

Tello J, Lacasa A. 2004. Las enfermedades de origen edáfico y su control en los pimentonales del Campo de Cartagena. Una interpretación retrospectiva del sexenio 1979-1985. En: Lacasa A, Guerrero MM, Oncina M, Mora JA, eds. Desinfección de suelos en invernaderos de pimiento. Publicaciones de la Consejería de Agricultura, Agua y Medio Ambiente. Región de Murcia. Jornadas 16: 11-26. 



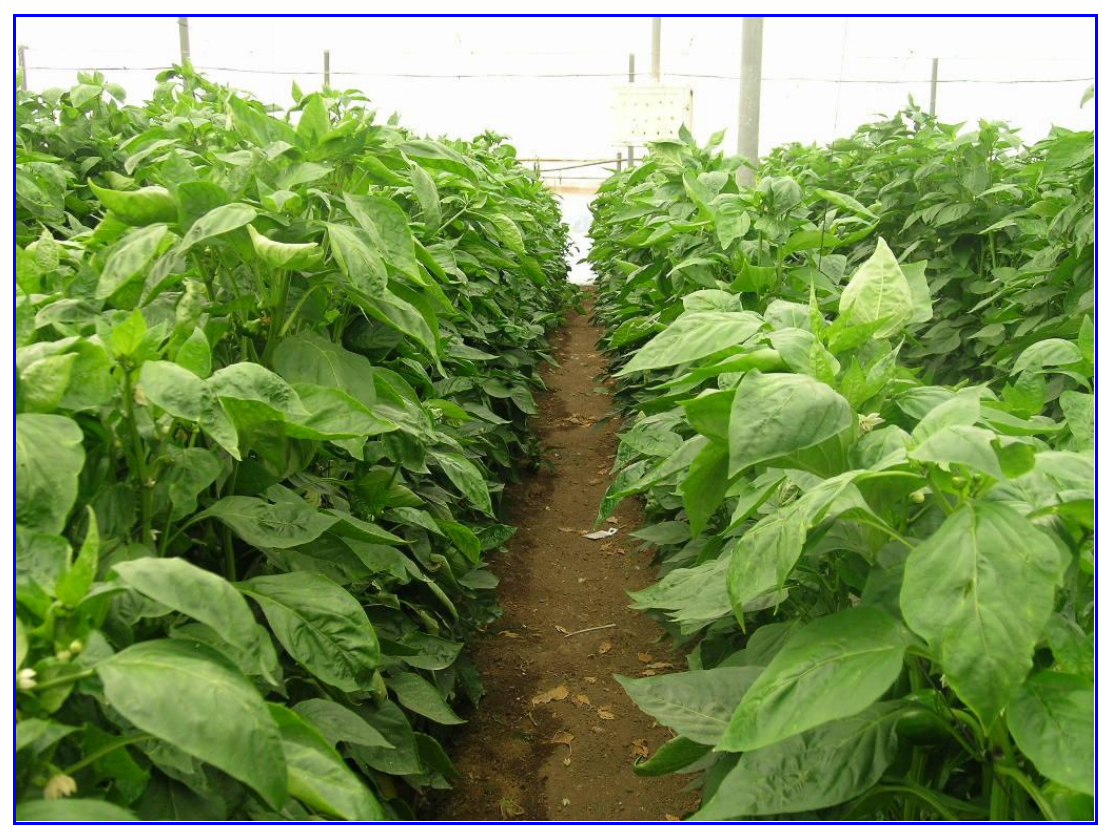

CAPÍTULO II

INTRODUCCIÓN 



\section{INTRODUCCIÓN}

\subsection{CARACTERÍSTICAS DEL CULTIVO DEL PIMIENTO EN LOS INVERNADEROS DE LA REGIÓN DE MURCIA}

\subsubsection{El pimiento en el contexto de la horticultura regional}

En la Región de Murcia el pimiento es un cultivo tradicional con gran arraigo entre los agricultores de las vegas de los ríos Segura y Guadalentín y, sobre todo, en el Campo de Cartagena. En su vertiente industrial el pimiento para pimentón o de "bola" se tiene constancia que fue cultivado por los monjes del monasterio de los Jerónimos en La Ñora a principios del siglo XVI (Cánovas, 1996). En la década de los años ochenta del pasado siglo el pimiento para pimentón ocupó la mayor superficie (Cánovas, 1996). Las insistentes epidemias de virus como el Potato virus Y (PVY) o el Cucumber mosaic virus (CMV) y en particular del virus del bronceado del tomate (Tomato spoted wilt virus, TSWV), comprometieron la viabilidad del cultivo, hasta el punto de desaparecer de la comarca del Campo de Cartagena, quedando limitado su cultivo a unos cientos de hectáreas en el Valle del Guadalentín.

El cultivo del pimiento en invernaderos se inició en los años setenta del pasado siglo en la zona costera del Campo de Cartagena, ante las expectativas de la llegada de las aguas del Trasvase Tajo-Segura (Rico, 1983). Las tentativas de cultivar otras hortalizas en los nuevos invernaderos de la zona no progresaron, probablemente por las características climáticas de la zona y por la escasa especialización de los agricultores, que sin embargo eran especialistas en cultivar pimiento para pimentón al aire libre.

Fue con la llegada del agua del Trasvase cuando se produjo el desarrollo del cultivo del pimiento en invernadero. En 1984 ocupaba 778 ha y en 1997 eran 1.549 ha las destinadas al pimiento. Pese a las epidemias del virus del bronceado del tomate que se produjeron a partir de 1990 el cultivo se consolidó, ocupando en el 20001.712 ha, 1.810 ha en 2003 y 1.559 ha en 2006 (Estadísticas Agrarias de la Región de Murcia). La dificultad para disponer de agua de calidad, la competencia en los mercados internacionales, las modificaciones en la forma de desinfectar el suelo, el aumento del costo energético y la apertura de expectativas de alternancia con otros cultivos como el calabacín y en menor medida el melón, han hecho que la superficie disminuya de forma progresiva (1.452 ha en 2009, 1.222 ha en 2011 y 1.188 en 2012) (Estadísticas Agrarias de la Región de Murcia).

Pese a todo, es la segunda hortaliza más cultivada en invernadero en la Región de Murcia, tras el tomate y es considerado como un cultivo estratégico desde el punto de vista social para la comarca del Campo de Cartagena (López, 1998), donde se localiza el $98,3 \%$ de la superficie de invernaderos ocupada por su cultivo y donde se ha desarrollado un núcleo de comercialización especializado.

En los municipios de San Pedro del Pinatar, San Javier, Torre Pacheco, Los Alcázares y Cartagena de Murcia y de Pilar de la Horadada (Alicante), es la actividad principal agrícola y el soporte económico de cinco agrupaciones de productores de hortalizas: tres sociedades cooperativas limitadas y dos sociedades agrarias de transformación que reúnen a los cultivadores de más del $50 \%$ de la superficie. El resto de los productores canalizan la comercialización y las ventas a través de seis 
alhódigas o de sus propias estructuras comerciales, como empresas comercializadoras y exportadoras.

Forma parte de una horticultura regional intensiva muy tecnificada, dinámica, moderna y competitiva, con marcada proyección a la exportación a países europeos. El cultivo del pimiento coexiste en el tiempo con cultivos invernales de lechuga, brócoli, alcachofa, apio, calabacín, habas, etc., y estivales de melón, sandía, pimiento, maíz dulce, etc., al aire libre y se alterna en los invernaderos con calabacín, melón o guisante.

Casi toda las superficie de pimiento en invernadero se cultiva con arreglo a normas de producción integrada, habiendo más de 100 ha calificadas como ecológicas, lo que añade un interés particular por este cultivo en la comarca, por su valor añadido. Genera gran cantidad de mano de obra, en la fase de producción en los invernaderos, en los almacenes de confección y alhódigas, en empresas auxiliares de invernaderos, proveedores de plásticos, riegos, fertilizantes, fitosanitarios, embalaje, transporte, industria, etc. La relativa cercanía de los mercados europeos, la suavidad del clima invernal, el grado de especialización y de tecnificación de las explotaciones permite a la comarca ser competitiva en calendarios y precios, lo que ha abocado a un monocultivo de alto valor y elevado grado de especialización (López, 1998), siendo básica la convergencia hacia la consecución de denominación de producción de calidad.

La competencia con los cultivos de Almería, donde el pimiento ocupó 7.300 ha en la campaña 2010-2011 (Anuario de Estadística del Ministerio de Medio Ambiente, Medio Rural y Marino, 2011), se produce en el inicio de la primavera y recientemente en el final del verano.

\subsubsection{La tecnología del cultivo en los invernaderos}

\section{Los tipos de invernaderos}

Las estructuras de los invernaderos han variado sensiblemente con el tiempo, coexistiendo en la actualidad invernaderos antiguos con invernaderos de alta tecnología.

Son escasos los que todavía se cultivan, de aquellos construidos cuando se inició el cultivo protegido en esta comarca, a principio de los años 70 del pasado siglo. Una parte han sido ligeramente reformados para adaptarlos al sistema de riego por goteo, a las maquinarias de aplicación de fitosanitarios, a los sistemas de entutorado y al uso de contenedores para la recolección. Son generalmente de pequeñas dimensiones (1.000 a $2.000 \mathrm{~m}^{2}$ ), de tipo "parral" o "capilla", de poca altura, soportes de madera de eucaliptos o de tubo de hierro galvanizado por los que han sido sustituidos. Presentan sistemas deficitarios de ventilación y dificultades para la mecanización de las labores. Sin embargo mantienen sus potenciales productivos.

La mayoría fueron construidos entre finales de los años 80 del siglo pasado y principios del presente. Son de mayores dimensiones, de tubos de hierro galvanizado con alturas en el borde de 2 a 2,5 m y entre 4 y 5 en la cumbrera, de tipo "parral" o "capilla", con capillas sencillas (la mayoría) o multicapilla (son minoría). La superficie del invernadero oscila entre 2.500 y $6.000 \mathrm{~m}^{2}$, para los de capilla simple, y entre 10-30.000 $\mathrm{m}^{2}$ los de varias capillas adosadas. Están dotados de amplias zonas de ventilación lateral, y adaptados (la mayoría) o construidos (los menos) con ventilación cenital. Tras las ayudas proporcionadas para mejorar las estructuras, casi 
todos están dotados de automatismos para la apertura de las ventilaciones. Algunos disponen de pantallas de sombreo y/o de sistemas de aspersión para la refrigeración.

Sobre la superficie ocupada por antiguos invernaderos se han construido, en la última década, estructuras multitúneles de mayores dimensiones que las "capillas". Están provistos de tecnologías para la ventilación, la regulación de la temperatura por pantallas o por aspersión en las zonas de pasillos, con mayores espacios entre soportes y alturas en los laterales de $4 \mathrm{~m}$ y electrificados. En algunos casos, la superficie cubierta por estos multitúneles adosados supera las 5 ha.

Las cubiertas utilizadas en la actualidad son de plástico tricapa de tres años de duración en todos los modelos, tipos y dimensiones de invernaderos. Se han probado los plásticos fotoselectivos con distintas características, pero su uso todavía no se ha extendido, por no compensar las mejoras al costo adicional.

Los sistemas de calefacción que hace una década se empezaron a utilizar han quedado en desuso por el costo energético que suponen. Todavía se mantienen algunos sistemas de apoyo térmico nocturno para evitar las heladas o para paliar los efectos de las bajas temperaturas invernales.

Los sistemas de ventilación, necesarios para regular las condiciones ambientales, tienen una componente de manejo para evitar las inmigraciones de plagas (mosca blanca, lepidópteros noctúidos o pirálidos), en particular de los insectos transmisores de virosis como los trips (Frankliniella occidentalis) o de pulgones. Por ello, todos los invernaderos disponen de mallas en las aperturas de ventilación de 16x10 hilos/cm en las laterales y de 10x6 hilos/cm en las cenitales, de forma que se reducen las inmigraciones de plagas y se mantienen las adecuadas condiciones ambientales.

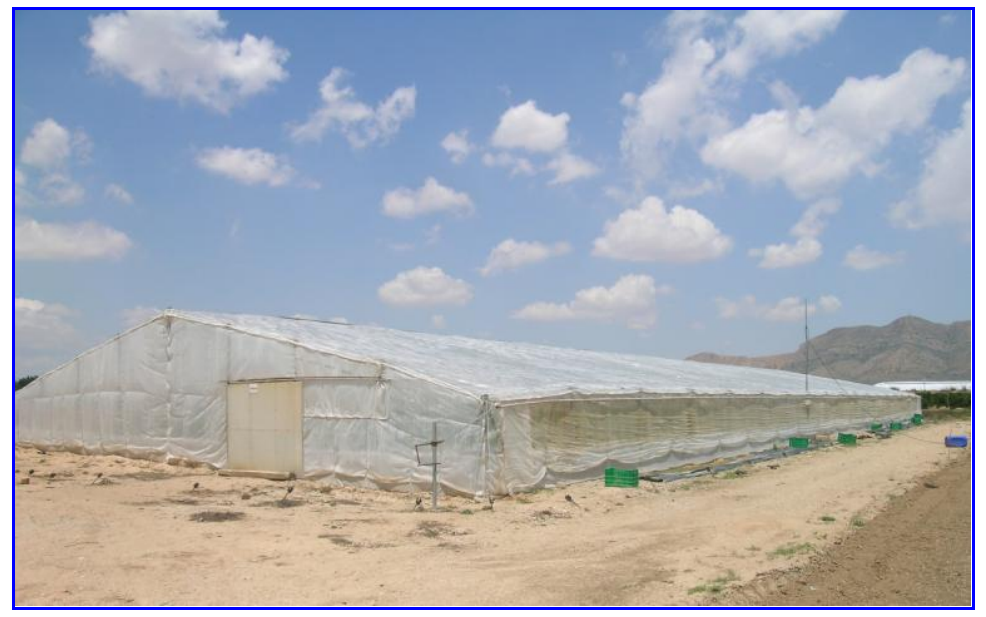

Foto 1. Invernadero tipo parral.

\subsubsection{El ciclo de cultivo}

Desde su instauración como cultivo protegido en el Campo de Cartagena, el pimiento ha sido un monocultivo en la mayor parte de los invernaderos, dado que el ciclo habitual anual mantiene el suelo ocupado durante de 8 a 10 meses, dependiendo del tamaño de la explotación y de la orientación comercial, necesitando los otros meses para retirar los restos del cultivo y para las labores preparatorias del siguiente. Según las fechas en que el cultivo permanece en el invernadero se pueden distinguir, en la actualidad, tres tipos de ciclos (Tabla 1), siempre ajustados a las ofertas que puedan realizar otras zonas productoras con las que se compite en los mercados 
locales y en la exportación, a la que se destina más del 60\% de la cosecha. En la organización de las plantaciones se procura evitar solapes con las producciones en los sistemas protegidos de Almería.

Tabla 1. Ciclos de cultivo de pimiento en el Campo de Cartagena.

\begin{tabular}{|l|l|l|l|}
\hline Ciclo & Trasplante & Inicio recolección & Lugar de cultivo \\
\hline Extra-temprano & $\begin{array}{l}15 \text { de noviembre a } \\
22 \text { de diciembre }\end{array}$ & $\begin{array}{l}15 \text { de marzo a } \\
15 \text { de abril }\end{array}$ & Invernadero \\
\hline Temprano & $\begin{array}{l}25 \text { de diciembre a } \\
20 \text { de enero }\end{array}$ & $\begin{array}{l}20 \text { de abril a } \\
15 \text { de mayo }\end{array}$ & Invernadero \\
& $\begin{array}{l}25 \text { de enero a } \\
28 \text { de febrero }\end{array}$ & $\begin{array}{l}20 \text { de mayo a } \\
5 \text { de junio }\end{array}$ & Invernadero \\
\hline Tardío & 10 de marzo & 20 de junio & Invernadero \\
& 10 de mayo & 10 de julio & Aire libre \\
\hline Extra-tardío & \multicolumn{2}{|l}{} \\
&
\end{tabular}

El pimiento es un monocultivo en la mayor parte de los invernaderos y se viene repitiendo de forma ininterrumpida desde hace más de 20 años en más del $50 \%$ de la superficie, y desde hace más de 10 años en el 90\%. En los últimos años la tendencia está cambiando debido a:

- La supresión del bromuro de metilo para la desinfección de los suelos (en 2006-07 fue la última campaña de usos críticos) y las deficiencias mostradas por las alternativas químicas y no químicas en algunos suelos.

- La implantación en la comarca de una gran empresa de comercialización de otras hortalizas, en particular de cucurbitáceas permite tener al alcance un mercado para las cosechas de cultivos alternativos o rotacionales.

- Las restricciones en la disponibilidad de agua de calidad, lo que dificulta el cultivo del pimiento o se requiere de inversiones para la desalación de aguas subterráneas o marinas.

Además, con el establecimiento de estrategias no químicas para el control de los patógenos del suelo, se ha incrementado paulatinamente la superficie en la que el pimiento se alterna (en ciclos de dos años) con cucurbitáceas como el calabacín o el melón o con el guisante. Esto ha supuesto una disminución de la superficie de pimiento próxima al 20\% en 2011-12 en relación a la de la campaña 2007-08.

Era tradicional el realizar un cultivo de pimiento grueso al aire libre con plantación al inicio de la primavera, y con la llegada del virus del bronceado del tomate se había dejado de hacer. Recientemente, tras los cultivos alternativos de invierno (guisante o calabacín), se están realizando plantaciones tardías (entre mediados de marzo y principios de mayo) en los invernaderos, para cosechar durante el verano y principios de otoño.

\section{Ciclo extra-temprano}

Es el predominante en los invernaderos de la comarca del Campo de Cartagena. La plantación se realiza desde principios de noviembre hasta enero. Una plantación más precoz implicaría un mayor riesgo en el ataque de enfermedades, fundamentalmente de Botrytis, y de virosis transmitidas por pulgones como elPVY y el CMV, o por trips como el TSWV lo que ocasionaría pérdidas de producción y de calidad en los frutos. En este ciclo de primavera, la recolección suele iniciarse en marzo-abril y terminar en agosto-septiembre, según sean los precios, obteniéndose 
una producción media de $10-12 \mathrm{~kg} \mathrm{~m}^{-2}$. Predominan las variedades de tipo "Lamuyo", aunque cada vez es más frecuente el uso de variedades de tipo "California". Las primeras cosechas se pueden solapar con las últimas de Almería.

\section{Ciclo temprano}

Con el anterior es el realizado mayoritariamente en la comarca. Tratando de evitar las bajas temperaturas del inicio del invierno se planta desde finales de diciembre hasta mediados o finales de enero, para iniciar la recolección a partir de mediados de abril cuando las producciones de Almería descienden. Los riesgos de epidemias de virosis se reducen considerablemente y también de hongos de evolución aérea. Predominan las variedades de tipo "California", con producciones medias próximas o superiores a $10 \mathrm{~kg} \mathrm{~m}^{-2}$ y final del ciclo desde finales de agosto hasta principios de octubre, dependiendo del tipo o tamaño de la explotación y de las labores preparatorias, en particular del tipo de desinfección del suelo.

\section{Ciclo tardio}

En zonas de riesgos de frío en el invierno o en invernaderos con estructuras antiguas se suele retrasar la plantación a finales de enero o mediados de febrero, para iniciar la recolección a partir de mediados de mayo o principios de junio. Los ries gos de contratiempos fitosanitarios por virosis o enfermedades fúngicas de evolución aérea se reducen y aunque las producciones unitarias disminuyen en relación a los anteriores ciclos, la calidad en esos meses es superior a la de los tempranos en esas fechas de inicio de la cosecha. Salvo que los precios sean favorables el final del cultivo suele ser similar al del ciclo temprano. Predominan las variedades de tipo "California" con producciones unitarias de 8 a $10 \mathrm{~kg} \mathrm{~m}^{-2}$.

\section{Ciclo extra-tardio}

El pimiento rota con cultivos invernales de cucurbitáceas o de guisante. Generalmente los sucede sin mediar desinfección del suelo, aunque en suelos contaminados por Phytophthora spp. y/o Meloidogyne sp. se suele realizar una desinfección parcial. La plantación se realiza entre mediados de marzo y principios de mayo, para iniciar la recolección a principios de julio y finalizar el cultivo a partir de mediados de septiembre hasta mediados de octubre. Suelen utilizarse variedades de tipo "Lamuyo" en los invernaderos por ser el tipo predominante en las plantaciones al aire libre que se realizan en esas fechas. Los ries gos de epidemias del virus del bronceado del tomate suelen ser altos por coincidir el inicio del cultivo con el final del cultivo de alcachofa, con el que coexiste. Las producciones unitarias son más bajas que en los ciclos anteriores y el destino de la producción suele ser el mercado nacional de consumo en fresco y la industria.

\subsubsection{Las labores culturales}

En los cuarenta años de cultivo protegido las técnicas culturales han evolucionado con los avances tecnológicos y las innovaciones de los propios agricultores, con las características de los invernaderos y los sistemas de gestión del ambiente, con la estructura varietal o con el destino de las producciones. Rico (1983) recopiló las formas de cultivo, los tipos de invernaderos, las variedades cultivadas y sus características, etc., cuando apenas el cultivo se había instaurado en la comarca 
del Campo de Cartagena y se proyectaba el futuro de esta zona de nuevos regadíos hacia cultivos de primor con alto valor añadido, como un núcleo especializado de producción y comercialización.

En 1997 la inquietud de cultivadores asociados a cooperativas y de sus técnicos se inclinó por la aplicación de métodos bioló gicos o integrados en el control de las plagas, lo que se tradujo en que, a partir de 2001, en más del $95 \%$ de los invernaderos el cultivo se realiza bajo criterios y controles de producción integrada, priorizando los medios biológicos y biotécnicos en las actuaciones.

\section{Preparación del suelo para la plantación}

Es habitual que al finalizar el cultivo de pimiento precedente se retiren las mangueras de riego, los hilos y perchas del entutorado y se retiren las plantas o las ovejas las consuman, sacando en ese caso los tallos más gruesos. Sin embargo en una parte importante de la superficie los restos del cultivo precedente se entierran utilizando una fresadora. En este caso, se extiende a continuación el abonado orgánico de fondo y los correctores, se da un pase o dos de subsolador y se entierra la enmienda orgánica con una labor de fresadora.

$\mathrm{Si}$ la desinfección del suelo se realiza mediante biosolarización, inmediatamente después de haber enterrado las plantas y la enmienda, se riega (por aspersión o con las mangueras de riego por goteo, colocándolas en dos posturas en sendos días consecutivos) y se cubre el suelo con plástico de polietileno de 160 ó 200 galgas, permaneciendo sellado un mínimo de seis semanas o hasta el momento de preparar el invernadero para la plantación.

La desinfección química es utilizada en más del 60\% de los invernaderos. La mezcla de 1,3-dicloropropeno y cloropicrina se aplica después de enterrar la enmienda orgánica, de extender las mangueras de riego en las líneas donde se van a poner las plantas en la campaña siguiente y de colocar el plástico de polietileno de 140, 160 ó 200 galgas. Se humedece el suelo mediante riegos de 3-4 horas en dos días consecutivos o alternos y a continuación, o 7-4 días más tarde, se incorpora el desinfectante en el agua de riego. Tras un plazo de seguridad de 21 días, para la disipación de los productos, se levantan los plásticos, esperando de 10 a 15 días más antes de plantar. Cada vez son menos los agricultores que dan un pase de fresadora después de la desinfección a todo el terreno, siendo frecuente la desinfección "en línea", sin labores posteriores y plantando en las líneas donde se ha aplicado el producto, ahorrando las tareas de plegado de mangueras y el desplegado posterior para la plantación.

\section{El marco de plantación}

Es tradicional en la comarca el realizar la plantación en líneas simples, con orientación norte-sur, separadas $1 \mathrm{~m}$. En la línea, las plantas se separan 0,40 m, lo que supone una densidad de 2,5 plantas $\mathrm{m}^{-2}$. En uno de los laterales del invernadero o en el centro suele dejarse un pasillo de $0,80 \mathrm{~m}$, aunque en algunos no se dejan espacios de acceso en los bordes del invernadero, accediendo a las líneas desde el exterior.

Es habitual plantar con el suelo seco, regando a continuación, aunque algunos prefieren plantar con el suelo humedecido, para evitar el mínimo estrés. Las plantas se disponen manualmente o ayudados por un "pico-pato" en la proximidad del goteador en un pequeño surco. Tras los primeros riegos de "postura" y "enjuague" y una vez que la planta ha arraigado se hace un nuevo surco a unos $10 \mathrm{~cm}$ de la línea 
de plantas donde se colocará la manguera de riego, con el objeto de evitar la asfixia de cuello a la que es sensible el pimiento.

\section{El riego}

Sistemas de riego por goteo están instalados en todos los invernaderos desde principios del presente siglo. Se utilizan mangueras de 12 ó $16 \mathrm{~mm}$ de diámetro, con goteadores a $0,40 \mathrm{~m}$ y descargas de 2 a $41 \mathrm{~h}^{-1}$.

El riego de plantación suele ser copioso, para humedecer una banda de suelo de unos $20 \mathrm{~cm}$. Se suele dar un riego de enjuague con poca agua, antes de someter a la planta a déficit, con el objeto de que desarrolle un sistema radicular profundo y abundante. Algunos agricultores labran la banda del riego de postura para poder hacer el surco a 10-15 cm del tronco donde colocan la manguera y desde donde la planta recibirá el agua. En ocasiones, sobre la línea de goteadores se coloca una banda de plástico de acolchado negro, que ayuda a mantener el agua, a reducir humedad en el ambiente y al manejo de aguas de baja calidad, retirándolo cuando la planta ha alcanzado el tamaño suficiente como para sombrear la zona húmeda (Martínez, 2005).

A partir del cuajado de los primeros frutos de la cruz, el riego se realiza con cadencia cada vez más corta, en base a las necesidades del cultivo y a condiciones ambientales como la temperatura y la radiación incidente, que pueden ocasionar el manchado de los frutos o "blossom end rot".

\section{El entutorado}

El entutorado tiene por objeto: a) mantener erguidas las plantas para facilitar la ventilación, el cuajado, la poda (cuando se realiza), la aplicación de los fitosanitarios y la recolección. b) facilitar el desplazamiento de los organismos beneficiosos (en particular los ácaros fitoseidos) en las fases iniciales del desarrollo del cultivo en que las plantas no se llegan a tocar entre ellas.

Los sistemas usados en la actualidad son para cultivos en los que no se practica poda de fructificación ni de regeneración. Hay variantes adaptadas a las características constructivas del invernadero o a la forma de retirar los hilos al final del cultivo (semi-mecanizada o manual).

En la mayor parte de los invernaderos se clavan arquillos metálicos de 0,20$0,25 \mathrm{~cm}$ de ancho y 1,50 m de altura en el extremo de las filas donde se ha dejado el pasillo de servidumbre. O bien tubos de hierro galvanizado, de 2 a 2,5 m, instalados en los extremos de las filas, en estructuras de multitúneles. Los arquillos se sujetan a la estructura del invernadero por la parte superior con hilos de rafia.

Los primeros hilos de entutorado sirven de vías de desplazamiento de los ácaros fitoseidos, por lo que, se colocan a la altura de la primera cruz de la planta los dos hilos longitudinales a ambos lados de los arquillos. Cada 3 o 4 plantas los hilos longitudinales se atan juntos, de forma que los dos toquen el tallo de las plantas para que los fitoseidos pasen desde los sobres en que se liberan (se pone un sobre colgado de una rama, cada cinco plantas) a las otras plantas del grupo, colonizándolas. El hilo que une los dos hilos longitudinales más bajos, se ata al alambre que hay dispuesto sobre la fila de plantas a unos $2 \mathrm{~m}$ de altura.

A medida que las plantas van creciendo se ponen hilos laterales a diferentes alturas y se van uniendo con hilos atados a los verticales o con perchas de $20 \mathrm{~cm}$ sujetas al hilo vertical, de forma que se forma un macizo de similar anchura. Es 
habitual que, en el extremo de la fila que no hay arquillo, los hilos longitudinales se aten a los alambres verticales de la estructura del invernadero que sirven de apoyo a los faldones laterales del plástico.

\section{El abonado}

En todos los invernaderos reutilizan sistemas de fertirrigación, disponiendo de tanque para las disoluciones o para los abonos líquidos. La mayoría tiene instalados programadores de abonado con sistemas informáticos más o menos automatizados.

Los abonados de fondo con enmiendas orgánicas (generalmente estiércoles de origen animal), correctores minerales y abonos minerales se complementan con el aporte en cobertera de nitrógeno, $\mathrm{P}_{2} \mathrm{O}_{5}$ y de $\mathrm{K}_{2} \mathrm{O}$ y aplicados en forma de nitrato amónico, fosfato monoamónico y nitrato potásico o sulfato potásico, respectivamente, todo ello fraccionado en varias aportaciones, que no comienzan a realizarse hasta que los frutos de la cruz no presentan el tamaño de una castaña, aproximadamente, para evitar la caída de los frutos precoces recién cuajados. Las cantidades a aportar se determinan en base a las extracciones de las cosechas (Rincón et al., 2005 y 2006) de acuerdo a las producciones esperadas. Los equilibrios en los aportes de macronutrientes varían según el estado fenológico y las condiciones ambientales (temperaturas, radiación, riego, características fisico-químicas del suelo, etc.). En el cuajado el equilibrio suele ser 1-1-1 y ya iniciada la recolección, 2-0,51,5 (González et al., 1995). La mayor parte de los productores disponen de servicios técnicos y comercializan la cosecha a través de entidades con certificaciones específicas. El abonado se realiza siguiendo las recomendaciones de las normas de producción integrada, las cuales tienen en cuenta la sensibilidad de la comarca para la contaminación de las aguas subterráneas y marinas por nitratos.

El abonado con micronutrientes (calcio, hierro, zinc, manganeso, etc.) se realiza de la misma forma que los macronutrientes, aunque con intervalos de aplicación más largos (Rincón et al., 2005 y 2006).

\section{La recolección}

El calendario de recolección depende del ciclo de cultivo, del tipo de variedad y de las exigencias de las comercializadoras, lo que está relacionado con el tipo de envasado y conservación. La cadencia para las cosechas de frutos rojos suele ser una vez por semana, siendo de dos veces por semana para los frutos amarillos, aunque depende de las fechas. Las recolecciones de frutos con coloración verde suelen ser semanales o sin cadencia constante, ajustándose a las necesidades de las comercializadoras.

Los frutos se recolectan (con color verde, rojo o amarillo) cuando han alcanzado el grado adecuado de consistencia en el caso de los verdes y el porcentaje de superficie mínimo de coloración en el caso de los rojos o amarillos. Es frecuente recolectar con coloración verde la primera cosecha en el caso de plantas sobrecargadas o inviernos y primaveras frías, con el objeto de favorecer el desarrollo de las plantas.

La producción media depende del ciclo de cultivo y del aprovechamiento comercial así como de las variedades, de la forma de cultivo y de las condiciones ambientales de la campaña. 


\subsubsection{Los tipos de pimientos cultivados en los invernaderos}

Cuando se inició el cultivo de pimiento en invernaderos del Campo de Cartagena se utilizaron variedades de frutos de carne gruesa, cuadrados largos de maduración en rojo. Poco después se empezaron a comercializar semillas de hîbridos con las mismas características (tipo Lamuyo F1), con buen comportamiento en ambientes variados y también en los invernaderos (Costa, 1978; Rico, 1983).

El pimiento no ha sido una excepción dentro de las hortalizas, y la evolución de los tipos y variedades cultivadas en los invernaderos ha ido paralela a la disponibilidad de material vegetal más productivo y mejor adaptado a las condiciones del Campo de Cartagena, a los requerimientos comerciales de los mercados a los que se ha dirigido la producción, a la calidad de las aguas de riego (del Trasvase Tajo-Segura, de pozos, desaladas, depuradas, mezclas, etc.), a las características ambientales de los invernaderos (en particular a las cubiertas) y a la especialización de los productores, tradicionalmente de vocación pimentonera.

A la estructura varietal actual de los cultivos de la comarca, se han incorporado un abanico de tipos y variedades con las que se pueden surtir los mercados europeos más variados.

Los tres tipos de frutos mayoritarios son:

Tipo A: Sección longitudinal cuadrangular (tipo California)

Tipo B: Sección longitudinal rectangular (tipo Lamuyo)

Tipo C: Sección longitudinal triangular (tipo Dulce Italiano)

Las coloraciones básicas de los frutos en la cosecha son: rojo, verde y amarillo, aunque se pueden encontrar variedades de frutos anaranjados, morados y de distintas tonalidades de blancos. Además, se pueden encontrar variedades con formas cónicas, muy dulces, picantes (para uso condimentos), tipo Padrón o guindillas para condimentos o como complementos culinarios.

La superficie dedicada a variedades de tipo California ha aumentado (supone más del 50\% de la superficie), (González, 2002) no solo por ser más demandados, sino porque facilitan la instalación de organismos beneficiosos como los Orius (utilizados en el control biológico de las plagas). Son producciones comercializadas a través de cooperativas y alhóndigas especializadas.

Desde 2002 la mayor parte de las variedades tienen resistencias incorporadas al virus del bronceado del tomate, aunque la resistencia fuera remontada por las poblaciones del virus desde 2004. En la actualidad, cada vez es más frecuente utilizar variedades con resistencias al virus del moteado suave del pimiento (Pepper mottle mild virus, PMMV), tanto en los tipos California como en los tipos Lamuyo. Una parte de las nuevas variedades tiene buen comportamiento frente a enfermedades fúngicas de evolución aérea como el oídio (Leveillula sp.) y muestran cierto grado de tolerancia a factores adversos como el rajado, el blossom end rot, la asfixia radicular, y se espera que en los próximos años a los problemas fitosanitarios de origen edáfico como Phytophthora spp. y nematodos. 


\subsection{PROBLEMAS FITOSANITARIOS}

Los problemas fitosanitarios de los suelos de los invernaderos de pimiento del Campo de Cartagena no son muy diferentes de los de los cultivos protegidos o al aire libre de otras zonas productores del mundo.

Algunos son considerados como factores limitantes del cultivo desde hace más de una veintena de años (Tello y Lacasa, 1997). La "seca" o "tristeza" causada por Phytophthora capsici y el nematodo agallador Meloidogyne incognita han estado presentes en buena parte de los invernaderos (Tello y Lacasa, 2004; Bello et al., 2004) desde la instauración del cultivo en la comarca, y en la actualidad siguen siendo los patógenos más relevantes.

Al igual que ocurre en los cultivos de pimiento para pimentón en Extremadura (Rodríguez-Molina et al., 2010; Morales et al., 2011) y en los invernaderos del País Vasco (Larregla, 2012; comunicación personal), también en los invernaderos del Campo de Cartagena se ha encontrado a Phytophthora parasitica involucrada en la muerte de las plantas con síntomas de "seca" o "tristeza" (Guerrero et al., 2012).

La reiteración del monocultivo en los invernaderos ha provocado la aparición de fenómenos de fatiga del suelo que se traducen en depresiones vegetativas en las plantas y en reducciones de la producción, lo que se puede interpretar como un factor limitante del monocultivo.

\subsubsection{La "seca" o "tristeza" producida por Phytophthora spp.}

Al poco tiempo de instaurarse el cultivo en la comarca, antes de que llegaran las aguas del Trasvase Tajo-Segura, comenzaron a aparecer los primeros invernaderos con plantas afectadas de marchitez que con el tiempo se traducía en una desecación total de la planta. En aquellos momentos, Phytophthora capsici fue la especie causante de la muerte de las plantas (Tello y Lacasa, 1997, 2004), como lo era en otras zonas españolas productoras de pimiento (Tello, 1984, Palazón 1988, Bartual et al., 1991) o de otras partes del mundo (Chellemi et al., 2001; Chellemi, 2004). Es relativamente reciente la constancia de que $P$. parasitica es en la actualidad la especie preferentemente asociada a las plantas muertas por marchitez y la predominante en los suelos de los invernaderos cultivados de pimiento. Generalmente se trata de suelos pesados, en los que las alternativas químicas al bromuro de metilo muestran deficiencias en la penetración o en la dispersión del desinfectante en el suelo.

Al parecer, la contaminación con $P$. capsici de la nueva zona de cultivo se produjo a través del material vegetal que se plantó en los primeros invernaderos. Los primeros semilleros se realizaron en la Vega del Río Segura, donde se hacían los del pimiento de "bola", que en aquellos momentos ya se encontraba contaminada por el hongo (Tello et al., 1978). Sobre la presencia de $P$. parasitica en la zona se piensa que pudo ser debida a que algunos invernaderos fueron cultivados de clavel en la década de los años ochenta del pasado siglo o a la implantación de cultivos de cítricos en la comarca, cuyos plantones se ha constatado en ocasiones que están contaminados del hongo (Lacasa, 2011; comunicación personal). Las escorrentías por lluvias torrenciales podría ser la vía de dispersión de las dos especies, en particular de $P$. parasitica que accedería a los invernaderos desde las parcelas de cítricos. 


\subsubsection{Phytophthora spp.}

El género Phytophthora se encuadra en los Oomicetos de la familia Pythiaceae, incluido en el reino Myceteae, en la actualidad parece aceptarse que se incluya en el reino de los Chromista en base a algunos caracteres diferenciadores como: la composición de la pared celular, su ciclo vital que es casi todo diploide, la formación de zoosporas biflageladas, la incapacidad para sintetizar esteroles, etc. (Gunderson et al., 1987; Erwin y Ribeiro, 1996).

Todas las especies de Phytophthora tienen el micelio diploide hialino, de uniforme o irregular grosor (en determinados medios de cultivo algunas especies lo tienen toruloso, con protuberancias), cenocítico, con escasos tabiques. En medios de cultivo las colonias son densas, el micelio se presenta aéreo, de aspecto radiado o ligeramente estrellado, con bordes redondeados o sinuosos, y también hay parte del micelio sumergido en el medio, donde se pueden observar las protuberancias (Tuset, 1977). La composición del medio de cultivo, la luz, el $\mathrm{pH}$, la tensión de $\mathrm{CO}_{2} \mathrm{u}$ oxígeno y la temperatura, ejercen una influencia notable en la velocidad de crecimiento del micelio o de la colonia (Tuset, 1977; Erwin y Ribeiro, 1996). El rango de temperaturas en el que se da crecimiento miceliar es amplio $\left(1 \mathrm{a} 37^{\circ} \mathrm{C}\right)$, con óptimos a $20-28^{\circ} \mathrm{C}$, siendo de resaltar que el límite térmico máximo en el que hay crecimiento miceliar es una característica específica utilizada en la separación taxonómica de especies (Erwin y Ribeiro, 1996).

En condiciones favorables producen esporangios, en cuyo interior se forman las zoosporas, como forma de reproducción asexual y estrategia de dispersión. Se forma sobre esporangióforos que tienen un diámetro similar al de las hifas. En algunas especies los esporangios se pueden formar desde la base de un esporangio ya maduro y se denominan proliferantes (Erwin y Ribeiro, 1996). Pueden tener formas esféricas, subesféricas, ovoides, elipsoidales, turinadas, obturinadas, limoniformes, piriformes, obpiriformes y dimensiones variadas. En el extremo apical pueden o no presentar una papila más o menos pronunciada, que se descompone para que puedan emerger las zoosporas (Erwin y Ribeiro, 1996). Los esporangios pueden tener o no un pedicelo basal, y pueden desprenderse del esporangióforo con facilidad (caducos) o no (no caducos). Las características y dimensiones de los esporangios son elementos de gran importancia para la diferenciación de especies. Al microscopio tienen una coloración amarilla. Los factores ambientales y la composición de los medios de cultivo influyen en la formación de los esporangios.

Las zoosporas salen del esporangio por diferencia de presión osmótica. Son biflageladas con un flagelo más largo que el otro. Son la forma de inóculo que permite la diseminación en el suelo aprovechando la facilidad para nadar en el agua, siendo consideradas la forma de inóculo más apropiada para infestar las plantas. La emergencia de las zoosporas se puede estimular in vitro, sometiendo el cultivo con

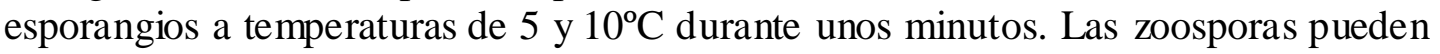
ser diseminadas por el agua de lluvia e incluso por el aire (Ristaino y Gumpertz, 2000).

Algunas especies pueden producir clamidosporas, que son formas de supervivencia o conservación en medios poco propicios para el desarrollo (Erwin y Ribeiro, 1996). Son esféricas u ovoides, generalmente hialinas o de color marrón oscuro, cuando maduran; pueden estar en el extremo de la hifa o en posición intercalar. Su presencia o ausencia en determinados medios de cultivo es utilizado como carácter diferenciador en la identificación de las especies (Tuset, 1977). En rangos de temperatura de 18 a $30^{\circ} \mathrm{C}$ pueden germinar originando numerosos tubos germinativos; en el suelo constituyen unidades infectivas. 
Las clamidosporas se diferencian de los hinchamientos hifales que aparecen en algunas especies, en que estos no están delimitados en el micelio por tabiques o septos como lo están las clamidosporas. Son esporas que tienen engrosada la pared, que es simple (Erwin y Ribeiro, 1996).

La capacidad de producir estructuras sexuales es una característica del género Phytophthora. El oogonio es la componente femenina y el anteridio la masculina. El oogonio está separado de las hifas por un septo, es globoso o casi globoso, hialino (en ocasiones se pigmenta ligeramente tomando coloración amarilla o marrrón) (Erwin y Ribeiro, 1996). El anteridio puede ser esférico, oval, claviforme o cilíndrico, está separado de la hifa por un septo y se une a la base del oogonio, atrapándolo (anfigino) o por la parte hemisférica inferior (paragino). La forma de unión del anteridio al oogonio es un carácter diferenciador de grupos de especies.

La fusión de los núcleos del anteridio y el oogonio en el interior de éste, da lugar a la oospora diploide. Si la oospora ocupa todo el volumen del oogonio se denomina plerótica y si queda un espacio entre la pared del oogonio y la oospora se denomina aplerótica, estas diferencias ayudan a separar e identificar las especies. La oospora germina después de romperse la latencia y forma uno o múltiples tubos germinativos, los cuales pueden dar lugar, inmed iatamente, a esporangios o a micelio (Erwin y Ribeiro, 1996).

Algunas especies son auto-fértiles (homotálicas), mientras que otras son autoestériles (heterotálicas), en estas últimas se precisa la presencia simultánea de los dos tipos de compatibilidad (A1 y A2) creciendo en un medio adecuado para que se formen las oosporas. El papel en el campo de las oosporas en las especies heterotálicas, además del de supervivencia y persistencia en el tiempo, que cumplen en las especies homotálicas, permaneciendo sobre los restos del vegetal enfermo, parece ser que es el de originar variabilidad a través de la recombinación, lo que puede originar nuevas variantes patogénicas (Andrivon, 1995).

Las características morfológicas del micelio, esporangios o estructuras sexuales, son los elementos básicos para diferenciar especies dentro de los seis grupos taxonómicos que estableció Waterhouse $(1963 ; 1970)$. Las dos especies de las que se tratará en este trabajo se encuadran en el Grupo II y se pueden diferenciar entre sí porque: a) $P$. capsici produce esporangios sobre largos pedicelos, caducos, con formas de ovoides a alargados. b) $P$. parasitica produce esporangios más redondeados que la anterior, no caducos. 

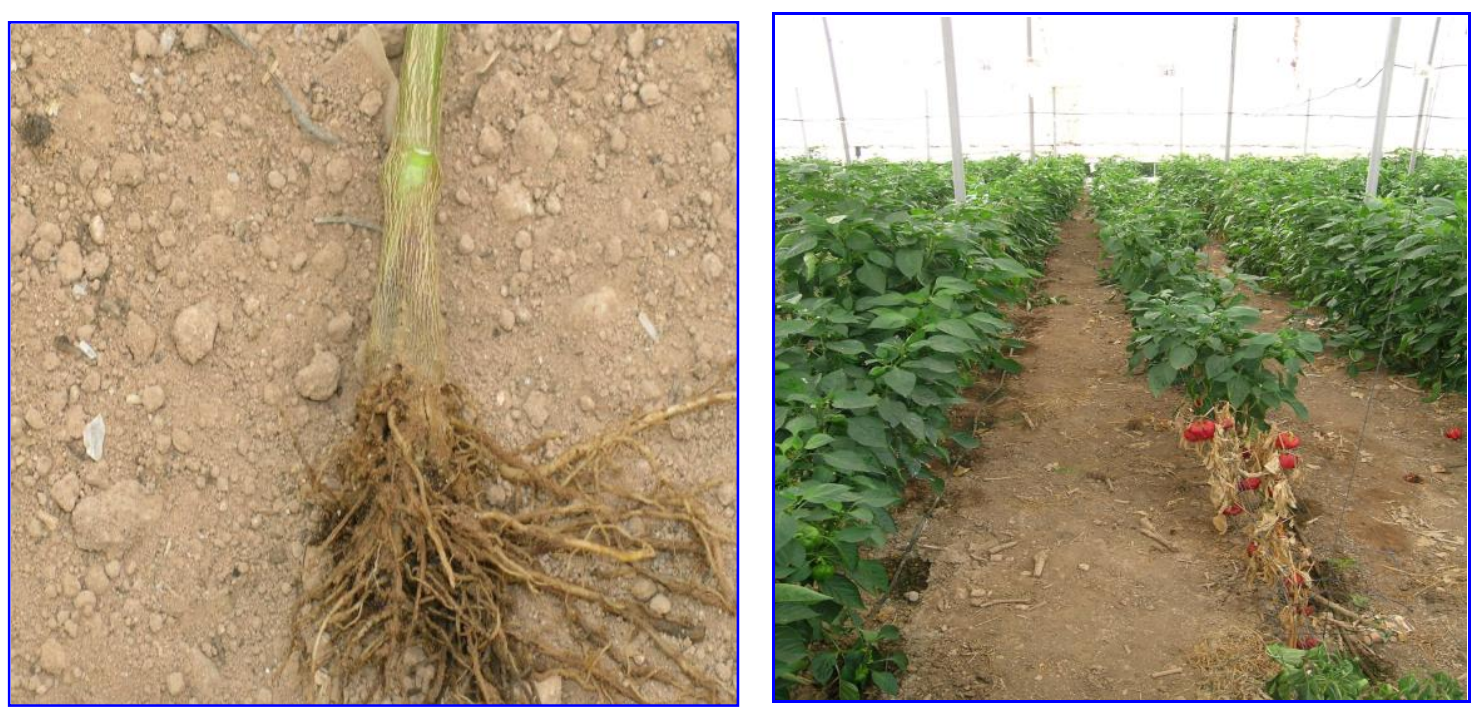

Fotos 2 y 3. Lesión producida por Phytophthora sp. (izquierda) y síntomas del hongo (derecha) en plantas de pimiento.

\subsubsection{La "tristeza" o "seca"}

Los síntomas que producen las dos especies en pimiento se caracterizan por: al inicio de la infección la planta sufre un marchitamiento que se va acentuando con el paso del tiempo ("tristeza") hasta que se seca ("seca"). Las epinastias suponen pérdida de turgencia de los tejidos (Palazón y Palazón, 1989), manteniendo su color verde un cierto tiempo, hasta que, finalmente, terminan por secarse, sin desprenderse de la planta. Esta última característica diferencia el ataque de Phytophthora spp. del de Verticilliun dahliae (traqueomicosis que puede afectar al pimiento en zonas templadas), y provoca defoliación. La manifestación de los síntomas es más violenta cuanto mayor es la temperatura en verano.

Con los primeros síntomas de marchitez, se observa una alteración en la raíz y la zona del cuello, en donde los tejidos aparecen necrosados, con un color marrón intenso. El sistema radicular, en especial las raicillas jóvenes, se ven afectadas sectorial (suele ser frecuente en cultivos con sistemas de riego por goteo) o totalmente. Según avanza el ataque, la raíz principal se ve afectada en alguna de sus partes o completamente. En este momento el proceso de marchitez suele ser ya irreversible y se inicia el desecado de la planta. La raíz termina por descomponerse totalmente y en el cuello aparecen placas deprimidas del cilindro cortical, de color marrón que se van extendiendo en sentido vertical a lo largo del tallo. En ocasiones y cuando el síntoma es muy pronunciado, es frecuente que el cilindro xilemático tome coloración oscura o negra bajo la mancha deprimida e incluso a lo largo del tallo. Este síntoma suele aparecer en el caso de que los órganos afectados sean las raíces, asociándose a la asfixia que se produce al perder la funcionalidad las mismas. Son fácilmente confundibles con los de la asfixia radicular.

La epidemia progresa en el sentido de las filas del cultivo o en el del movimiento del agua de riego, cuando es por gravedad o surcos. En las condiciones de los invernaderos del Campo de Cartagena no se han encontrado daños en la parte superior del tallo, en las ramas o en las hojas, aunque se tiene constancia de la aparición de ataques de ese tipo en cultivos de pimiento para pimentón de la Vega del Guadalentín (Lacasa, 2010; comunicación personal).

En una prospección realizada en los invernaderos del Campo de Cartagena, Lacasa y Guirao (1997) encontraron que más del $38 \%$ se encuentran contaminados 
de $P$. capsici y en más del $15 \%$ la incidencia de la "tristeza" era considerada por los agricultores como grave por sobrepasar el $20 \%$ de plantas muertas, pese a la desinfección anual de los suelos con bromuro de metilo y la aplicación de fungicidas específicos en las primeras fases del cultivo. En la actualidad la presencia de $P$. parasitica (Guerrero et al., 2012) en los invernaderos de esa comarca se estima que tiene la misma incidencia que hace 15 años tenía $P$. capsici.

\subsubsection{Los nematodos noduladores o agalladores}

Son varias las especies del género Meloidogyne que afectan al pimiento en el ámbito mundial de la producción. De ellas, cuatro: $M$. incognita, $M$. arenaria, $M$. javanica y M. hapla se han citado en España (Bello et al., 2004), siendo las de mayor importancia por los daños que producen a escala mundial y por estar ampliamente distribuidas (Dijan-Caporalino et al., 1999, 2007). Otras dos especies: M. chitwoodi y $M$. fallax, están menos extendidas, son consideradas de cuarentena para la mayor parte de los países europeos (Dijan-Caporalino et al., 2007) y todavía no han sido citadas en España.

Las especies de Meloidogyne presentan diformismo sexual mientras que las hembras tienen el cuerpo esférico en forma de pera y son endoparásitas, los machos son filiformes y liberados. Los estados evolutivos móviles son también filiformes con la región caudal adelgazada. Adultos y juveniles disponen de un estilete robusto que hincan en las raíces para alimentarse de las células corticales.

Las hembras producen huevos en masas blanquecinas primero y marrones cuando maduran. De los huevos emergen los juveniles en estado J2, ya que el primer estado de desarrollo (J1) se produce en el interior del huevo. El estado J2 liberado tiene capacidad para desplazarse emigrando en dirección a las raíces o bien se dispersa a favor de los movimientos del agua en el suelo. Establecido el contacto con la raíz, hinca el estilete y penetra ligeramente en el tejido, moviéndose entre las células hasta alcanzar los vasos y migrar por ellos. En la zona cortical de diferenciación celular, se instala de forma sedentaria, alimentándose de "células gigantes", multinucleadas que se han formado por acción de las substancias inyectadas por el juvenil. Las células próximas a las afectadas, aumentan de tamaño, formando en el tejido nódulos o agallas. Evolucionan, pasando por dos estados juveniles más, J3 y J4, sedentarios, carentes de estilete, hasta convertirse en adultos (Williamson y Gleason, 2003).

En condiciones favorables las hembras maduran en unos 15 a 30 días, liberando los huevos englobados en una masa mucilaginosa con enzimas que tienen efectos líticos sobre las células de las raíces de las plantas, lo que permite que los huevos alcancen el exterior de la raíz, sobre la superficie de los nódulos o agallas, formando masas redondeadas que albergan unos 500 huevos. Los huevos permanecen protegidos en las masas hasta que las condiciones de humedad, temperatura y estímulos de los exudados radiculares de las plantas son adecuadas. La especie se reproduce por partenogénesis telítoca, pudiendo prescindir del concurso del macho (Orton, 1973).

El ciclo de desarrollo de $M$. incognita varía según la temperatura. Se considera que la temperatura óptima de desarrollo es de $28{ }^{\circ} \mathrm{C}$, para la cual el ciclo completo dura unos 30 días. A $20^{\circ} \mathrm{C}$ dura 57-60 días (Orton, 1973). La temperatura influye también sobre la actividad y la movilidad de la fase migratoria (J2). Así, la capacidad para penetrar en las raíces y para infestar la planta se ve afectada a $18^{\circ} \mathrm{C}$. A temperaturas superiores a $35^{\circ} \mathrm{C}$ la reproducción se inhibe (Ploeg y Maris, 1999), aunque se pueden producir biotipos capaces de adaptarse a esas condiciones, lo que 
es indicativo de la capacidad de respuesta y adaptación de esta especie cosmopolita a condiciones variadas, incluso extremas.

Los daños en las plantas se expresan por un debilitamiento general, con reducción en el crecimiento y en el tamaño, con entrenudos más cortos, amarilleamientos en las hojas apicales, que empiezan por la parte basal central de la hoja o del foliolo y avanzan hacia los bordes, terminando por blanquear toda la superficie cuando la infestación es intensa y prolongada. En las raíces se presentan nódulos o agallas, primero en las raíces secundarias, y en las principales después llegando a deformarlas pronunciadamente. Las agallas se instalan en la zona cortical pero alcanzan al sistema vascular, reduciendo la absorción de nutrientes y agua (Abad et al., 2003), por lo que cuando la infestación es muy acentuada, se presenta marchitez en la copa de la planta. La cosecha disminuye en cantidad y calidad, y solo en situaciones extremas las plantas llegan a secarse. Además, los efectos negativos se agravan, en algunas ocasiones, por interacciones de otros patógenos o con factores abióticos como los excesos de agua.

\subsubsection{Meloidogyne incognita, el proble ma re-emergente en los invernaderos del}

\section{Campo de Cartagena}

Desde la instauración del cultivo en los invernaderos del Campo de Cartagena se tiene constancia de la presencia de nematodos en los suelos de los invernaderos y de que los daños requerían de actuaciones para paliarlos (Rico, 1983). Este autor cita a Meloidogyne incognita, sin que se hubiera realizado un estudio de identificación de las especies que se asociaban al cultivo y recomendaba tratamientos con nematicidas en preplantación.

Además de M. incognita se ha citado la presencia de M. javanica (Bello et al., 1997a, 2004; Cenis y Fuchs, 1988), siendo M. incognita la más frecuente, la más abundante y la más agresiva, provocando daños de gran importancia en los suelos donde no se adoptan medidas eficaces de control (Bello et al., 2004; Robertson et al., 2006; Piedra-Buena et al., 2007; Ros et al., 2004a, 2005, 2006, 2007 y 2008).
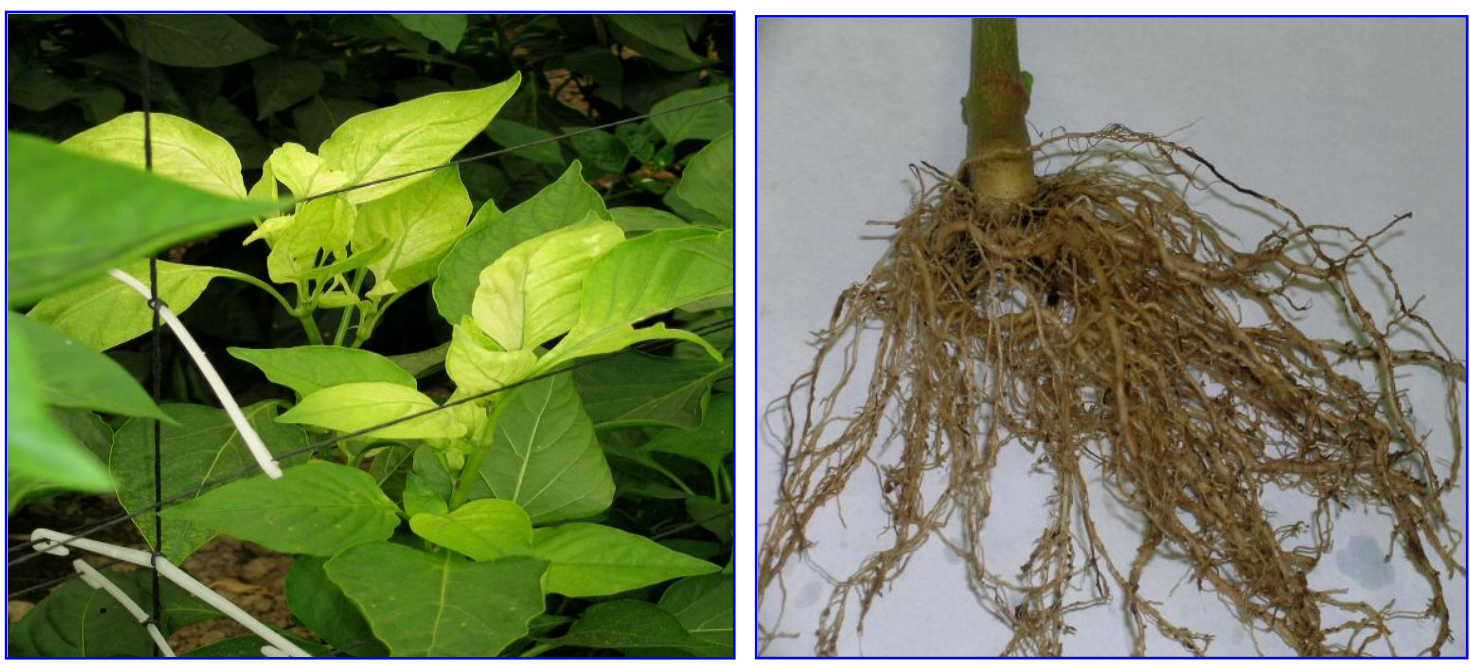

Fotos 4 y 5. Amarilleos provocados por nematodos (izquierda) y nódulos (derecha), en plantas de pimiento. 
La mayor parte de los suelos del Campo de Cartagena, están contaminados de nematodos en particular de $M$. incognita, dada su polifagía y adaptación a zonas cálidas y dada la estructura productiva de la zona donde se alternan y coexisten cultivos sensibles en sistemas de producción intensiva de hortalizas al aire libre. Los suelos de los invernaderos de esta comarca no son una excepción al resto y la importancia de los nematodos se hace más patente en los invernaderos destinados a producciones ecológicas (Bello et al., 1997a). Quizás el que los invernaderos se construyeran en suelos previamente cultivados de hortalizas sensibles, sea la explicación de la presencia de $M$. incognita, o también contaminaciones por maquinarias.

El cambio en la estructura varietal (mayoría de variedades de tipo California) pudiera explicar que sea $M$. incognita la mayoritariamente detectada, al poder ser portadoras de resistencias específicas a M. javanica (Bello et al., 1997a y 2004; Robertson et al., 2006), incluso cuando se cultiva pimiento a continuación de tomate y son importantes los daños sobre este último.

En párrafos precedentes indicábamos que la comarca del Campo de Cartagena tiene un dilatado historial en el cultivo de pimiento para pimentón, sin que se hubieran señalado a los nematodos como plagas o productores de enfermedades a este cultivo en ésta o en otras comarcas de la región. Por contra, desde el inicio del desarrollo del cultivo de pimiento grueso en los invernaderos (a mediados de los años 70 del pasado siglo) se señalaron a los nematodos como un problema para el cultivo (Tello y Lacasa, 1997; 2004). Con el empleo anual del bromuro de metilo en todos los invernaderos Meloidogyne sp. dejó de aparecer en el catálogo de patógenos importantes del cultivo no considerando que fuera un problema por parte de los cultivadores (Bello et al., 1997a).

En ambientes mediterráneos, según Bello y Tello (1997b), el género Meloidogyne sería el único grupo de nematodos que justificaría el uso del bromuro de metilo para la desinfección de los suelos, para su control en sistemas de producción intensiva de pimiento, pues los individuos pertenecientes a los géneros Ditylenchus y Pratylenchus se hallan muy localizados y pueden controlarse con nematicidas convencionales. De esta forma, la retirada del bromuro de metilo ha afectado en gran medida al control de los nematodos formadores de nódulos como $M$. arenaria, $M$. javanica y $M$. incognita, cuya área de riesgo se encuentra en el litoral mediterráneo, sur de la península, Baleares y Canarias (Bello et al., 2004).

El uso de la mezcla de 1,3-dicloropropeno y cloropicrina, considerada alternativa universal al bromuro de metilo ha supuesto una disminución en la eficacia de la desinfección frente a los nematodos, siendo los resultados del control aleatorios o dependientes del tipo de suelo, de la densidad poblacional, del estado del suelo en el momento de la aplicación y de la forma de aplicación. Con el paso del tiempo se han hecho más abundantes los casos de invernaderos desinfectados con la mezcla en los que el cultivo ha presentado daños en las raíces y síntomas en la parte aérea acompañados de pérdidas de producción, como ya señalaran Lacasa et al. (2006). En definitiva los nematodos han emergido como problema fitopatosanitario de los suelos de los invernaderos, ya que la desinfección con bromuro de metilo enmascaró su presencia, al no alcanzar niveles de daños significativos.

Las tentativas de rotaciones con otros cultivos susceptibles a las especies de Meloidogyne sp. como el calabacín o el melón se han saldado con un aumento de las poblaciones que llegan a ser limitantes para el cultivo rotacional y para el cultivo principal que es el pimiento o que se produzcan pérdidas en este último que no se producían con anterioridad. 


\subsubsection{La fatiga de los suelos por monocultivos reiterados}

El cansancio o fatiga del suelo es conocido desde antiguo (Chen et al., 1991) y es definida como la perturbación de la fertilidad del suelo debida a causas múltiples que pueden ser acumulativas, sucesivas o simultáneas (Bouhot, 1983).

En el Capítulo 4 se realiza una revisión bibliográfica extensa sobre las causas y la forma de corregirla, antes de tratar el tema de forma específica para el caso del pimiento en invernaderos.

Como se ha indicado en los antecedentes, el monocultivo de pimiento desde hace más de 15-20 años se realizaba en más del 95\% de los invernaderos del Campo de Cartagena (Lacasa y Guirao, 1997) y en la actualidad se mantiene en más del 75\% de la superficie.

El efecto del monocultivo continuado se traduce en una reducción en la producción, variable según el año de reiteración y el cultivo, acompañada de un menor desarrollo de la planta y amarilleamientos del follaje, lo que los agricultores advierten al dejar de desinfectar (Lacasa y Guirao, 1997) y que denominan "cansancio" y que se ha podido comprobar, tanto en invernaderos con más de 15 años de reiteración (Guirao et al., 2004) como en invernaderos con dos años de reiteración (Guerrero et al., 2004b).

En los invernaderos de pimiento la fatiga desaparece tras una desinfección del suelo con desinfectantes generales totales, por lo que la causa parece tener una componente microbiológica muy marcada (Martínez et al., 2005 y 2011; Martínez, 2008).

Los trabajos de Martínez (2008) y Martínez et al. (2005, 2011) apuntan hacia la posible relación entre la composición de la microbiota fúngica y su acumulación en el suelo y la reducción del desarrollo de las plantas de pimiento y la pérdida de cosecha. En cultivos de solanáceas se acumula $F$. solani (Tello y Lacasa, 1990) en el suelo, sin que se tengan pruebas de implicaciones patogénicas directas, pero sí efectos depresivos en las plantas (Martínez, 2008).

En definitiva, la fatiga del suelo se puede considerar como un problema fitosanitario o de salud del suelo en los monocultivos de pimiento de los invernaderos del Campo de Cartagena, que requiere de medidas para paliar sus efectos.

\subsection{CONTROL DE LAS ENFERMEDADES DEL SUELO EN CULTIVOS DE PIMIENTO EN INVERNADERO}

En los cultivos hortícolas intensivos, el control de las enfermedades producidas por los patógenos del suelo implica una complejidad mayor que en los cultivos extensivos (Katán, 2005) y el cultivo de pimiento en los invernaderos del Campo de Cartagena no es una excepción.

Así, las estrategias de control tradicionalmente recomendadas, como la rotación de cultivos, son de difícil aplicación en el sistema de producción de pimiento en la Región de Murcia, por su alto grado de especialización, y por cuestiones relativas a la oferta comercial. Es práctica habitual en la zona la desinfección del suelo por medios químicos y no químicos para el control de las patologías del suelo en la mayoría de cultivos hortícolas, incluido el pimiento. 
En la actualidad, algunos agricultores están dando un giro importante en sus explotaciones intentando introducir la rotación de cultivos como forma de evitar o paliar la incidencia de las patologías.

Por otra parte se está haciendo un esfuerzo importante para la introducción de resistencias a los principales patógenos (Phytophthora sp. y Meloidogyne sp) en variedades comerciales o en porta-injertos. El injerto es una forma eficaz de control (Ros et al., 2004b, 2007, 2011) y una técnica disponible en la actualidad, mientras se evalúa el comportamiento de las primeras variedades con resistencias a nematodos y/o a Phytophthora sp.

\subsubsection{La desinfección del suelo}

Desde el inicio del desarrollo del cultivo del pimiento en los invernaderos del Campo de Cartagena la desinfección del suelo ha sido una práctica cultural habitual en toda la superficie, tanto para el control de los patógenos como para paliar los efectos de la fatiga del suelo. Los primeros desinfectantes utilizados fueron el metam sodio, el 1,3-dicloropropeno y fungicidas o nematicidas de aplicación al suelo.

A finales de los años 70, se introdujo en España el bromuro de metilo, extendiéndose su empleo en la zona durante los años 80. Es a partir de 1988 cuando la desinfección del suelo con bromuro de metilo se adoptó como práctica cultural en toda la superficie (Lacasa y Guirao, 1997). El amplio espectro de actividad, la facilidad para la aplicación y la rapidez de su acción justificaron su uso durante más de dos décadas. La formulación empleada tradicionalmente era 98:2 (98\% de bromuro de metilo y $2 \%$ de cloropicrina) (Foto 6), a dosis de $60 \mathrm{~g} \mathrm{~m}^{-2}$ bajo polietileno de 200 GG (50 micras), aplicado en frío.

Los acuerdos internacionales adoptados por el Methyl Bromide Technical Options Comitte (MBTOC) obligaron a utilizar plástico VIF (virtually impermeable film) a partir de 1997, con el objeto de reducir las emisiones a la atmósfera, al mismo tiempo que se disminuía la dosis de 60 a $30 \mathrm{~g} \mathrm{~m}^{-2}$. La no disponibilidad de alternativas técnicas y económicamente viables para este cultivo permitió utilizar reducidas cantidades de bromuro de metilo acogiéndose el pimiento de los invernaderos de la Región de Murcia y del Sur de la Comunidad Valenciana a "usos críticos" (CUN: Critical Use Nomination), moratorias temporales para aquellos sectores en los que se demostró que no había alternativa al fumigante. Los usos críticos en la Región de Murcia se acabaron el 31 de diciembre de 2006 y durante ellos se utilizó la formulación 67:33 (67\% de bromuro de metilo y 33\% de cloropicrina) aplicada en fumigación en frío a $40 \mathrm{~g} \mathrm{~m}^{-2}$ con plástico VIF de $0,04 \mathrm{~mm}$.

Los trabajos para desarrollar alternativas viables (químicas y no químicas) continúan en la actualidad, aunque algunas tengan ciertas connotaciones técnicas que es preciso poner a punto para su aplicación comercial (Guerrero et al., 2004a; 2004b). Muchos fumigantes (algunos de antiguo uso) han sido de nuevo reevaluados. El dazomet primero y recientemente el metam sodio han sido inscritos en el Anexo I del registro único europeo, mientras otros como el 1,3-dicloropropeno primero y luego la cloropicrina han sido excluidos del mencionado anexo, disponiendo en la actualidad de autorizaciones excepcionales de uso por no disponerse de alternativas.

Además de las alternativas químicas, muchas otras han sido y están siendo evaluadas: como son el empleo de cultivares resistentes, la solarización (sola o combinada con otros métodos de control de patógenos del suelo), la biofumigación, la biosolarización, el injerto, los agentes de biocontrol, sistemas o estrategias integradas, etc. 
En los últimos 13 años, los estudios llevados a cabo por el Equipo de Protección de Cultivos del IMIDA parecen indicar que no hay una alternativa única que ofrezca la solución a los problemas como lo era el bromuro de metilo para el cultivo de pimiento en invernadero. Sin embargo, la asociación o su combinación con métodos no químicos pueden proporcionar niveles de eficacia equiparables con este fumigante.

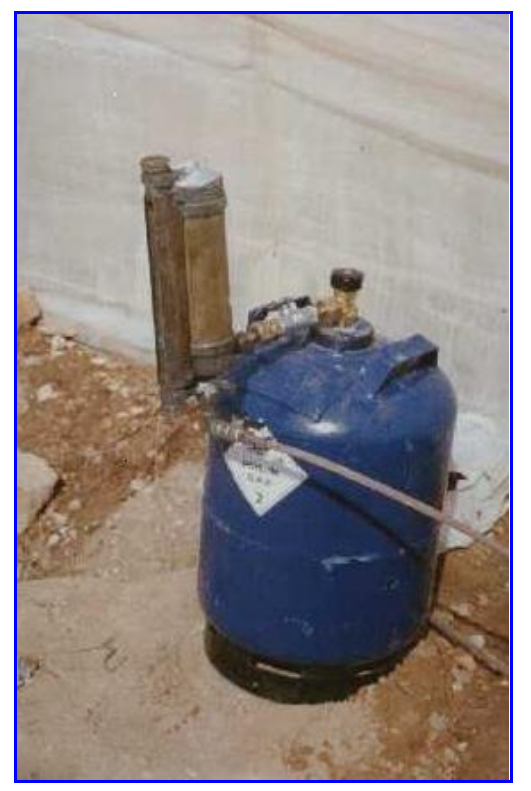

Foto 6. Botella de bromuro de metilo y dosificador.

\subsubsection{Desinfectantes químicos}

\section{El 1,3-dicloropropeno}

A principios de los años 40 del pasado siglo se descubrieron los efectos sobre los nematodos en los cultivos de piña de las islas Hawai, siendo en la actualidad utilizado, en preplantación, en numerosos cultivos herbáceos y arbóreos, por la eficacia en el control de la mayor parte de especies de nematodos fitopatógenos (Gilreath et al., 2001, 2004a, Noling et al., 2001). A dosis altas (35-50 $\mathrm{g} \mathrm{m}^{-2}$ ) se le atribuyen efectos sobre la germinación de algunas malas hierbas (Haar et al., 2001), sobre insectos y algunos hongos (Hafez et al., 2000; Martin, 2003), por lo que se puede considerar como un desinfectante del suelo.

Desde 1977 estaba autorizado su uso en gran número de cultivos en la mayoría de los países europeos. En 2009 se desestimó su inclusión en la lista del Anexo I de la Directiva 414 de la Comisión Europea, referente a las substancias autorizadas para su uso en agricultura. Desde principios de 2010 se dispone del producto para su uso excepcional en algunos cultivos, entre ellos el pimiento, con autorizaciones por 120 días. La última de estas autorizaciones se ha concedido para su uso entre el 15 de julio de 2012 y el 15 de noviembre del mismo año.

En los inicios del desarrollo del cultivo del pimiento en los invernaderos del Campo de Cartagena se utilizó para el control de los nematodos (Rico, 1983). Pocos años después fue relegado por el bromuro de metilo. Desde 2005 se viene utilizando asiduamente como componente de una mezcla con cloropicrina. Se aplica en el agua de riego y los resultados en el control de los nematodos resultan variables con el tipo de suelo, la época de desinfección y la forma de aplicación. Las deficiencias en el 
control de los nematodos se deben a las dificultades para la difusión en suelos pesados, en la degradación por microorganismos del suelo en invernaderos con altos niveles de materia orgánica y temperaturas del suelo superiores a $40^{\circ} \mathrm{C}$ (Dungan et al., 2001). La eficacia mejora cuando se utilizan plásticos VIF o HDPE, al reducir las emisiones a la atmósfera (Gilreath et al., 2004a).

\section{Metam sodio, metam potasio y dazomet}

La actividad biocida de estos compuestos se debe a la formación de isotiocianatos al descomponerse (Pocino, 1997; Shem-Tov et al., 2006). El metilisotiocianato es considerado como un desinfectante general con acción parcial y efectos herbicidas, insecticidas, fungicidas y nematicidas (Ma et al., 2000; Sullivan, 2000).

La acción fungicida del metam sodio ya se descubrió en la década de los 50 (Rosskopf et al., 2005) del pasado siglo y no fue hasta los 60 cuando comenzó a comercializarse. Los tres productos presentan facilidades para la aplicación (los primeros son líquidos y se aplican en el agua de riego, el dazomet se formula en forma de gránulos y se aplica por incorporación mediante labor de fresadora), en relación a otros desinfectantes con mayores riesgos toxicológicos.

Según Hafez et al. (2000), la eficacia depende de los factores relacionados con las características edáficas del suelo y varios autores señalan la importancia de la temperatura del suelo en el momento de la aplicación para que sea eficaz (Ma et al., 2000), ya que, a mayor temperatura, mayor eficacia, sin sobrepasar los $40^{\circ} \mathrm{C}$, pues se pasaría a generar fitotoxicidad en el cultivo. Otros autores señalan que la efectividad depende del contacto del desinfectante con los organismos diana en el caso del metam sodio y de la liberación de metil isotiocanato y su distribución uniforme en el suelo para el dazomet.

En las condiciones del Sureste español (Pocino, 1997) presenta resultados aceptables de metam sodio en cultivos como pimiento, tomate, berenjena, pepino cuando los niveles de infestación son bajos en invernaderos con pocos años de monocultivo. Sin embargo, en ensayos más recientes realizados en invernaderos del Campo de Cartagena, tanto el metam sodio como el dazomet han resultado poco eficaces para el control de Phytophthora $s p$. y Meloidogyne sp. en cultivos de pimiento (Ros et al., 2004a). Los resultados mejoraban al combinar el metam sodio con la solarización, con la biosolarización o con el injerto (Ros et al., 2003).

La falta de eficacia del metam sodio en los invernaderos del Campo de Cartagena ya se manifestó en los inicios del desarrollo del cultivo en esta comarca, lo que abocó al uso del bromuro de metilo. Para algunos autores, la pérdida o falta de eficacia del metam sodio o del dazomet, en algunos invernaderos, está motivada por la dificultad de penetración y expansión en el suelo (Martin, 2003). Cebolla (2000) señala que la pérdida de eficacia tras la aplicación reiterada en el mismo suelo se debe a que es degradado por microorganismos del suelo que se seleccionan con la reiteración.

Con la aplicación de metam sodio, Larregla (2003) obtuvo aceptables niveles de control de $P$. capsici en cultivo de pimiento en invernaderos del País Vasco, no sucediendo lo mismo con Phytophthora sp. en los invernaderos de la Región de Murcia (Ros et al., 2004a). 


\section{La cloropicrina}

Procede de la reacción del ácido pícrico con hipoclorito de calcio, siendo Stenhouse el primero que la sintetizó en 1848 y fue empleada como desinfectante de suelo por primera vez tras la Segunda Guerra Mundial, por su acción sobre hongos (Wilhelm, 1965).

La degradación en el suelo, comienza dos días después de la aplicación, proporcionando dióxido de carbono, óxido de nitrógeno y cloro (Jeffers y Wolfe, 1993) principalmente por mecanismos abióticos (Zheng et al., 2004) y por bacterias del género Pseudomonas spp. (Dungan et al., 2001). La vida media de permanencia en el ambiente se ha estimado en 20 días (Gan et al., 2000). La degradación en el suelo se acelera al aumentar la temperatura, siendo independiente de la textura, estimándose una vida media en el suelo de 1 día (Ajwa et al., 2004). Algunos autores consideran que la degradación adiciona fertilizantes nitrogenados al suelo (Wilhelm, 1965), mejorando el desarrollo de las plantas. Asimismo, aseguran que, cuando se sella con plástico, su eficacia es mayor que el bromuro de metilo en las mismas condiciones, siendo las concentraciones del producto más altas en el centro de la parcela desinfectada que en los laterales.

Además de los efectos sobre los hongos (Wilhelm, 1965; Clerjeau et al., 1974), se le atribuyen algunos efectos sobre malas hierbas y sobre nematodos (Wilhelm y Paulus, 1980; Rodríguez-Kábana, 1998; Porter et al., 1999; Gilreath et al., 2004b), pero su eficacia es deficiente cuando las infestaciones son elevadas. Por ello, se ha combinado con otros productos para completar su espectro de acción (Motis y Gilreath, 2002), cuando los hongos no son el principal problema fitopatológico, como ocurre en algunas regiones de Italia y España (Gullino et al., 2003; Minuto et al., 2006; Lacasa et al., 1999, 2002, 2007).

El uso con fines bélicos, supuso que se dejara de utilizar en agricultura. Ante la necesidad de prescindir del bromuro de metilo, en cuya formulación se adicionaba cloropicrina como indicador, se retomó el uso de este desinfectante, tanto en aplicaciones por inyección como en el agua de riego, siendo incluida en la lista de substancias utilizables en agricultura por parte de la Comisión Europea con carácter provisional. Como el 1,3-dicloropropeno se halla excluida en la actualidad del Anexo 1 de la Directiva 91/414 de la Unión Europea y se dispone de un periodo de 120 días para su uso de forma excepcional en cultivos hortícolas intensivos, incluido el pimiento.

La eficacia en suelos arcillosos con alto contenido en materia orgánica es menor que en los arenosos con bajo contenido en materia orgánica (Minuto et al., 2006). En las condiciones de los cultivos de pimiento del Campo de Cartagena, se han determinado las dosis de aplicación y el espectro de acción y la eficiencia desinfectante (Guerrero et al., 2007), mostrando deficiencias notables en el control de nematodos y de malas hierbas. Se ensayó la combinación con óxido de propileno y con dimetil disulfito, mejorando la eficacia del espectro de actividad (Lacasa et al., 2006), así como con el injerto.

\section{Mezcla dicloropropeno+cloropicrina}

La mezcla compatible de las dos substancias se realizó para complementar el efecto nematicida del 1,3-dicloropropeno (Eger, 2000) con los efectos fungicidas y bactericidas de la cloropicrina (Rodríguez-Kábana, 1998). 
En el último cuarto del pasado siglo ya se realizaron mezclas de ambos productos y se utilizaron en el continente americano, pero no en el europeo. Ha sido recientemente cuando se ha extendido su uso como alternativa al bromuro de metilo. En más de 160 trabajos se muestra que se han obtenido niveles de control de los patógenos y producciones similares o superiores a las obtenidas con la desinfección del suelo con bromuro de metilo en diferentes cultivos hortícolas (Ajwa et al., 2002, 2003, 2004; Porter et al., 2006). Por ello, se ha considerado a la mezcla como la alternativa universal al bromuro de metilo. En la actualidad, en la Unión Europea su uso está limitado como lo están sus componentes, disponiendo de una autorización de 120 días para su uso de forma excepcional en cultivos hortícolas intensivos, incluido el pimiento en invernadero, en varios países europeos, entre ellos España.

Algunos autores (Ajwa et al., 2002; Cebolla et al., 2004) señalan que la eficacia de este fumigante depende del grado de humedecimiento del suelo en el momento de la incorporación, la cantidad de agua empleada durante y después de la incorporación de los productos al suelo, del caudal de los emisores, de la densidad de goteadores, y de las características del sellado. Según Locascio y Dickson (2000), la eficacia desinfectante es mejor al aplicarlo en el agua de riego por goteo que al aplicarlo por inyección, ya que la distribución de los gases en el suelo resulta más uniforme. La eficacia mejora cuando se utilizan plásticos semi-permeables (PEHD) o impermeables (VIF) a los gases, al reducir las emisiones a la atmósfera de los dos compuestos (Ou et al., 2001; Gilreath et al., 2004a).

Para el cultivo de pimiento en los invernaderos del Campo de Cartagena la dosis de aplicación del producto recomendada es de 400 a 5001 ha $^{-1}$ (Lacasa et al., 2002), el sellado con plástico VIF de $0,04 \mathrm{~mm}$ mejora la eficacia frente a Phytophthora sp., el desarrollo vegetativo y se obtiene una producción similar a la del bromuro de metilo, con respecto al sellado con polietileno de $0,05 \mathrm{~mm}$ (Lacasa et al., 2003). La forma de humedecer el suelo antes de la aplicación parece influir menos que la forma de incorporación de la mezcla al suelo, siempre que el perfil de 25-30 cm de profundidad quede humedecido (que no saturado) (Lacasa et al., 2006).

La utilización de la mezcla como desinfectante del suelo, utilizando plástico de polietileno y aplicándola en el agua de riego se ha mostrado como una alternativa al bromuro de metilo, proporcionando un buen control de Phytophthora sp., un control aceptable de malas hierbas y de M. incognita (Guerrero et al., 2004b). Cuando se ha reiterado su aplicación en años consecutivos se ha observado un aumento de la efectividad de la desinfección, incluso con mejoras en la producción (Guerrero et al., 2006). En combinación con el injerto sobre porta-injertos resistentes a $M$. incognita y a Phytophthora $s p$. se podría usar a dosis inferiores a las recomendadas (Ros et al., 2004c).

\subsubsection{Desinfección por medios no químicos}

Las tentativas de utilizar medios no químicos de desinfección del suelo se inician en los invernaderos del Campo de Cartagena a principios de los años ochenta con los primeros ensayos de solarización (Cenis y Fuchs, 1988). Pasados 10 años de estas publicaciones se retomaron los trabajos, adicionando enmiendas orgánicas de origen animal a la solarización (Lacasa et al., 2002; Guerrero et al., 2004a y b), como una solución para las producciones ecológicas, basándose en los métodos de biofumigación. El control de los patógenos principales y la reducción de los efectos de la fatiga del suelo son los objetivos principales.

Los antecedentes y fundamentos de estos métodos se tratarán con detalle en el Capítulo 5, en particular en lo concerniente a la biosolarización o biodesinfección. 
Sin embargo, se exponen aquí los antecedentes relativos a la biofumigación y a la solarización.

\section{La biofumigación}

Varios autores se refieren a la biofumigación como el efecto supresivo que provoca la generación de isotiocianatos por la hidrólisis de los glucosinolatos presentes en las plantas de la familia Brassicaceae, ya se entierren en fresco (Kirkegaard et al., 1993; Brown y Morra, 1997; Sarwar et al., 1998; Zasada y Ferris, 2003) o en seco después de un procesado industrial (Lazzeri y Manici, 2000; Lazzeri et al., 2004). Los compuestos liberados (metil o alil-isotiocianatos) tienen efectos sobre gran parte de la microbiota de los suelos, siendo comparable su acción a la de los compuestos de síntesis (metam-sodio, metam-potasio, dazomet) que generan las mismas moléculas biocidas al descomponerse en el suelo (Angus et al., 1994). La actividad es general y parcial ya que tiene efecto sobre insectos, hongos, nematodos, virus, bacterias y malas hierbas (Kirkegaard y Sawar, 1998), pero no elimina totalmente las poblaciones.

La hidrólisis de los glucosinolatos genera gran cantidad de compuestos, de los que los isotiocianatos se consideran los más tóxicos, mostrando un amplio espectro de actividad biocida; sin embargo, un determinado isotiocianato muestra diferente toxicidad según el patógeno sobre el que actúa (Sawar et al., 1998). Dado que la gama y cantidad de compuestos generados depende de la especie de brasica, es preciso tenerlo en cuenta a la hora de seleccionarla para su uso biofumigante. Kirkegaard y Sawar (1998) indicaron que el poder biofumigante de un determinado genotipo frente a un patógeno específico depende de la biomasa total y de la proporción de cada parte de la planta que contribuye a la biomasa total, de la concentración y el tipo de cada glucosinolato en la parte predominante de la planta así como de la toxicidad frente al patógeno de los productos que se generan en la hidrólisis de glucosinolatos.

El efecto biofumigante no parece ser exclusivo de las brasicas, ya que la descomposición de numerosas enmiendas orgánicas, como estiércoles de origen animal o urbano, subproductos industriales, etc, da lugar a compuestos con actividad biocida como el amoniaco, ácido nitroso, ácidos orgánicos volátiles (Lazarovits et al., 1999; Bailey y Lazarovits, 2003; Tenuta y Lazarovits, 2002; Tenuta et al., 2002; Lazarovits et al., 2005; Abbasi et al., 2004).

En base a estas últimas consideraciones Bello et al. (1999b, 2000) definieron el término biofumigación como "la acción de las sustancias volátiles producidas en la biodegradación de la materia orgánica en el manejo de los patógenos de las plantas", asociando la actividad biofumigante a todo tipo de materia orgánica (estiércol, restos de cosecha, abonos verdes, etc.) y residuos agroindustriales (residuos de industria papelera, azucarera, etc.), lo cual es contemplado por Bonannomi et al. (2007) u Oka (2010) al mismo nivel de eficacia que las brasicas, indicando que pueden favorecer o potenciar los efectos supresivos en los suelos en que se incorporan.

Las enmiendas orgánicas para ser usadas como biofumigantes en el control de patógenos son diferentes de las utilizadas como mejoradoras de las propiedades del suelo, por las características de los materiales utilizados, por la dosis y por el método de aplicación (Piedra-Buena, 2004). Para conseguir buenos resultados en la desinfección del suelo es necesario que la materia orgánica esté en vías de descomposición, con una relación C/N entre 8-20 (Bello et al., 2000). La cantidad a utilizar ha de cumplir los requerimientos contemplados en el Real Decreto 261/1996 
de 16 de febrero sobre protección de las aguas contra la contaminación producida por los nitratos procedentes de fuentes agrarias. El sellado del suelo (humedeciéndolo, cubriéndolo con plástico o cualquier otro acolchado, etc) parece conveniente para retener los gases y así facilitar su actividad, generalmente de carácter biostático cuando los patógenos son nematodos, lo que supone prolongar el efecto en el tiempo (Díez-Rojo et al., 2006, Zanón, 2009).

Pero con la aplicación de enmiendas biofumigantes para la desinfección del suelo se ha puesto de manifiesto que se producen modificaciones en las características físicas y químicas del suelo, mejorando la disponibilidad de nutrientes utilizables por la planta e incrementando las poblaciones de los nematodos saprófagos (Bello et al., 2004; Díez-Rojo, 2010).

En las condiciones del Levante y Sureste de España la biofumigación no ha proporcionado resultados relevantes en el control de los patógenos del suelo, ya que las condiciones de aridez y sequía estivales no permiten que la actividad del biosolarizante se prolongue en el tiempo. El sellado con agua tiene efectos en los primeros centímetros, pero pronto se deseca la parte superficial del suelo haciéndose permeable a los gases emitidos en la biodegradación de la enmienda. La repetición del humedecimiento supone un enfriamiento del suelo, lo que frena los procesos de emisión de los gases.

Por ello se ha combinado la biofumigación con la solarización, tal como se indicará en el Capítulo 5, para aumentar la eficacia en el control de los patógenos edáficos.

\section{La solarización}

En base a las experiencia realizadas en Israel, Katan (1981) definió la solarización como una forma de desinfección del suelo aprovechando la energía solar incidente en un suelo humedecido y cubierto con una lámina de plástico (generalmente polietileno transparente). El uso de acolchados de los cultivos con plástico permitió poner de manifiesto el efecto sobre la planta de la cobertura del suelo con plástico transparente u opaco (Katán et al., 1976). La temperatura alcanzada en profundidades del suelo superiores a los $20 \mathrm{~cm}$ es suficiente para reducir las poblaciones de los patógenos, en particular en áreas de alta insolación y estaciones cálidas del año (Cenis, 1986; Cenis y Fuchs, 1988; Chellemi et al., 1994 y 1997; Coelho et al., 1999).

La solarización se puede definir como un proceso de desinfección hidrotermal del suelo que tiene lugar por la captura pasiva de la radiación solar estando el suelo húmedo y cubierto con una lámina de plástico transparente (normalmente de polietileno) (Katan, 1981). La actividad sobre la microbiota se debe a la acción de la temperatura. La aplicación de este método de desinfección del suelo tiene gran dependencia de las condiciones climáticas, por lo que su utilización queda restringida a zonas con climas áridos en los que se registran altas temperaturas y elevada radiación solar (Chellemi et al., 1994). En estas zonas se ha comprobado su eficacia en el control de numerosos patógenos, tanto fúngicos como nematodos (Katan y DeVay, 1991).

Al efecto térmico hay que adicionar el derivado de la acumulación de gases procedentes de la descomposición de la materia orgánica que pueda haber en el suelo (Gamliel et al., 2000; Oka, 2010). Además, el sellado plástico supone que se reduzca el contenido en oxígeno en el suelo en la biodescomposición de la materia orgánica, 
produciéndose situaciones de hipoxia o anoxia, limitando la densidad poblacional de los microorganismos patógenos (Block et al., 2000).

En la comarca del Campo de Cartagena se llevaron a cabo los primeros ensayos de solarización de suelos (Cenis, 1986) orientados al control de Phytophthora sp. y de Meloidogyne sp. (Cenis y Fuchs, 1988), obteniendo buenos resultados frente al hongo, pero la incidencia de los nematodos en el tomate que se puso como indicador de la eficacia desinfectante fue elevada, no diferente al testigo no desinfectado. Sin embargo, no observaron daños en el cultivo del pimiento, probablemente debido a que el suelo estaba contaminado de $M$. javanica al que muchas variedades de pimiento son resistentes (Djian-Caporalino et al., 2011). Escuer et al. (2004) indican que la solarización, por sí sola no es siempre un método eficaz, especialmente en el control de organismos móviles como son los nematodos, que por la acción del calor se desplazan a zonas más profundas y se incorporan de nuevo con el laboreo que se realiza al preparar el suelo para plantar el cultivo.

La combinación de la solarización con la aplicación bajo el plástico de productos químicos fumigantes como el metam sodio mejora la eficacia del fumigante y de la solarización (Ros et al., 2004a). Lo mismo sucede con la incorporación de antagonistas biológicos o enmiendas orgánicas (Barres et al., 2006; Bello et al., 2004).

\subsubsection{Control de los patógenos sin desinfección}

\subsubsection{La resistencia genética}

\section{a) Resistencia a Phytophthora sp.}

Los proyectos de introducción de resistencia a Phytophthora $s p$. en variedades de pimiento para el cultivo en los invernaderos del área mediterránea se interrumpieron a mediados de los años ochenta del pasado siglo, cuando se extendió el uso del bromuro de metilo para la desinfección anual de los suelos (Tello y Lacasa, 1997).

Los trabajos sobre la resistencia y Phytophthora capsici se habían iniciado en Europa a principios de la década de los años 70 del pasado siglo por Pochard y Chamboned (1971) y Ponchet et al., (1972). Estaban orientados al conocimiento de las características de la resistencia, la naturaleza de los mecanismos funcionales y los genes implicados (Pochard et al., 1976; Pochard y Daubezè, 1980; Palloix et al., 1988; Gil, 1988; Palazón, 1988; Gil et al., 1991; Bartual et al., 1991 y 1993). También en otras partes del mundo se habían planteado estudios en el mismo sentido y sobre la forma de introducirla en variedades comerciales (Barksdale et al., 1984; Bosland y Lindsey, 1991; Guerrero-Moreno y Laborda, 1980; Reifschneider et al., 1986; Walker y Bosland, 1999).

Inicialmente no hubo concordancia en el modelo de genética de la resistencia a $P$. capsici, al haber encontrado diferentes fuentes de resistencia con expresiones distintas, las cuales parece dependían de las características genéticas ("backgrounds") de los parentales susceptibles donde eran introducidas (Walker y Bosland, 1999). Para un mismo parental portador de resistencia, como Serrano Criollo de Morelos 334, se proponían modelos genéticos diferentes según los autores de los estudios (Gil et al., 1991; Guerrero-Moreno y Laborda, 1990; Reifschneider et al., 1992). Tales diferencias quizás eran debidas a la metodología utilizada en los experimentos, a utilizar diferentes genitores susceptibles para los estudios, a la posible variabilidad de 
los aislados del hongo, a las condiciones ambientales en las que se realizaban las inoculaciones, a la forma de inoculación o al órgano de la planta, inoculado, etc. El trabajo de Walker y Bosland (1999) viene a corroborarlo, al obtener modelos genéticos diferentes cruzando el Serrano Criollo de Morelos-334 con Early Jalapeño y con Keyston como parentales sensibles. Tampoco parece haber acuerdo en el número de genes mayores que intervendrían en la resistencia, pudiéndose presentar efectos epistásicos aditivos de genes menores que coadyuvan a la manifestación de la resistencia (Bartual et al., 1991; 1993). Los genes mayores y los menores parecen ser los mismos en la resistencia a $P$. capsici y a $P$. parasitica (Bonnet et al., 2007), si bien son más los implicados en la resistencia a $P$. parasitica que a $P$. capsici.

La complejidad de la resistencia a una o a las dos especies parece mayor si como indican Monrroy y Bosland (2011) la respuesta de los órganos de la plantas (raíces, tallo, hojas) fuera diferente ante un mismo aislado de $P$. capsici, o a la inversa, que determinados aislados mostraran cierta especificidad parasitaria frente a determinados órganos.

La resistencia introducida en pimientos utilizados como porta-injertos o en variedades pre-comerciales parece comportarse de forma satisfactoria ante las poblaciones de Phytophthora sp. de los invernaderos del Campo de Cartagena (Ros et al., 2004b), donde se ha asistido a un cambio en la predominancia de $P$. parasitica sobre $P$. capsici en los últimos años. En los últimos años, algunos de los patrones portadores de resistencia a $P$. capsici que se han evaluado en los invernaderos de esta comarca han sido afectados por $P$. parasitica en proporciones bajas (Martínez et al., 2012), lo que se interpreta como indicativo de posibles variaciones en la interacción hospedante-patógeno. La influencia de la variedad sobre la expresión de la resistencia del porta-injertos o la variación en la patogeneicidad de los aislados de $P$. parasitica pudieran explicar este comportamiento. Entre tales variaciones se puede encontrar la especificidad mostrada por algunos aislados de $P$. parasitica que afectan al pimiento en otras zonas de cultivo (Morales, 2011).

La utilización de materiales (porta-injertos o variedades) resistentes no parece pueda evitar el uso de desinfectantes en pre-plantación, que se hace necesaria para paliar los efectos de la fatiga del suelo propia del monocultivo y asociada a la microbiota fúngica no patógena (Martínez et al., 2011).

\section{b) Resistencias a Meloidogyne sp.}

Como se ha indicado anteriormente, de las cuatro especies de Meloidogyne (M. incognita, $M$. arenaria, $M$. javanica y $M$. hapla) que producen daños al pimiento se han encontrado en el Campo de Cartagena $M$. incognita, $M$. javanica y $M$. arenaria (Bello et al., 1997, 2004), siendo la primera la más abundante y extendida, así como la que mayores daños produce.

La resistencia genética a nematodos en pimiento ha sido estudiada desde hace más de medio siglo. En 1957 Hare (1957) identificó en la línea "Santaka XS" de Capsicum annum un gen dominante $\mathrm{N}$, que le confería resistencia frente a $M$. incognita. Más tarde se comprobó que a temperaturas superiores a $28^{\circ} \mathrm{C}$ la expresión de este gen se veía comprometida (Thies y Fery, 1998, 2002). En las líneas de "Carolina Hot" la resistencia a $M$. incognita está gobernada por dos genes, con un alelo dominante $\mathrm{N}$ y otro recesivo (Fery y Dukes, 1996). En la misma línea de trabajo (Fery y Thies, 2000) encuentran que la resistencia a $M$. incognita en $C$. chinense "PA 426" está ligada a un único gen dominante que es alélico con el gen 
dominante $\mathrm{N}$ de $C$. annum en "Carolina Cayende", aunque no se ha confirmado que este gen proporcionara resistencia a $M$. arenaria.

Hendy et al. (1985) identificaron cinco genes dominantes (Me1 a Me5) en $C$. annum que confieren resistencia frente a varias especies de Meloidogyne; se encontraron dos genes Me1 y Me2 en PM 217; dos genes Me3 y Me4 en PM 687 y el último gen Me5 en Yolo Wonder (Dijan-Caporalino et al., 1999, Souza-Sobrinho et al., 2002). Los cinco genes actúan individualmente con una interacción gen a gen. El gen Me6 controla específicamente la resistencia a $M$. arenaria y $M$. javanica en "Yolo Wonder" (Wang y Bosland, 2006). En Criollo de Morelos (CM 334) se encontró el gen Me7 que confería un amplio nivel de resistencia a $M$. arenaria, $M$. incognita y M. javanica (Pergard et al., 2005). Otros dos genes Mech-1 (en PM 217) y Mech-2 (en CM 334) fueron identificados para el control de $M$. chitwoodi (DijanCaporalino et al., 2004). Los genes Me3, Me1 y Me7 son dominantes y termoestables, con amplio espectro de resistencia. Los Mech-1 y Mech-2 actúan impidiendo la reproducción del nematodo (Djian-Caporalino et al., 1998, 1999, 2004). Thies et al. (2009) indican que el gen $\mathrm{N}$ de "Carolina Wonder" y "Charleston Belle" es distinto e independiente del Me3, tras realizar las pruebas de alelismo.

Se han introducido algunos de estos genes en porta-injertos y en variedades pre-comerciales. La mayor parte de los porta-injertos comerciales disponibles son portadores del gen $\mathrm{Me} 7$, cuyo comportamiento en las condiciones de los invernaderos del Campo de Cartagena es bueno (Ros et al., 2004d, 2005, 2007, 2008). Sin embargo, la resistencia conferida por este gen es remontada al reiterar el cultivo de plantas injertadas en el mismo invernadero durante más de tres años consecutivos, no ocurriendo lo mismo cuando el gen introgresado es el Me1 (Ros et al., 2011).

El remonte de las resistencias en pimiento por algunas poblaciones virulentas es imputado por algunos autores al efecto de la temperatura. Thies y Fery (1998) lo indican para Charleston Bell y en Carolina Wonder cuando las temperaturas del suelo estuvieron comprendidas entre 28 y $32^{\circ} \mathrm{C}$ y el suelo infestado por M. incognita. Sin embargo, también se presenta a temperaturas inferiores (Ros et al., 2004e, 2008, 2011; Robertson et al., 2006) en los invernaderos del Campo de Cartagena, de forma específica a la resistencia conferida por el gen Me7. Esta virulencia se ha señalado para poblaciones de otras zonas productoras de pimiento tanto para el gen Me7 como para el gen Me3 (Djian-Caporalino et al., 2011), que según los últimos autores pudiera ser alélico del Me7.

La facilidad con la que se remonta la resistencia al gen Me7 y al gen Me3 viene a indicar que se hace necesario el establecimiento de estrategias integradas de manejo de tales resistencias para evitar la selección de poblaciones virulentas, por ejemplo con desinfecciones parciales del suelo en preplantación por medios químicos (Ros et al., 2003) o mediante biosolarización (Guerrero et al., 2012; Martínez et al., 2012).

\section{c) Injerto del pimiento en porta-inje rtos resistentes}

La dificultad de introducir resistencias a patógenos del suelo en variedades comerciales, ha hecho que se orientaran los primeros trabajos de control de Phytophthora sp. y Meloidogyne sp. por medios genéticos a la incorporación de las resistencias en materiales vegetales no productivos, que se pudieran utilizar como porta-injertos. Tales materiales se caracterizarían, además de por ser portadores de los genes de resistencia, por ser vigorosos. 
A diferencia de otros cultivos hortícolas como la sandía, el pimiento solo presenta buena afinidad cuando se usan como porta-injertos especies o cultivares del género Capsicum (Miguel, 1997). Los utilizados como parentales portadores de resistencia (Smith $N^{\circ}$ 5, Serrano Criollo de Morelos 334, etc.) a P. capsici o líneas de $C$. chinense, $C$. frutescens, $C$. chacoense o de $C$. annuum para $M$. incognita, confieren poco vigor a las plantas, por lo que se suelen utilizar híbridos o líneas intermedias obtenidas en los procesos de introducción de resistencias a ambos patógenos en variedades comerciales (caso de Phyo 636, Phyo 637, P-51, Línea 29, etc.) o de híbridos efectuados con tal fin como el cruce de C. annuum "Murasabi" x C. chinense $\mathrm{n}^{\mathrm{o}} 3341$ (Miguel, 1997).

Ya en el período de 1978 a 1981 cuando no se disponían de soluciones (desinfección del suelo con bromuro de metilo) para los problemas planteados por $P$. capsici en los cultivos intensivos del Levante y Sureste español, Miguel (1997) realizó los primeros ensayos de injerto, buscando soluciones al problema planteado por la "tristeza" en los cultivos de la zona costera de Valencia. Obtuvo buenos niveles de control de la enfermedad utilizando como patrón a Smith $\mathrm{N}^{\mathrm{o}} 5$ y algo inferiores con los híbridos o líneas P-29 y Phyo 636. Con cualquiera de los portainjertos, las producciones resultaron ser iguales o inferiores a las del testigo sin injertar, para el que la incidencia de la enfermedad era muy elevada (superior al $80 \%$ ). Al utilizar los patrones un poco más vigorosos (P-29 y P-51), se aumentaba la producción, pero en ningún caso superaba a la de las plantas no injertadas cultivadas en suelo desinfectado con bromuro de metilo. En aquellos momentos los nematodos no constituían un problema para los cultivos de pimiento, por lo que no se evaluó el comportamiento de los anteriores patrones frente a Meloidogyne sp.

Cuando se iniciaron los trabajos de investigación para buscar alternativas al bromuro de metilo para los cultivos de pimiento de la Región de Murcia, se retomó el injerto como una posibilidad. Así, desde 1998 hasta la actualidad, en el Equipo de Protección de Cultivos del IMIDA se ha venido estudiando el injerto de variedades de pimiento sobre porta-injertos resistentes a Phytophthtora spp. y a $M$. incognita como una alternativa al uso del bromuro de metilo. Se han realizado estudios sobre el comportamiento de estos patrones en suelo sin desinfectar y en combinación con suelo parcialmente desinfectado por métodos químicos y no químicos, frente a ambos patógenos en distintos invernaderos con diferentes casuísticas, y también los efectos de la combinación patrón variedad (Ros et al., 2004d, 2005, 2006, 2007, 2008).

Han sido numerosos los porta-injertos que se han comportado satisfactoriamente frente a Phytophthora $s p$. y la resistencia se ha comportado como estable, salvedad hecha de algunos casos de infecciones tempranas o de poblaciones de $P$. parasitica que se muestran infectivas en materiales portadores de resistencia a $P$. capsici. Sin embargo, son algo menos numerosos los patrones que presentan buen comportamiento frente a Meloidogyne incognita (Ros et al., 2004e, 2005, 2006, 2007, 2008). La resistencia de estos patrones se comporta como estable frente a algunas poblaciones de Meloidogyne incognita de los invernaderos del Campo de Cartagena (Ros et al., 2007, 2008), pero se han seleccionado poblaciones virulentas que son capaces de remontar la resistencia, al reiterar el cultivo de esos patrones en algunos invernaderos (Ros et al., 2007 y 2008). Tal comportamiento hace que no se considere el injerto por si solo como una alternativa al bromuro de metilo. Cuando se combina el injerto con la desinfección del suelo (ya sea por medios químicos o mediante biosolarización) se logra mantener avirulentas las poblaciones 
obteniéndose buenos niveles de control de los nematodos y cosechas similares a las del bromuro de metilo (Ros et al., 2003, 2005, 2007; Guerrero et al., 2012).

El comportamiento de la resistencia a Meloidogyne incognita de los patrones comerciales y experimentales portadores del gen Me7 presenta no solo las deficiencias inherentes a la selección de poblaciones virulentas, sino que una parte de las plantas se infestan con bajos índices de nodulación (forma de evaluar la severidad del daño en las raíces) sin que se lleguen a manifestar síntomas (amarilleos, reducción en el desarrollo, etc.) de la enfermedad en la parte aérea de las plantas. Este comportamiento hace pensar que la expresión y manifestación de la resistencia está influenciada por las características de la base genética en la que se introduce (Djian-Caporalino et al., 2011; Sánchez et al., 2012), al menos cuando se trata del gen Me7; sin embargo, el nivel de resistencia proporcionado por el gen Me1 no parece verse influenciada por el "background" en el que se introduce.

\subsection{OBJETIVOS}

\subsubsection{Objetivo general}

Desde el inicio del cultivo del pimiento en los nuevos invernaderos del Campo de Cartagena, surgidos al amparo de la llegada del agua del Trasvase TajoSegura, Phytophthora capsici y Meloidogyne spp. se presentaron como los dos principales problemas fitosanitarios del suelo. P. capsici, causante de la "tristeza" o "seca" del pimiento, se reveló como un factor limitante del cultivo, mientras el nematodo quedaba enmascarado por la enfermedad fúngica. El monocultivo se implantó en la mayor parte de la superficie, al no disponer de alternativas viables técnica y económicamente para la rotación de cultivos en los invernaderos. La desinfección del suelo con bromuro de metilo se estableció como el método eficaz y duradero de control de los patógenos y la forma de paliar los efectos de la reiteración del monocultivo (Lacasa y Guirao, 1997).

La retirada del bromuro de metilo como desinfectante del suelo en base a acuerdos internacionales, planteó la búsqueda de alternativas para su sustitución. Al mismo tiempo se puso de manifiesto la necesidad de poner a punto y en práctica métodos sostenibles de control de los patógenos para los cultivos ecológicos que empezaban a emerger y para los sistemas de producción integrada.

Las iniciativas tomadas para dar respuesta a las anteriores necesidades pusieron de manifiesto que era necesario conocer con más detalle aspectos básicos de los patógenos principales y las consecuencias del monocultivo reiterado que se ve nía practicando desde hacía más de dos lustros, para que los nuevos métodos de desinfección se fundamentaran y ajustaran a las premisas de los métodos de producción integrada y ecológica.

El objetivo general de la tesis se encuadra en la búsqueda de alternativas a la desinfección del suelo con bromuro de metilo o con productos químicos, y plantea evaluar la biosolarización (biofumigación con solarización) como método de desinfección de los suelos de los invernaderos del Campo de Cartagena (Murcia), orientado al control de los patógenos principales y a paliar los efectos de la fatiga del suelo. 


\subsubsection{Objetivos específicos}

Los objetivos específicos que se abordaron fueron:

1) Determinar la identidad del patógeno que ocasionaba los síntomas de "tristeza" o "seca" en las plantas de pimiento de los invernaderos del Campo de Cartagena, teniendo como referencia los estudios realizados en la comarca entre 1977 y 1997.

2) Caracterizar la fatiga del suelo de los invernaderos de pimiento, que como consecuencia de la reiteración del monocultivo los agricultores identificaban con reducción en el desarrollo de las plantas y en pérdidas de producción al dejar de utilizar el bromuro de metilo como desinfectante del suelo.

3) Implementar la biosolarización o biodesinfección del suelo para hacer compatible su eficacia como desinfectante del suelo con el ciclo habitual del cultivo de pimiento en los invernaderos del Campo de Cartagena. La implementación se ampararía en la evaluación de enmiendas orgánicas biofumigantes y en fechas de aplicación apropiadas al ciclo de cultivo, así como en la estabilidad y durabilidad de los efectos al aplicarla reiteradamente. 


\subsection{BIBLIOGRAFÍA}

Abad P, Favery B, Rosso MN, Castagnone-Sereno P. 2003. Root-Knot nematode parasitismo and host responce: molecular basis of a sophisticated interaction. Mol Plant Pathol 4: 217-224.

Abbasi PA, Conn KL, Lazarovits G. 2004. Suppression of Rhizoctonia and Pythium damping-off of radish and cucumber seedlings by addition of fish emulsion to peat mix or soil. Can J Plant Pathol 26: 177-187.

Ajwa HA, Trout T, Mueller J, Wilhelm S, Nelson SD, Shatley D. 2002. Application of alternative fumigants through drip irrigation systems. Phytopathology 92: 13491355 .

Ajwa HA, Fennimore S, Kabir Z, Martin F, Duniway J, Browne G, Trout T, Goodhue R and Guerrero L. 2003. Strawberry yield under reduced application rates of chloropicrin and inline in combination with Metham Sodium and VIF. Proc 2003 Annual International Research Conference on Methyl Bromide Alternatives and Emissions Reductions, San Diego, CA. Paper 2.

Ajwa HA, Trout T. 2004. Drip application of alternative fumigants to Methyl Bromide for strawberry production. Hort Science 39: 1707-1715.

Andrivon D. 1995. Biology, ecology, and epidemiology of the potato late blight pathogen Phytophthora infestans in soil. Phytopathology 85: 1053-1056.

Angus JF, Gardner PA, Kirkegaard JA, Desmarchelier JM. 1994. Biofumigation: isothiocyanates released from Brassica roots inhibit growth of the take-all fungus. Plant and Soil 162:107-112

Anuario de Estadística 2011. Ministerio de Medio Ambiente, Medio Rural y Marino.

Bailey KL, Lazarovits G. 2003. Suppressing soil-borne diseases with residue management and organic amendments. Soil and Tillage Research 72:169-180.

Bartual R, Marsal JI, Carbonell EA, Tello JC, Campos T. 1991. Genética de la resistencia a Phytophthora capsici Leonian en pimiento. Boletín de Sanidad Vegetal Plagas 17: 3-124.

Bartual R, Lacasa A, Marsal JI, Tello JC. 1993. Efectos epistáticos en la resistencia a Phytophthora capsici Leonian en pimiento (Capsicum annuum). Boletín de Sanidad Vegetal Plagas 19 (3): 485-490.

Barksdale TH, Papavizas GC, Jonhnston SA. 1984. Resistance to foliar blight and crown rot of pepper caused by Phytophthora capsici. Plant Dis 68:506-509.

Barres MT, Bello A, Jordá C, Tello JC. 2006. La eliminación del bromuro de metilo en la protección de cultivos como modelo mundial para la conservación del medio ambiente. MAPA, Madrid, $515 \mathrm{pp}$. 
Bello A, Escuer, M, Sanz R, López-Pérez JA, Guirao P. 1997a. Biofumigación, nematodos y bromuro de metilo en el cultivo de pimiento. En: López A, Mora JA, eds. Posibilidad de Alternativas Viables al Bromuro de Metilo en Pimiento de Invernadero. Consejería de Medioambiente, Agricultura y Agua, Murcia, España, 67-108.

Bello A, Tello J. 1997b. El bromuro de metilo en agricultura mediterránea. En: A. Bello A, González JA, Pérez Parra A, eds. Alternativas al bromuro de metilo en agricultura. Consejería de Agricultura y Pesca, Junta de Andalucía, 19-30.

Bello A, López-Pérez JA, Díaz-Viruliche L, Sanz R, Arias M. 1999a. Biofumigation and local resources as methyl bromide alternatives. 3rd International Workshop "Alternatives to methyl bromide for the Southern European Countries", 7-10 diciembre, Heraclion, Creta, Grecia, pp. 17.

Bello A, López-Pérez JA, Díaz-Viruliche L, Sanz R, Escuer M, Herrero J. 1999b. Biofumigation and organic amendments. In: Regional Workshop on Methyl Bromide Alternatives for North Africa and Southern European Countries, United Nations Environment Programme (UNEP), Francia, pp. 113-141.

Bello A, López-Pérez JA, Sanz R, Escuer M, Herrero J. 2000. Biofumigation and organic amendments. Regional Workshop on Methyl Bromide Alternatives for North Africa and Southern European Countries, United Nations Environment Programme (UNEP), Francia, 113-141.

Bello A, López-Pérez JA, García-Álvarez A. 2003. Biofumigación en agricultura extensiva de regadío. Producción integrada de hortícolas. CSIC-Caja Rural de Alicante, Mundi-Prensa, Madrid, 670 pp.

Bello A, López-Pérez A, García Álvarez S, Arcos C, Ros C, Guerrero MM, Guirao P, Lacasa A. 2004. Biofumigación con solarización para el control de nematodos en cultivo de pimiento. En: Lacasa A, Guerrero MM, Oncina M, Mora JA, eds. Desinfección de suelos en invernaderos de pimiento. Publicaciones de la Consejería de Agricultura, Agua y Medio Ambiente. Región de Murcia. Jornadas 16: 129-207.

Bonanomi G, Antignani V, Pane C, Scala F. 2007. Suppression of soilborne diseases with organic amendments. Journal Plant Pathology 89 (3), 311-324.

Bonnet J, Danan S, Boudet C, Barchi L, Sage-Palloix AM, Caromel B, Palloix A, Lefebvre V. 2007. Are the polygenic architectures of resistance to Phytophthora capsici and $P$. parasitica independent in pepper? Theor Appl Genet 115:253-264.

Bosland PW, Lindsey DL. 1991. A seedling screen for Phytophthora Root Rot of pepper, Capsicum annuum. Plant Dis 75: 1048-1050.

Bouhot D. 1983. La fatigue des sols. Position du probleme et principe du diagnostique. 23 Colloque de la Societe Francaise de Phytopatologie. INRA, Paris, 922.

Brown PD, Morra MJ. 1997. Control of soil-borne plant pests using glucosinolate containing plants. Advances in Agronomy 61: 167-231. 
Cánovas F. 1996. Santomera y los pimientos. Santomera. Murcia. 133 pp.

Cebolla V. 2000. Alternativas químicas y no químicas al bromuro de metilo. Fruticultura Profesional 115: Extraordinario 89.

Cebolla V, Bartual R, Maroto V. 2004. Water volume as related to effectiveness of 1,3-dichloropropene and chloropicrin moisture by drip irrigation for a strawberry crop in Spain. Acta Horticulturae 698: 77-82.

Cenis JL. 1986. Desarrollo de un enfoque cuantitativo de la solarización y aplicación al control del nematodo Meloidogyne javanica (Treub) Chit. Tesis doctoral ETSIA. Universidad Politécnica de Madrid, 372 pp.

Cenis JL, Fuchs P. 1988. Efecto comparado de la solarización y el metam sodio en cultivo de pimiento (Capsicum annuum L.) en invernaderos. ITEA 75:21-23.

Clerjeau M, Dauple, P, Gineaux G, Leroux JP, D’oleon F. 1974. Deus méthodes de lutte contre la maladie des racines liégeuses de la tomate ou «corky-root». IEfficacité comparée de divers fumigants contre la «corky-root» de la tomate du a Pyrenochaeta lycopersici: Defanse des Vegetaux: 25-32.

Coelho L, Chellemi D O, Mitchell D J. 1999. Efficacy of soil solarization and cabbage amendment for the control of Phytophthora spp. in North Florida. Plant Disease 83:293-99.

Costa JC. 1978. Variedades de pimiento para cultivo bajo invernadero plástico en la comarca del Campo de Cartagena. Hoja Técnica INIA, 25: 15 pp.

Chen Y, Gamliel A, Stapleton JJ, Aviad T. 1991. Chemical, physical, and microbial changes related to plant growth in disinfested soils. En: Katan J, De Vay JE, eds. Soil solarization pp 103-129.

Chellemi DO, Olson SM, Mitchell DJ. 1994. Effects of soil solarization and fumigation on survival of soilborne pathogens of tomato in northermn Florida. Plant Dis 78: $1167-1172$.

Chellemi DO, Olson SM, Mitchell DJ, Secker I, McSorley R. 1997. Adaptation of soil solarization to the integrated management of soilborne pests of tomato under humid conditions. Phytopathology 87:250-258.

Chellemi D, Mirusso J, Nance J, Shuler K. 2001. Evaluation of technology and application methods for chemical alternatives to methyl bromide. Proc. Annu. Res. Conf. Methyl bromide Alternatives Emission Reductions. 15: 1-2.

Chellemi DO. 2004. Integrating soil disinfestations programs into crop production systems. Acta Horticulturae 698: 105-114.

Díez-Rojo MA, Bello A, Escuer M, López-Pérez JA, García Álvarez A. 2006. Nematodos fitoparásitos encontrados en Castilla y León. Alternativas no químicas de control. MAPA, Madrid, 254 pp. 
Díez-Rojo MA. 2010. Bases agronómicas para la utilización de restos agrarios en biodesinfección de suelos. Tesis doctoral. ETSIA, Universidad Politécnica de Madrid, 327 pp.

Djian-Capolarino C, Pijarowski L, Januel A, Lefebvre V, Caranta C, Chauvet JC, Blattes A, Palloix A, Damalsso A, Abad P. 1998. Characterising and fine mapping of the $M e 3$ gene conferring heat-stable resistance to root-knot nematodes (Meloidogyne spp.) in pepper (Capsicum annum L) using AFLPs. Proc. $10^{\text {th }}$ Eucarpia Meeting on Genetics and Breeding of Capsicum and Eggplants, 7-11 Sept. Avignon, France. pp. 125-128.

Djian-Caporalino C, Pijarowski, L, Januel A, Lefebvre V, Daubèze AM, Palloix A, Dalmasso A, Abad P. 1999. Spectrum of resistance to root-knot nematodes and inheritance of heat-stable resistance in pepper (Capsicum annum L.). Theor Appl Genet 99: 496-502.

Djian-Capolarino C, Berthou F, Fazari A, Lefebvre A, Palloix A, Pergard A, Pijarowski L. 2004. Genetic, cytological and molecular bases of the resistance to root-knot nematodes (Meloidogyne spp.) in pepper (Capsicum annum L). Proc. $12^{\text {th }}$ Eucarpia Meeting on Genetics and Breeding of Capsicum and Eggplants, 17-19 May 2004, Noordwijkerhout, the Netherlands. pp.180.

Djian-Caporalino C, Molinari S, Palloix A, Ciancio A, Fazari A, Marteu N, Ris N, Castagnone-Sereno P. 2011. The reproductive potential of the root-knot nematode Meloidogyne incognita is affected by selection for virulence against major resistance genes from tomato and pepper. Eur J Plant Pathol 131(3): 431-440.

Dungan RS, Gan J, Yates SR. 2001. Effect of temperature, organic amendments rate and moisture content in the degradation of 1.3-dichloropropene in soil. Pest Manag Sci 57: 1107-1113.

Eger JE. 2000. Efficacy of telone products in Florida crops: a seven year summary. Proc. Ann. Intern. Res. Conf. on Methyl bromide Alternatives Emission Reductions. EPA Orlando, US A, November, 40: 1-2.

Erwin DC, Ribeiro OK. 1996. Introduction to the genus Phythophthora. Páginas 1-7 en: Phythopthora Diseases Worldwide. D.C. Erwin, O.K. Ribeiro. The American Phythopathological Society, St. Paul, M.N. 562 pp.

Escuer M, Cano A, Bello A. 2004. Nematodos fitoparásitos de la Región de Murcia y alternativas de control. En: Lacasa A, Guerrero MM, Oncina M. and Mora JA, eds. "Desinfección de suelos en invernaderos de pimiento". Consejería de Agricultura, Agua y Medio Ambiente. Región de Murcia. Jornadas 16: 27-57.

Estadística Agraria de Murcia 2000-2003-2006-2009-2012. Ed. Comunidad Autónoma de la Región de Murcia. Consejería de Agricultura y Agua.

Fery RL, Dukes PD. 1996 The Inheritance of Resistance to the Southern Root-knot Nematode in 'Carolina Hot' Cayenne Pepper. J Amer Soc Hort Sci 121(6): 10241027. 
Fery RL, Thies JA. 2000. Inheritance of resistance to the peanut root-knot nematode in Capsicum chinense. J Amer Soc Hort Sci 125: 615-618.

Gamliel A, Austerweil M, Kritzman G. 2000. Non-chemical approach to soilborne pest management-organic amendments. Crop Protection 19:847-853.

Gan J, Yates SR, Ernest FF, Jury W. 2000. Degradation and volatilization of the fumigant chloropicrine after soil treatment. Journal of Environmental Quality 29: 1122-1128.

Gil R. 1988. Resistencia a Phytophthora capsici en pimiento. Tesis Doctoral. ETSIA. Universidad Politécnica de Valencia, 369 pp.

Gil R, Palazón C, Cuartero J. 1991. Genetics of resístanse to Phytophthora capsici in the pepper line SCM-334. Plant Breeding, 107:50-55.

Gilreath JP, Noling JW, Jones JP, Locascio SJ, Chellemi DO. 2001. Three years of soilborne pest control in tomato with 1,3-D+cloropicrin and solarization. Annual International Research Conference on Methyl Bromide Alternatives and Emissions Reductions. San Diego, California (USA), 5-9. November, 13:1-3.

Gilreath JP, Santos BM, Gilreath PR, Jones JP, Nolin JW. 2004a. Efficacy of 1,3dichloropropenc plus chloropicrin application methods in combination with pabulate and napropamide in tomate. Crop Protection 23: 1187-1191.

Gilreath JP, Noling JW, Santos MB. 2004b. Methyl bromide alternatives for bell pepper (Capsicum anuum) and cucumber (Cucumis sativus) rotations. Crop Protection 23: 347-351.

González A, Vicente F, Fernández J, Franco J. 1995. Actualidad y perspectivas del pimiento para consumo en fresco en la región de Murcia. Agrícola Vergel 164: 449458.

Guerrero-Moreno A, Laborda JA. 1980. Current status of pepper breeding for resistance to Phytophthora capsici in Mexico. Synopses of the IVth Meeting of Capsicum Working Group of Eucarpia I.V.T. Wageningen. The Nederlands: 52-56.

Guerrero MM, Guirao P, Lacasa A, Ros C, Torres J, Martínez MC, Oncina M, Bielza P, Contreras J. 2004a. La mezcla de dicloropropeno y cloropicrina, una alternativa al bromuro de metilo para la desinfección de suelos para el pimiento. En "Desinfección de suelos en invernaderos de pimiento". Lacasa A, Guerrero MM, Oncina M, Mora JA, eds. Publicaciones de la Consejería de Agricultura, Agua y Medio Ambiente. Jornadas 16: 99-128.

Guerrero MM, Ros C, Barceló N, Martínez MA, Martinez MC, Guirao P, Bielza P, Lacasa A. 2004b. Eficacia de nuevos desinfectantes de suelo de invernaderos de pimiento. Actas de Horticultura 42: 14-19.

Guerrero MM, Ros C, Martínez MA, Martínez MC, Bielza P, Contreras J, Lacasa A. 2006 .Uso reiterado de 1,3-dicloropropeno+ cloropicrina en la desinfección de suelos 
de invernaderos de pimiento. Actas XXXVI Seminario de Técnicos y especialistas en Horticultura. Ibiza. Ministerio de Agricultura, Pesca y Alimentación: 41-49

Guerrero MM, Martínez MA, Ros C, Bello A, Fernández P, Martínez MC, Lacasa A. 2007. Eficacia de la biosolarización como desinfectante del suelo en invernaderos de pimiento. Actas de Horticultura 48: 451-454.

Guerrero MM, Lacasa CM, Hernández A, Martínez V, Martínez MA, Ros C. 2012. Biosolarización e injerto para el manejo integrado de los patógenos del suelo en cultivos de pimiento en invernadero. Actas de Horticultura 60: 321-326.

Guirao P, Guerrero MM, Ros C, Lacasa A, Beltrán C, Martínez MC, Torres J, Oncina M, Contreras J. 2004. La reducción de dosis del bromuro de metilo en el cultivo de pimiento y el calendario de retirada. En: Lacasa A, Guerrero MM, Oncina M, Mora JA, eds. Desinfección de suelos en invernaderos de pimiento. Publicaciones de la Consejería de Agricultura, Agua y Medio Ambiente. Región de Murcia. Jornadas 16:61-78.

Gullino ML, Camponogar A, Gasparrini A, Rizzo V, Cini C, and Garibaldi A. 2003. Replacing Methyl Bromide for soil disinfestations: The Italian experience and its implications for other countries. Plant Disease 87: 1012-1019.

Gunderson JH, Elwood H, Ingold A, Kindle K, Sogin ML. 1987 Phylogenetic relationships between chlorophytes, chrysophytes, and oomycetes. Proc Natl Acd Sci USA, 84:5823-5827.

Haar M, Fennimore S, Ajwa H. 2001. Weed control efficacy of drip irrigation applied chloropicrin, metam sodium and 1,3-D. Annual Internacional Research Conference on Methyl Bromide Alternatives and Emissions Reductions. San Diego, California (USA), 5-9 November: 90: 1-4.

Hare WW. 1957. Inheritance of resistance to root-knot nematodes in pepper. Phytopathology 47: 455-459.

Hafez SL, Haroutunian G, Sundararaj P. 2000. Biofumigation and basamid-an alternative integrated approach to methyl bromide for vegetabke and fruit production in Lebanon. Proceedings of Annual International Research Conference on Methyl Bromide Alternatives and Emissions Reductions 19: 1-2. November, 6-9, Orlando (Florida), USA.

Hendy H, Pochard E, Dalmaso A. 1985. Transmission héréditaire de la résistance aux nematodes Meloidogyne chitwood (Tylenchida) portée pae 2 lignées de Capsicum annum L. Etude de descendances homozygotes issues d'androgenèse. Agronomie 5: 93-100.

Jeffers DP, Roberts PA. 1993. Effect of planning date and host genotype on the rootknot nematode- Fusarium wilt diseae complex of cotton. Phytopathology 83: 645654. 
Katan J, Greenberger A, Alon H, Grinstein A. 1976. Solar heating by polyethylene mulching for the control of diseases caused by soilborne pathogens. Phytopathology 66: 683-688.

Katan J. 1981. Solar heating (solarization) of soil control of soilborne pets. Annual Reviews of Phytopathology 19:211-236.

Katan J, de Vay JE (Eds). 1991. Solarization. CRC Press Boca Ratón Ann Arbor, Boston, London, 267 pp.

Katan, J. 2005. Soil disinfestation: One minute befote Methyl Bromide phase out. Procedures of VI International Symposium on Chemical and Non-Chemical Soil and Substrate Disinfestation. Acta Horticulturae 698: 19-25.

Kirkegaard JA, Gardner J, Desmarchelier JM, Angus JF. 1993a. Biofumigation using Brassica species to control pest and diseases in horticulture and agriculture, en: Wrather, N., Mailes, R.J. (Eds.), Proceedings of 9th Australian Research Assembly on Brassicas. Wagga Wagga (Australia). 5-7 October. Proceedings: 77-82.

Kirkegaard JA, Sarwar M. 1998. Biofumigation potential of brassicas - I. Variation in glucosinolate profiles of diverse field-grown brassicas. Plant and Soil 201: 71-89.

Lacasa A, Guirao P. 1997. Investigaciones actuales sobre alternativas al uso del bromuro de metilo en pimiento de invernadero. En: López A, Mora JA, eds. Publicaciones de la Consejería de Medio Ambiente, Agricultura y Agua. Jornadas 11: 47-50.

Lacasa A, Guirao P, Guerrero MM, Ros C, Bello A, Bielza P, López JA. 1999. Alternatives to Methyl Bromide for sweeet pepper cultivation in platichouse in South-East Spain. $3^{\text {rd }}$ International Workshop "Alternatives to Methyl Bromide for the Southern European Countries", December, 7-10 Heraclion, Crete, Grecia. Proceedings. 41- 44.

Lacasa A, Guerrero MM, Guirao P, Ros C. 2002. Alternatives to methyl bromide in vegetable crops and strawberry crops in Spain. En: T.A. Batchelor, J.M. Bolívar (Edits). Proceedings of the International Conference on Alternatives to Methyl Bromide. The Remaining Challenges. Seville, Spain, 5-8 March. European Commission, Brussels, Belgium, 172-177.

Lacasa A, Guerrero MM, Ros C, Guirao P, Martínez MA, Barceló N, Martínez MC, Bielza P, Oncina M. 2003. El riego previo a la aplicación de Telone C-35 como desinfectante del suelo. Agrícola Vergel 263: 579-589.

Lacasa A, Ros C, Guerrero MM, Martínez MA, Barceló N, Torres J, Beltrán C, Bielza P. 2006. Distribución del agua en la aplicación del 1,3-dicloropropeno + cloropicrina para la desinfección de invernaderos de pimiento. Agrícola Vergel 292: 201-211. 
Larregla S. 2003. Etiología y epidemiología de la "Tristeza" del pimiento en Bizkaia: su control. Tesis Doctoral. Universidad del País Vasco-Euskal Herriko Unibertsitatea, $756 \mathrm{pp}$.

Lazarovits G, Conn KL, Potter J. 1999. Reduction of potato scab, Verticillium wilt, and nematodes by soymeal and meat and bone meal in two Ontario potato fields. Can J Plant Pathol 21: 345-353.

Lazarovits G, Conn KL, Abbasi PA, Tenuta M. 2005. Understanding the mode of action of organic soil amendments provides the way for improved management of soilborne plant pathogens. Acta Horticulturae 689:215-224.

Lazzeri L, Manici LM. 2000. The glucosinolate-myrosinase system: A natural and practical tool for biofumigation. Acta Horticulturae 532: 89-95.

Lazzeri L., O. Leoni, L.M. Manici. 2004. Biocidal plant dried pellets for biofumigation. Ind Crop Prod 20: 59-65.

Locascio SD, Dickson DW. 2000. Broadcast vs in-row application of 1,3-D plus chloropicrin as an alternative for to mato fumigants. Annual Internacional Research Conference Bromide Alternatives and Emissions Reduction, San Diego (California) USA, 3-6 November, 14: 1-3.

López, A. 1998. El bromuro de metilo y el cultivo de pimiento en invernadero en el Campo de Cartagena. FECOAM 17:21-27.

Ma GL, Becker JO, Gan J, Dungan R, Papiernik SK, Yates SR. 2000. Temperatureenhanced efficacy of methyl isothiocyanate for soilborne pests control. Proceedings of Annual International Research Conference on Methyl Bromide Alternatives and Emissions Reductions, 99:1-3. November, 6-9, Orlando (Florida), US A.

Martin FK. 2003. Development of alternative strategies for management of soilborne pathogens currently controlled with methyl bromide. Annual Reviews of Phytopathology 41: 325-350.

Martínez MA, Guerrero MM, Ros C, Martínez MC, Lacasa A, Tello J. 2005. Effects of biofumigation plus solarization on crop microbiology. Ind ustrial crops and rural development. Proceedings of Annual Meeting of the Association for the Advancement of industrial crops, 17-21 September, Murcia Spain, 237-244.

Martínez MA, Martínez MC, Bielza P, Tello J, Lacasa A. 2011. Effect of biofumigation wit manure amendments and repeated biosolarization on Fusarium density in pepper crops. Journal Ind ustrial Microbiology Biotechnology 38:3-11.

Martínez V, Lacasa CM, Guerrero MM, Martínez MC, Ros C. 2012. El injerto en pimiento, un complemento a la biosolarización tardía para el control de patógenos del suelo en cultivos ecológicos. Actas del Congreso de la SEAE 31:1-13.

Miguel A. 1997. El injerto como alternativa al uso del bromuro de metilo. En: López A, Mora JA, eds. Posibilidad de alternativas viables al bromuro de metilo en 
pimiento de invernadero. Publicaciones de la Consejería de Medio Ambiente, Agricultura y Agua. Región de Murcia. Jornadas 11: 47-50

Minuto A, Mullino ML, Lamberti F, D’addabbo T, Tescari E, Ajwa H, and Garibaldi A. 2006. Application of an emulsifiable mixture of 1.3-dichloropropene and chloropicrin against root knot Nematodes and Soilborne Fungi for Greenhouse Tomatoes in Italy. Crop Protection 25 (12): 1244 -1252.

Monroy A, Bosland P.W. 2011. Identification of novel physiological races of Phytophthora capsici causing foliar blight using the New Mexico recombinant inbred pepper lines set ass a host differential. J Amer Soc Hort Sci 136 (3): 205-210.

Morales-Rodríguez MC, Rodríguez-Molina MC, Picón-Toro J, Palo C, Palo Núñez EJ, Duarte MS, García-Gallego A. 2011. La Tristeza del pimiento causada por Phytophthora nicotianae: efecto de la edad de la planta en la gravedad de la enfermedad. Actas de Horticultura 58: 172-175.

Motis TN, Gilreath JP. 2002. Stimulation of nutsedge emergence with chloropicrin. In: 2002 Annual International Research Conference on Methyl Bromide Alternatives and Emissions Reductions. MBAO: 71-72.

Noling JW, Gilreath JP, Rosskopf ER. 2001. Alternatives to methyl bromide field research efforts for nematode control in Florida. Annual International Research Conference on Methyl Bromide Alternatives and Emissions Reductions, San Diego, CA. Paper 14, 1-3.

Oka Y. 2010. Mechanisms of nematode suppression by organic soil amendments: a review. Appl Soil Ecol 44, 101-115.

Orton KJ. 1973. Meloidogyne incognita. C.I.H. Descriptions of Plant-parasitic Nematodes. Set 1 n³, 4 pp.

Ou LT, Thomas JE, Allen LH, McComarck, LA, Vu JC, Dickson DW. 2001. Dispersion and emissions of 1-3D in Florida field soil. Annual International Research Conference on Methyl Bromide Alternatives and Emissions Reductions, San Diego, California, USA, 5-9 November 1, 1-2.

Palazón C. 1988. Estudio de los posibles métodos de control de la "Tristeza" o "Seca" del pimiento. Tesis Doctoral, Universidad Politécnica de Valencia. Valencia, $231 \mathrm{pp}$.

Palazón C, Palazón I. 1989. Estudios epidemiológicos sobre la «tristeza» del pimiento en la zona del Valle Medio del Ebro. Boletín Sanidad Vegetal de Plagas 15: 233-262.

Palloix A, Daubèze AM, Pochard E. 1988. Phytophthora root rot of pepper: influence of host genotype and pathogen strain on the inoculum density-disease severity relationships. J Phytopathology 123: 25-33. 
Pegard A, Brizzard G, Fazari A, Soucaze O, Abad P, Djian-Caporalino C. 2005. Histological Characterization of Resistance to Different Root-Knot Nematode Species Related to Phenolics Accumulation in Capsicum annuum. Phytopathology 95 (2): $158-165$

Piedra-Buena A. 2004. Agroecología de Meloidogyne Göldi, 1892 (Nematoda: Heteroderidae) en cultivos hortícolas protegidos. Tesis Doctoral. Escuela Técnica Superior de Ingenieros Agrónomos, Universidad de Almería 397 pp.

Piedra-Buena A, García-Álvarez A, Díez- Rojo MA, Ros C, Fernández P, Lacasa A, Bello A. 2007. Use of pepper crop residues for the control of root-knot nematodes. Bioresour Technol 98:2846-2851

Pocino S. 1997. Metan sodio y metam potasio como alternativa al uso del bromuro de metilo. En: López A, Mora JA eds. Posibilidad de alternativas viables al bromuro de mtilo en pimiento de invernadero. Publicacines de la Consejería de Medio Ambiente, Agricultura y Agua. Jornadas 11:37-40.

Pochard E, Chambonnet D, 1971. Méthodes de sélection du piment pour la résistance au Phytophthora capsici et au virus du concombre. 1st. Eucarpia Meeting on Capsicum. Ann. Fac. Sci. Agr. Univ. Torino, 7: 270-281.

Pochard E, Clerjeau M, Pitrat M. 1976. La resistance du piment, Capsicum annuum à Phytophthora capsici Leon. I. Mise en evidence d'une induction progressive de la resistance. Ann Amelior Plantes 26 (I): 35-50.

Pochard E, Daubezè AM. 1980. Recherche et evaluation des composantes d’une resistance polygenique: la resistance du piment a Phytophthora capsici. Ann Amelior Plantes 80: 377-398.

Ponchet J, Ricci P, Andreoli C, Auge G. 1972. Métodes selectives d isolement du Phytophthora nicotianae f. sp. parasitica (dastur) Waterh a partir du sol. Ann Phytopathology 4(2): 97-108.

Porter IJ, Brett RW, Wiseman B. 1999. Alternatives to methyl bromide: chemical fumigants or integrated pest management systems? Australasian Plant Pathology, 28: $65-71$.

Porter IJ. 2006. Experiences in Methyl Bromide phase-out in the strawberry sector of Australia. In: International Workshop on Alternatives to Methyl Bromide for strawberries and flowers, August 22 -23, 2006 Ixtapan de la Sal, Mexico.

Ploeg AT, Maris PC. 1999. Effect of temperature on the duration of the life cycle of a Meloidogyne incognita population. Nematology 1:89-393.

Reifschneider FJB, Café-Filho AC, Rego AM. 1986. Factors affecting expression of resistance in pepper (Capsicum annuum) to blight caused by Phytophthora capsici in screening trials. Plant Pathol 35: 451-456 
Rico J. 1983. Cultivo del pimiento de carne gruesa en invernadero. Ministerio de Agricultura, Pesca y Alimentación. 268 pp.

Rincón L, Pérez A, Abadía A, Sáez J, Pellicer C. 2005. Fertirrigación localizada en un cultivo de pimiento grueso de invernadero en producción integrada. I Respuesta productiva y balance del agua de riego. Agrícola Vergel 286: 488-493

Rincón L, Pérez A, Abadía A, Sáez J, Pellicer C. 2006. Fertirrigación localizada en un cultivo de pimiento grueso de invernadero en producción integrada. II Lixiviación de nutrientes. Agrícola Vergel 287: 347-556.

Ristaino JB, Gumpertz MC. 2000. New frontiers in the study of dispersal and spatial analysis of epidemics caused by species in the genus Phytophthora. Annual Review of Phytopathology 38: 541-576.

Robertson L, López-Pérez JA, Bello A, Díez-Rojo MA, Escuer M, Piedra-Buena A, Ros C, Martínez C. 2006. Characterization of Meloidogyne incognita, M. arenaria and $M$ hapla populations from Spain and Uruguay parasitizing pepper (Capsicum annum). Crop Protection 25: 440-445.

Rodríguez-Kábana R. 1998. Alternatives to methyl bromide for soil disinfestation. In: Bello A, González JA, Arias M, Rodríguez-Kábana R eds.: Alternatives to methyl bromide for the Southern European countries. CSIC DG XI: 17-31.

Rodríguez-Molina MC, Morales-Rodríguez MC, Palo C, Palo E, Verdejo E, Duarte Maya MS, Picón-Toro J. 2010. Short communication. Phytophthora nicotianae, the causal agent of root and crown rot (Tristeza disease) of red pepper in La Vera region (Cáceres, Spain). Span J Agric Res 8 (3): 770-774.

Ros C, Guerrero MM, Lacasa A, Guirao P, Martínez MA, Barceló N, Martínez MC, López JA, Bello A, Rodríguez I. 2003. Evaluación de patrones de pimiento para el control de patógenos en cultivos ecológicos de invernadero. Actas de Horticultura, 39: 38-40.

Ros C, Guirao P, Lacasa A, Guerrero MM, Beltrán C, Bielza P, Martínez MC, Torres J, Oncina M. 2004a. El metam sodio y el dazomet en la desinfección del suelo en invernaderos de pimiento. En: López A, Mora JA, eds. Publicaciones de la Consejería de Medio Ambiente, Agricultura y Agua. Jornadas 11:37-40.

Ros C, Guerrero MM, Lacasa A, Guirao P, González A, Bello A, López JA, Martínez MA. 2004b. El injerto en pimiento. Comportamiento de patrones frente a hongos y nematodos. En: Lacasa A, Guerrero MM, Oncina M, Mora JA, eds. Desinfección de suelos en invernaderos de pimiento. Publicaciones de la Consejería de Agricultura, Agua y Medio Ambiente. Región de Murcia. Jornadas 16: 279-312.

Ros C, Guerrero MM, Rodríguez I, Martínez MA, Martínez MC, Barceló N, Guirao P, Lacasa A. 2004c. La desinfección parcial del suelo y el injerto en pimiento de invernadero. Agrícola Vergel 268:200-209. 
Ros C, Guerrero MM, Martínez MA, Barceló N, Martínez MC, Rodríguez I, Guirao P, Bello A, Lacasa A. 2004d. Integrated management of sweet pepper rootstocks resis tant to pathogens in greenhouses. Acta Horticulturae 698: 305-310.

Ros C, Guerrero MM, Bello A, Barceló N, Martínez MA, Martínez MC, Lacasa A. 2004e. Variaciones en la patogeneicidad de las poblaciones de Meloidogyne incognita en pimiento. En: XII Congreso de la Sociedad Española de Fitopatología. Lloret de Mar, Gerona, 27 al 30 septiembre. Resúmenes, 247.

Ros C, Guerrero MM, Martínez M A, Martínez M C, Barceló N, Lacasa A, Bello A. 2005. Comportamiento de la resistencia de patrones de pimiento a Meloidogyne incognita. Actas Portuguesas de Horticultura 7 (3): 187-192.

Ros C, Guerrero MM, Martínez MA, Lacasa A, Bello A. 2006. Integrated management of Meloidogyne resistence in sweet pepper in greenhouses. Bulletin OILB/Crop 29 (4): 319-324.

Ros C, Martínez MA, Guerrero MM, Torres J, Lacasa CM, Lacasa A, Bello A. 2007. Comportamiento de la resistencia a Phytophthora y Meloidogyne de patrones de pimiento. Actas de Horticultura 48:534-537.

Ros C, García C, Hernández MT, Lacasa A, Fernández P, Pascual JA. 2008. Effects of biosolarization as metil bromide alternative for Meloidogyne incognita control on quality of soil under pepper. Biology and Fertility of Soils 45:37-44.

Ros C, Guerrero MM, Lacasa CM, Martínez V, Martínez C, Sánchez E, Costa J, Lacasa A. 2011. Behavior of Resistance to Meloidogyne incognita and Phytophthora spp. pepper rootstock. In: International Symposium on Vegetable Grafting, University of Tuscia, Italy, 3-5 October.

Sánchez F, Ros C, Torres J, Hernández A, Martínez MC, Bielza P, Costa J. 2012. Evaluación de genotipos de pimiento para su utilización en la mejora genética de porta-injertos resistentes a Meloidogyne incognita. Actas de Horticultura 62: 97-98.

Sarwar M, Kirkegaard JA, Wong PTW, Desmarchelier JM. 1998. Biofumigation potential of brassicas. III. In vitro toxicity of isothiocyanates to soil-borne fungal pathogens. Plant and Soil 20: 103-112.

Souza-Sobrinho F, Maluf WR, Gomes LA, Campos VP. 2002. Inheritance of resistance to Meloidogyne incognita race 2 in the hot pepper cultivar Carolina Cayenne (Capsicum annuum L.). Genet Mol Res 1:271-279.

Sullivan DA. 2000. Metam sodium sealing methods to increase dose of biocide and improve efficacy. Proceedings of Annual International Research Conference on Methyl Bromide Alternatives and Emissions Reductions, 53: 1.3. November, 6-9, Orlando (Florida), USA.

Tello J, Costa J, Lacasa A, Campos T. 1978. La importancia del diagnóstico en el control de las enfermedades micológicas del pimiento. La Verdad, 19 de febrero: 30. 
Tello J, Lacasa A. 1990. Fusarium oxysporum en los cultivos intensivos del litoral mediterráneo de España. Fase parasitaria (fusariosis vasculares del tomate y del clavel) y no parasitaria. Boletín Sanidad Vegetal 19, 190 pp.

Tello J, Lacasa A. 1997. Problemática fitosanitaria del suelo en el cultivo del pimiento en el campo de Cartagena. En: López A, Mora JA, eds. Publicaciones de la Consejería de Medio Ambiente, Agricultura y Agua. Jornadas 11:11-18.

Tello J, Lacasa A. 2004. Las enfermedades de origen edáfico y su control en los pimentonares del Campo de Cartagena. Una interpretación retrospectiva del sexenio 1979-1985. En: Lacasa A, Guerrero MM, Oncina M, Mora JA, eds. Desinfección de suelos en invernaderos de pimiento. Publicaciones de la Consejería de Agricultura, Agua y Medio Ambiente. Región de Murcia. Jornadas 16: 11-26.

Tenuta M, Lazarovits G. 2002. Ammonia and nitrous acid from nitrogenous amendments kill the microsclerotia of Verticillium dahliae. Phytopathol 92: 255-264.

Tenuta M, Kenneth LC, Lazarovits G. 2002. Volatile fatty in liquid swine manure can kill microsclerotia of Verticillium dahliae. Phytopathology 92: 548-552.

Thies JA, Fery RL. 1998. Modified expression of the $N$ gene for root-knot nematode resistance in pepper at high soil temperatures. J Amer Soc Hort Sci 123: 1012-1015.

Thies JA, Fery RL. 2002. Heat stability of resistance to souther root-knot in nematodo in bell pepper genotypes homozygous and heterozygous for the $\mathrm{N}$ gen. $\mathrm{J}$ Amer Soc Hort Sci 127 (3): 371-375.

Thies JA, Ariss JJ. 2009. Comparison between the $\mathrm{N}$ and Me3 genes conferring resistance to the root-knot nematode (Meloidogyne incognita) in genetically different pepper lines (Capsicum annum). Eur J Plant Pathol 125: 545-550

Tuset JJ. 1977. Contribución al conocimiento del género Phytophthora en España. Anales INIA Serie Protección Vegetal 7: 11-106.

Walker SJ, Bosland PW. 1999. Inheritance of Phytophthora root rot and foliar blight resistance in pepper. J Amer Soc Hort Sci 124 (1): 14-18

Wang D, Bosland PW. 2006. The genes of Capsicum. HortScience 41(5), 1169-1187.

Waterhouse GM. 1963. Key to the species of Phytophthora de Bary. Mycological papers No. 92.22 pp. Common weath Mycological Institute. Kew, Surrey. England.

Waterhouse GM. 1970. The genus Phytophthora de Bary. Mycological papers No 122 CMI. Kew, Surrey. England

Wilhelm S. 1965. Pythium ultimum and the soil fumigation growth response. Phytopathology 55: 1016-1020.

Wilhelm GY, Paulus AO. 1980. How soil fumigation benefits the California strawberry ind ustry. Plant Dis 64: 264-270. 
Williamson VM, Gleason CA. 2003. Plant-nematode interactions. Current Opinion in Plant Biology 6: 327-333.

Zanón MJ. 2009. Efecto de la biofumigación y biosolarización en el control de bacterias fitopatógenas. Tesis Doctoral, Escuela Universitaria de Ingenieros Agrónomos. Universidad Politecnica de Valencia, 301 pp.

Zasada IA, Ferris H. 2003. Sensitivity of Meloidogyne javanica and Tylenchulus semipenetrans to isothiocyanates in laboratory assays. Phytopathology 93: 747- 750.

Zheng W, Yates SR, Guo M, Papiernik SK and Kim J. 2004. Transformation of chloropicrin and 1.3-dichloropropene by Metham Sodium in a combined application of fumigants. Journal of Agricultural Food Chemistry 52:3002-3009. 


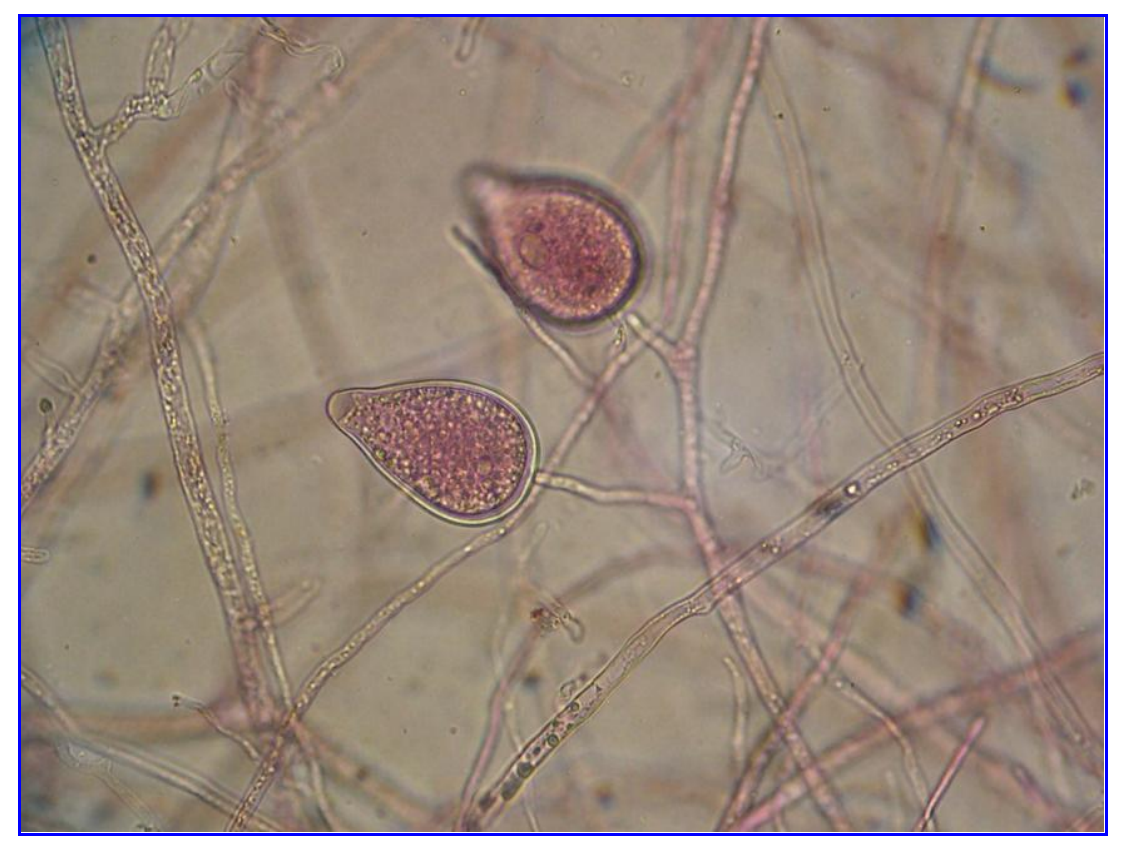

GAPÍTULO III

\section{CARACTERIZACIÓN DE LAS POBLACIONES DE PHYTOPHTHORA SP. DE LOS INVERNADEROS DE PIMIENTO DEL CAMPO DE CARTAGENA}





\section{CARACTERIZACIÓN DE LAS POBLACIONES DE PHYTOPHTHORA SP. DE LOS INVERNADEROS DE PIMIENTO DEL CAMPO DE CARTAGENA}

\subsection{INTRODUCCIÓN}

La expansión del cultivo de pimiento en invernaderos del Campo de Cartagena (Murcia) y del Sur de la provincia de Alicante, a finales de los años 70 y principios de los 80 del pasado siglo (Rico, 1983; Tello y Lacasa, 1997), llevó consigo la diseminación de Phytophthora capsici en el material vegetal de plantación (Tello y Lacasa, 1997). Los planteles se realizaban en almácigos de la Vega del río Segura, cuyos suelos se encontraban contaminados (Tello et al., 1978) y por cuyo efecto habían desaparecido los cultivos de pimiento para pimentón de la Vega (Bartual et al., 1991), o bien, en los semilleros realizados en la misma comarca en los invernaderos previamente infectados a partir de los trasplantes procedentes de la Vega (Tello y Lacasa, 2004).

A principios de la década de los 80 del pasado siglo, la "seca" o "tristeza" del pimiento se presentaba en la zona como el principal problema fitopatológico del cultivo (Tello, 1984; Legaz, 1985; Bartual et al., 1991; Tello y Lacasa, 1997), llegando a comprometer la expansión del mismo, de no existir eficaces remedios (Tello y Lacasa, 2004; Lacasa y Guirao, 1997). Estos autores, lo mismo que Bartual et al. (1991) y Tello y Lacasa (1997) consideran que la gravedad de la enfermedad se redujo en base a: a) La obtención de plantas con cepellón, al reducir la contaminación inicial y limitar la dispersión con el material vegetal de plantación, b) El control del agua de riego, al pasar de sistemas de cultivo con riego en surcos a riego por goteo y c) La generalización de la práctica de la desinfección anual de los suelos.

La asidua aplicación de bromuro de metilo antes de cada cultivo vino a minimizar los efectos de la enfermedad, reduciéndose el número de invernaderos afectados a partir de la mitad de la década de los años 80. La muerte de plantas en esos invernaderos se debía a recontaminaciones de los suelos producidas por aguas de escorrentías, por carencias en los drenajes o por deficiencias en la desinfección, (Lacasa y Guirao, 1997), siendo una situación que se presentó hasta el final del uso del bromuro de metilo y que se repite en la actualidad en algunos de los invernaderos donde se aplican las alternativas de desinfección que lo sustituyen, ya sean químicas o no químicas.

Entre 1977 y 1986 se realizaron en la zona estudios de etiología y epidemiología de la enfermedad (Tello et al., 1978; Tello, 1984; Tello y Lacasa, 1997), algunos han sido publicados (Tello y Lacasa, 2004), con el propósito de orientar las estrategias de control. La evolución de las desinfecciones de los suelos con distintos productos químicos, la medida de los efectos de la regulación del agua en el suelo y la aplicación de productos químicos al suelo a lo largo del cultivo, se acompañaron de estudios detallados de las características fisiológicas, de compatibilidad genética y de patogeneicidad de las poblaciones del hongo en el área del cultivo (Tello, 1984; Legaz, 1985; Bartual et al., 1991). Estos últimos estudios sirvieron de base para la caracterización de la resistencia a P. capsici en el pimiento (Bartual et al., 1991, 1993, 1994), elemento imprescindible para el diseño de estrategias de introducción de dicha resistencia en variedades comerciales. 
Del análisis de la bibliografía especializada parece desprenderse que no se ha llegado a llevar a la práctica la introducción de resistencia a $P$. capsici en variedades con valor comercial actual, quizás motivado por haber encontrado en la desinfección del suelo con bromuro de metilo una solución universal y estable al problema, en todas las áreas mundiales de producción de pimiento, cuyos suelos están contaminados por el hongo (Chellemi et al., 2001; Chellemi, 2004). El bromuro de metilo se ha utilizado como desinfectante del suelo en todos los países europeos productores de pimiento en invernadero Holanda, Bélgica, Francia, Italia y España (MBTOC, 2007) para paliar los efectos de los patógenos del suelo y de la fatiga producida por reiteración del cultivo en el mismo suelo. Fuera del ámbito europeo el bromuro de metilo es utilizado, por los mismos motivos, en EE.UU (Chellemi et al., 2001; Chellemi, 2004, 2006) Israel (MBTOC, 2007), Japón (MBTOC, 2007), Turquía (Yucel, 1995) o Uruguay (Bernal, 2004), como principales productores y en otros países donde el cultivo tiene menor relevancia, contemplados en el Artículo 5 del Protocolo de Montreal, como Argentina, China, Corea, Jordania, Egipto, Marruecos, Guatemala, Méjico o Costa Rica.

La necesidad de eliminar el uso del bromuro de metilo como desinfectante de los suelos de los invernaderos del Campo de Cartagena (Murcia) y del Sur de la provincia de Alicante destinados al cultivo de pimiento, planteó, en 1996-97 la búsqueda de alternativas para paliar los efectos de los patógenos del suelo ( $P$. capsici y Meloidogyne incognita, como los más importantes) y de la fatiga, derivada del monocultivo de pimiento que se practica en la zona desde hacía más de 20 años (Lacasa y Guirao, 1997). Entre las alternativas, se volvía a considerar la resistencia genética a $P$. capsici, bien introducida en variedades comerciales, bien en porta-injertos, como una solución de mínimo impacto medioambiental y sin riesgos para la seguridad alimentaria y para la seguridad de los productores.

Dado que habían trascurrido más de 10 años desde que se hubieran realizado los estudios etiológicos, epidemiológicos y de caracterización de las poblaciones de Phytophthora $s p$. que afectan a los cultivos, sin que hubieran mediado seguimientos evolutivos en la zona, se requería de nuevos estudios sobre los mismos aspectos con el fin de advertir cambios en el comportamiento del hongo (derivados de las variaciones en las estructuras productivas: nuevas variedades, nuevos sistemas de producción y metodologías de cultivo, etc) o de confirmar la actualidad y vigencia de los datos obtenidos entre 1977 y 1986.

\subsection{OBJETIVOS}

Se pretende caracterizar las poblaciones de Phytophthora sp. de los invernaderos del Campo de Cartagena (Murcia) y del Sur de la provincia de Alicante.

Los parámetros utilizados para la identificación son:

a) Las temperaturas cardinales de desarrollo miceliar.

b) El tipo de compatibilidad genética.

c) La patogeneicidad en relación al pimiento.

El conocimiento de estos aspectos permitirá plantear adecuadas estrategias de control de la enfermedad, bien sea por medios químicos o no químicos en particular sobre el uso de las resistencias genéticas, como forma de paliar los efectos de la "tristeza" o "seca" en el pimiento. 


\subsection{MATERIAL Y MÉTODOS}

\subsubsection{Origen de los aislados}

Los aislados estudiados se obtuvieron de plantas de pimiento afectadas de "tristeza" o "seca" en invernaderos de productores de pimiento en la comarca del Campo de Cartagena. En la elección se procuró abarcar la mayor amplitud de situaciones, incluyendo sistemas de desinfección, variedades, fechas a lo largo del ciclo de cultivo, distribución dentro de un mismo invernadero y partes (raíz y parte basal del tallo) de la planta. A la base inicial de 24 aislados recolectados en la campaña (97-98) (Grupo 1) obtenidos en invernaderos con plantas afectadas (Tabla 1), se añadieron 30 aislados obtenidos en las campañas 00-01 y 01-02 (Tabla 1) en invernaderos comerciales donde se realizaban ensayos de alternativas al bromuro de metilo (Grupo 2) y más tarde otros 16 aislados obtenidos en las campañas 2004-05 y 2005-06 (Tabla 1) en invernaderos donde se evaluaba el injerto y otras alternativas no químicas como sustitutivos del bromuro de metilo o de la mezcla de 1,3-dicloropropeno+cloropicrina (Grupo 3).

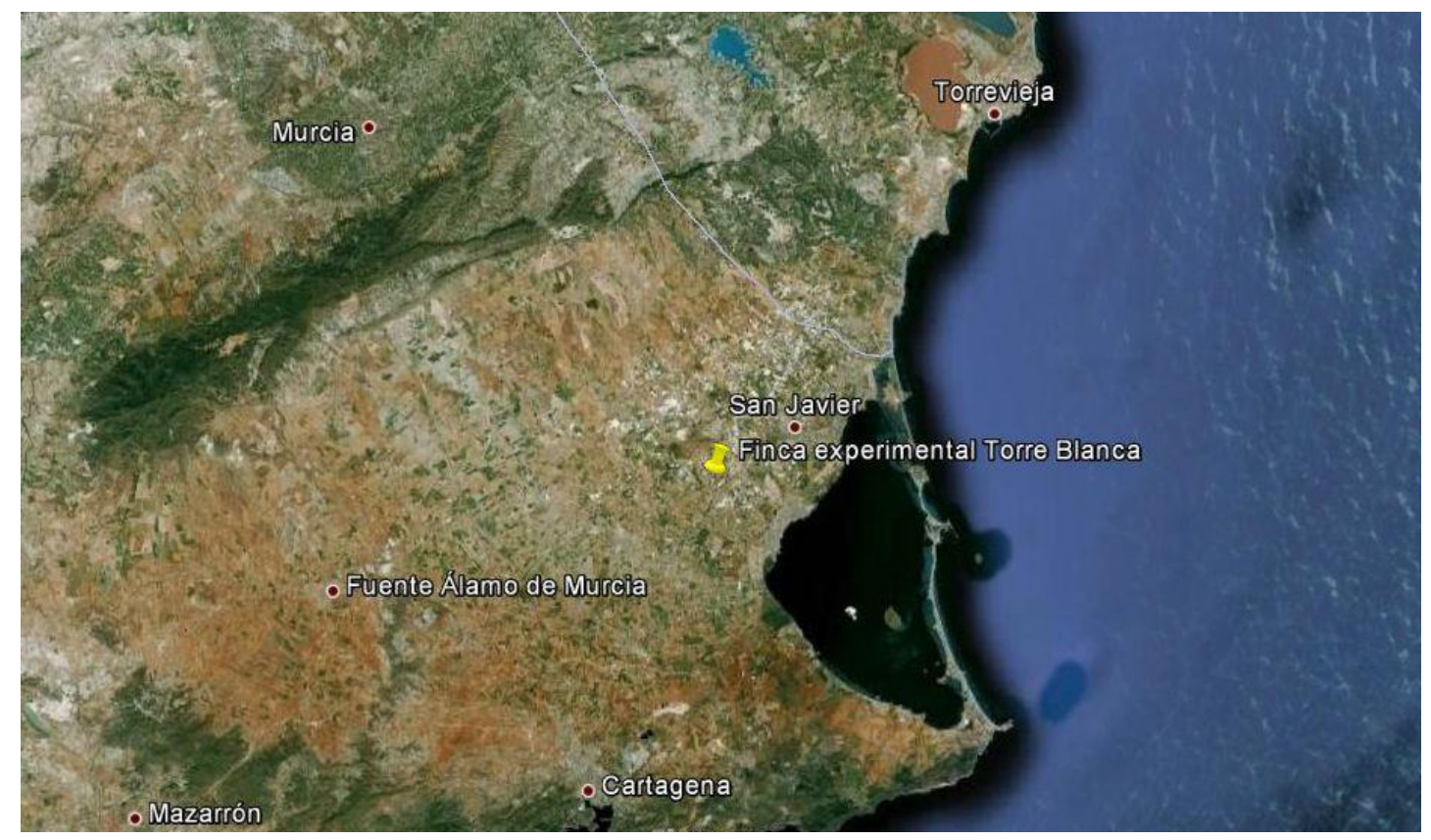

Figura 1. Zonas de origen de los aislados. Comarca del Campo de Cartagena y Sur de A licante.

Los aislados se obtuvieron a partir de tejidos vegetales afectados, sembrados en medio específico P (Ponchet et al., 1972) y en medio agar jugo V8 modificado mediante la adición de fungicidas y con antibióticos (PARPH, Bowers y Mitchell, 1991). Se purificaron en los medios específicos y se conservaron en medio general PDA. 
Tabla 1. Aislados de Phytophthora sp. obtenidos de plantas de pimiento en inve rnade ros del Campo de Cartagena (Murcia).

\begin{tabular}{|c|c|c|c|c|c|}
\hline Referencia & $\begin{array}{c}\text { Invernade ro y } \\
\text { localidad }\end{array}$ & $\begin{array}{l}\text { Antigüedad } \\
\text { monocultivo }\end{array}$ & Variedad & $\begin{array}{c}\text { Parte de la } \\
\text { planta de donde } \\
\text { se aisló }\end{array}$ & $\begin{array}{c}\text { Año de } \\
\text { aislamiento }\end{array}$ \\
\hline \multicolumn{6}{|l|}{ GRUPO 1} \\
\hline Phyp 1 & A. El Mirador & 16 años & Atol & Raíz & $97 / 98$ \\
\hline Phyp 2 & A. El Mirador & 16 años & Atol & Base tallo & $97 / 98$ \\
\hline Phyp 3 & A. El Mirador & 16 años & Atol & Raíz & $97 / 98$ \\
\hline Phyp 4 & A. El Mirador & 16 años & Atol & Raíz & $97 / 98$ \\
\hline Phyp 5 & B. El Mirador & 19 años & Maribel & Raíz & 97/98 \\
\hline Phyp 6 & B. El Mirador & 19 años & Maribel & Base tallo & $97 / 98$ \\
\hline Phyp 7 & B. El Mirador & 19 años & Maribel & Raíz & $97 / 98$ \\
\hline Phyp 8 & B. El Mirador & 19 años & Maribel & Raíz & $97 / 98$ \\
\hline Phyp 9 & B. El Mirador & 19 años & Maribel & Raíz & $97 / 98$ \\
\hline Phyp 10 & B. El Mirador & 19 años & Maribel & Raíz & $97 / 98$ \\
\hline Phyp 11 & B. El Mirador & 19 años & Maribel & Raíz & $97 / 98$ \\
\hline Phyp 12 & B. El Mirador & 19 años & Maribel & Raíz & $97 / 98$ \\
\hline Phyp 14 & B. El Mirador & 19 años & Maribel & Raíz & $97 / 98$ \\
\hline Phyp 15 & B. El Mirador & 19 años & Maribel & Base tallo & $97 / 98$ \\
\hline Phyp 16 & C. T Pacheco & 18 años & Paraíso & Base tallo & $97 / 98$ \\
\hline Phyp 17 & C. T Pacheco & 18 años & Paraíso & Raíz & $97 / 98$ \\
\hline Phyp 18 & C. T Pacheco & 18 años & Paraíso & Base tallo & $97 / 98$ \\
\hline Phyp 19 & C. T Pacheco & 18 años & Paraíso & Raíz & $97 / 98$ \\
\hline Phyp 20 & C. T Pacheco & 18 años & Paraíso & Raíz & $97 / 98$ \\
\hline Phyp 21 & C. T Pacheco & 18 años & Paraíso & Raíz & $97 / 98$ \\
\hline Phyp 22 & C. T Pacheco & 18 años & Paraíso & Base tallo & $97 / 98$ \\
\hline Phyp 23 & C. T Pacheco & 18 años & Paraíso & Raíz & $97 / 98$ \\
\hline Phyp 24 & C. T Pacheco & 18 años & Paraíso & Raíz & $97 / 98$ \\
\hline \multicolumn{6}{|l|}{ GRUPO 2} \\
\hline Phyp 25 & B. San Javier & 18 años & Orlando & Raíz & $00-01$ \\
\hline Phyp 26 & B. San Javier & 18 años & Orlando & Raíz & $00-01$ \\
\hline Phyp 27 & B. San Javier & 19 años & Orlando & Raíz & $01-02$ \\
\hline Phyp 28 & B. San Javier & 19 años & Orlando & Raíz & 01-02 \\
\hline Phyp 29 & B. San Javier & 19 años & Orlando & Raíz & $01-02$ \\
\hline Phyp 30 & G. San Javier & 9 años & Herminio & Base tallo & $01-02$ \\
\hline Phyp31 & G. San Javier & 9 años & Herminio & Raíz & 01-02 \\
\hline Phyp 32 & K'. San Javier & 20 años & Orlando & Raíz & $00-01$ \\
\hline Phyp 33 & $\mathrm{~K}^{\prime}$. San Javier & 20 años & Orlando & Raíz & $00-01$ \\
\hline Phyp 34 & $\mathrm{K}^{\prime}$. San Javier & 0 años & Orlando & Raíz & $00-01$ \\
\hline Phyp 35 & K'. San Javier & 21 años & Orlando & Base tallo & $01-02$ \\
\hline Phyp36 & K'. San Javier & 21 años & Orlando & Raíz & $01-02$ \\
\hline Phyp 37 & K'. San Javier & 21 años & Orlando & Raíz & $\overline{01-02}$ \\
\hline Phyp 38 & K'. San Javier & 21 años & Orlando & Raíz & 01-02 \\
\hline Phyp 39 & K. San Javier & 20 años & Orlando & Base tallo & $00-01$ \\
\hline Phyp 40 & K. San Javier & 20 años & Orlando & Raíz & $00-01$ \\
\hline Phyp 41 & K. San Javier & 20 años & Orlando & Base tallo & $00-01$ \\
\hline
\end{tabular}


Tabla 1. Aislados de Phytophthora sp. obtenidos de plantas de pimiento en invernade ros del Campo de Cartagena (Murcia). (Continuación).

\begin{tabular}{|c|c|c|c|c|c|}
\hline Referencia & $\begin{array}{c}\text { Invernadero y } \\
\text { localidad }\end{array}$ & $\begin{array}{l}\text { Antigüe dad } \\
\text { monocultivo }\end{array}$ & Variedad & $\begin{array}{c}\text { Parte de la } \\
\text { planta de donde } \\
\text { se aisló }\end{array}$ & $\begin{array}{c}\text { Año de } \\
\text { aislamiento }\end{array}$ \\
\hline Phyp 42 & K. San Javier & & Orlando & Raíz & $00-01$ \\
\hline Phyp 43 & K. San Javier & años & Orlando & Raíz & $01-02$ \\
\hline Phyp 44 & K. San Javier & años & Orlando & Raíz & 01-02 \\
\hline Phyp 45 & PT. P. Horadada & 5 años & Herminio & Base tallo & $\overline{01-02}$ \\
\hline Phyp 46 & PT. P. Horadada & 5 años & Herminio & Raíz & $01-02$ \\
\hline Phyp 47 & PO. P. Horadada & años & Orlando & Raíz & $01-02$ \\
\hline Phyp 48 & PO. P. Horadada & años & Orlando & Base tallo & $\overline{01-02}$ \\
\hline Phyp 49 & PO. P. Horadada & 2 años & Orlando & Raíz & $01-02$ \\
\hline Phyp 50 & PO. P. Horadada & 2 años & Orlando & Raíz & $01-02$ \\
\hline Phyp 51 & PO. P. Horadada & 2 años & Orlando & Raíz & $01-02$ \\
\hline Phyp 52 & PO. P. Horadada & 2 años & Orlando & Raíz & $01-02$ \\
\hline Phyp 53 & XB. San Javier & 9 años & Orlando & Raíz & $00-01$ \\
\hline Phyp 54 & XB. San Javier & 9 años & Orlando & Raíz & $00-01$ \\
\hline \multicolumn{6}{|l|}{ GRUPO 3} \\
\hline Phyp 55 & $\bar{B}^{\prime}$. El Mirador & 21años & Orlando & Raíz & $04-05$ \\
\hline Phyp 56 & $\mathrm{B}^{\prime}$. El Mirador & 21años & Orlando & Raíz & $04-05$ \\
\hline Phyp 57 & $\overline{B^{\prime} .}$ El Mirador & 1 1años & Orlando & Base tallo & $04-05$ \\
\hline Phyp 58 & B’. El Mirador & 1años & Orlando & Base tallo & $04-05$ \\
\hline Phyp 59 & B’. El Mirador & 21años & Orlando & Raíz & $04-05$ \\
\hline Phyp 60 & K. San Javier & 25 años & Quito & Base tallo & $05-06$ \\
\hline Phyp 61 & K. San Javier & 25 años & Quito & Base tallo & $05-06$ \\
\hline Phyp 62 & K. San Javier & 25 años & Quito & Raíz & $05-06$ \\
\hline Phyp 63 & K. San Javier & 25 años & Quito & Raíz & $05-06$ \\
\hline Phyp 64 & MSP. S Javier & 8 años & RS-10RZ & Base tallo & $05-06$ \\
\hline Phyp 65 & MSP. S Javier & años & RS-10RZ & Base tallo & $05-06$ \\
\hline Phyp 66 & MSP. S Javier & años & RS-10RZ & Raíz & $05-06$ \\
\hline Phyp 67 & MSP. S Javier & años & RS-10RZ & Raíz & $05-06$ \\
\hline Phyp 68 & NC. El Mirador & 1 años & Herminio & $\begin{array}{l}------ \\
\end{array}$ & $05-06$ \\
\hline Phyp 69 & NC. El Mirador & 21 años & Herminio & --------- & $05-06$ \\
\hline Phyp 70 & NC.El Mirador & 21 años & Herminio & 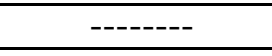 & $05-06$ \\
\hline
\end{tabular}

\subsubsection{Estudios morfológicos}

Se observaron y midieron aquellos caracteres que son más representativos para identificar las especies, tal como indican (Waterhouse, 1963, 1970; Larkin et al., 1993; Satour y Butler, 1968; Erwin y Ribeiro, 1996), basándose en las siguientes características: morfología de las colonias y del micelio; presencia de clamidosporas en medios sólidos; morfología de los esporangios y de los órganos sexuales.

\section{a) De las características de las colonias y del micelio}

Las características de las colonias y del micelio se observaron en medio PDA (patata-dextrosa-agar), en medio agar-jugo V8 y en medio agar-jugo de guisante de acuerdo con Tello et al. (1991a). Del borde de una colonia de 7 días de edad crecida en medio PDA se extrajeron discos de $4 \mathrm{~mm}$ de diámetro y se sembraron 3 placas de Petri de $9 \mathrm{~cm}$ de diámetro conteniendo $20 \mathrm{ml}$ cada uno de los medios, se sellaron las placas 
con Parafilm y se incubaron en estufa a $25^{\circ} \mathrm{C}$ y oscuridad, observando las características de la colonia y del micelio a partir del sexto día.

Se observaron las características de los 42 aislados marcados en amarillo en la Tabla 1.

\section{b) De las características de los esporangios}

Los aislados se cultivaron en placas de Petri con medio V8. Cuando hubo crecido el micelio se cortaron tiras de $0,4 \times 2 \mathrm{~cm}$ de medio con micelio y se pusieron en una placa de Petri con agua y nitrato potásico al 1\%, incubándolas durante 3 a 7 días bajo luz fluorescente continua. Pasado el tiempo los esporangios se habían formado en el borde de los trozos, se tomaba una porción del lateral del trozo disponiéndolo en un portaobjetos; se añadió una gota de colorante lactofusina; se cubrió con un cubre-objetos y se examinó la preparación al microscopio para observar y medir los esporangios. Las placas con los medios sólidos utilizados para el cultivo de las colonias se mantuvieron en incubación en estufa a $25^{\circ} \mathrm{C}$ y oscuridad para averiguar si producían esporangios en estos medios, realizando las observaciones cada 7 días hasta un máximo de 30 días.

Se midieron 25 esporangios cada uno de los 32 aislados marcados en azul en la Tabla 1.

\section{c) De las características de los órganos sexuales y la compatibilidad genética}

Para la producción de oosporas y para determinar el tipo de compatibilidad genética de los aislados se realizaron cultivos pareados de los aislados con otros dos de $P$. capsici caracterizados con tipos A1 (código 59) y A2 (código 50) procedentes de la colección de la Estación de Patología del suelo del INRA de Antibes (Francia) y proporcionadas por el Laboratorio de Patología Vegetal del Departamento de Producción Vegetal de la Universidad de Almería, para los dos primeros grupos de aislados de la Tabla 1 y con los tipos A1 y A2 de $P$. capsici del CBS para los aislados del Grupo 3 de la Tabla 1.

Los cultivos pareados se realizaron en medios sólidos agar-jugo V8 (Erwin y Ribeiro, 1996) y agar jugo de guisante, sin enriquecer con b-sitosterol como recomiendan Bowers y Mitchell (1991) y atendiendo las indicaciones de Tello et al. (1991a), ya que en los trabajos de Tello (1985) y Bartual et al. (1991) se utilizó el primer medio, además del medio agar-harina de maíz y en el de Legaz (1985) se utilizaron tanto el agar-jugo V8 como el agar-jugo de guisante, siendo estos trabajos los de referencia para nuestra comparación.

En tres placas de Petri de $90 \mathrm{~mm}$ de diámetro conteniendo $20 \mathrm{ml}$ de cada medio de cultivo, se colocaron, a unos $5 \mathrm{~cm}$ de distancia, un disco de $4 \mathrm{~mm}$ de diámetro del aislado problema (cuyo tipo de compatibilidad genética se pretendía determinar) crecido en medio PDA durante 7 a 10 días y un disco de la misma dimensión y características de los aislados (A1) y (A2) de referencia. Las placas se incubaron en estufa a $25^{\circ} \mathrm{C}$ y en oscuridad (Bowers y Mitchell, 1991; Tello et al,. 1991a), durante 30 a 60 días.

Para conocer el homotalismo, los aislados se sembraron en tres placas con medio agar-jugo V8 y en otras tres con medio agar-jugo de guisante. Se incubaron en estufa a $25^{\circ} \mathrm{C}$ y en oscuridad durante 60 días.

De la zona central de la placa donde se cruzaba el micelio de los aislados complementarios se cogió un trozo de medio, se puso en un porta-objetos, se añadió una gota de agua estéril, se cubrió con un cubre-objetos y se calentó en la llama del mechero de alcohol hasta que se fundió el medio. Se midieron las dimensiones: máxima del oogonio y la longitud y anchura del anteridio. Al ser las oosporas pleróticas no se midió la dimensión de la misma al coincidir con la del oogonio. 
En todos los casos las observaciones se realizaron cada semana, examinando la zona de solape o confrontación miceliar.

De cada uno de los 24 asilados coloreados de verde en la Tabla 1 se midió el diámetro de 25 oogonios y las dimensiones de otros tantos anteridios, presentando solo los resultados obtenidos en medio agar-jugo V8 por ser donde más precoz y abundante fue la formación de órganos sexuales.

\subsubsection{Crecimiento miceliar a diferentes temperaturas}

El conocimiento de las temperaturas cardinales (óptimo, máxima y mínima) miceliar en medios sólidos se considera de gran importancia como indicador orientativo del comportamiento epidemioló gico de la enfermedad (Tello, 1984).

Para 45 aislados (coloreados de violeta en la Tabla 1) se determinó la velocidad del crecimiento miceliar a las temperaturas constantes de: $5,10,15,20,30,35$ y $40^{\circ} \mathrm{C}$. De cada aislado se sembraron 5 placas (repeticiones) conteniendo $20 \mathrm{ml}$ de medio PDA. En el centro de la placa se puso un disco de $4 \mathrm{~mm}$ de diámetro extraído de otra placa con medio PDA en el que el aislado a estudiar había crecido a $25^{\circ} \mathrm{C}$ y oscuridad durante 7 días, tomando el disco del perímetro de la colonia. Las placas sembradas se mantuvieron en incubadores a las temperaturas mencionadas y en oscuridad. Cada 2 días se midieron dos diámetros perpendiculares entre sí de la colonia desarrollada. Para el cálculo del desarrollo se restaron $4 \mathrm{~mm}$ a los diámetros medidos.

\subsubsection{Patogeneicidad de los aislados}

\section{Producción del inóculo}

Los aislados se cultivaron en placas de Petri conteniendo $20 \mathrm{ml}$ de medio PDA incubadas en estufa a $25^{\circ} \mathrm{C}$ y oscuridad durante 7 días, de forma que la colonia cubriera, en la mayor parte de los casos, toda la superficie del medio.

\section{Producción de las plantas}

Tanto la producción de las plantas a inocular como las inoculaciones se realizaron en cámaras climatizadas donde se dieron las siguientes condiciones: $22-25^{\circ} \mathrm{C}$; 40-65\% de HR durante el periodo iluminado de la jornada y del 88-100\% durante el periodo oscuro; fotoperiodo de 14:10 horas y una luminosidad de unos 6.000 lux, proporcionados por tubos fluorescentes.

Las semillas se desinfectaron bañándolas en lejía (40 g de cloro activo/l) rebajada con agua durante 10 minutos, después se lavaron bajo el grifo. El semillero se realizó en cubetas de plástico blanco de 48,5x32 x8 cm $(7,5$ l) conteniendo un sustrato formado por sustrato hortícola y perlita al $50 \%$ en volumen, desinfectado en autoclave a $120^{\circ} \mathrm{C} \mathrm{y} 1 \mathrm{~kg}$ $\mathrm{cm}^{-2}$ durante 1 hora. Cuando se inició la formación de la 4 hoja se repicaron las plantas del semillero a bandejas de las mismas dimensiones conteniendo similar sustrato, disponiendo 10 plantas en cada bandeja; se regaron tres veces por semana y en el último riego de la semana se abonaron con una solución nutritiva completa de macro y micronutrientes. 


\section{Inoculaciones}

Se han utilizado dos métodos de inoculación para determinar la patogeneicidad de los aislados indicados por (Tello et al., 1991b):

a) El de decapitación de las plantas descrito por Pochard y Chambonnet (1971) que permite establecer comparaciones cuantitativas en relación al grado de patogeneicidad (Bartual et al., 1991, 1993), al realizar los estudios que nos sirven de comparación y referencia. La única variación en relación al método descritos por los autores mencionados estuvo en la cobertura del inóculo depositado sobre el tallo decapitado, que fue Parafilm en lugar de aluminio.

b) El de riego al sustrato en el que se cultivan las plantas, que permite conocer la patogeneicidad de los ais lados al cuello y a la raíz de las plantas, teniendo en cuenta que la respuesta de la planta puede ser distinta al mismo aislado o si se prefiere, el aislado puede presentar cierta especialización parasitaria por un determinado órgano de la planta, como señalan Monroy y Bosland (2009).

Con cada aislado y tipo de inoculación se inocularon las 10 plantas de pimiento de la variedad Sonar (Clause Semances) cultivadas en una bandeja con un sustrato de turba (sustrato hortícola) y perlita (1:1 en volumen), dejando una bandeja de plantas sin inocular, como testigo. Cada 3 días se midió la longitud de la lesión producida por el hongo en el tallo, realizando 4 mediciones consecutivas. En el caso de la inoculación por riego al sustrato las observaciones se realizaron dos veces por semana.

\section{a) Inoculación por decapitación del tallo}

Cuando las plantas tuvieron formada la octava hoja se decapitaron con un bisturí desinfectado. Luego se colocó una pastilla del aislado cultivado en medio PDA de forma que el micelio quedara en contacto con el tallo cortado. La pastilla se tomó del borde de una colonia de 7 días de desarrollo. Luego se cubrió la pastilla y el extremo del tallo decapitado con un dedal de Parafilm, ajustándolo al tallo. Las plantas, una vez inoculadas se mantuvieron en la cámara en la que se daban las condiciones antes indicadas, regándolas tres veces por semana y abonándolas con una solución nutritiva completa en el último riego de la semana. Cada 3 días se midió el trozo de tallo colonizado por el hongo, quitando el dedal de protección tras la primera medición. Las medidas se repitieron durante dos semanas.

\section{b) Inoculación por riego al sustrato}

El inóculo se preparó triturando y batiendo en $100 \mathrm{ml}$ de agua destilada estéril el contenido de una placa de Petri de $9 \mathrm{~cm}$ con $20 \mathrm{ml}$ de medio PDA en el que se había desarrollado el hongo hasta alcanzar el borde de la placa, necesitando para ello de unos 7 días de incubación en estufa a $25^{\circ} \mathrm{C}$. El batido se diluyó en agua destilada estéril hasta 1 1. Cada planta se inoculó con $100 \mathrm{ml}$ de la disolución haciendo dos agujeros en las proximidades del tallo y depositando el inóculo con una pipeta. En el momento de la inoculación las plantas tenían 4 hojas desarrolladas. Tras depositar el inóculo cerca de cada planta se regó con igual cantidad de agua que de disolución de inóculo. Las bandejas se regaron tres veces por semana y se abonaron con una solución nutritiva completa en el último riego de la semana. 
Cada vez que se regaba se realizaban los controles, anotando el número de plantas marchitas. Cuando la marchitez se consideró irreversible se arrancaron y se analizaron las lesiones del cuello y de la raíz en medios PDA y en medio PARPH. Cada dos semanas se tomó una muestra del sustrato que se analizó por el método de las trampas vegetales, utilizando pétalos inmaduros de clavel como trampa (Tello et al., 1991a).

Al finalizar el ensayo se arrancaron las plantas, se lavaron cuidadosamente las raíces y se examinaron, analizando las lesiones que pudieran presentar, trozos de raíz y trozos del cuello de todas ellas. Los trozos se sembraron en medio PDA y en medio PARPH.

Se utilizaron 41 aislados coloreados en rojo en la Tabla 1.

\subsection{RESULTADOS Y DISCUSIÓN}

\subsubsection{Características de las colonias y del micelio}

Los patrones de crecimiento de las colonias más comunes entre los aislados estudiados, en casi todas las temperaturas a las que han sido sometidos durante la incubación fueron: patrón de crecimiento no definido y estolonífero. Se encontraron casos de crecimiento con patrón petaloide, semiestelado o radiado. El margen de la colonia fue uniforme y en algunos casos irregular. A temperaturas altas (por encima de $30^{\circ} \mathrm{C}$ ) se encontraron algunas ligeras variaciones, sobre el comportamiento a temperaturas inferiores.

En las condiciones de los ensayos, todas las cepas estudiadas crecieron bien en los medios utilizados, produciendo en PDA un micelio aéreo, algodonoso raso, blanco, poco tabicado, con aspecto coralino, en la mayoría de las cepas poco pronunciado, aunque el de algunas sea marcadamente coralino (Fotos 1 y 2). En medio agar-guisante el micelio se mostró un poco menos coralino que en los otros dos medios, sin que se pueda considerar que el tipo de medio diferencie aislados. El aspecto compacto de las colonias les diferencian de las de P. capsici y P. citrophthora (Álvarez, 2007).

Se aprecia escasa variabilidad morfológica entre cepas tanto entre aislamientos procedentes de diferentes invernaderos y tipos de cultivo, como entre aislamientos obtenidos del mismo invernadero, en la misma o distinta fecha de muestreo, independientemente de la proximidad entre plantas. Lo mismo ocurre con cepas obtenidas de diferentes partes de las plantas, presentando gran similitud morfológica, tanto en la forma y en el aspecto de las colonias como en la forma y aspecto del micelio. Esta situación coincide con la señalada por Tello (1984) y por Legaz (1985) para las poblaciones de $P$. capsici obtenidas de pimiento en la Región de Murcia y para aislados de $P$. parasitica obtenidos de cítricos en las zonas citrícolas de la Comunidad Valenciana, de la Región de Murcia y de Andalucía (Álvarez, 2007). 

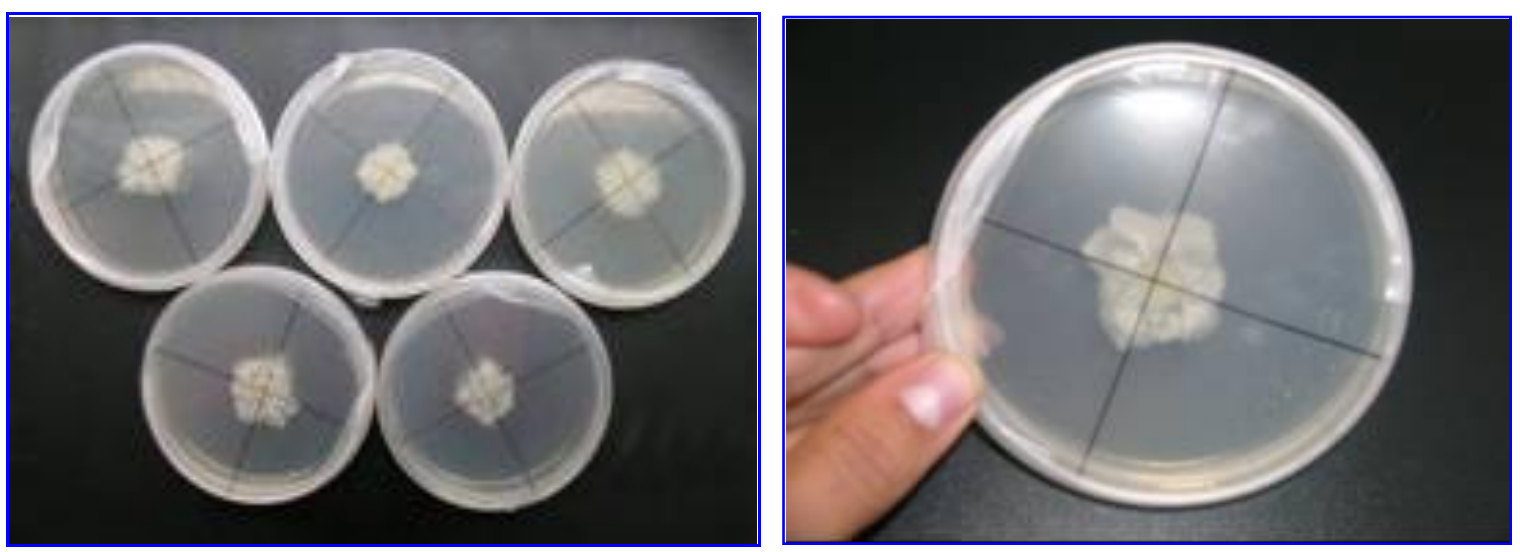

Foto 1. Crecimiento de colonias del hongo en medio PDA (izquierda). Detalle de ejes en placa para medida del diámetro de la colonia (derecha).

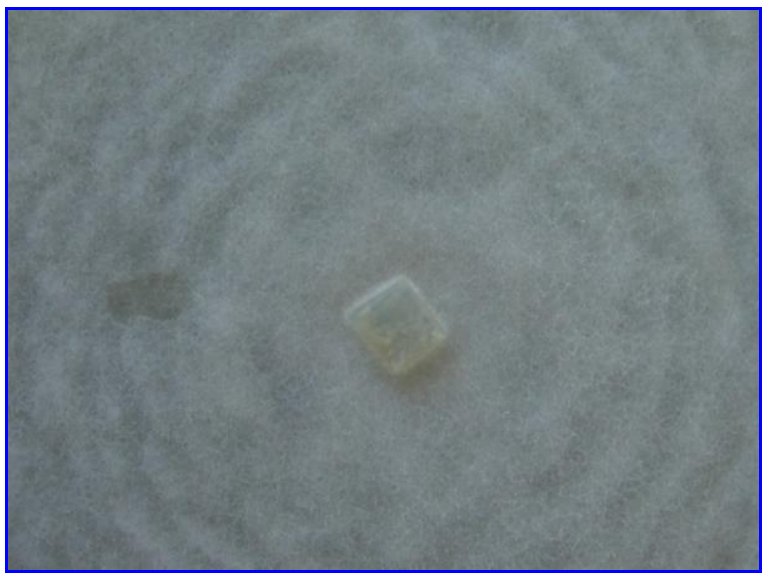

Foto 2. Micelio del hongo.

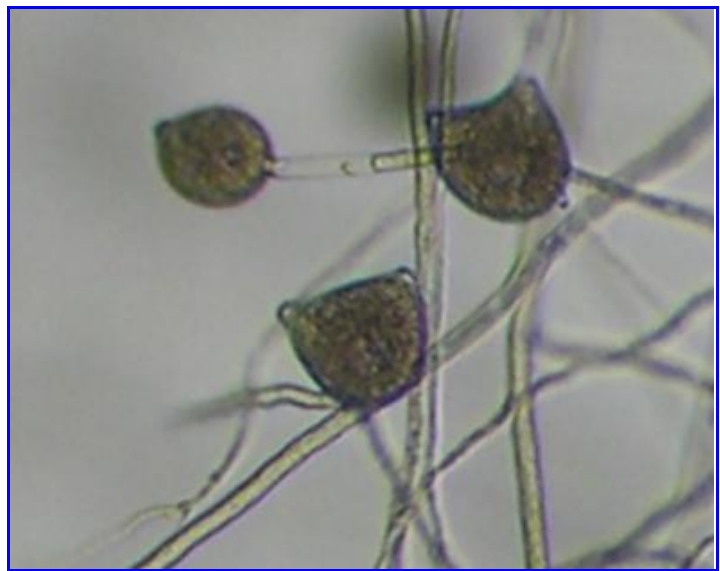

Foto 3. Esporangios bipapilados.

\subsubsection{Características de los esporangios}

Los resultados de las observaciones y mediciones se muestran en la Tabla 2. Todos los aislados produjeron hinchamientos hifales en los medios en que se desarrollaron. Este carácter, observado de forma generalizada en todos los aislados les separa de $P$. capsici que según Erwin y Ribeiro (1996) puede producir hinchamientos hifales, pero no con carácter general. Además, Bartual et al. (1991) no encuentran estas formaciones miceliares en los más de 50 aislados de $P$. capsici recolectados en cultivos de pimiento del área costera mediterránea española.

Los esporangios no tenían pedicelo lo que les confiere el carácter de no caedizos. Según Erwin y Ribeiro (1996) el carácter no caedizo o no pedicelado de los esporangios alejaría a estos aislados de $P$. capsici, especie mayoritariamente encontrada por Tello (1985) al prospectar las áreas productoras de pimiento de la Región de Murcia.

En todos los aislados se encontraron esporangios ovoides, que fueron mayoría en más del $80 \%$ de los aislados. En algunos grupos de aislados, coincidiendo con determinados invernaderos fueron abundantes los esporangios obturbinados. En un $30 \%$ de los aislados se encontraron esporangios limoniformes, en el $40 \%$ de los aislados se encontraron proporciones de esporangios esféricos, en casi el $50 \%$ se encontraron globosos y en una parte de estos, globosos bipapilados y tripapilados, que no superaron en ningún caso el $40 \%$ de los esporangios. Menos frecuentes fueron los elipsoides y algunos distorsionados. La forma mayoritaria de los esporangios aproxima a los aislados más a $P$. parasitica que a $P$. capsici. 
Las dimensiones de los esporangios es otro carácter tenido en cuenta en la identificación de las especies, en particular la relación longitud/anchura (L/A), para apoyar otros criterios más diferenciales. En los datos recogidos en la Tabla 2 la relación LA varía entre 0,98 y $1,52 \mu \mathrm{m}$ con un promedio de $1,37 \mu \mathrm{m}$ lo que se aproxima a las dimensiones propias de $P$. parasitica $(\mathrm{L} / \mathrm{A}<1,4)$. Mientras las dimensiones de los esporangios de $P$. capsici se muestran variables (Erwin y Ribeiro, 1996) y no parece tengan valor taxonómico. Los valores encontrados en nuestros aislados son similares a los indicados por Álvarez (2007) para aislados de P. parasitica obtenidos de cítricos. Las variaciones en los valores medios de la longitud y la anchura de los esporangios se han encontrado en aislados del mismo invernadero y de la misma campaña de cultivo, no pudiéndose establecer grupos de aislados por la procedencia (Tabla 2).

Por lo que se refiere a las características morfológicas de los esporangios, a sus dimensiones y a los hinchamientos hifales, se puede considerar que los aislados estudiados pertenecen a $P$. parasitica. Además, todos ellos han producido abundantes esporangios en medio agar-guisante, un $60 \%$ los produjeron en medio PDA, y tan solo 3 no los produjeron en medio V8 (en la Tabla 3 se puede apreciar el ejemplo del Grupo 2 de aislados). Con variaciones notables en el tiempo de incubación, todos produjeron clamidosporas en los medios en que se cultivaron, lo que refuerza la postura de incluir los aislados en $P$. parasitica. Erwin y Ribeiro (1996) indican que aunque algunos aislados de $P$. capsici pueden producir clamidosporas en los medios de cultivo, no parece un hecho frecuente, pero sí en el caso de $P$. parasitica. En los aislados de Phytophthora obtenidos de pimientos de la Región de Murcia e identificados como pertenecientes a P. capsici (Campos y Tello, 1977; Tello, 1984; Legaz, 1985) no se encontraron clamidosporas, ni en aislados del mismo hongo obtenidos de plantas de pimiento cultivadas en el Valle del Ebro (Palazón, 1988).

\subsubsection{Tipo de compatibilidad genética y dimensiones de los órganos sexuales}

El tipo de compatibilidad genética se determinó para todos los aislados, aunque solo de una parte se midieron el oogonio y el anteridio (Tabla 4). Se encontraron aislados de los dos grupos de compatibilidad genética. En dos invernaderos coexistían los dos tipos, en el mismo año de muestro y fueron aislados de plantas que no se encontraban muy alejadas en el invernadero. Un aislado (Phyp 28) del segundo grupo no produjo oosporas en ninguno de los medios (agar-guisante y V8) utilizados (Tabla 5). La proporción de aislados que se comportaron como estériles es algo inferior al encontrado por Álvarez (2007) al estudiar aislados de P. parasitica obtenidos de los cítricos españoles, que llegó al 9\%.

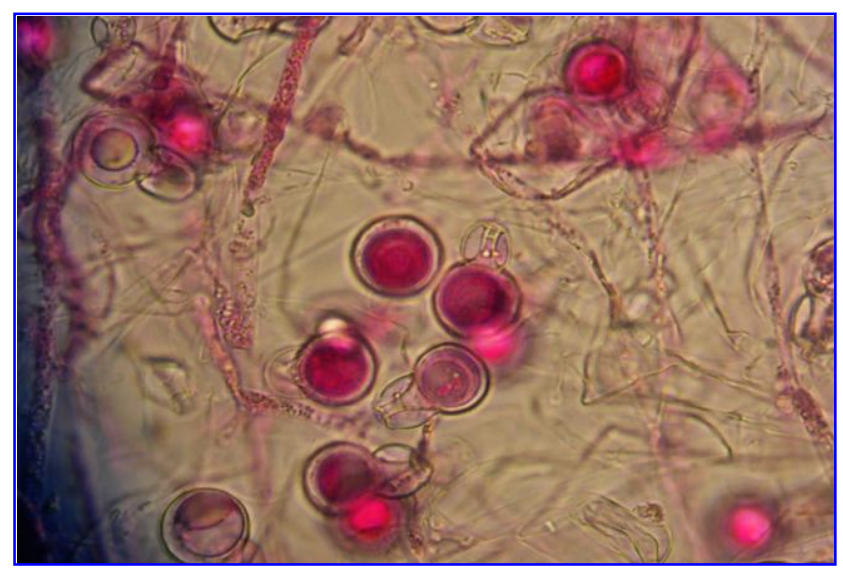

Foto 4. Órganos sexuales del hongo. 
No se encontró ningún aislado homotálico y algunos produjeron oosporas en medio Agar-guisante pero no en medio V8. Álvarez (2007) tampoco encontró aislados homotálicos en la amplia población de $P$. parasitica de los cítricos que estudió.

El 17\% de los aislados que produjeron órganos sexuales corresponde al tipo A2 y el $83 \%$ al tipo A1 (Foto 4). Esta proporción fue sensiblemente diferente a la encontrada por Álvarez (2007) en los cítricos, para cuya población encontró un 58,6\% del tipo A1 y el 41,4\% del A2. También en la población de los cítricos el anteridio era anfigino y el diámetro medio de las oosporas fue de $25,6 \mu \mathrm{m}$, muy similar al de las oosporas de los aislados de referencia que promediaron $24,4 \mu \mathrm{m}$. Sin embargo, la mayor parte de los aislados de referencia eran de tipo A1 de compatibilidad genética (Álvarez, 2007).

En nuestro caso, el diámetro de las oosporas promedió $24,47 \mu \mathrm{m}$, encontrándose este valor en el rango indicado por Erwin y Ribeiro (1996) que señala está comprendido entre 16 y $36 \mu \mathrm{m}$. Sin embargo, se han encontrado importantes diferencias en los promedios del diámetro de las oosporas por grupos de aislados. Así, los estudiados que fueron recolectados en los primeros años de muestreo (Grupo 1, años 1997-98) promediaron oosporas de 29,29 $\mu \mathrm{m}$ de diámetro, los recolectados entre los años 2000 y

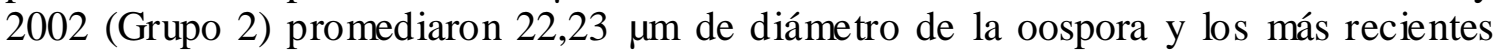
(Grupo 3 años 2004 a 2006) promediaron 21,89 $\mu \mathrm{m}$ de diámetro de la oospora (Tabla 4).

Tanto Tello y García (1977), Tello (1984), Legaz (1985) como Bartual et al. (1991), y Tello y Lacasa (1997) señalan que la totalidad de los aislados de P. capsici obtenidos de pimiento en áreas de cultivo del Levante y Sureste españoles, cuya compatibilidad genética fue estudiada, pertenecen al tipo de compatibilidad A1. La homogeneidad en el tipo de compatibilidad genética es un indicio de la estabilidad de la patogeneicidad de las poblaciones de $P$. capsici en estas zonas (Tello y Lacasa, 1997). Esta estabilidad supondría una garantía del comportamiento estable y duradero de las resistencias a este hongo cuando los materiales resistentes sean cultivados (Bartual et al., 1994), hecho ya advertido por Lacasa et al. (2002) al utilizar porta-injertos. Por el contrario, la coexistencia de aislados de los dos tipos de compatibilidad genética de $P$. parasitica en el mismo invernadero, que hemos encontrado, supone que la formación de oosporas en los suelos naturales sea posible y que la estabilidad patogénica se pueda ver modificada. Recientemente se ha constatado en algunos de estos invernaderos de los que se han obtenido aislados aquí estudiados, que la resistencia de algunos porta-injertos no se ha comportado frente a las poblaciones de $P$. parasitica como se esperaba lo hiciera frente a $P$. capsici, para la que se había introducido la resistencia (Lacasa, 2011; comunicación personal). Esto ha planteado se deban retomar estudios más detallados y amplios para reconducir la introducción de resistencias en los nuevos materiales vegetales de pimiento que se vayan a cultivar en esta zona y para el establecimiento de estrategias de uso de las resistencias. 
Tabla 2. Características morfológicas de esporangios de aislados de Phytophthora sp. obtenidos de plantas de pimiento en los invernade ros del Campo de Cartagena. (Valores medios con la desviación típica).

\begin{tabular}{|c|c|c|c|c|c|}
\hline Aislado & $\begin{array}{c}\text { Longitud (L) } \\
\text { en } \mu \mathrm{m}\end{array}$ & $\begin{array}{c}\text { Anchura (A) } \\
\mu \mathrm{m}\end{array}$ & $\begin{array}{c}\text { Relación } \\
\text { L/A }\end{array}$ & $\begin{array}{c}\text { Longitud } \\
\text { pe dicelo } \mu \mathrm{m}\end{array}$ & $\begin{array}{c}\text { Hinchamientos } \\
\text { hifales }\end{array}$ \\
\hline \multicolumn{6}{|l|}{ Grupo 1} \\
\hline Phyp 1 & $56,16 \pm 2,11$ & $40,32 \pm 3,88$ & 1,39 & 0,0 & Sí \\
\hline Phyp 2 & $49,68 \pm 1,60$ & $36,00 \pm 4,87$ & 1,38 & 0,0 & sí \\
\hline Phyp 3 & $57,04 \pm 2,25$ & $41,61 \pm 7,05$ & 1,36 & 0,0 & sí \\
\hline Phyp 4 & $68,25 \pm 0,98$ & $46,35 \pm 4,02$ & 1,47 & 0,0 & Sí \\
\hline Phyp 6 & $55,87 \pm 1,92$ & $36,72 \pm 4,76$ & 1,52 & 0,0 & Sí \\
\hline Phyp 8 & $45,30 \pm 1,21$ & $32,83 \pm 7,37$ & 1,32 & 0,0 & sí \\
\hline Phyp 9 & $52,65 \pm 3,73$ & $42,55 \pm 4,17$ & 1,23 & 0,0 & Sí \\
\hline Phyp 10 & $39,45 \pm 1,39$ & $29,08 \pm 5,45$ & 1,33 & 0,0 & Sí \\
\hline Phyp 15 & $56,16 \pm 1,77$ & $41,47 \pm 6,33$ & 1,37 & 0,0 & sí \\
\hline Phyp 17 & $47,32 \pm 2,44$ & $38,10 \pm 7,46$ & 1,24 & 0,0 & Sí \\
\hline Phyp 19 & $62,49 \pm 2,65$ & $47,33 \pm 9,05$ & 1,32 & 0,0 & Sí \\
\hline $\begin{array}{l}\text { Phyp } 20 \\
\end{array}$ & $53,56 \pm 2,50$ & $41,70 \pm 6,14$ & 1,28 & 0,0 & sí \\
\hline Phyp 21 & $49,39 \pm 1,66$ & $36,28 \pm 4,75$ & 1,36 & 0,0 & Sí \\
\hline Phyp 23 & $41,90 \pm 1,27$ & $29,37 \pm 4,36$ & 1,43 & 0,0 & Sí \\
\hline Phyp 24 & $56,76 \pm 3,00$ & $43,20 \pm 7,72$ & 1,34 & 0,0 & sí \\
\hline Medias G1 & 52,79 & 38,86 & 1,52 & $\mathbf{0 , 0}$ & \\
\hline \multicolumn{6}{|l|}{ Grupo 2} \\
\hline Phyp 39 & $41,3 \pm 5,40$ & $33,2 \pm 4,80$ & 1,24 & 0,0 & sí \\
\hline Phyp 41 & $40,8 \pm 9,42$ & $30,8 \pm 6,90$ & 1,36 & 0,0 & sí \\
\hline Phyp 42 & $37,8 \pm 5,20$ & $28,6 \pm 3,60$ & 1,32 & 0,0 & Sí \\
\hline Phyp 44 & $46,4 \pm 6,30$ & $35,6 \pm 3,30$ & 1,31 & 0,0 & sí \\
\hline Phyp 26 & $43,2 \pm 6,50$ & $30,3 \pm 4,80$ & 1,42 & 0,0 & Sí \\
\hline Phyp 27 & $56,6 \pm 9,40$ & $45,0 \pm 6,80$ & 1,29 & 0,0 & Sí \\
\hline Phyp 46 & $42,9 \pm 3,30$ & $36,7 \pm 2,60$ & 1,20 & 0,0 & Sí \\
\hline Phyp 47 & $38,0 \pm 4,74$ & $31,4 \pm 4,60$ & 1,24 & 0,0 & sí \\
\hline Medias G2 & 43,37 & 33,95 & 1,29 & $\mathbf{0 , 0}$ & \\
\hline \multicolumn{6}{|l|}{ Grupo 3} \\
\hline Phyp 55 & $48,4 \pm 3,90$ & $42,6 \pm 5,60$ & 1,13 & 0,0 & sí \\
\hline Phyp 43 & $41,0 \pm 5,10$ & $31,9 \pm 5,50$ & 1,28 & 0,0 & sí \\
\hline Phyp 60 & $49,2 \pm 6,30$ & $33,6 \pm 6,70$ & 1,46 & 0,0 & Sí \\
\hline Phyp 61 & $37,2 \pm 3,00$ & $37,6 \pm 3,70$ & 0,98 & 0,0 & Sí \\
\hline Phyp 62 & $57,7 \pm 6,30$ & $43,7 \pm 6,30$ & 1,32 & 0,0 & sí \\
\hline Phyp 63 & $52,1 \pm 6,30$ & $35,5 \pm 3,10$ & 1,46 & 0,0 & Sí \\
\hline Phyp 68 & $39,7 \pm 6,70$ & $28,2 \pm 3,50$ & 1,41 & 0,0 & sí \\
\hline Phyp 69 & $40,4 \pm 6,70$ & $28,1 \pm 3,00$ & 1,44 & 0,0 & Sí \\
\hline Phyp 70 & $36,8 \pm 5,40$ & $26,7 \pm 3,10$ & 1,38 & 0,0 & Sí \\
\hline Medias G3 & 44,72 & 34,21 & 1,32 & $\mathbf{0 , 0}$ & \\
\hline $\begin{array}{l}\text { Medias } \\
\text { Totales }\end{array}$ & 44,96 & 35,67 & 1,37 & 0,0 & \\
\hline
\end{tabular}


Tabla 3. Producción de esporangios en los medios sólidos PDA, Agar-guisante y V8 por los aislados del Grupo 2. Presencia SÍ/No, tiempo de incubación (días) a $25^{\circ} \mathrm{C}$.

\begin{tabular}{|c|c|c|c|}
\hline \multirow{2}{*}{ Aislado } & \multicolumn{3}{|c|}{ Medio de cultivo } \\
\hline & PDA & AG & V8 \\
\hline Phyp 5 & SÍ (29) & SÍ (7) & SÍ (29) \\
\hline Phyp 11 & $\mathrm{NO}$ & SÍ (7) & SÍ (29) \\
\hline Phyp 14 & SÍ (29) & SÍ (7) & SÍ (29) \\
\hline Phyp 7 & NO & SÍ (7) & SÍ (7) \\
\hline Phyp 27 & SÍ (29) & SÍ (7) & SÍ (7) \\
\hline Phyp 30 & NO & SÍ (7) & SÍ (29) \\
\hline Phyp 31 & $\mathrm{NO}$ & SÍ (7) & SÍ (29) \\
\hline Phyp 32 & SÍ (29) & SÍ (7) & Sİ (7) \\
\hline Phyp 33 & SÍ (29) & SÍ (7) & $\mathrm{NO}$ \\
\hline Phyp 34 & $\mathrm{NO}$ & SÍ (7) & SÍ (29) \\
\hline Phyp 35 & SÍ (29) & SÍ (7) & SÍ (29) \\
\hline Phyp 36 & NO & SÍ (7) & SÍ (7) \\
\hline Phyp 37 & $\mathrm{NO}$ & SÍ (7) & SÍ (7) \\
\hline Phyp 38 & $\mathrm{NO}$ & SÍ (7) & SÍ (7) \\
\hline Phyp 39 & $\mathrm{NO}$ & SÍ (7) & SÍ (29) \\
\hline$\overline{\text { Phyp } 40}$ & Sİ (36) & Sİ (7) & Sİ (29) \\
\hline Phyp 41 & SÍ (29) & SÍ (7) & SÍ (7) \\
\hline Phyp 42 & SÍ (29) & SÍ (7) & SÍ (7) \\
\hline Phyp 43 & SÍ (36) & SÍ (7) & SÍ (7) \\
\hline Phyp 44 & SÍ (29) & SÍ (7) & SÍ (29) \\
\hline Phyp 47 & Sİ (36) & SI (7) & Sİ (7) \\
\hline Phyp 48 & Sİ (36) & SI (7) & Sİ (36) \\
\hline Phyp 49 & SÍ (36) & SÍ (7) & NO \\
\hline Phyp 50 & SÍ (36) & SÍ (7) & SÍ (7) \\
\hline Phyp 51 & SÍ (36) & SÍ (7) & SÍ (7) \\
\hline Phyp 52 & SÍ (36) & SÍ (7) & SÍ (29) \\
\hline Phyp 45 & Sİ (36) & SÍ (7) & Sİ (29) \\
\hline Phyp 46 & SÍ 36) & SÍ (29) & SÍ (29) \\
\hline Phyp 53 & NO & SÍ (7) & SÍ (29) \\
\hline Phyp 54 & $\mathrm{NO}$ & SÍ (7) & SÍ (7) \\
\hline
\end{tabular}

\subsubsection{Crecimiento miceliar a diferentes temperaturas}

En la Tabla 6 se presentan los datos de crecimiento miceliar de algunos aislados de los grupos 1 y 2 a diferentes temperaturas. Como fecha límite para medir la evolución del desarrollo miceliar se tomaron 21 días, que es lo que tardan en cubrir completamente las placas la mayoría de las cepas a la temperatura de $30^{\circ} \mathrm{C}$, siendo ésta la que proporciona un crecimiento más rápido.

Solo dos aislados (Phyp 31 y Phyp 28) de los 45 estudiados crecieron a $5^{\circ} \mathrm{C}$, temperatura que resultó letal para los aislados Phyp 26 y Phyp 51.

A $10^{\circ} \mathrm{C}$ no se consiguió crecimiento de 11 aislados, siendo reducida la velocidad de crecimiento para la mayor parte de ellos. Los dos aislados que crecieron a $5^{\circ} \mathrm{C}$ se desarrollaron a la misma velocidad que a temperaturas superiores, lo que les aleja del comportamiento de la mayoría de los aislados, incluso del mismo grupo.

Todos los aislados se desarrollaron a temperaturas de $15,20,25$ y $30^{\circ} \mathrm{C}$, manteniendo unos ratios de crecimiento más elevados para las temperaturas de 25 y 
$30^{\circ} \mathrm{C}$, entre estos valores se encontraría la temperatura óptima de desarrollo para la mayor parte de ellos.

A $35^{\circ} \mathrm{C} 12$ aislados no crecieron, 2 crecieron menos de $2 \mathrm{~mm}$ y 8 menos de 5 $\mathrm{mm}$. Llama la atención el que no se desarrollaran a esta temperatura los dos aislados que crecieron a $5^{\circ} \mathrm{C}$. A $35^{\circ} \mathrm{C}$ se encontraron diferencias notables entre aislados y también entre los crecimientos medios de los aislados de los dos grupos, soportando mejor la alta temperatura los del Grupo 1. Los aislados de este grupo proceden de invernaderos muy antiguos, de estructuras bajas y frecuentemente inundados por escorrentías cuando se producen lluvias copiosas.

A $40^{\circ} \mathrm{C}$ no se obtuvo crecimiento para ningún aislado, resultando letal para todos.

El rango de temperaturas a las que crecen los aislados de los invernaderos de pimiento del Campo de Cartagena es similar al obtenido por Tello (1984), Legaz (1985) o Bartual et al. (1991) para aislados de $P$. capsici obtenidos de cultivos de pimiento del Levante y Sureste, pero difieren de los obtenidos por Álvarez (2007) para aislados de $P$. parasitica procedentes de cítricos de varias zonas productoras de España. Así, los aislados de cítricos no se desarrollaron a temperaturas inferiores a $15^{\circ} \mathrm{C}$ y presentan un ratio de crecimiento semanal a temperaturas de 20 a $35^{\circ} \mathrm{C}$ superior a la de nuestros aislados. Sin embargo, son similares las temperaturas óptimas de crecimiento y el límite máximo de temperatura de supervivencia que se sitúa próximo a $40^{\circ} \mathrm{C}$.

El crecimiento miceliar general a diferentes temperaturas se ajusta a una función polinómica como la que se muestra en la Figura 2 para el conjunto de 4 aislados del Grupo 1. Las mayores ratios de crecimiento se presentan a temperaturas de 25 a $30^{\circ} \mathrm{C}$, siendo similares los de 20 y $35^{\circ} \mathrm{C}$.

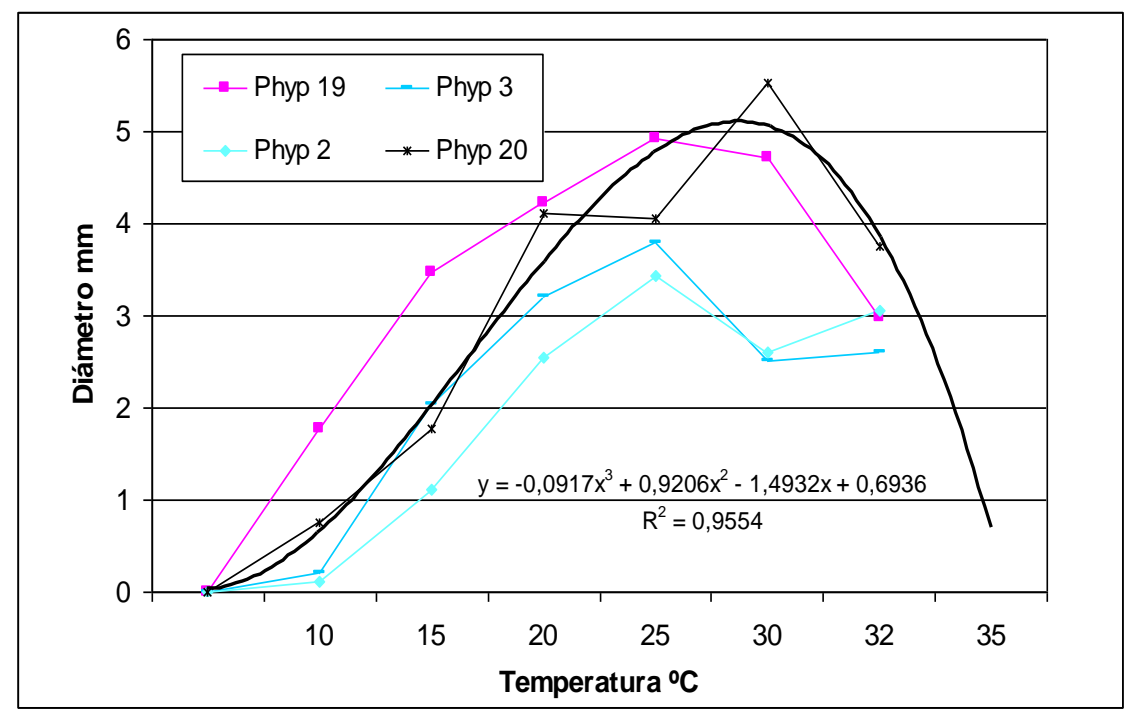

Figura 2. Ajuste del crecimiento miceliar a los 6 días de incubación de cuatro aislados a una función polinómica en relación a la temperatura.

Las temperaturas límite de crecimiento $\left(5-10^{\circ} \mathrm{C}\right.$ y $\left.35-40^{\circ} \mathrm{C}\right)$ parece guardan relación con la epidemiología de la enfermedad en los invernaderos. Así, al inicio del ciclo de cultivo en diciembre o enero, la temperatura del suelo en los invernaderos es, generalmente inferior a $15^{\circ} \mathrm{C}$ por lo que no es frecuente encontrar plantas muertas con síntomas de "tristeza" poco después del trasplante. A principios de febrero empiezan a aparecer las primeras plantas afectadas por Phytophthtora sp. (Guirao et al., 2004), estando la temperatura del suelo por encima de $15-18^{\circ} \mathrm{C}$, lo que permite multiplicarse al 
hongo en el suelo. Es a partir de mediados de mayo, cuando la temperatura del suelo está alrededor de $20-22^{\circ} \mathrm{C}$, cuando la progresión de la incidencia de la enfermedad aumenta de forma sensible, alcanzando los valores más altos de progresión a partir de mediados de junio (Guirao et al., 2004), cuando la temperatura del suelo se encuentra entre 25 y $28^{\circ} \mathrm{C}$, correspondiente al óptimo térmico para el crecimiento miceliar.

\subsubsection{Patogeneicidad de los aislados frente a pimiento}

La mayoritaria presencia de $P$. parasitica en los invernaderos prospectados era opuesta a la presencia exclusiva de $P$. capsici encontrada en los cultivos de pimiento (incluidos invernaderos de la zona de estudio) por Tello (1984), Legaz (1985) o Bartual et al. (1991). El cambio en la identidad del patógeno, hasta ahora limitante del cultivo, planteaba la necesidad de conocer los aspectos patológicos de los aislados de la especie mayoritariamente aislada de las plantas que presentaban síntomas de "seca" o "tristeza".

Las pruebas de patogeneicidad no han resultado muy aclaratorias ya que:

a) Solo 4 (Phyp 40, Phyp 43, Phyp 64, y Phyp 69) de los aislados inoculados por riego al sustrato fueron capaces de matar más de un $30 \%$ de las plantas, uno mató (Phyp 70) entre el 10 y el 30\% de las plantas y dos (Phyp 26 y Phyp 42) mataron una planta de las 10 inoculadas (Tabla 7).

b) En las inoculaciones por decapitación de la planta, 11 aislados (Phyp 22, Phyp 26, Phyp 33, Phyp 34, Phyp 43, Phyp 45, Phyp 46, Phyp 48, Phyp 50, Phyp 69, Phyp 70) produjeron una lesión superior a $30 \mathrm{~mm}, 9$ aislados produjeron lesiones de entre 15 y $30 \mathrm{~mm}$ y las lesiones producidas por el resto de los aislados fueron inferiores a $15 \mathrm{~mm}$, y 3 de estos últimos (Phyp 28, Phyp 56, Phyp 57) no produjeron lesión (Tabla 7). 
Tabla 4. Tipo de compatibilidad genética de los aislados y dimensiones de los órganos sexuales y sus características. (Valores medios con la desviación típica).

\begin{tabular}{|c|c|c|c|c|c|c|}
\hline Aislado & $\begin{array}{c}\text { Tipo } \\
\text { compatibilidad }\end{array}$ & $\begin{array}{c}\text { Diámetro } \\
\text { oogonio } \\
(\mu \mathrm{m})\end{array}$ & $\begin{array}{l}\text { Longitud } \\
\text { anteridio } \\
\qquad(\mu \mathrm{m})\end{array}$ & $\begin{array}{c}\text { Anchura } \\
\text { anteridio } \\
(\mu \mathrm{m})\end{array}$ & $\begin{array}{l}\text { Tipo } \\
\text { oospora }\end{array}$ & $\begin{array}{c}\text { Tipo } \\
\text { anteridio }\end{array}$ \\
\hline \multicolumn{7}{|l|}{ Grupo 1} \\
\hline Phyp 1 & A1 & $31,6 \pm 0,42$ & $12,31 \pm 1,38$ & $11,98 \pm 1,25$ & Plerótica & Anfigino \\
\hline Phyp 2 & $\overline{\mathrm{A} 1}$ & $30,4 \pm 0,43$ & $11,78 \pm 1,49$ & $10,83 \pm 1,38$ & Plerótica & Anfigino \\
\hline Phyp 3 & A1 & $27,6 \pm 1,20$ & $13,04 \pm 2,10$ & $12,77 \pm 1,69$ & Plerótica & Anfigino \\
\hline Phyp 4 & A1 & $30,1 \pm 1,45$ & $12,64 \pm 2,21$ & $11,53 \pm 1,37$ & Plerótica & Anfigino \\
\hline Phyp 6 & A1 & $30,74 \pm 0,88$ & $13,09 \pm 1,88$ & $12.22 \pm 1,43$ & Plerótica & Anfigino \\
\hline Phyp 8 & A1 & $31,10 \pm 0,69$ & $10,98 \pm 2,24$ & $11,03 \pm 1,54$ & Plerótica & Anfigino \\
\hline Phyp 9 & A1 & $26,42 \pm 0,68$ & $12,42 \pm 1,68$ & $11,45 \pm 1,73$ & Plerótica & Anfigino \\
\hline Phyp 10 & A1 & $31,41 \pm 1,14$ & $11,23 \pm 1,57$ & $12,04 \pm 1,82$ & Plerótica & Anfigino \\
\hline Phyp 15 & A1 & $29,04 \pm 0,61$ & $13,47 \pm 2,03$ & $11,48 \pm 1,43$ & Plerótica & Anfigino \\
\hline Phyp 17 & A1 & $30,57 \pm 1,10$ & $11,38 \pm 1,85$ & $11,31 \pm 1,56$ & Plerótica & Anfigino \\
\hline Phyp 19 & A1 & $31,99 \pm 0,85$ & $12,43 \pm 1,67$ & $11,89 \pm 1,75$ & Plerótica & Anfigino \\
\hline Phyp 20 & A1 & $23,40 \pm 0,72$ & $11,71 \pm 1,72$ & $12,02 \pm 1,36$ & Plerótica & Anfigino \\
\hline Phyp 21 & A1 & $25,63 \pm 0,71$ & $13,15 \pm 1,49$ & $11,67 \pm 1,84$ & Plerótica & Anfigino \\
\hline Phyp 23 & A1 & $29,52 \pm 0,79$ & $10,93 \pm 1,49$ & $11,03 \pm 1,38$ & Plerótica & Anfigino \\
\hline Phyp 24 & A1 & $31,58 \pm 1,55$ & $12,74 \pm 1,46$ & $12,02 \pm 1,52$ & Plerótica & Anfigino \\
\hline Medias G1 & & 29,29 & 12,22 & 11,64 & & \\
\hline \multicolumn{7}{|l|}{ Grupo 2} \\
\hline Phyp 39 & A1 & $22,10 \pm 1,67$ & $11,98 \pm 1,47$ & $14,16 \pm 2,29$ & Plerótica & Anfigino \\
\hline Phyp 41 & A2 & $23,47 \pm 1,58$ & $12,58 \pm 1,47$ & $11,54 \pm 1,76$ & Plerótica & Anfigino \\
\hline Phyp 42 & A1 & $22,76 \pm 1,59$ & $13,23 \pm 1,86$ & $12,31 \pm 1,19$ & Plerótica & Anfigino \\
\hline Phyp 44 & $\overline{\mathrm{A} 1}$ & $21,01 \pm 1,86$ & $11,88 \pm 1,49$ & $10,67 \pm 1,12$ & Plerótica & Anfigino \\
\hline Phyp 26 & $\mathrm{~A} 2$ & $23,02 \pm 3,87$ & $12,54 \pm 1,49$ & $11,43 \pm 1,41$ & Plerótica & Anfigino \\
\hline Phyp 27 & A1 & $22,08 \pm 1,25$ & $12,41 \pm 1,98$ & $11,41 \pm 1,39$ & Plerótica & Anfigino \\
\hline Phyp 46 & A1 & $21,27 \pm 2,12$ & $11,2 \pm 1,56$ & $12,54 \pm 1,0$ & Plerótica & Anfigino \\
\hline Phyp 47 & $\overline{\mathrm{A} 1}$ & $22,1 \pm 1,76$ & $12,6 \pm 1,58$ & $13,1 \pm 2,11$ & Plerótica & Anfigino \\
\hline Medias G2 & & 22,23 & 12,30 & 12,14 & & \\
\hline \multicolumn{7}{|l|}{ Grupo 3} \\
\hline Phyp 55 & A2 & $20,9 \pm 2,3$ & $13,3 \pm 1,4$ & $13,18 \pm 1,37$ & Plerótica & Anfigino \\
\hline Phyp 43 & A2 & $22,2 \pm 2,2$ & $14,6 \pm 2,6$ & $14,58 \pm 2,53$ & Plerótica & Anfigino \\
\hline Phyp 60 & A2 & $20,1 \pm 1,8$ & $13,9 \pm 1,8$ & $13,68 \pm 2,08$ & Plerótica & Anfigino \\
\hline Phyp 61 & A2 & $23,1 \pm 2,1$ & $12,5 \pm 1,4$ & $13,78 \pm 1,87$ & Plerótica & Anfigino \\
\hline Phyp 62 & A2 & $24,1 \pm 2,2$ & $13,9 \pm 1,8$ & $16,34 \pm 4,88$ & Plerótica & Anfigino \\
\hline Phyp 63 & $\mathrm{~A} 2$ & $22,1 \pm 1,8$ & $13,6 \pm 1,5$ & $17,01 \pm 3,68$ & Plerótica & Anfigino \\
\hline Phyp 68 & A1 & $20,5 \pm 1,27$ & $13,1 \pm 2,18$ & $12,56 \pm 1,51$ & Plerótica & Anfigino \\
\hline Phyp 69 & A1 & $21,1 \pm 1,87$ & $13,15 \pm 1,8$ & $12,26 \pm 2,01$ & Plerótica & Anfigino \\
\hline Phyp 70 & A1 & $22,93 \pm 1,87$ & $12,7 \pm 1,3$ & $12,09 \pm 1,78$ & Plerótica & Anfigino \\
\hline Medias G3 & & 21,89 & 13,41 & 13,94 & & \\
\hline Medias & & 24,47 & 12,64 & 12,57 & & \\
\hline
\end{tabular}


Tabla 5: Cruzamientos interespecíficos con las cepas A1 y A2 de los aislados del Grupo 2 en dos medios de cultivo: Agar-guisante y V8.

\begin{tabular}{|c|c|c|c|c|}
\hline \multirow{3}{*}{ Aislado } & \multirow{2}{*}{\multicolumn{2}{|c|}{$\begin{array}{c}\text { Aislado de referencia } \\
59 \text { (Tipo A1) }\end{array}$}} & \multirow{2}{*}{\multicolumn{2}{|c|}{$\begin{array}{c}\text { Aislado de referencia } \\
50 \text { (Tipo A2) }\end{array}$}} \\
\hline & & & & \\
\hline & Medio AG & Medio V8 & Medio AG & Medio V8 \\
\hline Phyp 25 & - & $\mathrm{nr}$ & + & + \\
\hline Phyp 26 & + & $\mathrm{nr}$ & $\mathrm{nr}$ & - \\
\hline Phyp 32 & - & $\mathrm{nr}$ & $\mathrm{nr}$ & + \\
\hline Phyp 33 & - & $\mathrm{nr}$ & + & + \\
\hline Phyp 34 & - & $\mathrm{nr}$ & - & + \\
\hline Phyp 39 & - & - & - & + \\
\hline Phyp 40 & $\mathrm{nr}$ & $\mathrm{nr}$ & + & + \\
\hline Phyp 41 & - & + & $\mathrm{nr}$ & - \\
\hline Phyp 42 & - & $\mathrm{nr}$ & + & + \\
\hline Phyp 43 & + & $\mathrm{nr}$ & $\mathrm{nr}$ & - \\
\hline Phyp 44 & - & $\mathrm{nr}$ & + & + \\
\hline Phyp 35 & - & $\mathrm{nr}$ & + & + \\
\hline Phyp 36 & - & $\mathrm{nr}$ & + & + \\
\hline Phyp 37 & - & $\mathrm{nr}$ & + & + \\
\hline Phyp 38 & - & $\mathrm{nr}$ & + & + \\
\hline Phyp 27 & - & $\mathrm{nr}$ & + & + \\
\hline Phyp 28 & - & $\mathrm{nr}$ & - & - \\
\hline Phyp 29 & - & - & + & + \\
\hline Phyp 53 & - & $\mathrm{nr}$ & + & + \\
\hline Phyp 54 & - & - & + & + \\
\hline Phyp 30 & - & $\mathrm{nr}$ & + & + \\
\hline Phyp 31 & - & $\mathrm{nr}$ & - & + \\
\hline Phyp 45 & - & $\mathrm{nr}$ & + & + \\
\hline Phyp 46 & - & $\mathrm{nr}$ & + & + \\
\hline Phyp 47 & - & $\mathrm{nr}$ & + & + \\
\hline Phyp 48 & - & - & + & + \\
\hline Phyp 49 & - & $\mathrm{nr}$ & $\mathrm{nr}$ & + \\
\hline Phyp 50 & - & $\mathrm{nr}$ & + & + \\
\hline Phyp 51 & - & $\mathrm{nr}$ & $\mathrm{nr}$ & + \\
\hline Phyp 52 & - & $\mathrm{nr}$ & + & + \\
\hline
\end{tabular}

\footnotetext{
Nota: +: encontradas oosporas, -: no encontradas oosporas, nr: no realizado el cruce.
} 
Tabla 6. Crecimiento miceliar (diámetro medio de la colonia, en $\mathbf{m m}$ ) de los aislados de Phytophthora sp. a los 21 días de incubación a varias temperaturas. Valores medios con la desviación típica.

\begin{tabular}{|c|c|c|c|c|c|c|c|c|}
\hline \multirow{2}{*}{ Aislados } & \multicolumn{8}{|c|}{ Diámetro de la col onia a las temperaturas } \\
\hline & $\mathbf{5}^{\circ} \mathrm{C}$ & $10^{\circ} \mathrm{C}$ & $15^{\circ} \mathrm{C}$ & $20^{\circ} \mathrm{C}$ & $25^{\circ} \mathrm{C}$ & $3^{\circ} \mathrm{C}$ & $35^{\circ} \mathrm{C}$ & $40^{\circ} \mathrm{C}$ \\
\hline \multicolumn{9}{|l|}{ Grupo 1} \\
\hline & $0 \pm 0,00$ & $0 \pm 0,00$ & $26,0 \pm 5,44$ & $65,1 \pm 3,06$ & $76,8 \pm 2,85$ & $74,9 \pm 2,71$ & $10,1 \pm 2,70$ & $0,0 \pm 0,00$ \\
\hline & $0 \pm 0,00$ & $3,9 \pm 1,19$ & $11,1 \pm 1,56$ & $62,7 \pm 4,04$ & $78,0 \pm 2,00$ & $64,0 \pm 6,15$ & $44,1 \pm 6,06$ & $0,0 \pm 0,00$ \\
\hline Phyp 3 & $0 \pm 0,00$ & $14,5 \pm 2,53$ & $73,3 \pm 2,57$ & $80,0 \pm 0,00$ & $66,6 \pm 10,3$ & $80,0 \pm 0,00$ & $65,4 \pm 8,41$ & $0,0 \pm 0,00$ \\
\hline Phyp 4 & $0 \pm 0,00$ & $4,5 \pm 2,6$ & $47,3 \pm 1,68$ & $65,8 \pm 3,34$ & $79,5 \pm 0,61$ & $78,2 \pm 1,20$ & $50,0 \pm 4,56$ & $0,0 \pm 0,00$ \\
\hline Phyp 7 & $0 \pm 0,00$ & $3,5 \pm 0,73$ & $10,1 \pm 2,00$ & $58,4 \pm 5,20$ & $77,7 \pm 2,63$ & $79,5 \pm 0,58$ & $57,1 \pm 1,84$ & $0,0 \pm 0,00$ \\
\hline Phyp 9 & $0,0 \pm 0,00$ & $8,6 \pm 3,41$ & $53,6 \pm 7,12$ & $65,2 \pm 2,31$ & $72,0 \pm 3,65$ & $67,7 \pm 3,31$ & $63,5 \pm 1,72$ & $0,0 \pm 0,00$ \\
\hline Phyp 10 & $0,0 \pm 0,00$ & $2,1 \pm 0,49$ & $62,2 \pm 6,02$ & $60,0 \pm 3,94$ & $80,0 \pm 0,00$ & $79,3 \pm 0,51$ & $58,2 \pm 5,21$ & $0,0 \pm 0,00$ \\
\hline Phyp 15 & $0,0 \pm 0,00$ & $6,7 \pm 3,28$ & $36,5 \pm 2,38$ & $53,8 \pm 4,19$ & $61,2 \pm 2,41$ & $77,0 \pm 1,30$ & $64,1 \pm 0,76$ & $0,0 \pm 0,00$ \\
\hline 16 & $\pm 0,00$ & $0,0 \pm 0,00$ & $35,7 \pm 2,43$ & $\pm 3,91$ & $60,6 \pm 3,91$ & $6 \pm 0,79$ & $0,0 \pm 0,00$ & $0,0 \pm 0,00$ \\
\hline 18 & $\pm 0,00$ & $0,0 \pm 0,00$ & $50,9 \pm 1,64$ & 4,21 & $66,9 \pm 3,41$ & $4,7 \pm 1,20$ & $3,3 \pm 3,4$ & $0,0 \pm 0,00$ \\
\hline Phyp 20 & $0 \pm 0,00$ & $0,0 \pm 0,00$ & $37,9 \pm 1,66$ & $76,5 \pm 1,28$ & $77,8 \pm 2,45$ & $77,7 \pm 1,24$ & $53,1 \pm 1,22$ & $0,0 \pm 0,00$ \\
\hline Phyp 21 & $0 \pm 0,00$ & $7,4 \pm 3,36$ & $41,5 \pm 1,64$ & $75,6 \pm 1,22$ & $80,0 \pm 0,00$ & $79,1 \pm 1,31$ & $0,0 \pm 0,00$ & $0,0 \pm 0,00$ \\
\hline p 23 & $0 \pm 0,00$ & $4,2 \pm 0,63$ & $34,0 \pm 3,12$ & $69,4 \pm 1,98$ & $71,0 \pm 6,09$ & $75,5 \pm 2,16$ & $0,0 \pm 0,00$ & $0,0 \pm 0,00$ \\
\hline & $\pm 0,00$ & $5,6 \pm 0,58$ & $38,0 \pm 1,84$ & $1,7 \pm 3,05$ & $71,2 \pm 6,09$ & $79,5 \pm$ & $71,0 \pm 1,04$ & $0,0 \pm 0,00$ \\
\hline Phyp 24 & $\pm 0,00$ & $6 \pm 0,61$ & $38,7 \pm 2$, &, 07 & $80,0 \pm 2,45$ & $80,0 \pm$ & $63,1 \pm 1,80$ & $0,0 \pm 0,00$ \\
\hline Medias & 0 & 4,3 & 39,8 & & & & 44,2 & 0 \\
\hline \multicolumn{9}{|l|}{ Grupo 2} \\
\hline & 00 & 00 & $24,6 \pm 2,63$ & & & & $0,0 \pm 0,00$ & $0,0 \pm 0,00$ \\
\hline & $0 \pm 0,00$ & $5,2 \pm 0,75$ & $15,6 \pm 3,61$ & $63,2 \pm 1,72$ & $76,5 \pm 2,95$ & 35 & $2,1 \pm 1,11$ & $0,0 \pm 0,00$ \\
\hline 29 & $0 \pm 0,00$ & $2,7 \pm 0,52$ & $24,7 \pm 0,82$ & 5,19 & $76,3 \pm 2,19$ & 09 & $0,4 \pm 0,38$ & 0,00 \\
\hline p 28 & $1,7 \pm 2,07$ & $80,0 \pm 0,00$ & $80,0 \pm 0,00$ & $80,0 \pm 0,00$ & $80,0 \pm 0,00$ & $80,0 \pm 0,00$ & $0,0 \pm 0,00$ & $0,0 \pm 0,00$ \\
\hline p 27 & $0,0 \pm 0,00$ & $0,0 \pm 0,00$ & $22,6 \pm 3,09$ & $29,0 \pm 4,81$ & $76,3 \pm 1,33$ & $76,1 \pm 2,13$ & $2,7 \pm 0,93$ & $0,0 \pm 0,00$ \\
\hline 30 & $0,0 \pm 0,00$ & $2,0 \pm 0,55$ & $50,3 \pm 4,49$ & $73,4 \pm 0,86$ & $64,2 \pm 7,11$ & $76,4 \pm 3,20$ & $0,8 \pm 0,26$ & $0,0 \pm 0,00$ \\
\hline 31 & $5,9 \pm 4,12$ & $80,0 \pm 0,00$ & $80,0 \pm 0,00$ & $\pm 0,00$ & $80,0 \pm 0,00$ & $80,0 \pm$ & $0,0 \pm 0,00$ & $0,0 \pm 0,00$ \\
\hline 32 & $, 0 \pm 0,00$ & $, 0 \pm 0,00$ & $54,3 \pm 1,70$ & $\pm 1,82$ & $77,4 \pm 1,28$ & $76,4 \pm 2,50$ & $0,0 \pm 0,00$ & $0,0 \pm 0,00$ \\
\hline & $\pm 0,00$ & $2,2 \pm 0,68$ & $38,8 \pm 2,21$ & $43,7 \pm 1,57$ & $73,7 \pm 1,21$ & $58,0 \pm$ & $0,0 \pm 0,00$ & $0,0 \pm 0,00$ \\
\hline & $\pm 0,00$ & $1,3 \pm 0,41$ & $72,2 \pm 0,82$ & $\pm 3,67$ & $79,3 \pm 1,21$ & 64 & $0,0 \pm 0,00$ & $0,0 \pm 0,00$ \\
\hline & & & $47,3 \pm 1$ & & $79,5 \pm 1,22$ & & $5,0 \pm 0,32$ & $\pm 0,00$ \\
\hline & & & $47,1 \pm 0$ & & & & $2,0 \pm 0,32$ & $0,0 \pm 0,00$ \\
\hline Phyp 37 & $0,0 \pm 0,00$ & $1,8 \pm 0,42$ & $21,8 \pm 1,21$ & $36,6 \pm 3,07$ & $75,9 \pm 0,74$ & $78,9 \pm 1,20$ & $5,0 \pm 0,32$ & $0,0 \pm 0,00$ \\
\hline Phyp 38 & $0,0 \pm 0,00$ & $2,6 \pm 0,80$ & $20,5 \pm 1,73$ & $35,9 \pm 2,18$ & $72,4 \pm 2,52$ & $75,9 \pm 2,06$ & $8,0 \pm 0,61$ & $0,0 \pm 0,00$ \\
\hline Phyp 39 & $0,0 \pm 0,00$ & $0,0 \pm 0,00$ & $34,3 \pm 3,14$ & $51,8 \pm 1,78$ & $73,7 \pm 1,29$ & $70,0 \pm 2,35$ & $0,0 \pm 0,00$ & $0,0 \pm 0,00$ \\
\hline Phyp 40 & $0,0 \pm 0,00$ & $4,0 \pm 1,95$ & $65,0 \pm 3,46$ & $77,3 \pm 1,60$ & $77,1 \pm 1,32$ & $68,2 \pm 4,93$ & $18,0 \pm 0,35$ & $0,0 \pm 0,00$ \\
\hline Phyp 41 & $0,0 \pm 0,00$ & $4,6 \pm 1,80$ & $34,7 \pm 0,98$ & $52,1 \pm 1,02$ & $76,1 \pm 0,58$ & $79,8 \pm 0,41$ & $0,0 \pm 0,00$ & $0,0 \pm 0,00$ \\
\hline Phyp 42 & $0,0 \pm 0,00$ & $4,0 \pm 0,84$ & $46,6 \pm 5,75$ & $47,3 \pm 1,94$ & $75,1 \pm 1,36$ & $78,3 \pm 0,68$ & $11,0 \pm 0,74$ & $0,0 \pm 0,00$ \\
\hline Phyp 43 & $0,0 \pm 0,00$ & $0,0 \pm 0,00$ & $29,9 \pm 1,43$ & $49,2 \pm 0,88$ & $73,4 \pm 1,69$ & $79,2 \pm 1,33$ & $4,0 \pm 0,20$ & $0,0 \pm 0,00$ \\
\hline Phyp 44 & $0,0 \pm 0,00$ & $3,1 \pm 0,92$ & $31,1 \pm 1,46$ & $55,2 \pm 2,82$ & $77,0 \pm 1,22$ & $78,5 \pm 1,34$ & $4,0 \pm 0,38$ & $0,0 \pm 0,00$ \\
\hline Phyp 47 & $0,0 \pm 0,00$ & $2,4 \pm 0,58$ & $30,3 \pm 2,82$ & $45,4 \pm 3,11$ & $77,1 \pm 3,97$ & $76,8 \pm 2,29$ & $11,0 \pm 0,66$ & $0,0 \pm 0,00$ \\
\hline Phyp 48 & $0,0 \pm 0,00$ & $3,1 \pm 1,24$ & $43,3 \pm 1,75$ & $55,2 \pm 1,78$ & $78,3 \pm 0,82$ & $79,7 \pm 0,61$ & $23,5 \pm 0,42$ & $0,0 \pm 0,00$ \\
\hline Phyp 49 & $0,0 \pm 0,00$ & $1,9 \pm 1,11$ & $29,0 \pm 2,85$ & $44,5 \pm 2,72$ & $79,2 \pm 0,82$ & $77,9 \pm 1,83$ & $18,7 \pm 0,98$ & $0,0 \pm 0,00$ \\
\hline Phyp 50 & $0,0 \pm 0,00$ & $0,0 \pm 0,00$ & $30,2 \pm 3,28$ & $68,7 \pm 1,51$ & $78,2 \pm 1,25$ & $77,2 \pm 1,75$ & $5,6 \pm 0,45$ & $0,0 \pm 0,00$ \\
\hline Phyp 51 & $0,0 \pm 0,00$ & $2,2 \pm 0,93$ & $30,3 \pm 2,02$ & $48,1 \pm 1,46$ & $78,5 \pm 1,67$ & $69,7 \pm 8,24$ & $8,3 \pm 0,68$ & $0,0 \pm 0,00$ \\
\hline
\end{tabular}


Tabla 6. Crecimiento miceliar (diámetro medio de la colonia, en $\mathbf{m m}$ ) de los aislados de Phytophthora sp. a los 21 días de incubación a varias temperaturas. Valores medios con la desviación típica. (Continuación).

\begin{tabular}{|c|c|c|c|c|c|c|c|c|}
\hline \multirow{2}{*}{ Aislados } & \multicolumn{8}{|c|}{ Diámetro de la coloni a a las temperatur as } \\
\hline & $5^{\circ} \mathrm{C}$ & $10^{\circ} \mathrm{C}$ & $15^{\circ} \mathrm{C}$ & $20^{\circ} \mathrm{C}$ & $25^{\circ} \mathrm{C}$ & $30^{\circ} \mathrm{C}$ & $35^{\circ} \mathrm{C}$ & $40^{\circ} \mathrm{C}$ \\
\hline \multicolumn{9}{|l|}{$\begin{array}{c}\text { Grupo } \\
2<\end{array}$} \\
\hline & $00+000$ & & & & & & & \\
\hline Phyp 45 & $0,0 \pm 0,00$ & $3,1 \pm 0,97$ & $28,9 \pm 2,22$ & $45,8 \pm 3,53$ & $78,9 \pm 0,97$ & $78,3 \pm 1,37$ & $12,3 \pm 0,26$ & $0,0 \pm 0,00$ \\
\hline Phyp 46 & $0,0 \pm 0,00$ & $0,0 \pm 0,00$ & $36,5 \pm 3,81$ & $49,2 \pm 1,17$ & $75,8 \pm 1,60$ & $76,8 \pm 1,51$ & $0,0 \pm 0,00$ & $0,0 \pm 0,00$ \\
\hline Phyp 53 & $0,0 \pm 0,00$ & $6,3 \pm 0,69$ & $59,8 \pm 2,25$ & $57,7 \pm 12,57$ & $73,0 \pm 4,01$ & $76,3 \pm 1,51$ & $20,1 \pm 0,41$ & $0,0 \pm 0,00$ \\
\hline Phyp 54 & $0,0 \pm 0,00$ & $2,3 \pm 0,52$ & $40,6 \pm 1,66$ & $73,2 \pm 2,42$ & $76,3 \pm 2,98$ & $78,7 \pm 1,60$ & $58,0 \pm 0,42$ & $0,0 \pm 0,00$ \\
\hline Medias & $\mathbf{0 , 3}$ & 7,5 & 39,9 & 55,6 & 76,2 & 75,8 & 7,5 & 0 \\
\hline $\begin{array}{l}\text { Medias } \\
\text { totales }\end{array}$ & 0,15 & $\mathbf{5 , 9}$ & 39,9 & 60,03 & $\mathbf{7 4 , 7}$ & 76,1 & 25,8 & $\mathbf{0}$ \\
\hline
\end{tabular}

Algunos aislados provocaron lesiones en las raíces, sin que la planta presentara síntomas de marchitez, no presentándose lesiones en el cuello de ninguna planta que no manifiesta síntomas de marchitez. De muchas de esas lesiones de las raíces se aisló el hongo.

El aislamiento de $P$. parasitica de lesiones que aparecen en las raíces cuando se inoculan con aislados de esta especie ha sido observado en coinfecciones de $P$. parasitica y Meloidogyne incognita en materiales de pimiento portadores de resistencia a $P$. capsici (por extensión, también a $P$. parasitica), sin que aparecieran síntomas de marchitez (Ros et al., 2011), ni interacción del nematodo sobre la resistencia al hongo.

Sobre el comportamiento mayoritario de los aislados de $P$. parasitica en nuestros ensayos (una gran parte no produjeron muerte de plantas) y las observaciones adicionales de Ros et al. (2011) sobre la aparición de lesiones en las raíces de las que se aísla el hongo, cabe pensar que $P$. parasitica pueda mostrarse en los invernaderos del Campo de Cartagena como un "especial parásito de debilidad" o que la expresión de su capacidad patogénica estuviera mediatizada por factores propios de los invernaderos de esta zona, que favorecen o facilitan la infección o la asociación a las plantas, factores que no se dan en las condiciones controladas en las que hemos realizado los ensayos, como por ejemplo el contenido en humedad en el suelo. Así, Martínez (2012, comunicación personal) en ensayos preliminares sobre el estudio de la influencia de la humedad de suelos naturales sobre patogeneicidad de aislados de P.capsici y $P$. parasitica, encuentra en condiciones controladas que los de $P$. capsici matan las plantas en situaciones de estrés, de capacidad de campo y de saturación en el mismo tiempo, mientras que los de $P$. parasitica matan las plantas de saturación en menos tiempo que a capacidad de campo y no llegan a matar a las plantas en situación de estrés hídrico.

Será preciso replantearse la metodología de estudio de la patogeneicidad para tratar de aclarar, si los aislados de $P$. parasitica que se obtienen de plantas afectadas de marchitez son los responsables directos de la muerte de las plantas en los invernaderos o si hay factores que influyen en la expresión de su capacidad patogénica en condiciones controladas. 
Tabla 7. Inoculaciones por decapitación y riego al sustrato de plantas de pimiento, variedad Sonar, con diferentes aislados de Phytophthora sp. obtenidos de plantas de pimiento con síntomas de "tristeza" en invernaderos del Campo de Cartagena.

\begin{tabular}{|c|c|c|c|c|c|}
\hline \multirow{3}{*}{ Aislado } & \multirow{3}{*}{$\begin{array}{c}\begin{array}{c}\text { Inoculación } \\
\text { por riego }\end{array} \\
\% \text { plantas } \\
\text { muertas }\end{array}$} & \multirow{2}{*}{\multicolumn{4}{|c|}{$\begin{array}{c}\text { Inoculación por decapitación del tallo } \\
\text { Longitud media de la lesión en mm }\end{array}$}} \\
\hline & & & & & \\
\hline & & 3 días & 6 días & 9 días & 12 días \\
\hline Phyp 1 & 0,0 & 7,6 & 12,5 & 14,1 & 17,5 \\
\hline Phyp 8 & 0,0 & 2,0 & 2,3 & 2,6 & 4,7 \\
\hline Phyp 9 & 0,0 & 2,2 & 2,3 & 3,8 & 5,8 \\
\hline Phyp 20 & 0,0 & 7,4 & 11,1 & 14,3 & 15,9 \\
\hline Phyp 22 & 0,0 & 23,8 & 27,9 & 30,2 & 32,8 \\
\hline Phyp 25 & 0,0 & 5,9 & 10,8 & 11,8 & 11,8 \\
\hline Phyp 26 & 10,0 & 15,0 & 23,9 & 31,9 & 44,5 \\
\hline Phyp 29 & 0,0 & 3,4 & 7,0 & 10,0 & 10,3 \\
\hline Phyp 28 & 0,0 & 0,0 & 0,0 & 0,0 & 0,0 \\
\hline Phyp 29 & 0,0 & 1,6 & 4,7 & 8,1 & 9,1 \\
\hline Phyp 33 & 0,0 & 12,1 & 26,9 & 32,7 & 32,7 \\
\hline Phyp 40 & 100,0 & 0,9 & 1,8 & 2,4 & 3,0 \\
\hline Phyp 34 & 0,0 & 16,9 & 26,0 & 32,0 & 41,1 \\
\hline Phyp 41 & 0,0 & 6,9 & 10,9 & 12,5 & 13,1 \\
\hline Phyp 35 & 0,0 & 2,5 & 8,7 & 11,6 & 13,3 \\
\hline Phyp 42 & 10,0 & 11,3 & 15,7 & 16,9 & 17,9 \\
\hline Phyp 36 & 0,0 & 3,7 & 9,4 & 11,8 & 13,0 \\
\hline Phyp 43 & 100,00 & 7,8 & 19,4 & 26,5 & 41,3 \\
\hline Phyp 37 & 0,0 & 3,4 & 9,4 & 11,0 & 12,7 \\
\hline Phyp 44 & 0,0 & 3,3 & 7,9 & 9,1 & 9,5 \\
\hline Phyp 38 & 0,0 & 4,8 & 11,5 & 14,2 & 15,8 \\
\hline Phyp 47 & 0,0 & 3,4 & 4,0 & 13,0 & 19,4 \\
\hline Phyp 48 & 0,0 & 7,1 & 11,3 & 25,8 & 32,5 \\
\hline Phyp 50 & 0,0 & 9,4 & 15,7 & 36,9 & 53,0 \\
\hline Phyp 52 & 0,0 & 2,4 & 3,8 & 9,8 & 13,8 \\
\hline Phyp 45 & 0,0 & 9,6 & 18,4 & 40,7 & 46,9 \\
\hline Phyp 46 & 0,0 & 6,5 & 21,6 & 32,6 & 41,0 \\
\hline Phyp 53 & 0,0 & 5,1 & 10,8 & 14,4 & 15,2 \\
\hline Phyp 54 & 0,0 & 0,8 & 4,4 & 5,6 & 7,2 \\
\hline Phyp 68 & 0,0 & 5,5 & 9,2 & 13,1 & 15,0 \\
\hline Phyp 69 & 40,0 & 19,5 & 27,8 & 33,0 & 37,7 \\
\hline Phyp 70 & 20,0 & 13,0 & 25,0 & 31,8 & 34,7 \\
\hline Phyp 56 & 0,0 & 0,0 & 0,0 & 0,0 & 0,0 \\
\hline Phyp 57 & 0,0 & 0,0 & 0,0 & 0,0 & 0,0 \\
\hline Phyp 58 & 0,0 & 1,2 & 1,6 & 2,1 & 2,1 \\
\hline Phyp 59 & 0,0 & 3,7 & 10,1 & 16,0 & 24,1 \\
\hline Phyp 64 & 40,0 & 2,3 & 5,2 & 6,4 & 9,4 \\
\hline Phyp 65 & 0,0 & 3,3 & 9,1 & 12,0 & 16,8 \\
\hline Phyp 66 & 0,0 & 0,0 & 0,9 & 2,0 & 3,3 \\
\hline Phyp 67 & 0,0 & 2,0 & 4,1 & 7,3 & 9,0 \\
\hline
\end{tabular}




\subsection{CONCLUSIONES}

Atendiendo a las características de los órganos asexuales y sexuales, los aislados obtenidos de plantas de pimiento con síntomas de "tristeza" en los invernaderos del Campo de Cartagena, se identificaron como Phytophthora parasitica, excepto el aislado Phyp 28 que no se ha podido identificar al no producir órganos sexuales.

En los invernaderos del Campo de Cartagena se han encontrado aislados de $P$. parasitica de los dos tipos de compatibilidad genética, A1 y A2.

En general los aislados no crecen a 5 ni a $40^{\circ} \mathrm{C}$ y algunos no lo hacen a $10^{\circ} \mathrm{C}$ ni a $35^{\circ} \mathrm{C}$. La temperatura óptima de crecimiento se sitúa entre 25 y $30^{\circ} \mathrm{C}$.

Muy pocos aislados se comportaron como patógenos frente al pimiento en cond iciones controladas, al inocularlo por riego al sustrato y unos pocos más presentaron una agresividad moderada al inocularlo por decapitación de la planta.

Los estudios de patogeneicidad en condiciones controladas no han ayudado mucho a explicar la situación observada en los invernaderos sobre la muerte de plantas por marchitez o "tristeza".

La presencia mayoritaria de $P$. parasitica en los invernaderos del Campo de Cartagena en la actualidad contrasta con los resultados de estudios precedentes en los que solo se encontró $P$. capsici. 


\subsection{BIBLIOGRAFÍA}

Álvarez LA. 2007. Estudios de etiología, epidemiología y control de un nuevo síndrome de lesiones en tronco y ramas principales de cítricos asociado a Phytophthora. Tesis doctoral Universidad Politécnica de Valencia, $232 \mathrm{pp}$.

Bartual R, Marsal JI, Carbonell EA, Tello JC, Campos T. 1991. Genética de la resistencia a Phytophthora capsici Leonian en pimiento. Boletín de Sanidad Vegetal de Plagas 17: 3-124.

Bartual R, Lacasa A, Marsal JI, Tello J. 1993. Efectos epistásicos en la resistencia a Phytophthora capsici Leonian en pimiento. Boletín de Sanidad Vegetal de Plagas 19 (3): 485-490.

Bartual R, Lacasa A, Marsal JL, Tello JC. 1994. Epistasis in thee resistance of pepper to Phytophthora stem blight (Phytophthora capsici L.) and its significance in the prediction of double cross performances. Euphytica 72:149-152.

Bowers JA, Mitchell DJ. 1991. Relationship between inoculum level of Phytophthora capsici and mortality of pepper. Phytopathology 81: 178-184.

Campos T, Tello J. 1979. Informe sobre supuesta Resistencia a $P$. capsici Leonian. En pimiento (var. Jericho). CRIDA 07. Valencia. 5 pp.

Chellemi DO, Rosskopf E, Mitchell D, Kannwischer-Mitchell B, Graham J. 2001. Changes in soil and plant health due to pest management and crop production practices. 2001 International Research Conference on Methyl Bromide Alternatives and Emissions Reduction, 5-8 Nov. California, 20-21.

Chellemi DO. 2004. Integrating soil disinfestations in the cropping systems. Acta Horticulturae 698: 105-114.

Chellemi DO. 2006. Effect of urban debris and soil management practices on plant parasitic nematodos, Phytophthora bligth and Pythium root rot of bell pepper. Crop Protection 25: 1109-1116.

Erwin DC, Ribeiro OK. 1996. Phytophthora diseases worldwide. APS Press, St. Paul, Minnesota, $562 \mathrm{pp}$.

Guirao P, Guerrero MM, Ros C, Lacasa A, Beltrán C, Martínez MC, Torres J, Oncina M, Contreras J. 2004. La reducción de dosis del bromuro de metilo en el cultivo de pimiento y el calendario de retirada. En: Lacasa A, Guerrero MM, Oncina M, Mora JA, eds. Desinfección de suelos en invernaderos de pimiento. Publicaciones de la Consejería de Agricultura, Agua y Medio Ambiente. Región de Murcia. Jornadas 16: 61-78.

Lacasa A, Guirao P. 1997. Investigaciones actuales sobre alternativas al uso del bromuro de metilo en pimiento en invernaderos delCampo de Cartagena. En: López A, Mora JA, eds. Publicaciones de la Consejería de Medio Ambiente, Agricultura y Agua. Jornadas 11:21-36. 
Lacasa A, Guerrero MM, Guirao P, Ros C. 2002. Alternatives to Methyl Bromide in sweet pepper crosps in Murcia. Conferencia Internacional sobre Alternativas al bromuro de metilo. Sevilla, 5-8 de marzo. Actas y resúmenes: 172-177.

Larkin RP, Ristaino JB, Campbell CL. 1993. Detection and quantification of Phytophthora capsici in soil. Phytopathology 83: 1057-1063.

Legaz C. 1985. Caracterización de cepas de Phytophthora capsici Leonnian, aisladas del litoral mediterráneo, con vistas a su utilización en programas de introducción de resistencia en pimiento. Trabajo Fin de carrera. EUITA. Orihuela (Alicante). Universidad Politécnica Valencia, 197 pp.

MBTOC 2007. Montreal Protocol on Substances that Deplete the Ozone Layer. 2006. En: Report of the Methyl Bromide Technical Options Committee United Nations Environment Programme. UNEP, 453 pp.

Monroy A, Bosland P.W. 2009. Phytophthora foliar bligth multi-race screening technique in Capsicum anuum L. Hort Science 44: 1181.

Monroy A, Bosland P.W. 2011. Identification of novel physiological races of Phytophthora capsici causing foliar blight using the New Mexico recombinant inbred pepper lines set ass a host differential. J Amer Soc Hort Sci 136 (3): 205-210.

Palazón C. 1988. Estudio de los posibles métodos de control de la "Tristeza" o "Seca" del pimiento. Tesis Doctoral, Universidad Politécnica de Valencia. Valencia, 231 pp.

Pochard E, Chambonnet D. 1971. Méthodes de sélection du piment pour la résistance au Phytophthora capsici et au virus du concombre. 1st. Eucarpia Meeting on Capsicum. Ann. Fac. Sci. Agr. Univ. Torino 7:270-281.

Ponchet J, Ricci P, Andreoli C, Auge G. 1972. Métodes selectives d'isolement du Phytophthora nicotianae f. sp. parasitica (dastur) Waterh a partir du sol. Ann. Phytopathology 4 (2): 97-108.

Rico J. 1983. Cultivo del pimiento de carne gruesa en invernadero. Ministerio de Agricultura, Pesca y Alimentación. 268 pp.

Ros C, Lacasa CM, Martínez V, Lacasa A. 2011. Interaction Meloidogyne incognita and Phytophthora spp. resistances in peppers rootstocks. International Symposium on Vegetable Grafting. Viterbo Italy, 3-5 october. Proceedings, 19.

Satour MM, Butler EE. 1968. Comparative morphological and physiological studies of the progenies from intraespecific matings of Phytophthora capsici. Phytopathology 58: 183-192.

Tello JC, García M. 1977. Prospección de enfermedades micológicas en plantas hortícolas (tomate, pimiento, melón, sandía y judía). Publicación de la $7^{a}$ División Agraria, 28 pp.

Tello J, Costa J, Lacasa A, Campos T. 1978. La importancia del diagnóstico en el control de las enfermedades micológicas del pimiento. La Verdad, 19 de febrero: 30. 
Tello JC. 1984. Enfermedades criptogámicas en hortalizas: observaciones en el litoral mediterráneo español. Comunicaciones INIA, Serie Prot Veg 22, 342 pp.

Tello J. 1985. Consideraciones sobre la taxonomía del género Phytophthora spp. de Bary. II Curso Internacional sobre la Protección Fitosanitaria en Plantaciones Frutales de Clima templado. Servicio de Investigación Agraria. Diputación General de Aragón, Zaragoza, $18 \mathrm{pp}$.

Tello J, Lacasa A. 1987. Alteraciones radiculares en pimiento y habas de origen no parasitario. Cuadernos de Fitopatología 10: 38-41.

Tello J, Varés F, Lacasa A. 1991a. Análisis de muestras. En "Manual de Laboratorio. Diagnóstico de hongos, bacterias y nematodos fitopató genos". Ministerio de Agricultura, Pesca y Alimentación. Madrid. Pp. 39-72.

Tello J, Vares F, Lacasa A. 1991b. Pruebas de patogeneicidad en: "Manual de laboratorio. Diagnóstico de Hongos, Bacterias y Nematodos Fitopatógenos". Ministerio de Agricultura, Pesca y Alimentación. Madrid. Pp. 79- 81.

Tello J, Lacasa A. 1997. Problemática fitosanitaria del suelo en el cultivo del pimiento en el Campo de Cartagena. En: López A, Mora JA, eds. Publicaciones de la Consejería de Medio Ambiente, Agricultura y Agua. Jornadas 11:11-17.

Tello J, Lacasa A. 2004. Las enfermedades de origen edáfico y su control en los pimentonares del Campo de Cartagena. Una interpretación retrospectiva del sexenio 1979-1985. En: Lacasa A, Guerrero MM, Oncina M, Mora JA, eds. Desinfección de suelos en invernaderos de pimiento. Publicaciones de la Consejería de Agricultura, Agua y Medio Ambiente. Región de Murcia. Jornadas 16:11-26.

Waterhouse GM. 1963. Key to the species of Phytophthora de Bary. Mycological papers, 92 CMI. Kew Surrey. England.

Waterhouse GM. 1970. The genus Phytophthora de Bary. Mycological papers, 122 CMI. Kew Surrey. England.

Yucel S. 1995. A study on soil solarization and combined with fumigant application to control Phytophthora crown blight (Phytophthora capsici Leonian) on peppers in the East Mediterranean region of Turkey. Crop Protection 14: 653-655. 



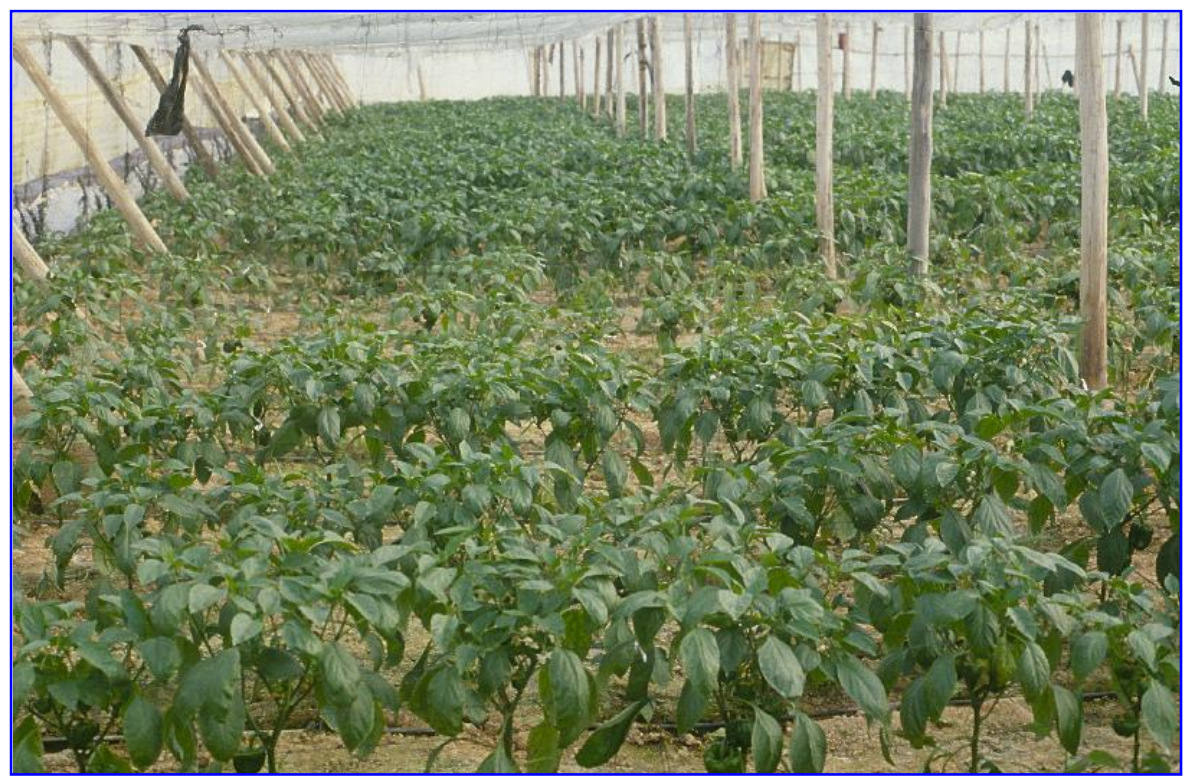

\title{
GAPITULO IV
}

\author{
CARACTERÍSTICAS DE LA FATIGA \\ DEL SUELO EN LOS INVERNADEROS \\ DE PIMIENTO DEL CAMPO DE \\ CARTAGENA (MURCIA)
}





\section{CARACTERÍSTICAS DE LA FATIGA DEL SUELO EN LOS INVERNADEROS DE PIMIENTO DEL CAMPO DE CART AGENA (MURCIA)}

\subsection{ANTECEDENTES}

En 2004, Tello y Lacasa (2004) realizaron una revisión retrospectiva de sus propios trabajos experimentales, llevados a cabo en el sexenio 1979-1985 en el Campo de Cartagena (Murcia) para controlar Phytophthora capsici. Los autores señalan que si cualquiera de los tratamientos de desinfección evaluados no proporcionaban aceptables niveles de control de la "tristeza" o "seca" del pimiento en todos los invernaderos, era recomendable el uso del bromuro de metilo por incrementar la producción. El "efecto bromuro", puesto en evidencia en esos experimentos, ha conducido a pensar en la existencia de una "fatiga" del suelo asociada al monocultivo del pimiento en los suelos de los invernaderos de esta comarca, que puede llegar, en ausencia de patógenos, a mermas de un 50\% de la producción (Lacasa et al., 2002; Guerrero et al., 2004).

El efecto de la fatiga del suelo sobre las mermas de producción no es un tema muy documentado bibliográficamente. En el caso del tomate Messiaen et al. (1991) indican que: ..."una encuesta realizada en el Sur de Francia evaluó entre un 20 y un $30 \%$ las pérdidas de rendimiento en tomates para la industria en explotaciones que manifestaban una fatiga del suelo por una repetición demasiado frecuente del cultivo". Indicando que Pyrenochaeta lycopersici era el agente principal. Para paliar el efecto de la "fatiga" indican no solo la conveniencia de la desinfección del suelo sino además el subsolado, que permite el acceso de las raíces a nuevas capas de suelo, contribuyendo a mejorar la vegetación.

La mayor parte de la bibliografía encontrada sobre la "fatiga del suelo" corresponde a observaciones parciales en cultivos concretos. Destaca la recopilación que se realiza en "La fatigue des sols. Diagnostic de la fertilité dans les systèmes culturaux", correspondiente al vigésimo tercer coloquio de la Sociedad Francesa de Fitopatología, celebrado en Versalles (Francia) en 1982. Tal recopilación es el trabajo más amplio sobre el tema que hemos encontrado.

\subsection{EL CONCEPTO DE FATIGA DEL SUELO}

En una revisión realizada por Cebolla y Maroto (2004) indican los términos anglosajones (soil sickness, soil fatigue, tired soil, replant disease) que expresan el concepto de "fatiga" que equivalen al conocido en la agricultura española de "tierra cansada" o en la francesa como "fatigue", todos ellos con alusiones antropomórficas. En nuestros planteamientos estos términos ("tierra cansada" o "fatiga del suelo") no parecen tan alejados a los estados de percepción del hombre, si se concibe el suelo como un "ente vivo", capaz de impedir la expresión de una enfermedad que se origina en él, tal como indican Tello y Bello (1995).

Antes de referirnos a la definición que se hace de la "fatiga del suelo", parece conveniente aclarar lo que en agronomía algunos denominan "factor limitante" para un cultivo. El término fue definido por Liebig (Bouhot, 1983a) para indicar que la 
carencia de cualquiera de los elementos básicos (N, P y K) significaba una reducción importante de la producción, quizás porque se refería el promotor de los abonos minerales, a la necesidad del uso de éstos para evitar dichas limitaciones. Sin embargo, no parece que los elementos básicos sean los únicos factores limitantes, tal como se manifiesta en la agricultura actual la reducción en la producción en monocultivos. La metodología del diagnóstico de la fatiga de los suelos parece deberá tener en cuenta otros factores limitantes además de los equilibrios nutricionales básicos de los cultivos, que se mantienen en los invernaderos de pimiento del Campo de Cartagena y sin embargo la reducción de cosecha puede llegar al $50 \%$.

A la acción de un patógeno concreto sobre el cultivo tampoco parece referirse la "fatiga", considerándose en ese caso a la enfermedad como el factor limitante. La relación causa-efecto se confirmaría por la aplicación de los postulados de Koch y la supresión de la causa, anularía el efecto. El fenómeno asimilable al de las "tierras cansadas" se expresa como un complejo síndrome: pérdida de rendimientos, reducción del desarrollo de las plantas, amarilleos, etc. Los factores limitantes que pueden intervenir en el proceso pueden ser múltiples y actuar de manera simultánea o sucesiva, con efectos acumulativos o puntuales. Por ello, resulta dificultoso poner de manifiesto experimentalmente, los factores que intervienen y efectuar una definición que abarque toda la complejidad.

No parece que el término "fatiga" tenga una aceptación unánime. Se aplica para describir una deformación irrecuperable de los metales sometidos a un esfuerzo y algunos encuentran similitud al aplicarlo al suelo considerado como algo vivo sometido a la presión del ininterrumpido monocultivo. Es conocido que las rotaciones o los barbechos son prácticas antiguas en agricultura para el mantenimiento de la fertilidad de los campos.

Se han emitido varias definiciones del término, no siempre concordantes. Scotto La Massasse (1983) indica que: "La fatiga específica de los suelos se define por la reducción del desarrollo de ciertos cultivos cuando éstos se repiten, dos o más veces, en ciertos suelos y cuyo origen queda por explicar". Bouhot (1983a) la define como "la perturbación de la fertilidad de los suelos debido a causas múltiples que pueden ser en el campo acumulativas, sucesivas o simultáneas". Para Cebolla y Maroto (2004), se trata de "un crecimiento deficiente y anómalo de plantas, así como una pérdida de producción en sistemas de cultivo continuado como los huertos replantados y los monocultivos en huerta y ornamentales". Hoestra (1983) indicaba que: "En Holanda, un país con una superficie limitada y una elevada densidad de población, la agricultura es, en general, intensiva. En estas condiciones no sorprende que los suelos manifiesten fatiga de manera regular. En mi opinión, las fatigas de los suelos están ligadas a los monocultivos o a cultivos repetidos con frecuencia y están causadas por un conjunto de factores, a menudo desconocidos o parcialmente conocidos". Sebillotte (1983) la define como: "La fatiga de los suelos, expresión peligrosamente antropomórfica, traduciría los efectos nefastos de una repetición de un sistema de cultivo o de algunos de sus componentes sobre la actitud del medio (el suelo interactuando con los otros componentes) para satisfacer las funciones que le son asignadas".

La pérdida de rendimiento productivo es el indicador en que fundamenta Sebillotte (1983) la expresión de la fatiga. Sin embargo, son muchos los factores que intervienen en el rendimiento del conjunto del cultivo, entre ellos: el ambiente aéreo y telúrico, las técnicas culturales, el material vegetal, etc., como para tener una idea precisa de la/s causa/s que originan la fatiga como indica Scotto La Massesse (1983). 
El hecho, sin embargo ha sido detectado hace tiempo en las agriculturas intensivas como indica Bouhot (1983a), al referirse a la fatiga de la siguiente forma: "Actualmente el hombre de campo observa que sus rendimientos no se materializan en lo esperado y nadie sabe porqué". Pero poca más información específica se ha generado desde aquellos años.

\subsubsection{Etiología de la fatiga del suelo}

Lejos de podernos referir a trabajos específicos sobre el pimiento, he mos encontrado en otros cultivos orientaciones en las que basar nuestros estudios etiológicos. Richard-Molard (1983) señala que la fatiga en los cultivos de remolacha azucarera en Francia estaba asociada a la intensificación del cultivo en los mismos campos sin respetar los principios agronómicos básicos para mantener la fertilidad del suelo, refiriendo que las pérdidas de producción se encontraban al mismo nivel que en los campos alemanes estimadas en un $30 \%$.

Bouhot (1983b), en una prospección realizada en 33 suelos de diferentes regiones francesas, establece que en el $97 \%$ de esos suelos el factor limitante está ligado a la presencia de nematodos, de hongos o a necrosis radiculares y que en el $45 \%$ la causa es imputable a bajos niveles de $\mathrm{pH}$ y carencias de potasio, fósforo, manganeso o zinc. No encuentra, una correlación positiva entre el bajo contenido en materia orgánica y el cansancio de las tierras, pero sí entre la repetición del cultivo y la fatiga de los suelos. A más intensificación mayor efecto fatiga. El estudio establece las bases para un modelo experimental de estudio de la fatiga.

Los trabajos de Bodet (1983) y Meynard y Bouhot (1983) ponen a punto métodos biológicos de evaluación de la fatiga en monocultivos de trigo o trigo realizado en zonas remolacheras, y obtiene respuestas significativas al tratar los suelos a $100^{\circ} \mathrm{C}$ en 22 de los 30 suelos estudiados. Sugieren que las necrosis radiculares que presentaban las plantas podrían estar originadas más por el sistema de cultivo que por el medio físico propiamente dicho.

En cultivos de espárrago en Suiza y Francia, Gindrat et al. (1983) y Moreau (1983) encuentran que la mortalidad de plantas en cuarto año de cultivo oscila entre el 20 y el $80 \%$ sin que la muerte se pueda imputar a una causa microbioló gica concreta, aislando Fusarium moniliforme, F. oxysporum, Acremonium sp. y Fusarium culmorum de las necrosis radiculares. Asociada a estas necrosis radiculares concluye Bouhot (1983b) estaría asociada la fatiga del suelo en el 69\% de los 42 suelos de espárrago estudiados, siendo $F$. oxysporum el hongo aislado predominantemente de las necrosis radiculares.

Al referirse al debilitamiento observado en plantas de fresón en Francia debido a un escaso desarrollo radicular de las plantas, Roudeillac (1983) hace referencia a las recomendaciones que Wilhelm y Paulus (1980) hacen para la desinfección de los suelos con formulados de bromuro de metilo en las zonas productoras californianas, donde no se conoce este síndrome. Roudeillac (1983) encuentra un escaso desarrollo del rizoma en plantas con sectores marrones o negros en las raíces. De esos sectores se aíslan hongos como Pythium sp., Fusarium sp., Cylindrocarpon sp., Rhizoctonia $s p$., etc, pero ninguno parece ser capaz de reproducir el síndrome. En la encuesta que se realizó en 860 parcelas de los fresares franceses encontró Roudillac (1983) que el $18 \%$ de los campos tenían más del 25\% de las plantascon síntomas de debilitamiento y estima que las pérdidas de producción varían entre el 30\% y el $50 \%$. Este síndrome podría estar relacionado con: textura y estructura del suelo, técnicas culturales, equilibrios físico-químicos y origen de la planta. Sin embargo, el autor indica que: "ciertos productores han comenzado, empíricamente, a desinfectar el suelo con 
bromuro de metilo como desinfectante más utilizado, lo que da en general una respuesta positiva".

Bouhot y Bonnel (1983) recogieron 27 muestras de suelos de fresón de diferentes regiones francesas y en condiciones controladas realizaron pruebas orientadas a discernir las causas de la fatiga. En un suelo nuevo para el cultivo no encontraron ningún factor limitante: no encontraron fatiga. En el $33 \%$ solo se expresó un factor limitante, mientra en el $63 \%$ fueron varios factores limitantes, fundamentalmente biológicos y nutricionales. Los defectos nutritivos afectaron al $81 \%$ y los microbiológicos al $74 \%$ de los suelos. El factor biológico limitante se manifesto en forma de necrosis radiculares a partir de las cuales se aislaron Fusarium oxysporum, F. solani, Cylindrocarpon sp., Rhizoctonia solani, Pythium sp., etc. y ninguno de estos hongos por si mismo fue capaz de reproducir el síndrome. Los autores califican a los mencionados hongos como "parásitos de debilidad". La desinfección del suelo con vapor de agua a $100^{\circ} \mathrm{C}$ anuló la presencia de la necrosis radicular. Además, el mejor desarrollo de las plantas se obtuvo cuando se asociaron la desinfección del suelo y se añadió regularmente, una solución nutritiva. Parece desprenderse de aquí que la interacción estado sanitario de las raíces y nutrición explicaría el debilitamiento de las plantas o fatiga de los suelos.

Para cultivos de tomate al aire libre Bouhot y Dumas (1983) indican que el cansancio de los suelos está relacionado con ausencia de rotaciones, supresión de abonos verdes, mecanización del cultivo, etc. y que se llega a reducir un tercio la cosecha. La fatiga se manifiesta por reducción en el número de frutos y que son de menor calibre, al tiempo que el sistema radicular está poco desarrollado y presenta diferentes grados de necrosis pudiendo encontrarse casos con raíces leñosas "Corky root" imputable a Pyrenochaeta lycopersici.

El amarilleamiento de las plantas y el enanismo acompañados de necrosis radiculares, de las que se aísla mayoritariamente Fusarium oxysporum, es el síndrome descrito por Bonnel y Bouhot (1983) para el apio como debido a la fatiga del suelo. En algunos suelos las necrosis radiculares y eldebilitamiento se atribuye al bajo contenido en materia orgánica, ya que el aporte de esta en los semilleros es suficiente para disipar el efecto depresivo. También Messiaen et al. (1991) señalan efectos similares de la materia orgánica para paliar la fatiga en cultivos de coliflor, escarola y perejil. Estos últimos autores especulan con la implicación de hongos del suelo, bacterias y nematodos en la fatiga del suelo en cultivos de alcachofas.

La complejidad de la etiología de la fatiga es puesta de manifiesto por Hoestra (1983) en los cultivos de patata de países centroeuropeos. La producción decrece hasta un $15 \%$ si se reitera el cultivo en el mismo suelo con carencia rotacional de 3 años, mientras es óptima si la rotación es de 6 años. Tal fatiga ha sido imputada a patógenos como Rhizoctonia solani, Verticillium dahliae, Streptomyces scabies y Meloidogyne hapla, que actuarían provocando enfermedad. Sin embargo, la fatiga pudiera estar relacionada con la presencia de Fusarium tabacinum, que aumenta en el suelo al repetir el cultivo en el mismo suelo. La inoculación de aislados del hongo no ha permitido reproducir el síndrome de fatiga ni tampoco mostró capacidad parasitaria alguna.

En cultivos de manzanos también se han descrito síndromes debidos a fatiga del suelo al realizar replantes y al aumentar la densidad de plantación (Hoestra, 1983), indicando un cierto grado de especificidad para el mismo cultivo. Hoestra (1983) comprobó en condiciones controladas que el tratamiento del suelo con desinfectantes generales (bromuro de metilo, cloropicrina, calentamiento del suelo) era suficiente para paliar o eliminar el efecto de la fatiga, lo que no lograba 
tratándolo con 1,3-dicloropropeno+dicloropropano. Los resultados se pueden interpretar como que la componente principal de la fatiga era microbiológica. Sin embargo, el aporte de materia orgánica y el posterior riego también tenían un efecto similar al de los desinfectantes generales. Probablemente, esto último (biofumigación) estaba actuando como una desinfección parcial del suelo de la que tenemos constancia en la actualidad, o que la humedad pudo ser desfavorable para el desarrollo de los microorganismos responsable de la fatiga, como apunta Hoestra (1983). En los replantes de cítricos en el Levante español, Cebolla y Maroto (2004) observan un síndrome similar y señalan pudiera estar relacionado con la presencia y abundancia de Tylenchulus semipenetrans.

Los casos que hemos descrito vienen a indicar que el fenómeno de la fatiga es complejo y no parece ser única la causa que la origina. No parece que todos los casos se ajusten a la hipótesis de "agentes patógenos importantes que en un principio no habrían podido ser descritos" como indican Cebolla y Maroto (2004), sería el caso de los cítricos. Tampoco hay definida una metodología experimental adecuada para el estudio o la puesta en evidencia del fenómeno de la fatiga y para el conocimiento de su etiología en cada caso.

\subsubsection{La fatiga y sus componentes}

\section{La componente fisica}

La depresión vegetativa de las plantas y las mermas en la producción como consecuencia de deficiencias en las características del suelo se asocia al fenómeno de fatiga, aunque no es fácil establecer tal relación como indican Stengel y Monnier (1983). Para estos autores, condiciones climáticas desfavorables para el cultivo durante tiempo prolongado, asfixias por compactación del suelo, postprecipitaciones excesivas, riegos abusivos y deficientes drenajes, podrían concurrir al mismo tiempo siendo dificultosa la demostración de la etiología de la fatiga. Se han señalado casos de asfixias por inadecuado manejo del riego por goteo en cultivos de habas y pimiento con hiperlenticelosis en los tallos del pimiento y podredumbres radiculares en ambas especies (Tello y Lacasa, 1987) sin que se pueda considerar un síndrome de fatiga. Se ha observado con la mejora de la velocidad de infiltración una reducción de los efectos depresivos y mermas en los rendimientos de cosecha en invernaderos con monocultivos de pimiento al biosolarizar el suelo aportando estiércoles de origen animal como enmienda biofumigante (Fernández et al., 2004 y 2005), sin que en este caso se hayan deslindado los elementos etiológicos del síndrome.

\section{La componente química}

La escasez de elementos nutritivos esenciales en el suelo, como consecuencia de las extracciones realizadas por el cultivo precedente, se manifiesta por una reducción del desarrollo de las plantas y por la aparición de anomalías fisiológicas o fisiopatías por el estado carencial. Esta manifestación de fatiga es paliada por el aporte de nutrientes, siendo poco habitual en los sistemas de cultivo modernos.

Los efectos negativos de compuestos químicos acumulados en el suelo sobre la vegetación de las plantas y sobre la producción se han puesto de manifiesto en numerosos cultivos, asociándose a fitotoxicidad. El origen de los compuestos acumulados puede estar en los excesivos aportes de abonos o a las alelosubstancias generadas por los cultivos precedentes o por los microorganismos asociados a esos 
cultivos. Los efectos beneficiosos o perjudiciales, directos o indirectos de las alelosubstancias fueron definidos por Rice en 1984, (Chiapusio et al., 2004) como alelopatía. En ocasiones este mecanismo no se asimila a un fenómeno de fatiga sino de fitotoxicidad. Así, se han encontrado pérdidas en el rendimiento de un cultivo de cacahuete realizado en un suelo previamente cultivado de sorgo, debido probablemente a que el sorgo produce sorgoleona como exudado radicular, compuesto que inhiben el crecimiento de numerosas adventicias (Hofman et al., 1996). Este efecto interespecífico se podría considerar como un indicativo de fatiga general en contraposición a la específica señalada para compuestos que afectan a la misma especie productora de la alelopatina (Llandó, 1998).

Según Chiapusio et al. (2004) todos los órganos vegetales contienen o producen sustancias potencialmente alelopáticas que se liberan al medio ambiente por volatilización, exudación radicular, lixiviación y descomposición de residuos vegetales. En plantas aromáticas como la salvia los terpenos producidos (alcanfor, cineola, a-pineno, etc.) se volatilizan afectando las plantas vecinas (Chiapusio et al., 2004) y la cineola dispersada puede ser retenida en el suelo e inhibir la proliferación de células de especies de Brassica (Koitababashi et al., 1998).

Las alelosubstancias procedentes de exudados radiculares pueden tener efectos sobre la composición microbiana del suelo. Así, De la Cuadra et al. (1992) encontraron que los alcaloides del altramuz, espartina y gramina tenían efectos fungicidas e impedían la germinación de las semillas de la avena loca.

Pero también los microorganismos asociados a un cultivo generan substancias que resultan nocivas para la misma planta. Así, Martínez et al. (2009) encontraron que los extractos crudos de algunos aislados de Fusarium oxysporum y Aspergillus $s p$., obtenidos de suelos cultivados de pimiento, mermaban el desarrollo de las plantas o inhibían la germinación de las semillas. Montoya et al. (2001) pusieron de manifiesto que los extractos acuosos de Alternaria alternata y Stemphylium botryosum reducían la germinación de las semillas y producían enanismo, falta de vigor y amarilleos en perejil, cilantro, eneldo y menta. También Llandó (1998) señala como algunos hongos son capaces de segregar fenoles (flavofenoles e isoprenoides) o compuestos nitrogenados (ácido fusárico) que limitan el crecimiento de las plantas. En contraposición a los efectos nocivos de alelosubstancias se encontrarían aquellas que promueven crecimiento de las plantas como las micorrizas (Tello et al., 1987) o el de las bacterias de los géneros Pseudomonas, Azotobacter y Bacillus que a partir de la adenina producen citoquininas (Llandó, 1998; Kloepper y Schorth, 1978; Kloepper et al., 1980).

El suelo en su complejidad biótica, con sus propiedades físicas y químicas, reacciona adsorbiendo los metabolitos en los coloides, inactivándolos temporalmente de forma reversible o permanente disminuyendo los efectos sobre la planta (Chiapusio et al., 2004). Otros ejemplos de efectos de moléculas alelopáticas han sido señalados por Chiapusio et al. (2004) como las cumarinas inhibiendo el desarrollo radicular del rábano; los flavonoides de la alfalfa retrasando el desarrollo de la planta; el ácido p-hidroxibenzoico inhibiendo el desarrollo radicular de la cebada; los monoterpenos que inhiben la germinación de las semillas del tomillo o las isoflavonas que inhiben la germinación del ajo.

En algunas ale lopatinas naturales se ha encontrado una vía para la obtención de herbicidas específicos, como es el caso de los ácidos hidroxámicos que a su poder insecticida en cereales se une su actividad herbicida tras la degradación química y microbiana del DIBOA en BOA redujo la biomasa de adventicias en un $93 \%$ en cereales (Barnes y Putnam, 1983; Barnes y Putnam, 1987). 


\subsubsection{La componente biológica o microbiológica}

Con frecuencia la fatiga del suelo se asocia a la presencia en el suelo de microorganismos que, no siendo productores de enfermedad, ejercen un efecto directo o indirecto sobre la planta. La complejidad de la asociación de microorganismos con la fatiga ha sido señalada por Messiaen et al. (1991) y sugieren la desinfección del suelo para paliarla como indicativo de que tal fatiga tiene una componente biótica que se reduce o elimina con la desinfección. La deficiencia en el diagnóstico etiológico de la fatiga señala Louvet (1979) se traduce en dificultades para remediar sus efectos en la práctica.

Los microorganismos implicados en el síndrome de fatiga son considerados como "parásitos de debilidad" por no producir enfermedad en condiciones adecuadas para parasitar la planta si esta se vegeta en condiciones óptimas. Walker (1975) señala que entre los microorganismos existen diferentes niveles de parasitismo, siendo la infección el punto común entre la simbiosis del organismo y la planta y el parasitis mo, siendo la producción de enfermedad la expresión drástica de este último.

Entre los microorganismos saprofitos estrictos y los parásitos obligados hay toda una graduación del parasitismo y la patogeneicidad que pueden originar. Tello et al. (1985a) indican para Fusarium solani en las judías que concurren: por una parte la acción que se manifiesta en forma de podredumbres radiculares, y por otra un incremento en el crecimiento y el peso de las plantas con respecto a las plantas testigo no inoculadas, cuando lo esperado era justamente lo contrario. Tello et al. (1997) hablan de "parasitismo dulce", "parásitos facultativos" y "saprofitos facultativos" para referirse a la relación del fresón y Cylindrocarpon sp., sin que se presenten síntomas de enfermedad, si encuentran debilitamiento de la planta. El término "parasitismo de debilidad" es utilizado por el autor en 1984 (Tello, 1984) en el mismo sentido que Messiaen et al. (1991) al hacer referencia a la fatiga de suelos cultivados de hortalizas.

Para Bonnel y Bouhot (1983) el síndrome de debilitamiento de la planta encontrado en el apio se asocia a Fusarium oxysporum y lo consideran como la etiología que conforma la fatiga del suelo en este cultivo. Pero Messiaen et al. (1991) se inclinan por crear una nueva forma especializada: Fusarium oxysporum fsp. radicis-apii como productora de la necrosis radicular descrita por Bonnel y Bouhot (1983). Messiaen et al. (1991) proponen para el espárrago la creación de una nueva especialización Fusarium oxysporum fsp. radicis-asparagi, cuando F. oxysporum era el hongo predominantemente aislado de las necrosis radiculares de las plantas debilitadas de espárrago, lo que ya habían sugerido Tello et al. (1985b). Ambos casos pueden ser considerados como ejemplos de un "parasitismo de debilidad", y podrían ser diferenciados de las formas especializadas productoras de podredumbres radiculares encontradas en cultivos como el tomate (Tello y Lacasa, 1990) o las cucurbitáceas (Moreno et al., 2001).

El "parasitismo de debilidad" podría interpretarse como la acción patogénica de un microorganismo sobre una planta que estaría expresando su parasitismo, bajo unas condiciones ambientales concretas y en un estado deficiente del hospedador. La respuesta positiva del cultivo a la desinfección del suelo se debería a la eliminación de los microorganismos implicados en procesos de parasitis mo de debilidad o patogeneicidad sub-clínica. 


\subsection{JUSTIFICACIÓN Y OBJETIVOS}

Al dejar de desinfectar con bromuro de metilo 98:2 (a $60 \mathrm{~g} \mathrm{~m}^{-2}$ con PE de 200 galgas o con $30 \mathrm{~g} \mathrm{~m}^{-2}$ con plástico VIF de 160 galgas) suelos de invernaderos donde el cultivo de pimiento se había repetido durante 18 años o solamente durante 2 años, se producían reducciones del desarrollo de las plantas y pérdidas de producción que superaban el $30 \%$ en el caso de los invernaderos más antiguos (Lacasa et al., 1999; Guirao et al., 2004) y el $12 \%$ en el de los invernaderos más recientes (Lacasa et al., 2002; Guerrero et al., 2004), pese a que en los suelos no se habían detectado patógenos, ni manifestado síntomas de enfermedad.

Los efectos medidos hacían sospechar de la manifestación de la fatiga, siendo la componente biológica la principal encargada en la causalidad, ya que la depresión vegetativa y productiva desaparecía al desinfectar los suelos con un biocida general total (bromuro de metilo 98:2), como ya habían puesto de manifiesto Bouhot et al. (1979a y b) para el apio, al desinfectar el suelo mediante calor húmedo a $120^{\circ} \mathrm{C}$.

La búsqueda de alternativas al bromuro de metilo, usado para desinfectar los suelos de los invernaderos de la comarca del Campo de Cartagena desde inicios de la década de los años ochenta del pasado siglo y anualmente desde 1988 hasta 2005, se planteó con dos premisas: el control de los patógenos del suelo (Phytophthora sp. y Meloidogyne incognita eran los principales), y el mantenimiento del nivel productivo del monocultivo. La resistencia genética a ambos patógenos incorporada a variedades o porta-injertos proporciona aceptables resultados para satisfacer las exigencias de la primera premisa. Sin embargo, el cultivo de variedades injertadas sobre portainjertos vigorosos y resistentes manifestaba efectos depresivos en la vegetación y pérdidas en las producciones, cuando se reiteraba la plantación en los mismos suelos no desinfectados (Martínez et al., 2009) durante tres años. El efecto de la fatiga se ponía de manifiesto al tratarse de porta-injertos del género Capsicum, de forma similar a como se manifestaba al cultivar las variedades sin injertar.

Por ello, como objetivo principal del trabajo, se planteó la determinación de las características de la fatiga del suelo en los invernaderos donde el pimiento se cultiva de forma reiterada. Los estudios se orientaron hacia el conocimiento de la especificidad, la supuesta naturaleza y el papel de la materia orgánica en la manifestación de los efectos depresivos de la reiteración del cultivo.

\subsection{MATERIAL Y MÉTODOS}

La complejidad etiológica de la fatiga del suelo hace que sean escasos los estudios sobre ella al carecer de métodos experimentales contrastados que resulten eficientes. Louvet (1979), proponía un procedimiento experimental que Messiaen et al. (1991) denominaron "método sintético". El método consiste en tratar de reproducir a escala reducida y en condiciones controladas o naturales el síndrome de la fatiga sobre plántulas cultivadas en la muestra de suelo a estudiar o en el suelo natural. Como contraste empírico se realizan tratamientos al suelo antes de la siembra o plantación para comprobar si con ellos se restablece el desarrollo normal de las plantas.

Los autores proponen cuatro tipos de actuaciones para estudiar los factores mayores en una primera fase, tales como: 
- Tratar el suelo con un biocida lo más enérgico posible para eliminar los supuestos microorganismos que puedan ser productores de enfermedad o dañinos para las plantas, pero incapaces por si mismos de producir una enfermedad bien caracterizada (factores biológicos).

- Aportar al suelo una solución nutritiva completa o complementaria a las características químicas del suelo para delimitar si la fatiga es debida a una deficiente o desequilibrada nutrición mineral de la planta (factores nutricionales).

- Aportar materia orgánica con el propósito de conseguir unas características físico-químicas del suelo, adecuad as para el cultivo (factores físico-químicos).

- Aportar carbón vegetal o carbón activo, con el fin de fijar posibles sustancias fitotóxicas (alelopatinas, micotoxinas, etc.), producidas por la actividad metabólica de residuos vegetales o de residuos de pesticidas (factores tóxicos).

En una segunda fase se abordaría un estudio más detallado y específico de aquel o aquellos factores que hubiesen delimitado la fatiga.

Basados en este modelo experimental se plantearon los ensayos en condiciones controladas con suelos procedentes de invernaderos con diferentes historiales de cultivo y reiteración del mismo.

\subsubsection{Procedencia y antecedentes de los suelos estudiados}

De los 32 invernaderos de la comarca del Campo de Cartagena donde se realizaron ensayos de desinfección del suelo, se seleccionaron 4 para los estudios de fatiga. Se codificaron como invernadero $B$, cuya tierra se utilizó en dos campañas codificado como B 1 y B 2. Invernaderos D, G, y el E, cuya tierra se utilizó en 3 campañas codificado como E 1, E 2 y E 3.

La selección se realizó procurando que fueran representativos de las problemáticas fitosanitarias del suelo de los cultivos de pimiento de la zona; de las estructuras e infraestructuras utilizadas; del ciclo de cultivo y de la conducta del mismo. En la Tabla 1 se recogen las características más relevantes de los invernaderos y sus antecedentes inmediatos a la toma de las muestras.

Con el objeto de ampliar el espectro de los antecedentes de los suelos, en cada invernadero se muestrearon parcelas con diferentes antecedentes inmediatos de desinfección, que pudieran establecer situaciones diferenciales de fatiga (Tabla 2). Las muestras se tomaron una vez finalizado el cultivo, después de haber transcurrido un ciclo vegetativo completo.

En todos los casos, salvo en el invernadero G, (por tratarse de producción en agricultura ecológica), se tuvo como referencia suelo desinfectado con bromuro de metilo (BM), bien a la dosis y sellados estánd ares hasta $1998\left(60 \mathrm{~g} \mathrm{~m}^{-2}\right.$ del formulado 98:2, y plástico de polietileno (PE) de 200 galgas $(0,05 \mathrm{~mm})$ ), bien a la dosis reducida y sellado con plástico VIF (Virtually Impermeable Film), obligatorio desde 1997 para las aplicaciones de BM $\left(30 \mathrm{~g} \mathrm{~m}^{-2}\right.$ del 98:2, plástico VIF de 160 galgas $(0,04 \mathrm{~mm}))$.

En algunos invernaderos se dispuso de suelo no desinfectado. En el invernadero $\mathrm{G}$ se muestreó solo el suelo no desinfectado, ya que los otros tratamientos eran de biosolarización, como el resto del invernadero. Los suelos del invernadero E se muestrearon después de la desinfección y antes de realizar la plantación, ya que se trataba de conocer el efecto específico de los desinfectantes sobre la fatiga. 


\subsubsection{Recogida de la tie rra y procesado de las muestras}

Se tomaron muestras de suelo de cada una de las repeticiones de cada tratamiento, de forma independiente, con el objeto de mantener el diseño de bloques al azar de los ensayos de desinfección.

Cuando finalizaron los cultivos que correspondían a distintos ensayos de desinfección, se retiraron los restos de las plantas y se labró, dando un pase de subsolador y otro de fresadora, como es habitual en la zona.

En el invernadero $G$ no se retiraron los restos de las plantas en uno de los tratamientos, enterrándolas con una labor de fresadora. A continuación se tomó tierra a una profundidad de 0 a $25 \mathrm{~cm}$, en al menos 6 puntos, homogéneamente repartidos, de cada parcela elemental; en los invernaderos B y D la tierra se tomó en 12 puntos de cada parcela elemental, que se mezclaban para formar una sola muestra al ser parcelas formadas por dos "claras" (clara es la superficie comprendida entre dos filas de postes consecutivos, en este caso miradas en sentido perpendicular al eje mayor del invernadero), con dos líneas de plantas en cada una (superficie de cada parcela: $114 \mathrm{~m}^{2}$ en el B y de $121 \mathrm{~m}^{2}$ en el D), mientras en los invernaderos E y G la parcela elemental la constituía una clara con tres líneas de plantas (superficie de cada parcela elemental: $60 \mathrm{~m}^{2}$ en el E y $75 \mathrm{~m}^{2}$ en el G).

Las muestras se codificaron mediante una letra que hacía referencia al invernadero de procedencia (B, D, E, G), seguida del tratamiento de desinfección que se había realizado en el campo (TI, T2, T3, T4, T5), especificado en la Tabla 2. En el invernadero E3 las muestras se tomaron después de realizada la desinfección y una vez que el suelo se había preparado para la plantación.

En el laboratorio las muestras se dejaron secar en cubetas de plástico sobre papel de filtro. Luego se desmenuzaron y se tamizaron con un tamiz de $2 \mathrm{~mm}$.

\subsubsection{Planteamiento de los ensayos}

Las muestras, una vez tamizadas se dividieron en tres fracciones que recibieron diferentes tratamientos: una fracción se desinfectó con bromuro de metilo (Brom-O-Gas, 98:2, a $60 \mathrm{~g} \mathrm{~m}^{-2}$ bajo plástico de PE de 200 galgas, que era la forma estándar de aplicación para desinfectar los suelos de pimiento en el Campo de Cartagena).

Para ello, se puso la tierra en cubetas de plástico sobre una lámina de plástico de 800 galgas en una parcela de un invernadero que se iba a desinfectar con el gas, se pusieron arquillos sobre las cubetas y sobre ellos una lámina de plástico de $\mathrm{PE}$ de 200 galgas para evitar contaminaciones o el goteo de la condensación; cubriendo la parcela se puso la lámina de plástico de sellado, enterrado en los bordes a una profundidad de 15-20 cm; la aplicación del gas se hizo con un dosificador volumétrico de precisión (Nolia McLean Co, Belmony LA 50) de 3 libras (1lb = 435,75 g) de capacidad y 0,1 lb de precisión; el plástico de sellado se levantó a los 7 días.

Otra fracción se desinfectó en autoclave a $120{ }^{\circ} \mathrm{C}$ y $1 \mathrm{~kg} \mathrm{~cm}^{-2}$ de presión durante 1 hora, en dos sesiones de 30 minutos separadas 24 horas, en bolsas de plástico con $2 \mathrm{~kg}$ de tierra.

La otra fracción no se desinfectó, actuando como referencia o testigo. Tampoco se desinfectaron las muestras del invernadero E3, ya que se tomaron antes de realizar la plantación y se pretendía conocer el efecto de la desinfección sobre la fatiga y la posible especificidad de ésta. Cada fracción de suelo estaba compuesta por 
330 ml multiplicado por el número de repeticiones, variando éstas según la disponibilid ad de tierra.

Para cada tratamiento de cada invernadero se determinó la capacidad de campo del suelo, una vez tamizado, con el objeto de calcular la dosis de riego a utilizar en los bioensayos.

\subsubsection{Bioensayos de especificidad}

Se realizaron en una cámara climatizada donde se dieron las siguientes condiciones: $23 \pm 1{ }^{\circ} \mathrm{C}$; HR del $45-60 \%$ durante el periodo iluminado de la jornada $\mathrm{y}$ del $85-100 \%$ durante el periodo oscuro; fotoperiodo de 14:10 horas L:O y una luminosidad aproximada de 6.000 lux.

Se utilizaron tres especies indicadoras pertenecientes a otras tantas familias botánicas (Tabla 3 ).

El apio se seleccionó en base a las referencias de Bouhot et al. (1979a y b), el pimiento por ser el cultivo estudiado y la lechuga por tratarse de una especie herbácea de otra familia y por ser fácilmente manejable en los experimentos.

La unidad elemental o repetición estuvo constituida por un vaso de plástico blanco de $330 \mathrm{ml}$ (Foto 1) en el que se pusieron $305 \mathrm{~g}$ del suelo a ensayar.

En cada vaso se pusieron 5 semillas pregerminadas de los correspondientes indicadores cubriéndolas con una capa de vermiculita de 0,3-0,4 $\mathrm{mm}$ de espesor, después de la siembra, para evitar la formación de costra. Se desinfectó la vermiculita en autoclave a $120^{\circ} \mathrm{C} \mathrm{y} 1 \mathrm{~kg} \mathrm{~m}^{-2}$ de presión durante una hora, tal como se hizo con los suelos.

Por cada muestra, tratamiento y planta indicadora se pusieron de 5 a 20 repeticiones (vasos). Los vasos se ubicaron en cubetas de plástico blanco en una disposición de bloques al azar, para evitar posibles efectos de localización en la cámara.

Los vasos se regaron tres veces por semana. El riego se efectuó por diferencia de peso, añadiendo agua hasta el nivel de capacidad de campo de cada suelo, utilizando una balanza (Sartorius TE 31025 de $3100 \mathrm{~g}$ ) con sensibilidad de 0,01 g.

Desde que las plantas tuvieron dos hojas desarrolladas se abonaron una vez por semana con una solución nutritiva completa, añadiendo el abono diluido con el agua de riego. Las plantas se mantuvieron en la cámara 2 meses. 
Tabla 1. Localización, antecedentes y características de los invernaderos.

\begin{tabular}{|c|c|c|c|c|c|c|c|c|c|}
\hline Invernadero & Propietario & Paraje & $\begin{array}{c}\text { Término } \\
\text { municipal }\end{array}$ & $\begin{array}{l}\text { Antigüedad } \\
\text { del cultivo }\end{array}$ & Phytophthora sp. & M. incognita & Variedad & Plantación & $\begin{array}{c}\text { Final } \\
\text { cultivo }\end{array}$ \\
\hline B 1 & Antonio Pére z & Los Rica & $\begin{array}{l}\text { San Javier } \\
\text { (El Mirador) }\end{array}$ & 15 años & Sí & Sí & Orlando & 2 enero & 11 agosto \\
\hline $\mathrm{D}$ & $\begin{array}{c}\text { Mariano } \\
\text { Madrid }\end{array}$ & Los Triviños & Torre Pacheco & 13 años & No & No & Paraíso & 27 noviembre & 2 agosto \\
\hline $\mathrm{G}$ & $\begin{array}{l}\text { Guillermo } \\
\text { Samper }\end{array}$ & Las Atalayas & $\begin{array}{c}\text { San Javier } \\
\text { (El Mirador) }\end{array}$ & 6 años & Sí & Sí & Herminio & 9 diciembre & 16 agosto \\
\hline B 2 & Antonio Pére z & Los Rica & $\begin{array}{l}\text { San Javier } \\
\text { (El Mirador) } \\
\end{array}$ & 16 años & Sí & Sí & Orlando & 13 enero & 7 septiembre \\
\hline E 1 & IMIDA & Los Camachos & Torre Pacheco & 4 años & No & Sí & Ribera & 14 diciembre & 16 agosto \\
\hline E 2 & IMIDA & Los Camachos & Torre Pacheco & 5 años & No & Sí & Ribera & 9 enero & 9 agosto \\
\hline E 3 & IMIDA & Los Camachos & Torre Pacheco & 6 años & No & Sí & Ribera & 17 diciembre & 27 julio \\
\hline
\end{tabular}

B 1 y B 2: corresponden a los códigos del invernadero B, utilizado en dos campañas de cultivo. E1, E 2, E3: corresponden a los códigos del invernadero E, utilizado en tres campañas de cultivo. 
Tabla 2. His torial de desinfección de los suelos y tratamientos realizados en el último cultivo.

\begin{tabular}{|c|c|c|c|}
\hline Invernadero & $\begin{array}{l}\text { Código } \\
\text { del suelo }\end{array}$ & Antecedentes de desinfección & Tratamientos últimos cultivos \\
\hline \multirow[t]{3}{*}{ B 1} & B1T1 & 14 años BM 98:2, $60 \mathrm{~g} \mathrm{~m}^{-2}$ & BM 98:2, $60 \mathrm{~kg} \mathrm{~m}^{-2}$ \\
\hline & B1T4 & 14 años BM 98:2, $60 \mathrm{~g} \mathrm{~m}^{-2}$ & $\mathrm{~B}+\mathrm{S} 7 \mathrm{~kg} \mathrm{~m}^{-2} \mathrm{EFO}+3 \mathrm{~kg} \mathrm{~m}^{-2} \mathrm{G}, \mathrm{PE}$ \\
\hline & B1T5 & 13 años BM 98:2, $60 \mathrm{~g} \mathrm{~m}^{-2}$ & No desinfectado \\
\hline \multirow[t]{2}{*}{$\mathrm{D}$} & DT1 & 12 años BM 98:2, $60 \mathrm{~g} \mathrm{~m}^{-2}$ & BM 98:2,60 $\mathrm{g} \mathrm{m}^{-2}$ \\
\hline & DT5 & 11 años BM 98:2, $60 \mathrm{~g} \mathrm{~m}^{-2}$ & No desinfectado \\
\hline $\mathrm{G}$ & GT3 & 4 años sin desinfección, 1 año B+S & No desinfectado \\
\hline \multirow[t]{3}{*}{ B 2} & B2T1 & 15 años BM 98:2, $60 \mathrm{~g} \mathrm{~m}^{-2}$ & BM 98:2, $60 \mathrm{~g} \mathrm{~m}^{-2}$ \\
\hline & B2T2 & 15 años BM 98:2, $60 \mathrm{~g} \mathrm{~m}^{-2}$ & Telone C-35, $50 \mathrm{~g} \mathrm{~m}^{-2}, \mathrm{PE}$ \\
\hline & B2T5 & 15 años BM 98:2, $60 \mathrm{~g} \mathrm{~m}^{-2}$ & No desinfectado \\
\hline \multirow[t]{4}{*}{ E 1} & E1T1 & 2 años BM 98:2, $30 \mathrm{~g} \mathrm{~m}^{-2}$ & BM 98:2, $30 \mathrm{~g} \mathrm{~m}^{-2}$, VIF Testigo \\
\hline & E1T3 & 2 años no desinfectado & $\mathrm{B}+\mathrm{S} 7 \mathrm{~kg} \mathrm{~m}^{-2} \mathrm{EFO}+3 \mathrm{~kg} \mathrm{~m}^{-2} \mathrm{G}, \mathrm{PE}$ \\
\hline & E1T4 & 1 año no desinfectado, 1 año B+S & $\mathrm{B}+\mathrm{S} 5 \mathrm{~kg} \mathrm{~m}^{-2} \mathrm{EFO}+2,5 \mathrm{~kg} \mathrm{~m}^{-2} \mathrm{G}, \mathrm{PE}$ \\
\hline & E1T5 & 1 año no desinfectado, 2 años $B+S$ & $\mathrm{~B}+\mathrm{S} 4 \mathrm{~kg} \mathrm{~m}^{-2} \mathrm{EFO}+2 \mathrm{~kg} \mathrm{~m}^{-2} \mathrm{G}, \mathrm{PE}$ \\
\hline \multirow[t]{4}{*}{ E 2} & E2T1 & 3 años no desinfectado & No desinfectado \\
\hline & E2T2 & 3 años de BM 98:2, $30 \mathrm{~g} \mathrm{~m}^{-2}$ VIF & BM 98:2,30 $\mathrm{g} \mathrm{m}^{-2}$ VIF \\
\hline & E2T3 & 2 años no desinfectado+1 año B+S & $\mathrm{B}+\mathrm{S}, 5 \mathrm{~kg} \mathrm{~m}^{-2} \mathrm{EFO}+2,5 \mathrm{~kg} \mathrm{~m}^{-2} \mathrm{G}, \mathrm{PE}$ \\
\hline & E2T5 & 1 año no desinfectado +3 años $B+S$ & $\mathrm{~B}+\mathrm{S}, 3 \mathrm{~kg} \mathrm{~m}^{-2} \mathrm{EFO}+1,5 \mathrm{~kg} \mathrm{~m}^{-2} \mathrm{G}, \mathrm{PE}$ \\
\hline \multirow[t]{4}{*}{ E 3} & E3T1 & 4 años no desinfectado & $\mathrm{B}+\mathrm{S}, 7 \mathrm{~kg} \mathrm{~m}^{-2} \mathrm{EFO}+2,5 \mathrm{~kg} \mathrm{~m}^{-2} \mathrm{G}, \mathrm{PE}$ \\
\hline & E3T2 & 4 años de BM 98:2,30 $\mathrm{g} \mathrm{m}^{-2}, \mathrm{VIF}$ & BM 98:2, 30 $\mathrm{g} \mathrm{m}^{-2}$ VIF \\
\hline & E3T3 & 2 años no desinfectado+2 años B+S & $\mathrm{B}+\mathrm{S}, 4 \mathrm{~kg} \mathrm{~m}^{-2} \mathrm{EFO}+2 \mathrm{~kg} \mathrm{~m}^{-2} \mathrm{G}, \mathrm{PE}$ \\
\hline & E3T5 & 1año no desinfectado+4 año B+S & $\mathrm{B}+\mathrm{S}, 2 \mathrm{~kg} \mathrm{~m}^{-2} \mathrm{EFO}+0,5 \mathrm{~kg} \mathrm{~m}^{-2} \mathrm{G}, \mathrm{PE}$ \\
\hline
\end{tabular}

EFO: Estiércol fresco de oveja; G: Gallinaza; PE: Polietileno; B+S: Biosolarizado

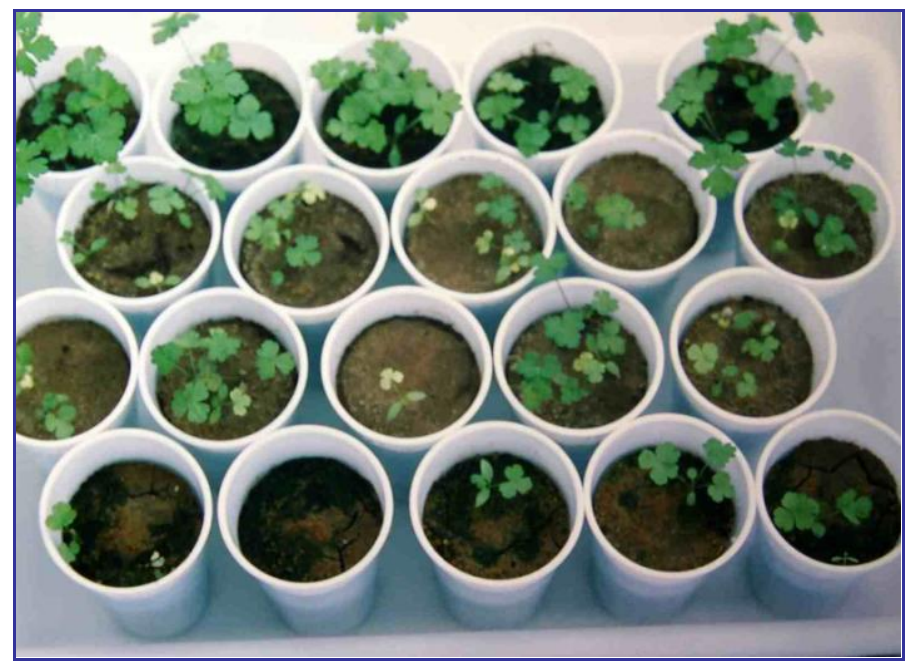

Foto 1. Distribución de vasos en ensayo de apio. 
Para evaluar los efectos sobre las plantas indicadoras en cada uno de los bioensayos (Tabla 3) se midieron los siguientes parámetros:

a) Altura de las plantas: en todos los casos se hizo al finalizar el ensayo, midiendo una a una las plantas, desde el cuello hasta el ápice, al tiempo que se anotaba el número de las supervivientes.

b) Peso de las plantas al finalizar el ensayo, unos 55-60 días después de la siembra o plantación.

- El peso fresco se obtuvo tras extraer cuidadosamente las plantas, lavar las raíces meticulosamente y secar el agua en un papel de filtro.

- El peso seco se obtuvo tras mantenerlas en una estufa de secado a $75^{\circ} \mathrm{C}$ durante 24 horas.

- Las pesadas se realizaron en una balanza analítica (Sartorius BL 1205 de 120 g) con una precisión de $0,1 \mathrm{mg}$.

c) La longitud de las hojas. Se midió la hoja más larga de cada planta, de cada repetición, desde el peciolo al extremo. En algunos de los bioensayos con pimiento, contabilizando, al mismo tiempo, el número de hojas por planta.

Este dato se dejó de tomar al comprobar que no aportaba elementos diferenciadores entre tratamientos que no quedaran reflejados en la altura o en el peso seco.

\subsubsection{Procesado de los datos}

El análisis principal de los datos para los diferentes parámetros medidos, cons is tió en comparar entre sí los tratamientos de laboratorio para cada uno de los tratamientos del suelo realizados en los invernaderos.

En el caso de las muestras tomadas en el invernadero E3, la comparación se realizó entre tratamientos del suelo, ya que las muestras no fueron sometidas a tratamientos de laboratorio. En todos los casos, los valores corresponden a las medias de las plantas de cada unidad elemental (vaso) y a la media de todas las repeticiones dentro de cada tratamiento (3) en el laboratorio de cada tratamiento en los invernaderos.

Para el procesado de los datos se ha utilizado el programa Excel de entorno de Windows. Para el análisis de la varianza y de comparación de las medias (test LSD al 95\%) se transformaron los datos mediante la función $\log _{10}$ (x) y se utilizó el programa Startgraphic, también en el entorno de Windows. 
Tabla 3. Plantas indicadoras y repeticiones por tratamiento de los bioensayos.

\begin{tabular}{|c|c|c|c|c|c|}
\hline Invernadero & $\begin{array}{l}\text { Tratamiento } \\
\text { invernadero }\end{array}$ & $\begin{array}{l}\text { Tratamiento } \\
\text { laboratorio }\end{array}$ & $\begin{array}{l}\text { Pimiento (Var. } \\
\text { Sonar) }\end{array}$ & $\begin{array}{c}\text { Lechu ga (var. Reina } \\
\text { Verde) }\end{array}$ & $\begin{array}{l}\text { Apio (var. } \\
\text { Monterrey) }\end{array}$ \\
\hline & & & Repeticiones & Repeticiones & Repeticiones \\
\hline \multirow[t]{9}{*}{ B 1} & B1T1 & $\mathrm{A}$ & 10 & & 17 \\
\hline & & $\overline{\mathrm{BM}}$ & -- & & -- \\
\hline & & $\mathrm{T}$ & 9 & & 17 \\
\hline & B1T4 & $\mathrm{A}$ & 9 & & 15 \\
\hline & & $\overline{B M}$ & -- & & -- \\
\hline & & $\mathrm{T}$ & 10 & & 15 \\
\hline & B1T5 & $\mathrm{A}$ & 10 & & 9 \\
\hline & & $\overline{\mathrm{BM}}$ & 10 & & 9 \\
\hline & & $\mathrm{T}$ & 10 & & 9 \\
\hline \multirow[t]{6}{*}{$\mathrm{D}$} & DT1 & $\bar{A}$ & 10 & & 16 \\
\hline & & BM & 10 & & 16 \\
\hline & & $\mathrm{T}$ & 10 & & 16 \\
\hline & DT5 & $\bar{A}$ & 9 & & 6 \\
\hline & & $\mathrm{BM}$ & 9 & & 6 \\
\hline & & $\mathrm{T}$ & 9 & & 6 \\
\hline \multirow[t]{3}{*}{$\mathrm{G}$} & GT3 & $\mathrm{A}$ & 5 & & 10 \\
\hline & & $\mathrm{BM}$ & 5 & & 10 \\
\hline & & $\mathrm{T}$ & 5 & & 10 \\
\hline \multirow[t]{9}{*}{ B 2 } & B2T1 & $\mathrm{A}$ & 16 & 16 & 15 \\
\hline & & $\mathrm{BM}$ & 16 & 16 & 15 \\
\hline & & $\mathrm{T}$ & 16 & 16 & 15 \\
\hline & B2T2 & $\mathrm{A}$ & 18 & 16 & 17 \\
\hline & & $\overline{\mathrm{BM}}$ & 18 & 16 & 17 \\
\hline & & $\mathrm{T}$ & 18 & 16 & 17 \\
\hline & B2T5 & $\mathrm{A}$ & 22 & 16 & 15 \\
\hline & & $\mathrm{BM}$ & 22 & 16 & 15 \\
\hline & & $\mathrm{T}$ & 22 & 16 & 15 \\
\hline \multirow[t]{12}{*}{ E 1 } & E1T1 & $\mathrm{A}$ & 21 & & 15 \\
\hline & & $\overline{\mathrm{BM}}$ & 21 & & 15 \\
\hline & & $\mathrm{T}$ & 21 & & 15 \\
\hline & E1T3 & $\mathrm{A}$ & 24 & & 15 \\
\hline & & $\overline{B M}$ & 24 & & 15 \\
\hline & & $\mathrm{T}$ & 24 & & 15 \\
\hline & E1T4 & $\mathrm{A}$ & -- & & 15 \\
\hline & & $\mathrm{BM}$ & 16 & & 15 \\
\hline & & $\mathrm{T}$ & 16 & & 15 \\
\hline & E1T5 & $\mathrm{A}$ & 16 & & 15 \\
\hline & & BM & -- & & 15 \\
\hline & & $\mathrm{T}$ & 16 & & 15 \\
\hline \multirow[t]{12}{*}{ E 2} & E2T1 & $\mathrm{A}$ & 10 & 8 & 15 \\
\hline & & $\overline{\mathrm{BM}}$ & 10 & 8 & 15 \\
\hline & & $\mathrm{T}$ & 10 & 8 & 15 \\
\hline & E2T2 & $\mathrm{A}$ & 15 & 5 & 19 \\
\hline & & $\overline{\mathrm{BM}}$ & 15 & 5 & 19 \\
\hline & & $\mathrm{T}$ & 15 & 5 & 19 \\
\hline & E2T3 & $\mathrm{A}$ & 15 & 3 & 15 \\
\hline & & $\overline{\mathrm{BM}}$ & 15 & 3 & 15 \\
\hline & & $\mathrm{T}$ & 15 & 3 & 15 \\
\hline & E2T5 & $\mathrm{A}$ & 15 & 6 & 15 \\
\hline & & $\overline{B M}$ & 15 & 6 & 15 \\
\hline & & $\mathrm{T}$ & 15 & 6 & 15 \\
\hline \multirow[t]{4}{*}{ E 3} & E3T1 & $\mathrm{T}$ & 10 & 10 & 10 \\
\hline & E3T2 & $\mathrm{T}$ & 10 & 10 & 10 \\
\hline & E3T3 & $\mathrm{T}$ & 10 & 10 & 10 \\
\hline & E3T5 & $T$ & 10 & 10 & 10 \\
\hline
\end{tabular}

A: Autoclave a $120^{\circ} \mathrm{C}$; BM: Bromuro metilo a $60 \mathrm{~g} \mathrm{~m}^{-2}$; $\mathrm{T}$ : Testigo 


\subsection{RESULTADOS Y DISCUSIÓN}

\subsubsection{Ajuste de la técnica utilizada}

\subsubsection{Elección del testigo de referencia}

Una de las dificultades mayores que se presentan en un trabajo experimental sobre fatiga del suelo es, sin duda, el establecimiento del testigo referente que proporcione el desarrollo óptimo de la planta. Este aspecto es uno de los más difíciles en agronomía.

Quizás no se conozcan las condiciones óptimas que permitan el mayor y mejor desarrollo de cada uno de los cultivos. Prueba de ello son las continuas y abundantes técnicas que tienden a incrementar la producción vegetal. Por este motivo se ensayó buscar unas respuestas repetibles en todos los ensayos. Para ello se trató el suelo con vapor de agua en autoclave, como se especificó anteriormente.

Estos resultados se obtuvieron utilizando suelos de dos invernaderos bien diferenciados desde el punto de vista de los antecedentes de desinfección del suelo y con diferente grado de expresión de los patógenos Phytophthora sp. y Meloidogyne incognita. Fueron los de los invernaderos B1T1, B1T4 y GT3 (Tabla 2). Mientras que en uno de ellos se había desinfectado anualmente durante los catorce años anteriores con bromuro de metilo, (muestras B1T1 y B1 T4), el otro invernadero (G) llevaba 4 años sin desinfectar químicamente y se cultivaba según la normativa de agricultura ecológica.

La aplicación del tratamiento con vapor de agua en autoclave se realizó durante 1 hora a $120^{\circ} \mathrm{C}$ (se fraccionó el tiempo de tratamiento: 30 minutos en cada desinfección, separadas 24 horas). Los resultados se muestran en la Figura 1. El parámetro medido fue el peso seco de las plantas después de 60 días de crecimiento.

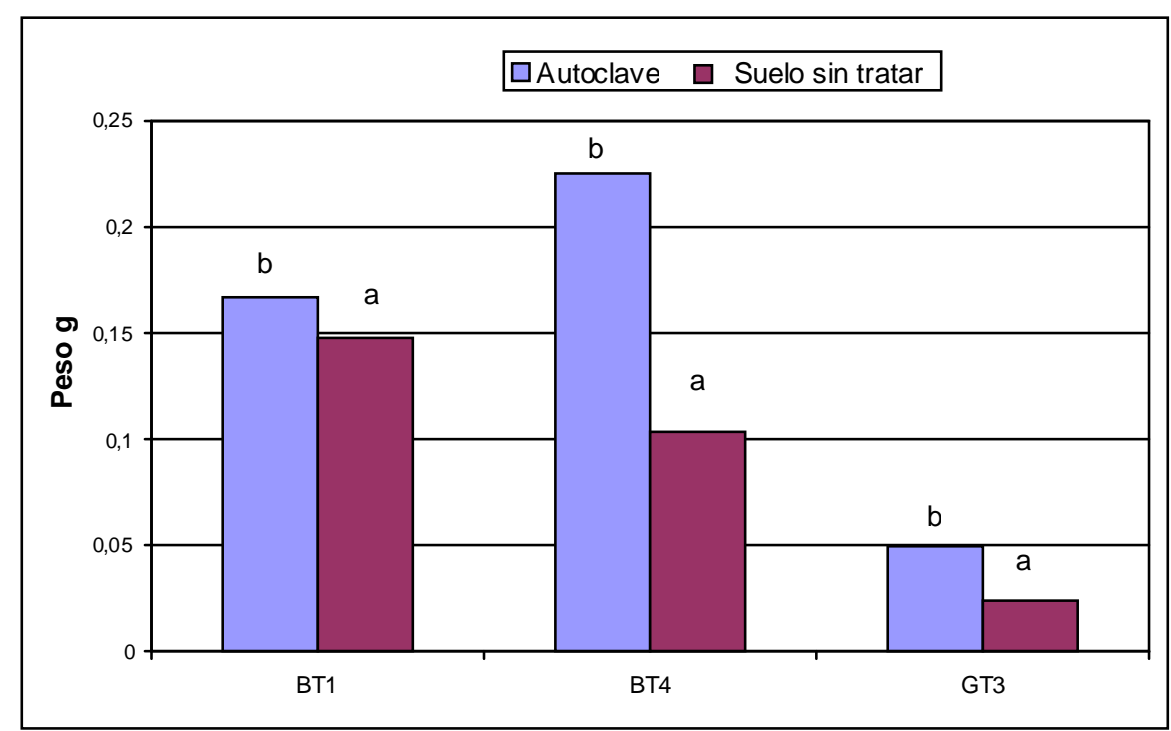

Las magnitudes de las barras con la misma letra en cada tratamiento no son significativamente diferentes $(\mathrm{P}>0.05)$ Los códigos BT1 Y BT4 corresponden a B1T1 y B1T4 respectivamente de la Tabla 3.

Figura 1. Peso seco (g) de las plantas de pimiento crecidas sobre suelos de invernaderos no tratados y tratados con vapor de agua. 
La Figura 1 proporciona una información clara, cualquiera que sea la muestra de suelo: la respuesta a la desinfección con vapor de agua es positiva, evaluando el peso seco de las plantas.

Por lo tanto, la desinfección en autoclave podría ser la referencia para comparar y evaluar el efecto fatiga.

La Figura 1 permite un comentario adicional importante. Si se observa la muestra GT3, que procede de un invernadero donde no se había desinfectado en los 4 años anteriores y, en el cual hubieron un $78 \%$ de plantas muertas por Phytophthora sp. y en las supervivientes se evaluó la nodulación de las raíces por M. incognita con un índice 6, según la escala de Bridge y Page (1981) (Lacasa et al., 2002; Martínez et al., 2002; Guerrero et al., 2002 y 2004). No hubo presencia de patógenos durante el desarrollo del ensayo y las raíces carecían de necrosis y nódulos.

Siendo esto así, lo que se manifiesta es un suelo mucho menos productivo con respecto a las otras dos muestras. Expresa, una fatiga del suelo. El efecto podría ser debido a que no se utilizaban en el invernadero abonos de síntesis y llevaba 4 años abonando con materia orgánica, dado que se estaba haciendo la trasformación a producción ecológica.

Una última observación es, que pese a la respuesta positiva obtenida con la desinfección en autoclave, no se apreciaron necrosis y/o nodulaciones en las raíces de las plantas, procediesen éstas de la muestra tratada o sin tratar.

\subsubsection{Selección de los parámetros para evaluar el desarrollo de las plantas}

Se evaluaron tres parámetros: la altura, el peso seco de las plantas y la longitud máxima de las hojas. Los resultados obtenidos para las muestras BT1, BT4 y GT3 se presentan en las Figuras 2, 3 y 4 (altura y longitud de hojas), el peso seco se mostró en la Figura 1.

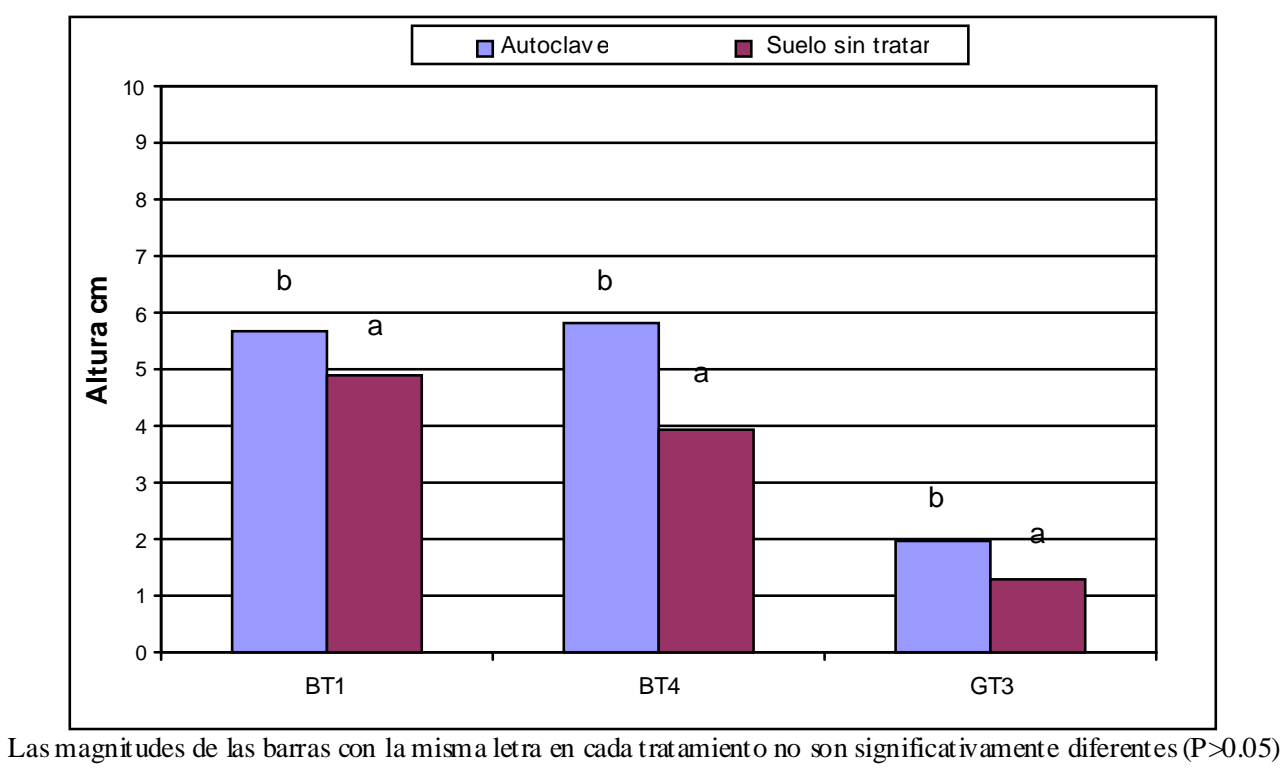

Figura 2. Altura (cm) de las plantas de pimiento crecidas sobre muestras de suelo no desinfectadas y desinfectadas en autoclave. 


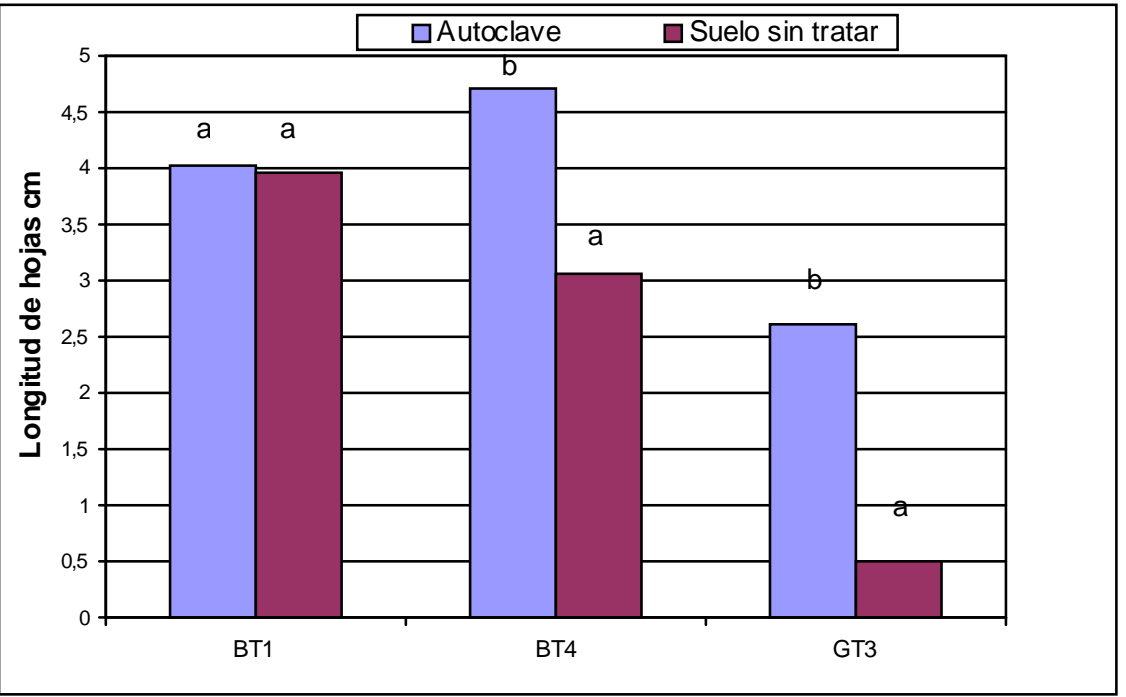

Las magnitudes de las barras con la misma letra en cada trat amient o no son significativamente diferentes $(\mathrm{P}>0.05)$

Figura 3. Lon gitud $(\mathrm{cm})$ de las hojas de plantas de pimiento crecidas sobre suelos no tratados y desinfectados en autoclave.

Se puede comprobar que los tres parámetros resultaron ser aceptables para evaluar los efectos de fatiga, dada la respuesta a los tratamientos. Sin embargo, la longitud de las hojas para la muestra BT1 y GT3 (Figura 4) aportó menor precisión, por esta razón se excluyó dicho parámetro en los ensayos posteriores.

Los resultados obtenidos permitieron seleccionar como parámetros para evaluar la presencia de fatiga en las muestras de suelos, el peso seco y altura de las plantas al finalizar los experimentos. De nuevo, en estos ensayos se reiteraba la observación experimental antes indicada que en ninguna de las muestras se observaron necrosis o nódulos radiculares al finalizar los ensayos. 


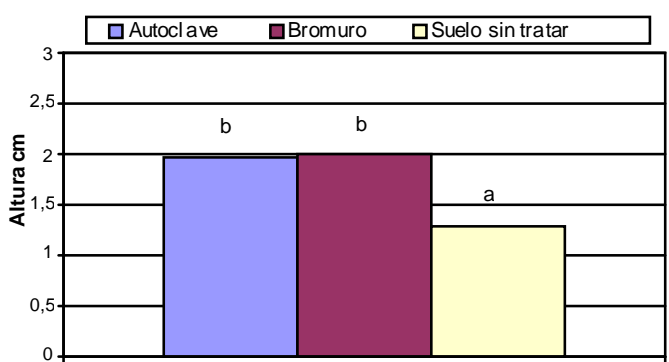

GT3

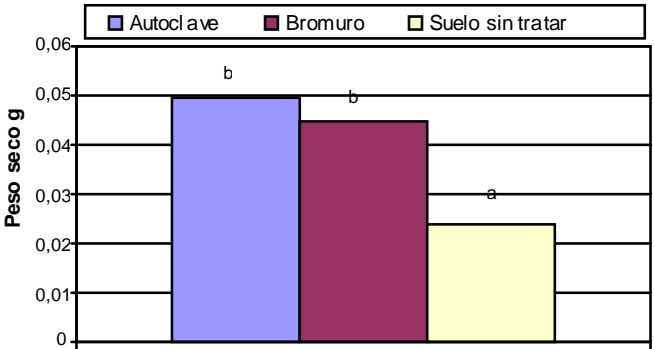

GT3

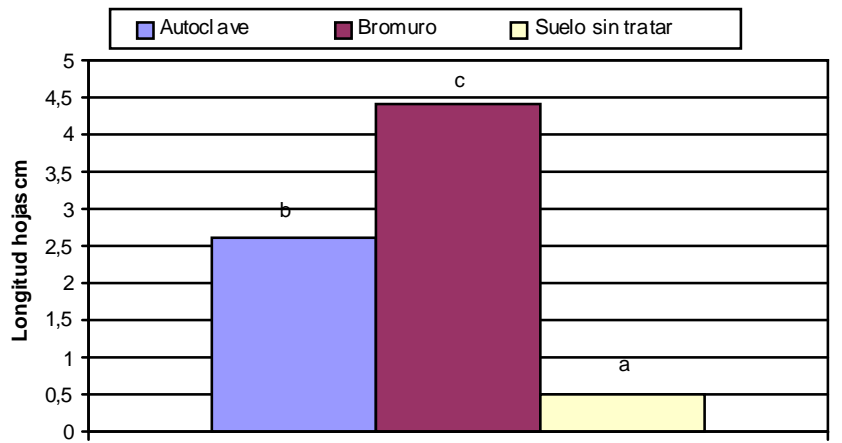

GT3

Las magnitudes de las barras con la misma letra en cada trat amiento no son significativamente diferentes $(\mathrm{P}>0.05)$

Figura 4. Altura, peso seco (g) y lon gitud máxima de las hojas después de tratar la muestra de suelo (GT3) en autoclave, con bromuro y sin tratar.

\subsubsection{Evaluación de la fatiga en muestras de suelos de invernaderos comerciales desinfectados por medios químicos o no químicos}

En este apartado se recoge el comportamiento de muestras de suelo tomadas de invernaderos con diferentes casuísticas: diferente antigüedad de monocultivo, diferentes tratamientos de desinfección y diferente presencia de patógenos telúricos del pimiento. Se estudió en muestras de los invernaderos codificados como B 1, D y G (Tablas 1 y 2).

\subsubsection{Evaluación de la fatiga en relación con los antecedentes culturales}

El monocultivo ininterrumpido de pimiento alcanzaba desde los 15 (invernadero B 1) hasta los 6 años (invernadero G). En lo referente a los tratamientos al suelo, desde la desinfección con bromuro de metilo desde 15 años atrás (invernadero B), prácticamente desde la implantación del cultivo, hasta la no desinfección química en los últimos 4 años (invernadero G). La presencia de los dos patógenos edáficos más importantes (Phytophthora sp. y M. incognita) con diferente intensidad de expresión (invernaderos G y B 1) hasta su ausencia en los muestreos (invernadero D).

Las Figuras 5 y 6 resumen la respuesta de las muestras de los invernaderos B1, D y $\mathrm{G}$, sobre suelos tratados en autoclave que actúa como referencia (testigo), con bromuro de metilo, y suelos sin tratar en laboratorio. 


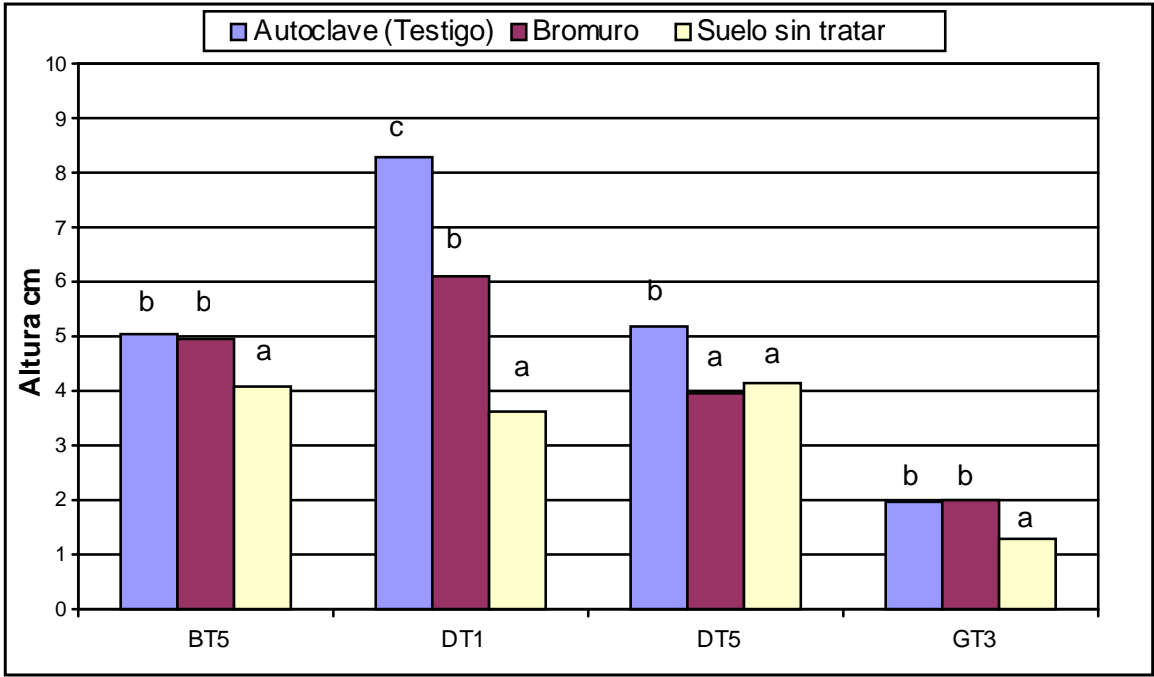

Las magnitudes de las barras con la misma letra en cada trat amiento no son significativamente diferentes $(\mathrm{P}>0.05)$

Figura 5. Altura de las plantas de pimiento sobre fracciones de suelos desinfectados en el laboratorio en autoclave, con bromuro de metilo y sin tratar. Invernaderos B 1, D y G. DT1: desinfectado con bromuro de metilo en el invernadero; DT5, BT5 y GT3 suelos no desinfectados en los invernaderos.

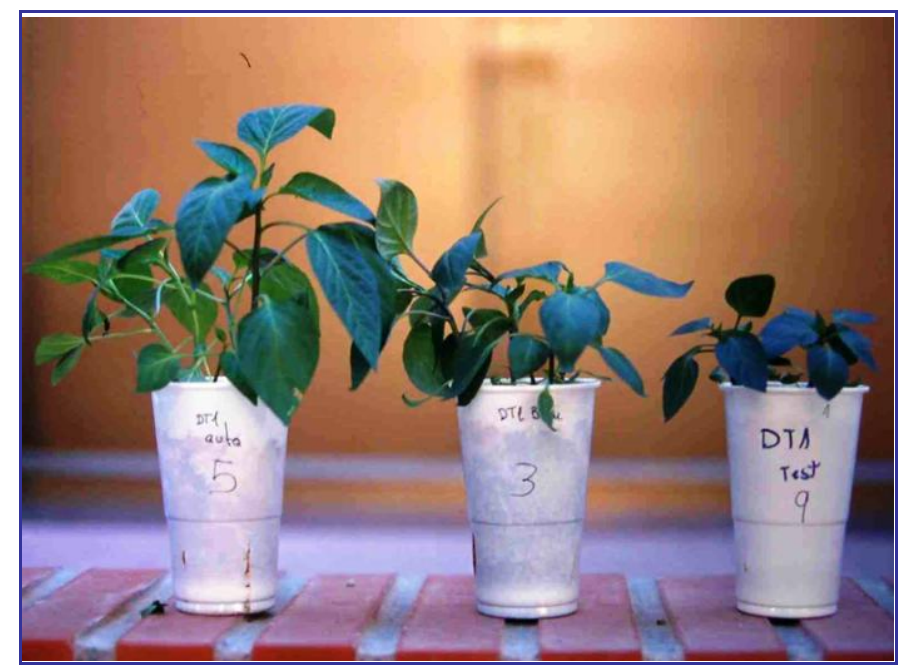

Foto 2. Plantas de pimiento sobre fracciones de suelo desinfectado en, de izquierda a derecha, autoclave, bromuro de metilo y no desinfectado, del invernadero D, tratamiento de BM. (DT1).

Para ambos parámetros aparece generalizada una respuesta positiva a los dos tratamientos de desinfección y desde ese punto de vista podría pensarse en la existencia del fenómeno de fatiga en las muestras. La Foto 2, aporta el efecto visual para apoyar los resultados expresados en los histogramas. Pero algunas particularidades podrían ayudar a matizar la válida generalización.

Las muestras del tratamiento GT3 del invernadero G presentaron un precario desarrollo de las plantas en comparación con las de los invernaderos B 1 y D. La razón hay que buscarla, en las características del suelo y en el hecho de no utilizar abono de síntesis (sería el factor limitante) por practicar un cultivo ecológico y enmendar solamente con materia orgánica. 


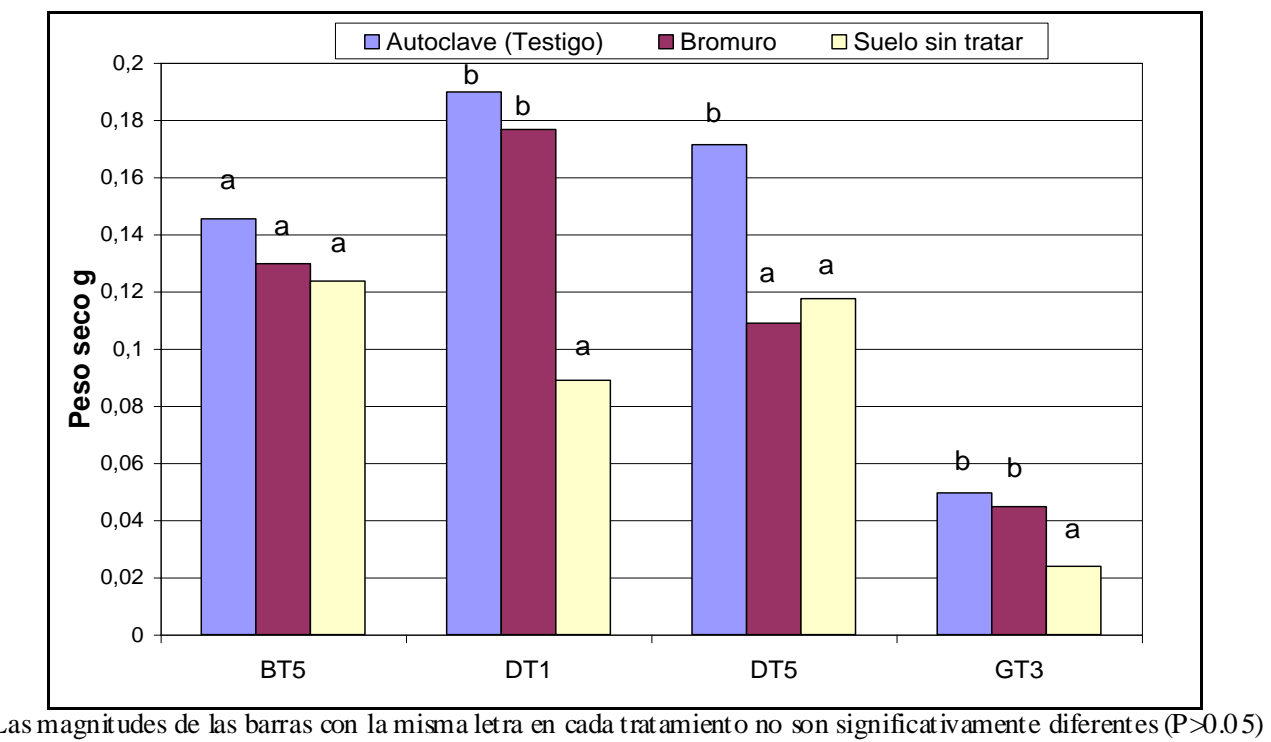

Figura 6. Peso seco de las plantas de pimiento sobre fracciones de suelos desinfectados en el laboratorio en autoclave, con bromuro de metilo y sin tratar. Invernaderos B 1, D, G. DT1: desinfectado con bromuro de metilo en el invernadero; DT5, BT5 y GT3 suelos no desinfectados en los invernaderos.

En el invernadero D se tomaron dos muestras bien diferenciadas. La muestra DT5 recogida de una parte en la que no se había desinfectado el suelo en los dos años anteriores, aunque los tratamientos con bromuro de metilo se habían practicado desde que se implantó el cultivo (Tabla 1). Y la DT1 donde sí se había desinfectado todos los años con bromuro de metilo. En dicho invernadero no se encontraron Phytophthora sp. ni $M$. incognita y en la parte no tratada las mermas de producción y la reducción del desarrollo de las plantas fueron superiores al $50 \%$ en el segundo año de no desinfectar el suelo (Lacasa et al., 2002; Guirao et al., 2004).

Las Figuras 5 y 6 muestran diferencias que podrían relacionarse en ausencia de patógenos, con el efecto reiterado de la desinfección con bromuro de metilo en el campo. O lo que es complementario, la no reiteración de la desinfección proporciona una disminución en el peso seco y alturas, que podría, sugerentemente, interpretarse co mo una fatiga acumulativa en el sentido de cuanto menos se desinfecta el suelo mayores son las mermas de producción en ausencia de patógenos conocidos e identificados. Una respuesta comparable se obtiene de la muestra BT5, recogida del suelo de un invernadero que no se había desinfectado con bromuro de metilo en los dos últimos años y por ello comparable con DT5, aunque la diferencia la establecería la presencia de Phytophthora sp. y $M$. incognita en el invernadero de procedencia, que no se manifestaron durante el desarrollo del ensayo.

Los resultados muestran lo que ocurre en los invernaderos, confiriéndole al procedimiento experimental un valor para interpretar lo que sucede en el campo.

En el siguiente experimento se evaluaron muestras procedentes del invernadero B 2 considerado como una repetición del año anterior (B 1). La muestra BT5 se repitió y constituyó el nexo de unión con la campaña anterior. Los resultados se resumen en las Figuras 7 y 8 para el peso seco y altura de las plantas. La fracción de suelo codificada como testigo en las gráficas hace referencia a suelo sin tratar en laboratorio.

En la Foto 3 se aporta el apoyo visual en lo concerniente al tratamiento con bromuro de metilo y en la Foto 4 a la desinfección en autoclave. 


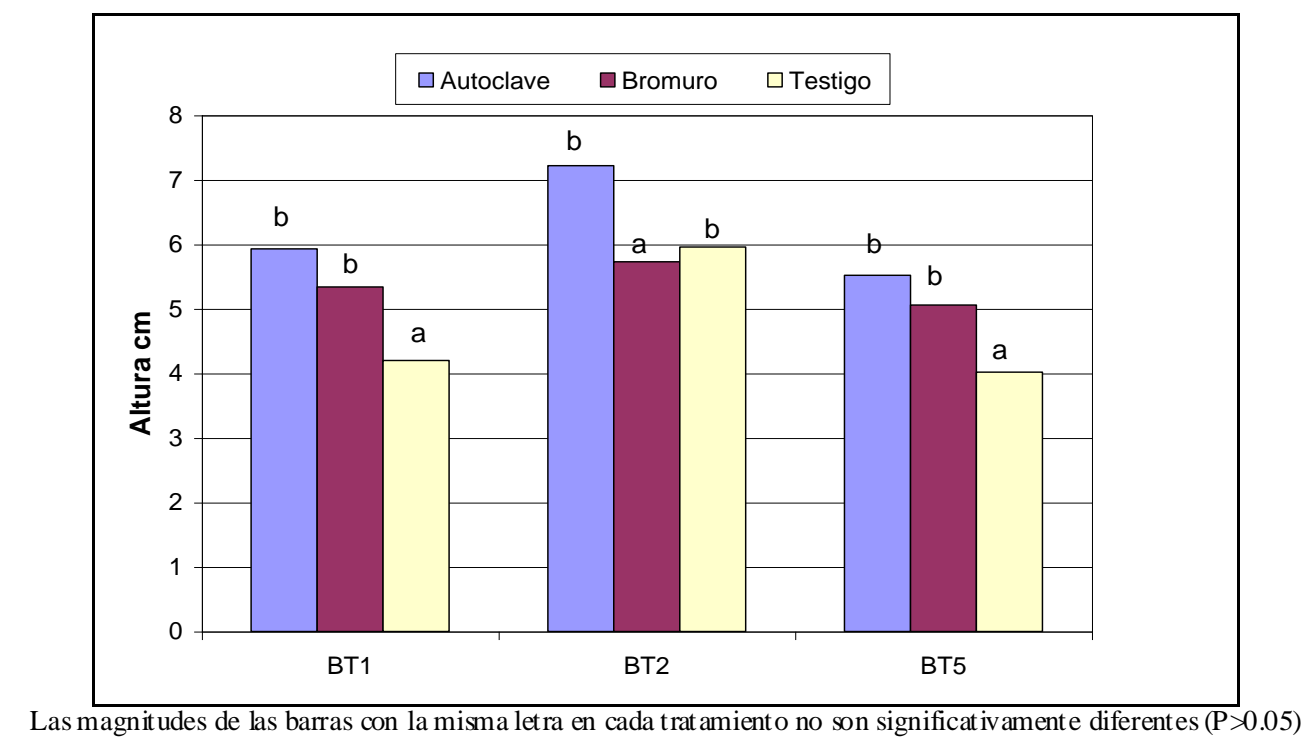

Figura 7. Altura de las plantas de pimiento sobre fracciones de suelos desinfectados en el laboratorio en autoclave, con bromuro de metilo y no desinfectadas (testigo). Invernadero B 2. BT1: suelo desinfectado con bromuro de metilo en el invernadero; BT2: desinfectado con Telone C-35 en el invernadero; BT5: no desinfectado.

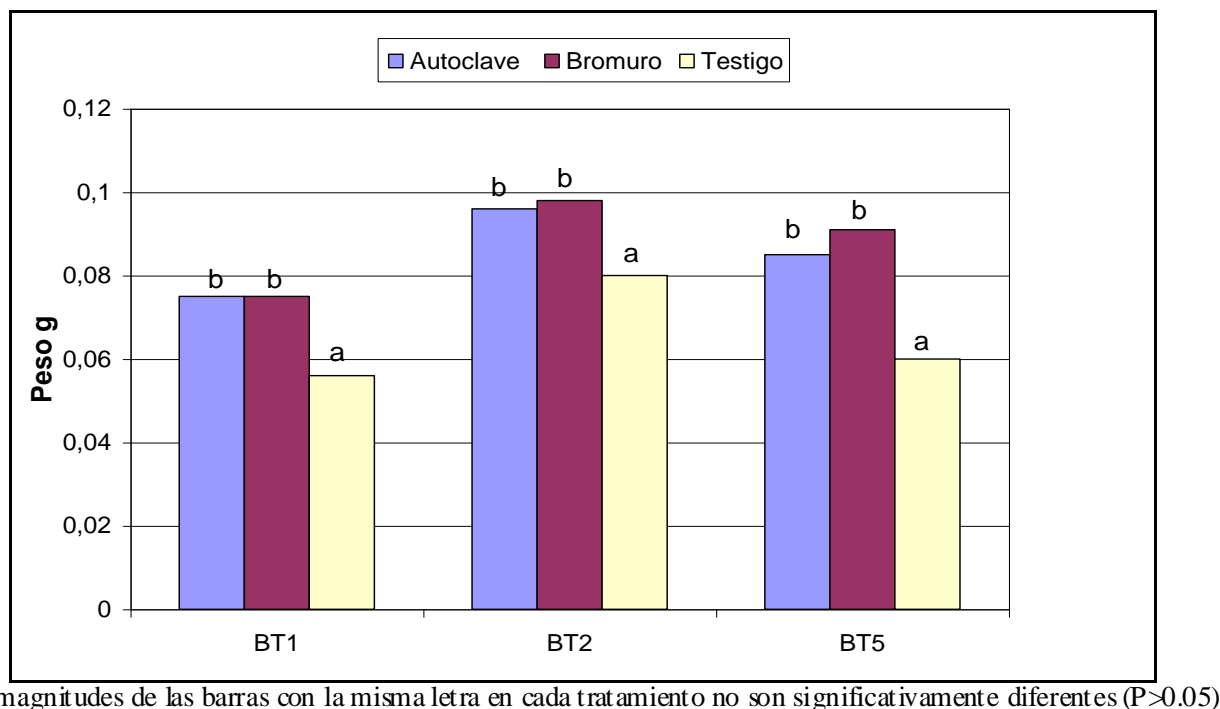

Figura 8. Peso seco de las plantas de pimiento sobre fracciones de suelos desinfectados en el laboratorio en autoclave, con bromuro de metilo y no desinfectadas (testigo). Invernadero B 2. BT1: suelo desinfectado con bromuro de metilo en el invernadero; BT2: desinfectado con Telone C-35 en el invernadero; BT5: no desinfectado.

Cualquiera que haya sido el tiempo trascurrido desde el último tratamiento de desinfección practicado en el suelo, el efecto de la desinfección se hace notar significativamente en el peso seco y altura de las plantas, confirmando los resultados del experimento anterior. Sin embargo, en las muestras de suelos tratados, con los códigos BT1 y BT2, hay una diferencia en los antecedentes.

Mientras en la campaña anterior en BT1 se aplicó bromuro de metilo en el campo, en la BT2 se desinfectó con Telone C-35. Este hecho parece incidir en la respuesta a favor 
de la muestra BT2. En ninguno de los experimentos se observaron necrosis o nódulos radiculares al finalizar.

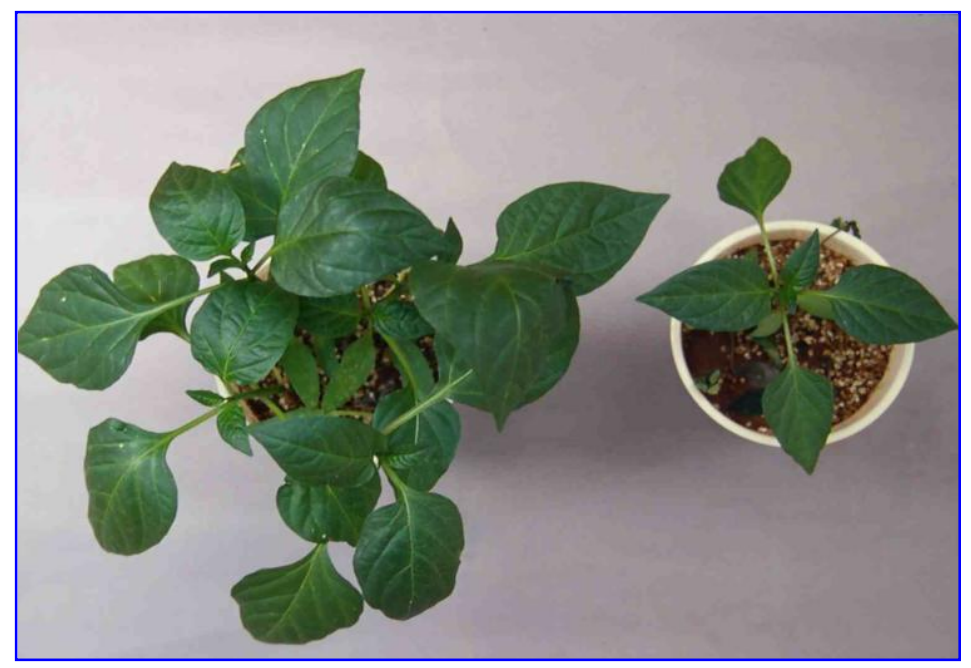

Foto 3. Plantas de pimiento sobre fracciones de suelo desinfectado en el laboratorio con bro muro de metilo (BM) (izquierda) y no desinfectado (T) (derecha), procedentes de un suelo no desinfectado (BT5) del invernadero B 2.

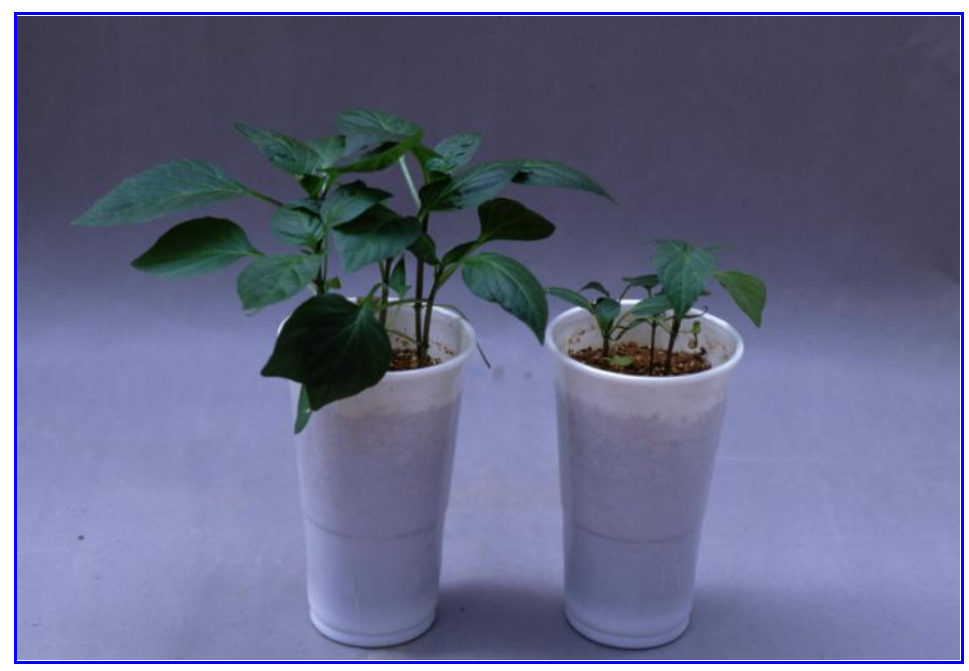

Foto 4. Plantas de pimiento sobre fracciones de suelo desinfectado en el laboratorio con autoclave (A) (izquierda) y no desinfectado (T) (derecha), procedentes de un suelo no desinfectado (BT5) del invernadero B 2.

\subsubsection{Evaluación de la especificidad de la fatiga del suelo}

Se utilizaron dos especies vegetales que se cultivan habitualmente en la Región de Murcia. Lechuga (Lactuca sativa) de la familia de las compuestas y apio (Apium graveolens) de las umbelíferas. Ambas han sido descritas en la literatura como ejemplos susceptibles de expresar fatiga durante su cultivo (Bonnel y Bouhot, 1983; Messiaen et al., 1991). Y en lechuga ha sido durante años reiteradamente observada en la Región de 
Murcia, sin haber podido aislar en ningún caso a la bacteria Rhizomonas suberifaciens asociada a los síntomas "Corky root” (Lacasa, 2009; comunicación personal).

Los resultados obtenidos para los suelos de los invernaderos B, D y G se presentan en las Figuras 9 y 10 para el apio. La fracción de suelo codificada como testigo en las gráficas hace referencia a suelo sin tratar en laboratorio.

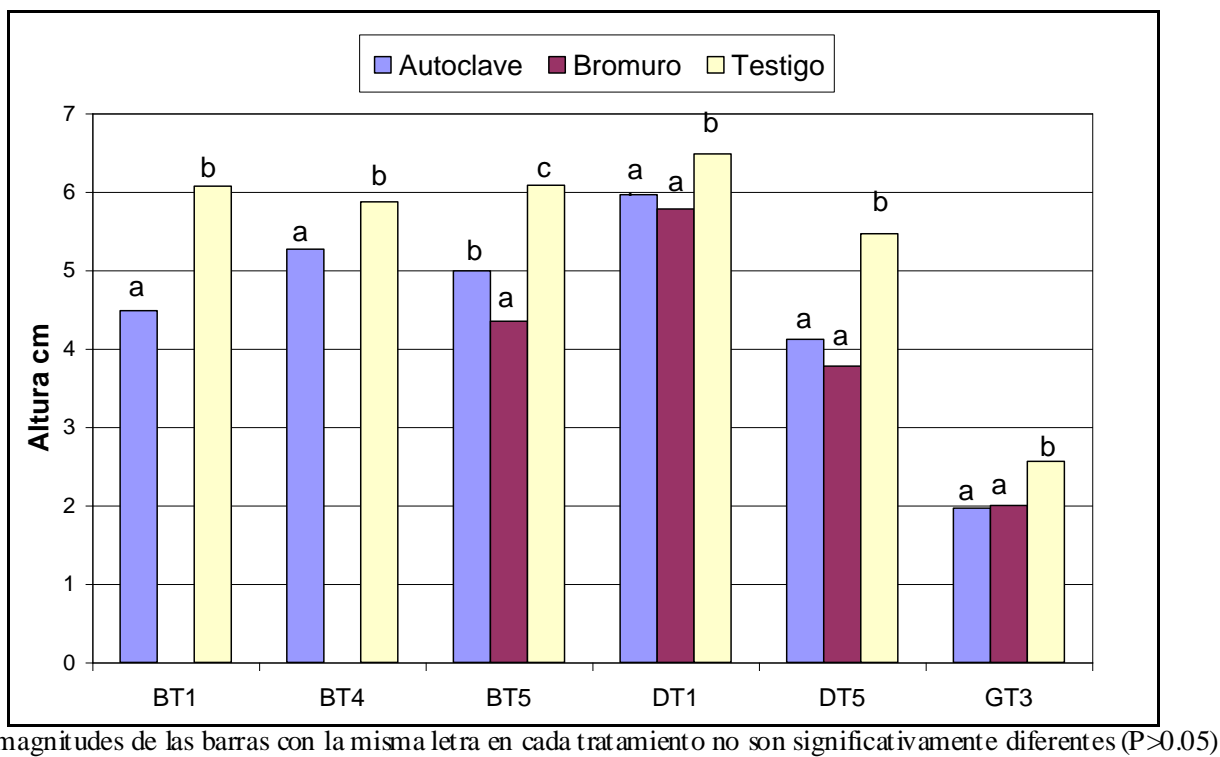

Figura 9. Altura de las plantas de apio sobre fracciones de suelos desinfectados en el laboratorio en autoclave, con bromuro de metilo y no desinfectadas (testigo). Sobre suelo desinfectado con bromuro de

metilo (BT1), biofu migado (BT4), no desinfectado (BT5), invernadero B 1. Suelo desinfectado con bromuro de metilo (DT 1), no desinfectado (DT5), invernadero D. Suelo no desinfectado, invernadero G.

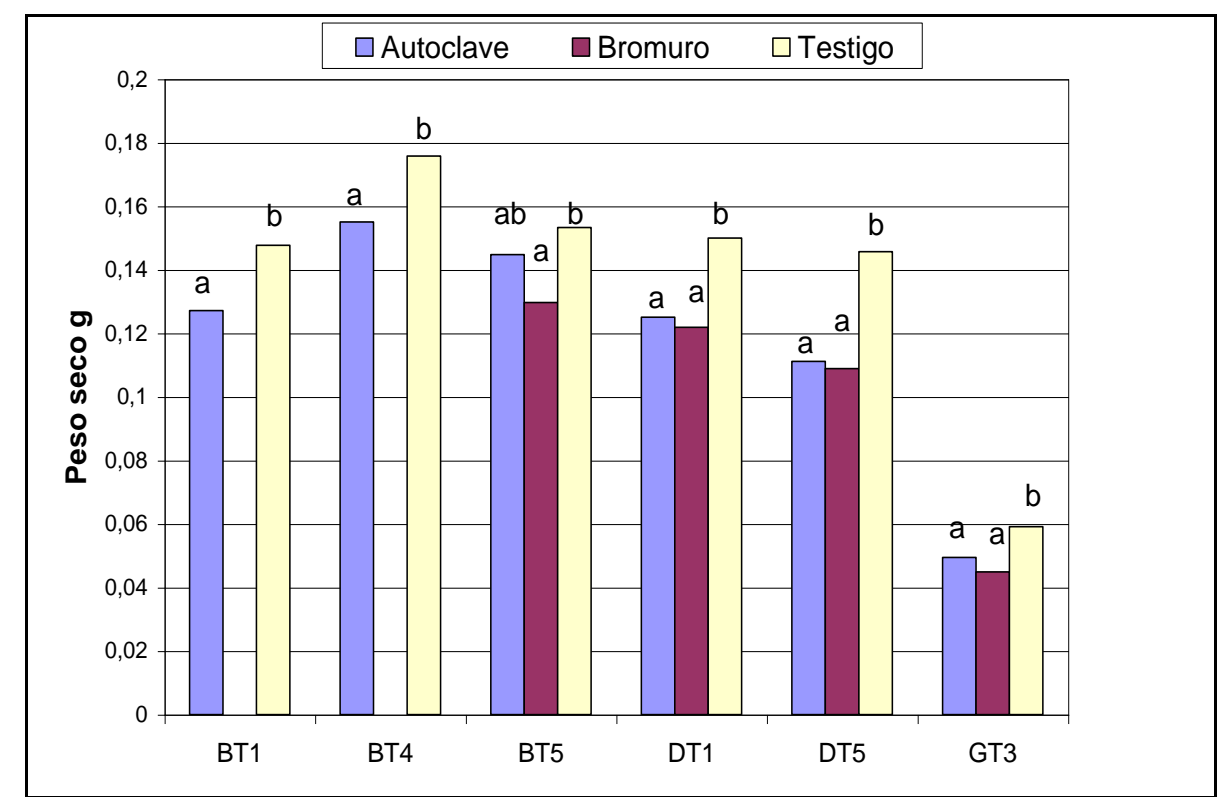

Las magnitudes de las barras con la misma letra en cada trat amient o no son significativamente diferentes $(\mathrm{P}>0.05)$

Figura 10. Peso seco de las plantas de apio sobre fracciones de suelos desinfectados en el laboratorio en autoclave, con bromuro de metilo y no desinfectadas (testigo). Sobre suelo desinfectado con bromuro de metilo (BT 1), biofu migado (BT4), no desinfectado (BT5), invernadero B 1. Suelo desinfectado con bromuro de metilo (DT1), no desinfectado (DT5), invernadero D. Suelo no desinfectado, invernadero G. 
Los resultados muestran: por un lado, que los mejores resultados en peso seco y altura de plantas se obtienen para las fracciones de las muestras del sue lo sin ningún tratamiento de desinfección en el laboratorio. Esto sugiere una cierta especificidad de la fatiga para el pimiento y por otro lado permite poner de manifiesto la existencia de la fatiga en los suelos con monocultivo de pimiento. Por otro lado, la respuesta negativa de la planta ante la desinfección, cualquiera que ésta fuere: física (autoclave) o química (bromuro de metilo). Ante este hecho se introdujo la lechuga en los experimentos para valorar esta sugerente especificidad. En la muestra del invernadero G (GT3) el factor limitante sigue expresándose al igual que en los ensayos con pimiento, pero dicho factor no interfiere en el sentido de que la desinfección incide negativamente sobre el apio.

Los suelos recogidos en el invernadero B 2 se evaluaron con ambas especies y uno de ellos (BT5) fue repetido. Los resultados concernientes al apio se recogen en las Figuras 11 y 12 (la fracción de suelo codificada como testigo en las gráficas hace referencia a suelo sin tratar en laboratorio) y su visualización en la Foto 5. En estos suelos se reproduce el mismo efecto, lo que permite corroborar los ensayos con los anteriores suelos y también las especulaciones realizadas con ellos.

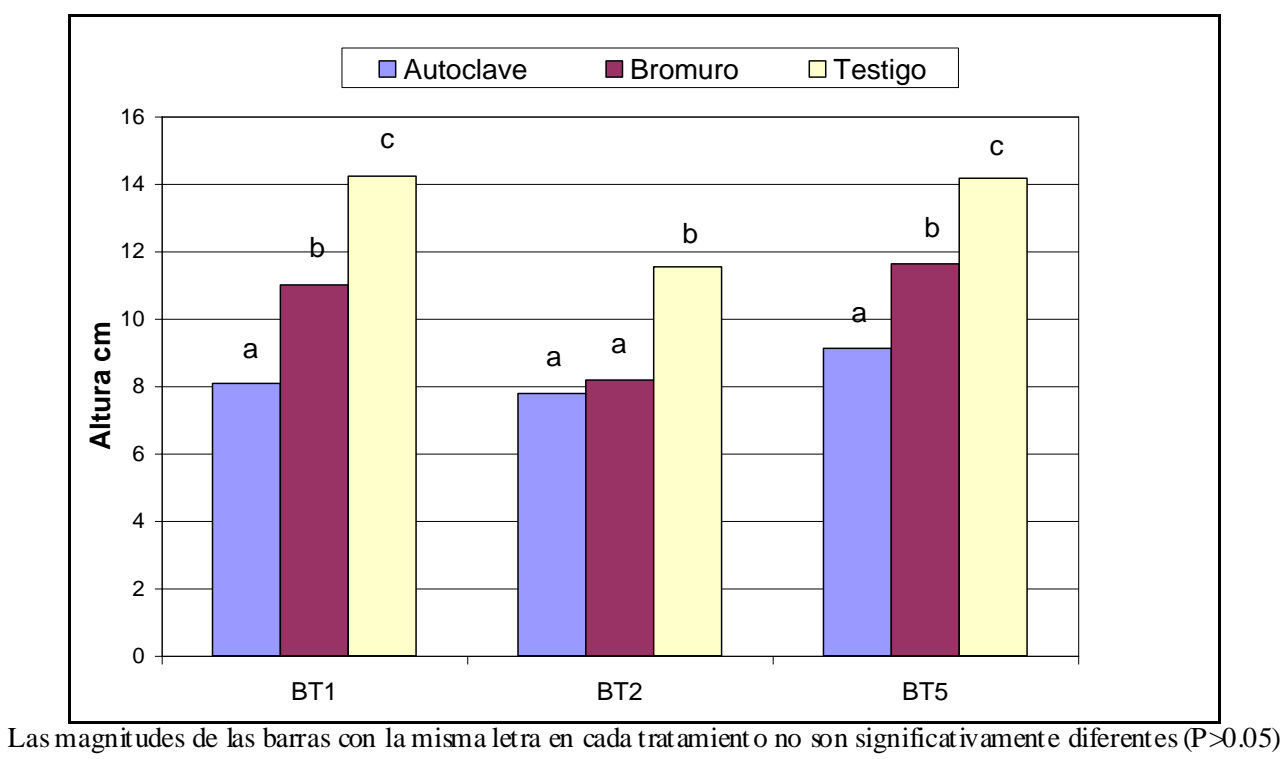

Figura 11. Altura de las plantas de apio sobre fracciones de suelos desinfectados en el laboratorio en autoclave, con bromuro de metilo y no desinfectadas (testigo). Sobre suelo desinfectado con bromuro de metilo (BT1), desinfectado con Telone C-35 (BT2), y no desinfectado (BT5). Invernadero B 2. 


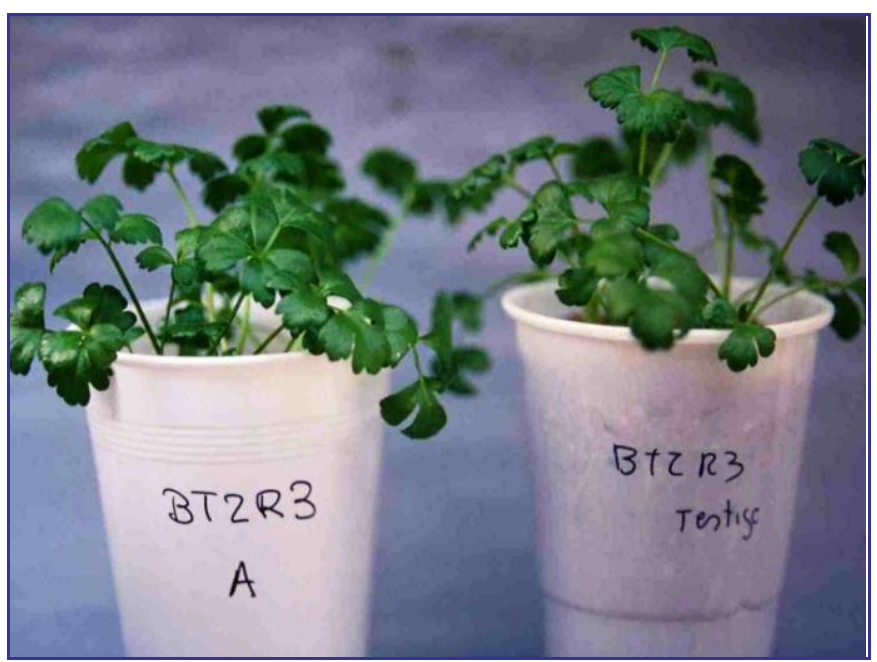

Foto 5. Plantas de apio sobre fracciones de suelo desinfectado en el laboratorio en autoclave (A) y no desinfectadas (Testigo). Invernadero B 2 suelo desinfectado con Telone C-35.

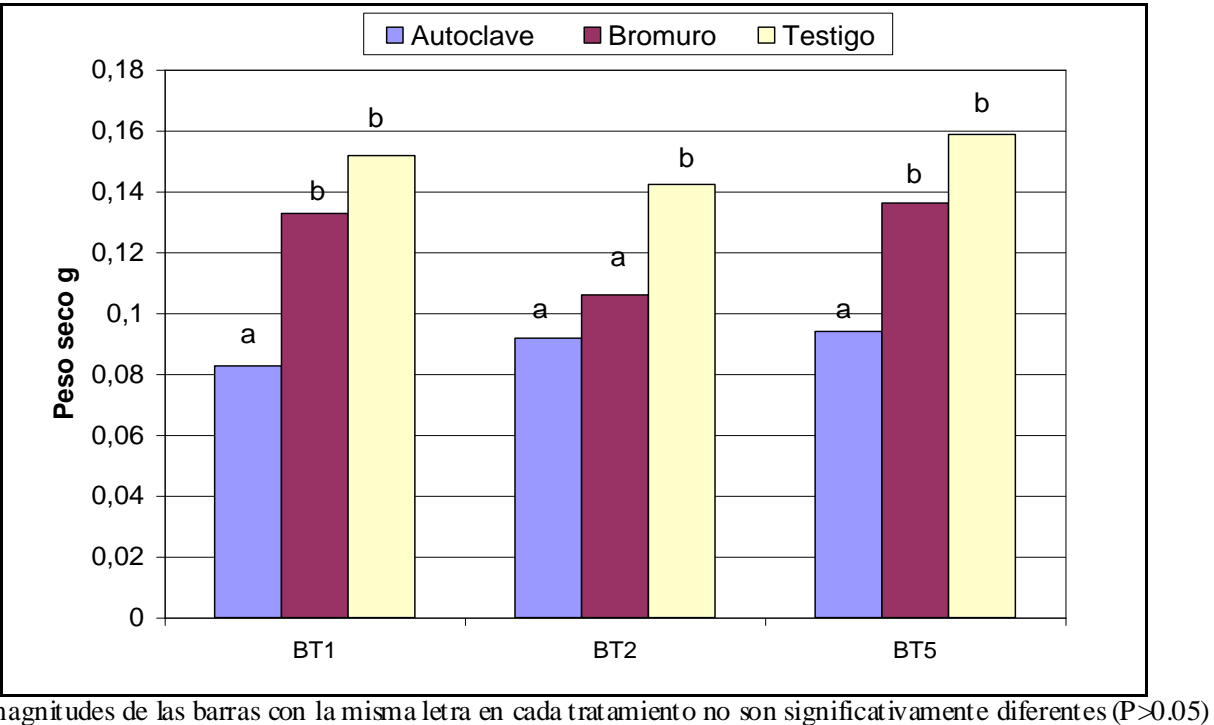

Figura 12. Peso seco de las plantas de apio sobre fracciones de suelos desinfectados en el laboratorio en autoclave, con bromuro de metilo y no desinfectadas (testigo). Sobre suelo desinfectado con bromuro de metilo (BT1), desinfectado con Telone C-35 (BT2) y no desinfectado (BT5). Invernadero B 2.

Los resultados concernientes a la lechuga se resumen en las Figuras 13 y 14 y la imagen ilustrativa en la Foto 6.

Sirven para confirmar la especificidad de la fatiga del suelo ocasionada por el monocultivo del pimiento que se detectó con el apio. Refuerza, además, que la desinfección de las muestras es contraproducente para incrementar el tamaño de las plantas en los ensayos.

Una observación experimental adicional, que reitera los resultados con pimiento, fue la ausencia en las raíces de las plantas de necrosis y/o nódulos al final de los ensayos. 


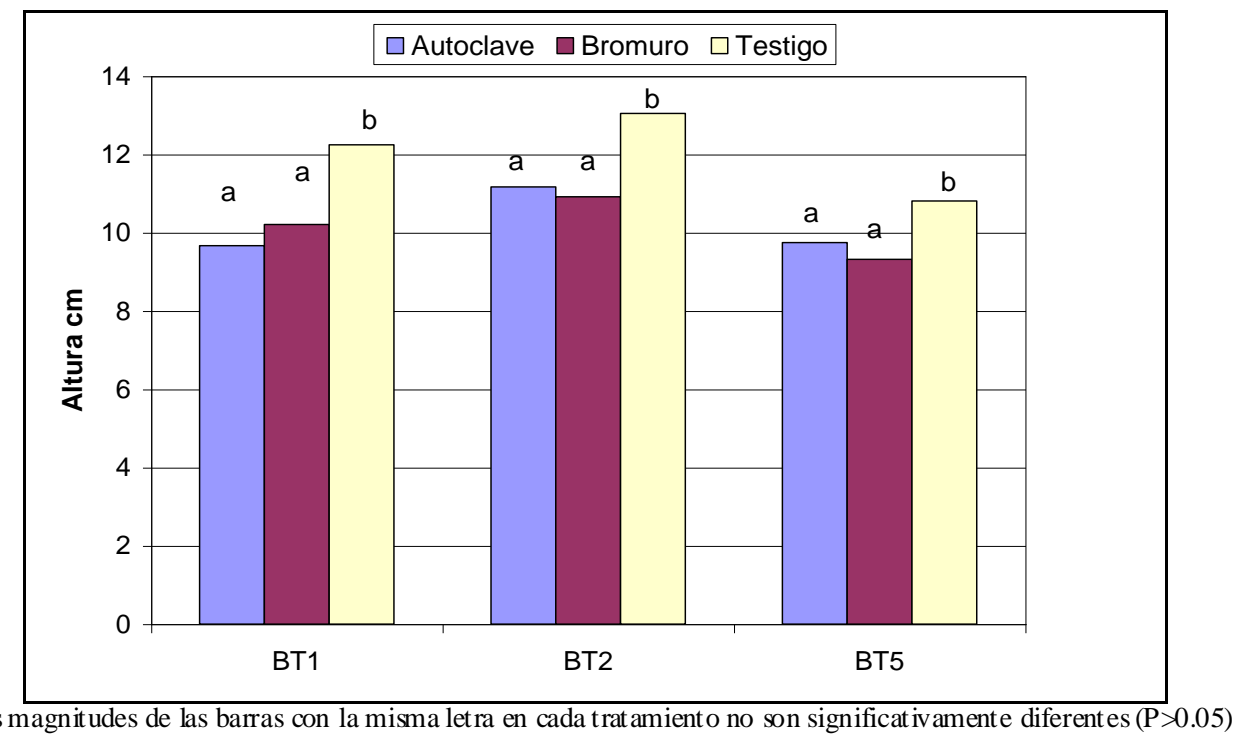

Figura 13. Altura de las plantas de lechuga sobre fracciones de suelos desinfectados en el laboratorio en autoclave, con bromuro de metilo y no desinfectadas (testigo). Sobre suelo desinfectado con bromuro de metilo durante 16 años (BT1), desinfectado con Telone C-35 (BT2), no desinfectado (BT5). Invernadero B 2.

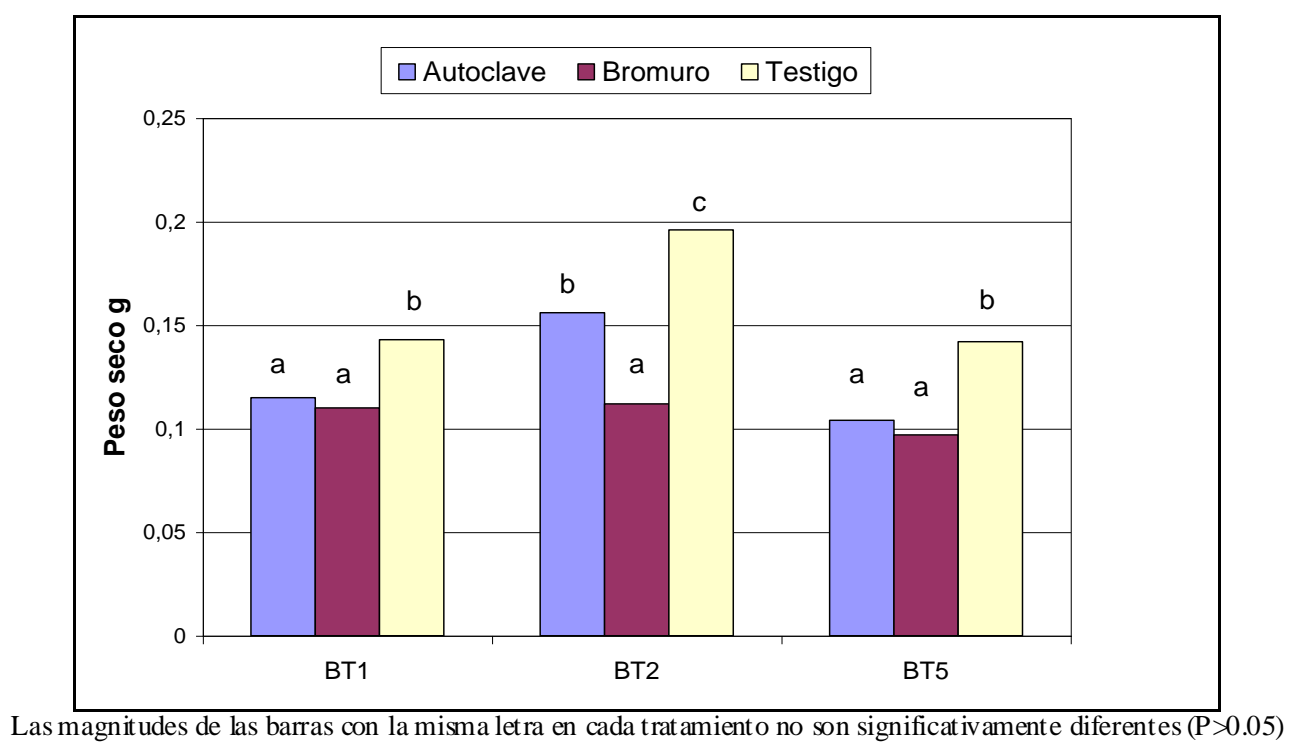

Figura 14. Peso seco de las plantas de lechuga sobre fracciones de suelos desinfectados en el laboratorio en autoclave, con bromuro de metilo y no desinfectadas (testigo). Sobre suelo desinfectado con bromuro de metilo durante 16 años (BT1), desinfectado con Telone C-35 (BT2), no desinfectado (BT5). Invernadero B 2. 


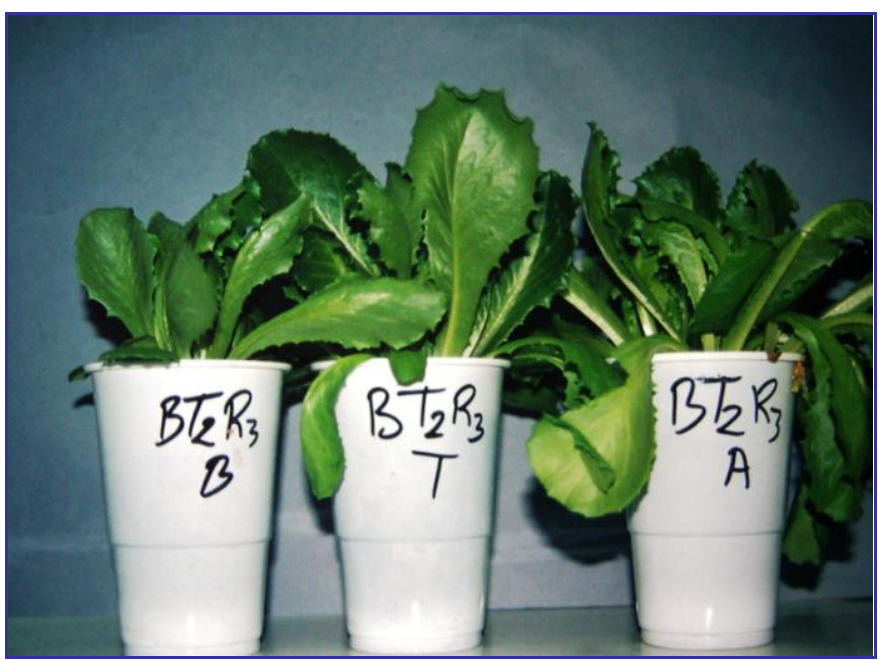

Foto 6. Plantas de lechuga sobre la fracción del suelo desinfectado en el laboratorio con bromuro de metilo (BM), testigo (T) y autoclave (A). Invernadero B 2. Suelo desinfectado con Telone C-35 (BT2).

Los experimentos presentados hasta ahora permiten varias reflexiones:

a) La fatiga del suelo debida a la reiteración del cultivo del pimiento en el Campo de Cartagena se ha comprobado experimentalmente, correspondiéndose dicho fenómeno al observado por Lacasa et al. (2002) y Guerrero et al. (2004) en los invernaderos de los agricultores.

b) La fatiga detectada desaparece en el suelo, cuando se desinfecta en el laboratorio con vapor de agua o con bromuro de metilo. Los experimentos en condiciones controladas muestran correspondencia con lo que ocurre en los invernaderos de los agricultores.

c) La fatiga detectada es específica para el pimiento y no se expresa con plantas de lechuga y apio. La desinfección de las muestras de suelo en autoclave o con bromuro de metilo, dan lugar a plantas con un menor desarrollo que las obtenidas en el suelo de pimiento con fatiga sin tratamiento alguno.

d) Todo parece indicar que la fatiga de las muestras de los suelos estudiados pudiese tener un origen microbiológico, como se mencionaba en la introducción para el apio, tomate, fresón, etc. Este aspecto ha sido corroborado por la observación de los sistemas radiculares de las plantas de los ensayos, en las que no se apreciaron necrosis o nódulos, pese a proceder algunas muestras de suelos muy infectados con Phytophthora sp. y $M$. incognita.

Estas especulaciones experimentales permitieron plantear la investigación que se discute en los apartados siguientes. Admitiendo además, la pregunta: ¿Podrían otras intervenciones en el suelo diferentes a la desinfección química o física hacer desaparecer el efecto fatiga? 


\subsubsection{Evaluación de la fatiga en muestras de suelos de invernaderos con ensayos de desinfección por medios no químicos}

En la revisión bibliográfica realizada en la introducción se ha recogido la importancia de la materia orgánica como "factor limitante" componente de la fatiga de los suelos. ¿Podría el uso de materia orgánica emular el "efecto bromuro"?¿Estaría esa materia orgánica en el origen del fenómeno de fatiga? Se plantearon ensayos que permitieran aportar información al respecto, antes de asignar a la fatiga específica, detectada en los pimentonares del Campo de Cartagena, una causalidad estrictamente microbiológica, como sugieren los apartados anteriores.

Los ensayos se llevaron a cabo con muestras de suelos tomadas en invernaderos donde se comparaba el efecto de la biofumigación+solarización (biosolarización) en comparación al bromuro de metilo, reiterando la primera en años consecutivos (Tabla 2).

\subsubsection{Evaluación de la fatiga y su relación con tratamientos de desinfección utilizando materia orgánica}

La materia orgánica utilizada fue estiércol fresco (poco descompuesto) de oveja y gallinaza. El procedimiento de aplicación fue una biosolarización: aplicación de solarización añadiendo al inicio del proceso diferentes cantidades de la materia orgánica poco descompuesta.

Se evaluaron las muestras de suelo del invernadero E 1 de las parcelas de los tratamientos ET1 y ET3. ET1 que había sido tratada en el campo con bromuro de metilo durante los 2 años anteriores y el tratamiento se repitió antes de recoger la muestra. Y ET3 que durante dos cultivos anteriores no había recibido ningún tratamiento el suelo, siendo enmendado al comenzar la campaña con materia orgánica y solarización $\left(7 \mathrm{~kg} \mathrm{~m}^{-2}\right.$ de estiércol fresco de oveja más $3 \mathrm{~kg} \mathrm{~m}^{-2}$ de gallinaza, es decir unas $100 \mathrm{t} \mathrm{ha}^{-1}$ ) (Tabla 2).

Los resultados, presentados en las Figuras 15 y 16 para la altura de las plantas y el peso seco ponen en evidencia que ambas muestras responden de una manera semejante y muy próxima a las muestras de suelo estudiadas en los apartados anteriores (invernadero B y D) pese a tener una antigüedad para el cultivo muy diferente. Por otro lado, las respuestas de ambos tratamientos al suelo son muy próximas, indicándonos que tanto el bromuro de metilo como la biosolarización parecen tener un mismo efecto para disminuir la fatiga del suelo. Sin embargo, hay una pequeña diferencia que merece ser subrayada: en la Figura 15 la altura de las plantas se equipara para ambos tratamientos (vapor de agua en autoclave y bromuro de metilo) sugiriendo que en el tratamiento con biosolarización la materia orgánica puede estar actuando como promotora del crecimiento. En cualquier caso en general, las muestras tratadas con bromuro no alcanzan el mismo efecto que el vapor de agua, permitiendo así tomarlo como testigo óptimo. En ninguna de las muestras se apreciaron podredumbres o nódulos en las raíces al finalizar los ensayos, ni signo alguno de parasitismo. 


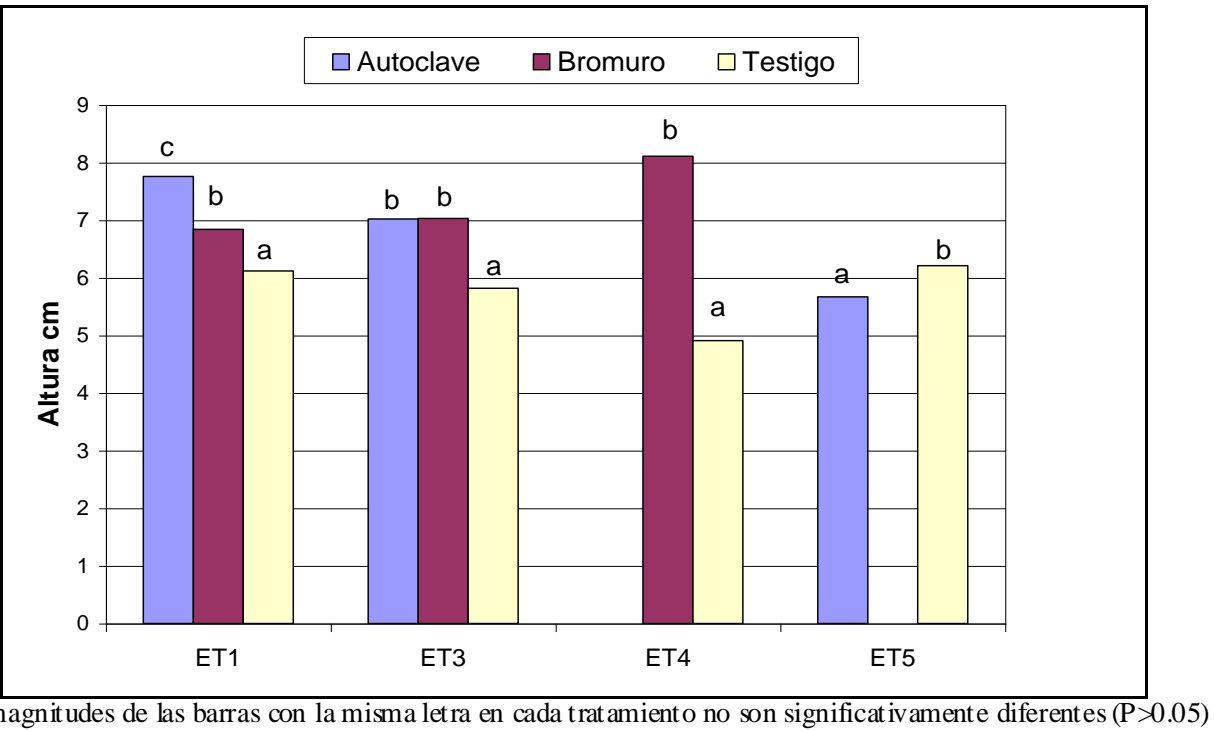

Figura 15. Altura de las plantas de pimiento sobre fracciones de suelos desinfectados en el laboratorio en autoclave, con bromuro de metilo y no desinfectadas (testigo). Invernadero E 1. Tratamientos ET 1: suelo desinfectado con bromuro de metilo; ET3: suelo biosolarizado 1 año; ET4: suelo biosolarizado 2 años; ET5: suelo biosolarizado 3 años.

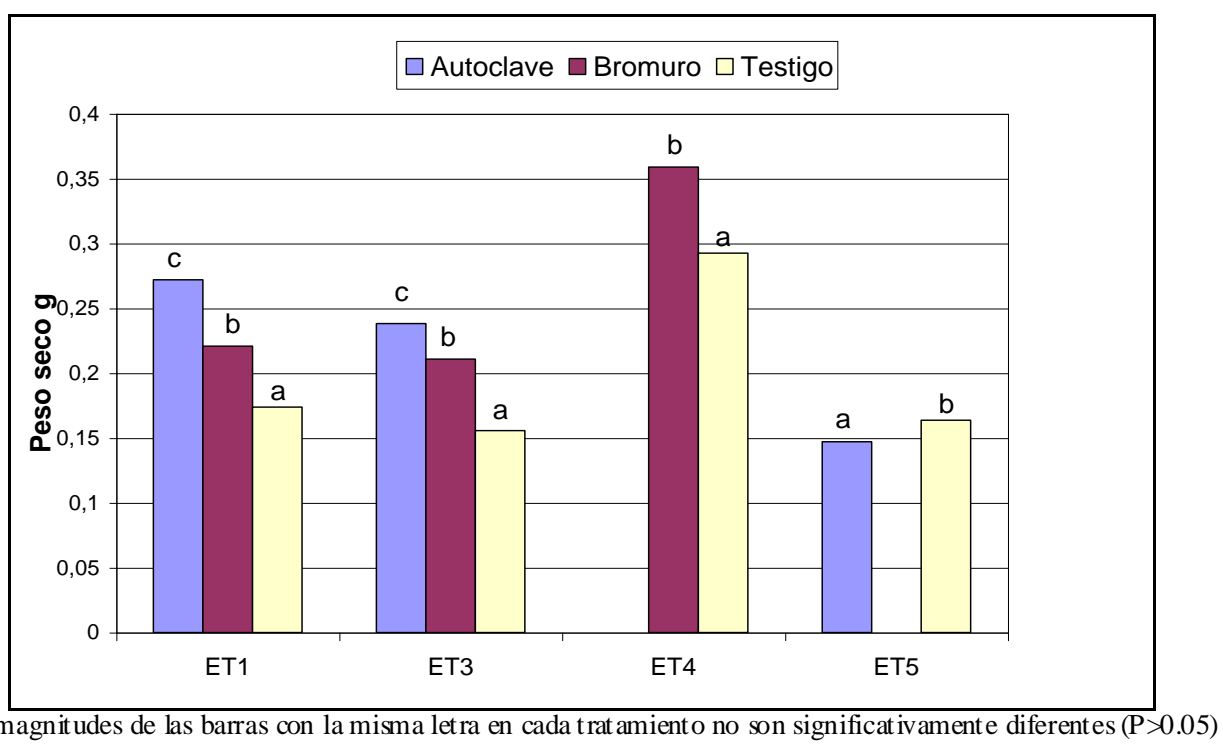

Figura 16. Peso seco de las plantas de pimiento sobre fraccion es de suelos desinfectados en el laboratorio en autoclave, con bromuro de metilo y no desinfectadas (testigo). Invernadero E 1. Tratamientos ET1: suelo desinfectado con bromuro de metilo; ET3: suelo biosolarizado 1 año: ET4: suelo biosolarizado 2 años; ET5: suelo biosolarizado 3 años.

Las muestras de suelos diferentemente tratados en ese mismo invernadero (E 2) al año siguiente, fueron evaluadas por el mismo procedimiento. La muestra codificada como ET1 corresponde al suelo no tratado en las 4 campañas anteriores; la codificada como ET2 había sido desinfectada con bromuro de metilo en las 4 campañas previas; la señalada como ET3 no se desinfectaron durante 2 campañas y en las 2 últimas se había biosolarizado, habiendo recibido el tratamiento previo a la recogida de muestras con $5 \mathrm{~kg}$ $\mathrm{m}^{-2}$ de estiércol fresco de oveja más $2,5 \mathrm{~kg} \mathrm{~m}^{-2}$ de gallinaza $\left(75 \mathrm{t} \mathrm{ha}^{-1}\right.$ de materia orgánica). Por último, la denominada ET5 en los 4 años de monocultivo de pimiento, durante el primero no se trató el suelo y en los tres siguientes se biosolarizó, utilizando en 
la campaña en la que se recogieron las muestras $3 \mathrm{~kg} \mathrm{~m}^{-2}$ de estiércol fresco de oveja más $1,5 \mathrm{~kg} \mathrm{~m}^{-2}$ de gallinaza (45 $\mathrm{t} \mathrm{ha}^{-1}$ de materia orgánica).

Los resultados se resumen gráficamente en las Figuras 17 y 18. A partir de ellos algunos comentarios son necesarios.

En las muestras sin tratar se pone en evidencia que las alturas y pesos secos de las plantas tienen magnitudes muy parecidas, incluyendo la muestra no desinfectada en los cuatro años anteriores.

Si se compara, en lo concerniente a la desinfección del suelo, con el invernadero G (Figuras 5 y 6) parecería como si en estos suelos la fatiga se expresase con menor intensidad o, incluso, como si no existiese dicha fatiga. Sin embargo, los tratamientos de desinfección realizados sobre las muestras tienen una respuesta positiva, tanto para el peso seco como para la altura y ello estaría indicando un cierto nivel de fatiga. En la muestra ET5, biosolarizada durante 4 años, se comprueba que la mejor respuesta se obtendría con la desinfección a base de bromuro de metilo. ¿Significaría este hecho que estos suelos tienen unas características que permiten actuar al bromuro de metilo con mayor eficacia? ¿Podría suponerse que el bromuro de metilo deja en estos suelos una fracción de la microbiota favorable al desarrollo de las plantas y el vapor de agua no?

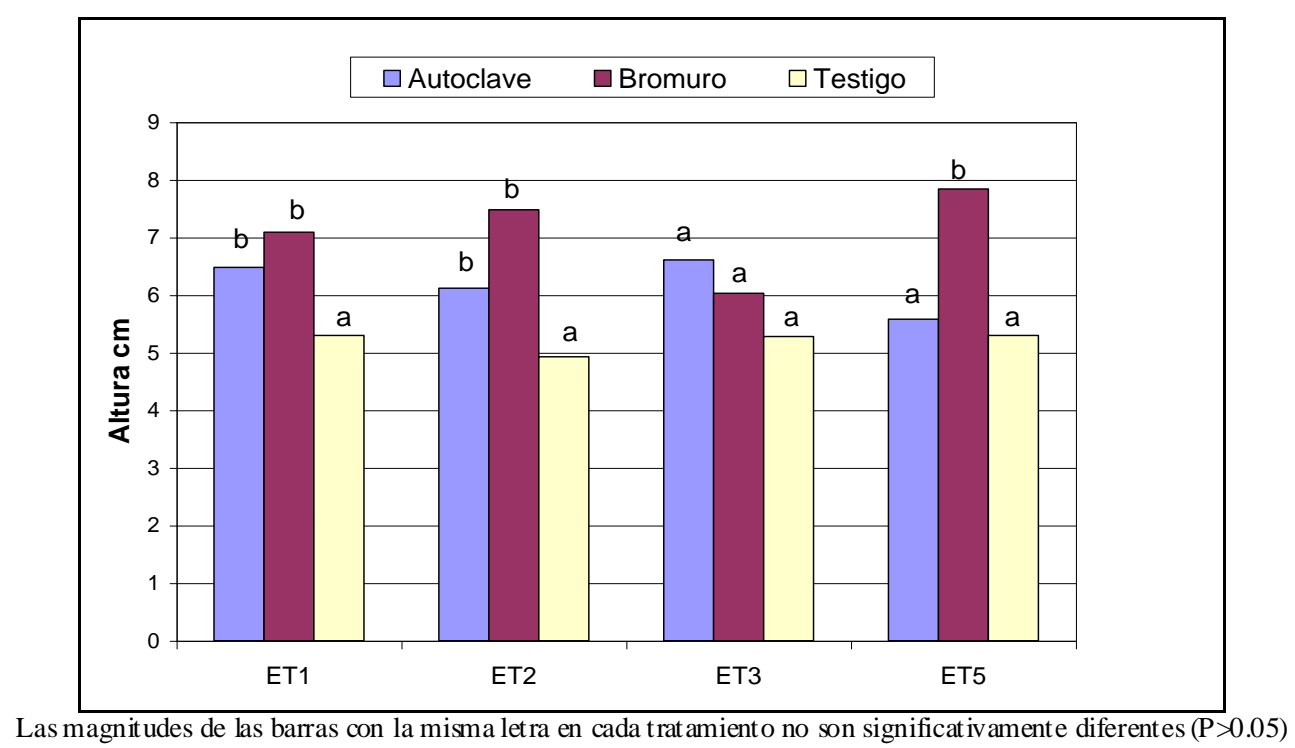

Figura 17. Altura de las plantas pimiento sobre fracciones de suelos desinfectados en el laboratorio en autoclave, con bromuro de metilo y no desinfectadas (testigo). Invernadero E 2. Tratamientos ET1: suelo no desinfectado; ET2: suelo desinfectado con bromuro de metilo; ET3: biosolarizado 2 años; ET5: biosolarizado 4 años. 


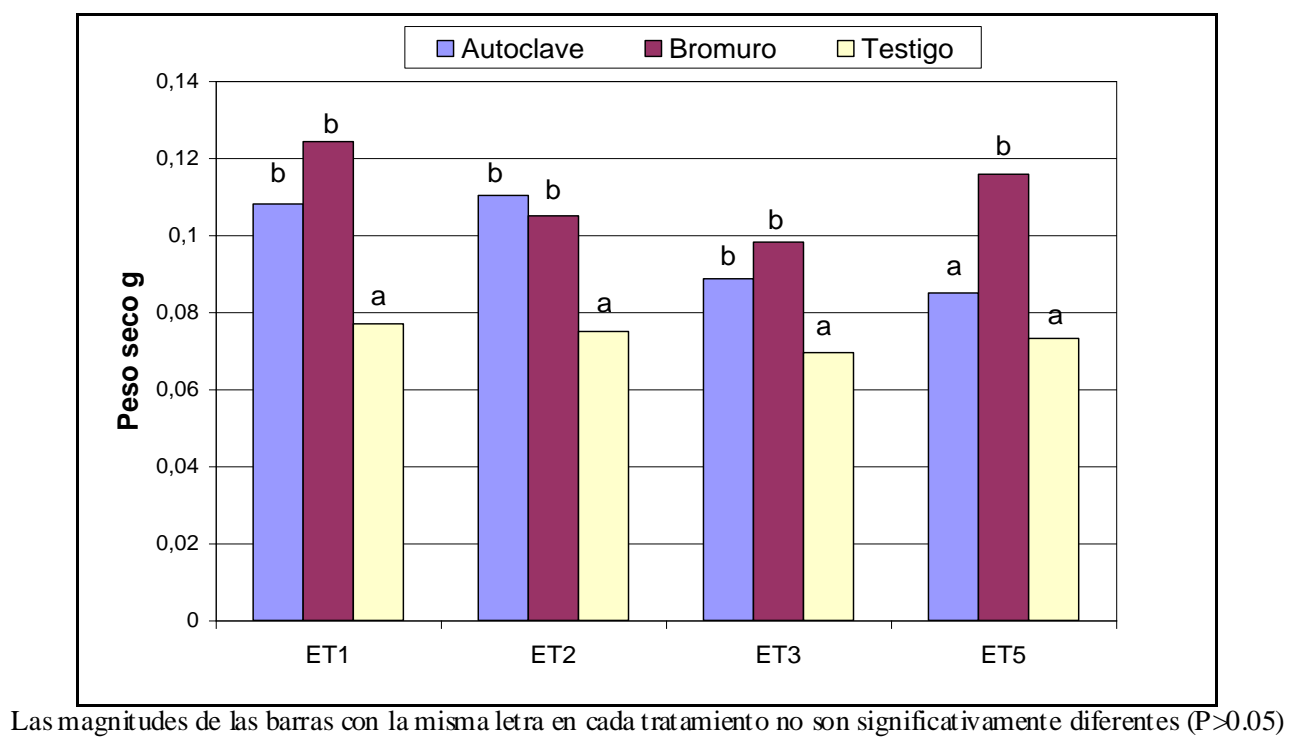

Figura 18. Peso seco de las plantas pimiento sobre fracciones de suelos desinfectados en el laboratorio en autoclave, con bromuro de metilo y no desinfectadas (testigo). Invernadero E 2. Tratamientos ET1: suelo no desinfectado; ET2: suelo desinfectado con bromuro de metilo; ET3: biosolarizado 2 años: ET5: biosolarizado 4 años.

Lo cierto es que no podrían asumirse diferencias entre el suelo no tratado (ET1) y el resto en lo que concierne al nivel de fatiga, aunque es evidente que ésta existe y da una respuesta positiva con respecto a los tratamientos de desinfección, pero la dimensión de la respuesta no permite una discriminación clara entre el suelo ET1 (sin tratar en los 4 años anteriores) y los tratados ET2, ET3 y ET5 por este tipo de experimentos. Es más, obsérvese como en el suelo con más años de biosolarización (ET5) la respuesta de la muestra al tratamiento con vapor es equiparable a la muestra no tratada (Figuras 17 y 18). ¿Podría significar este hecho una mejor actividad del bromuro de metilo en presencia de una mayor cantidad de materia orgánica? Véase como en el suelo ET5 la altura de las plantas muestra esa misma tendencia.

Estas preguntas basadas en las diferencias establecidas en los experimentos contrastados en condiciones controladas, motivaron una evaluación del método para los tratamientos realizados en campo. En esencia se pretendía comprobar si la biosolarización era capaz de eliminar la fatiga con una dimensión equiparable a la medida para el bromuro de metilo.

Las muestras estudiadas se recogieron del suelo del mismo invernadero de las que procedían las tomadas en campañas anteriores E 3, con algunas variantes. Las muestras se tomaron después de los tratamientos de desinfección y antes de la plantación. La muestra ET1 que no se había tratado en las 4 campañas anteriores, se biosolarizó (Tabla 2) con 95 t ha ${ }^{-1}$ de materia orgánica fresca; la ET2 recibía su quinto año de desinfección con bromuro; la ET3 que no se había desinfectado durante los tres primeros años recibía su tercera biosolarización (60 t ha $\mathrm{ha}^{-1}$ de materia orgánica) y la ET5 entraba en su quinta desinfección con biosolarización, que se practicaba disminuyendo, anualmente, la cantidad de materia orgánica, aportando $25 \mathrm{t} \mathrm{ha}^{-1}$ de la misma materia orgánica que para ET1 y ET3 (mezcla de estiércol fresco de oveja y gallinaza).

Los resultados se presentan en las Figuras 19 y 20 para altura y peso seco de las plantas. 


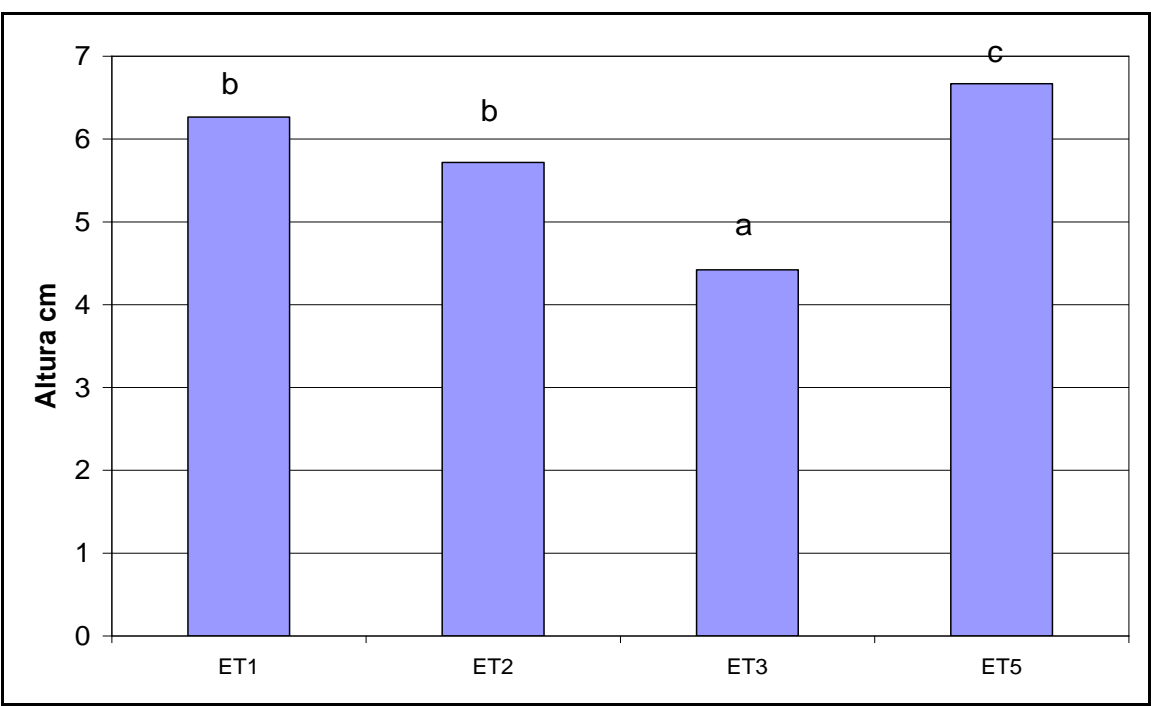

Las magnitudes de las barras con la misma letra no son significativamente diferentes $(\mathrm{P}>0.05)$

Figura 19. Altura de las plantas de pimiento sobre suelo biosolarizado un año (ET1), desinfectado con bromuro de metilo cinco años (ET2), biosolarizado 3 años (ET3), biosolarizado 5 años (ET5). Invernadero E 3.

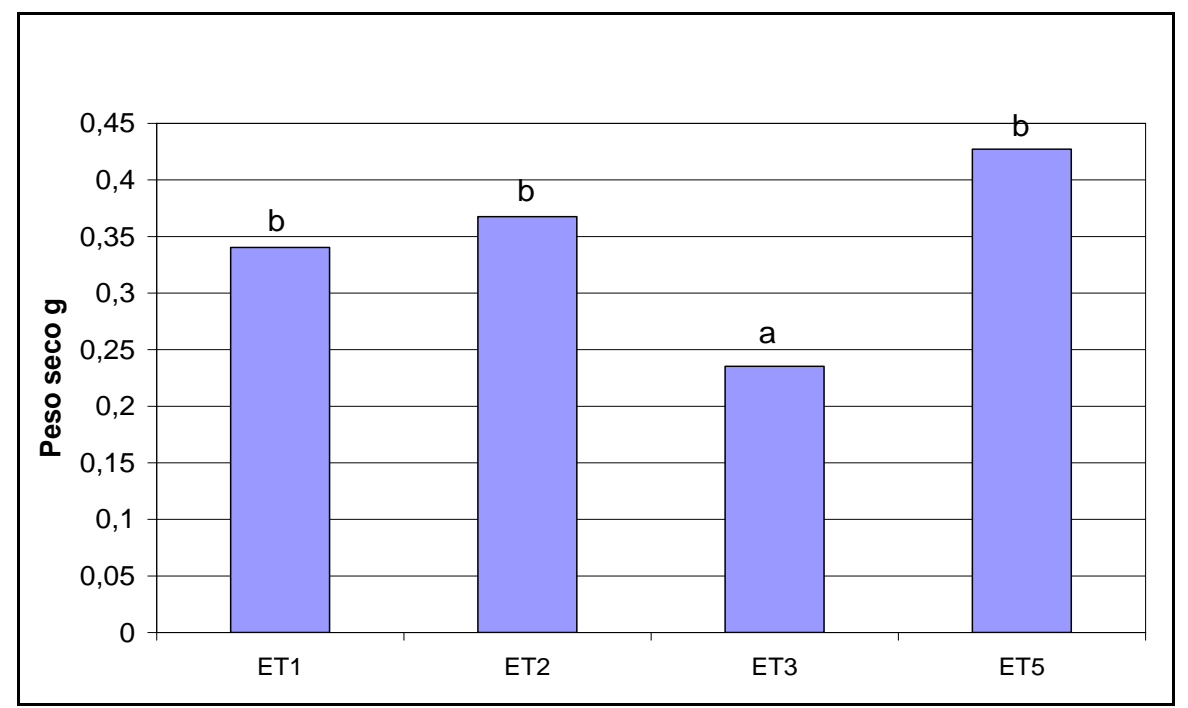

Las magnit udes de las barras con la misma letra no son significativamente diferentes $(\mathrm{P}>0.05)$

Figura 20. Peso seco de las plantas de pimiento sobre suelo biosolarizado un año (ET1), desinfectado con bromuro de metilo cinco años (ET2), biosolarizado 3 años (ET3), biosolarizado 5 años (ET5). Invernadero E 3.

La primera constatación es que las muestras ET1 (primer año de biosolarización) y la ET5 (quinto año de biosolarización) fueron comparables a la ET2 (quinto año de desinfección con bromuro de metilo), en cuanto al peso seco. Estos resultados siguen la misma tónica que lo encontrado en las muestras del año anterior cuyas fracciones fueron evaluadas en condiciones controladas. Además, corresponden con los obtenidos para los mismos parámetros y para la producción final en los invernaderos experimentales, dond e no se encontraron diferencias (Guerrero et al., 2004). La diferencia se presenta con la muestra ET3, que en la evaluación del peso seco y altura de las plantas en cámara fue menor significativamente. Este hecho no se ve reflejado en los ensayos en cámara de las muestras evaluadas en condiciones controladas y procedentes de los ensayos del año anterior (Figuras 17 y 18) donde Guerrero et al. (2004) encontraron una respuesta 
comparable con la reiteración del bromuro de metilo (ET2) para los parámetros de altura y de la producción comercial.

Hay que reiterar que en los experimentos no se apreciaron nódulos radiculares, pese a que en los suelos estuviera presente $M$. incognita. Tampoco ningún signo de parasitismo.

Los experimentos presentados en los invernaderos experimentales vuelven a poner en evidencia el fenómeno de la fatiga, pese a los pocos años de reiteración del cultivo. Sin embargo, este fenómeno es menor que en los suelos de los invernaderos de los agricultores. Véase para ello los valores del testigo en el campo (4 años sin desinfección) en las Figuras 9 y 10. Atendiendo al papel de la materia orgánica con solarización el efecto es comparable al de la reiteración del bromuro de metilo, emulando su acción al tamponizar el efecto fatiga.

Pese a que los métodos de desinfección de las muestras son diferentes, ambos crean una disminución equiparable de la microbiota fúngica (Yélamos et al., 2002; Martínez et al., 2009 y 2011) y desde esta óptica la desinfección con materia orgánica no aporta más explicación que la coincidente con la desinfección con bromuro de metilo: la fatiga tendría un carácter microbiológico. Esta observación no está avalada por la aparición de signos de parasitismo en las raíces como se ha descrito para el apio, el espárrago o el tomate. ¿Podría especularse, entonces, con alguna toxina microbiana o con alguna alelopatina?

\subsubsection{Evaluación de la especificidad de la fatiga en suelos biosolarizados}

Habiendo detectado la especificidad en las muestras de suelo recogidas en los invernaderos de los agricultores al utilizar plantas de apio y de lechuga, cabría preguntarse: ¿variaría tal especificidad al introducir materia orgánica en el proceso de desinfección del suelo?

Para estos experimentos se siguió la misma ordenación que para evaluar la fatiga con pimiento.

Las muestras recogidas en el invernadero E1, se comportaron en relación al apio como se presenta en las Figuras 21 y 22 y en la Foto 7.

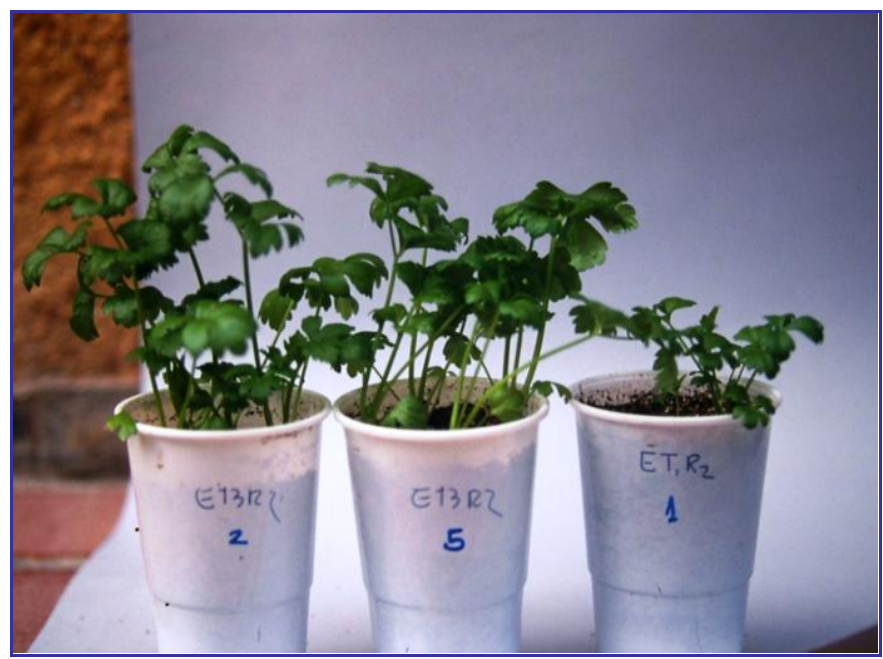

Foto 7. Plantas de apio sobre fracciones de suelo desinfectadas en el laboratorio, de izquierda a derecha, no desinfectada (T), desinfectada con bromuro de metilo (BM) y en autoclave (A). Invernadero E 1. 


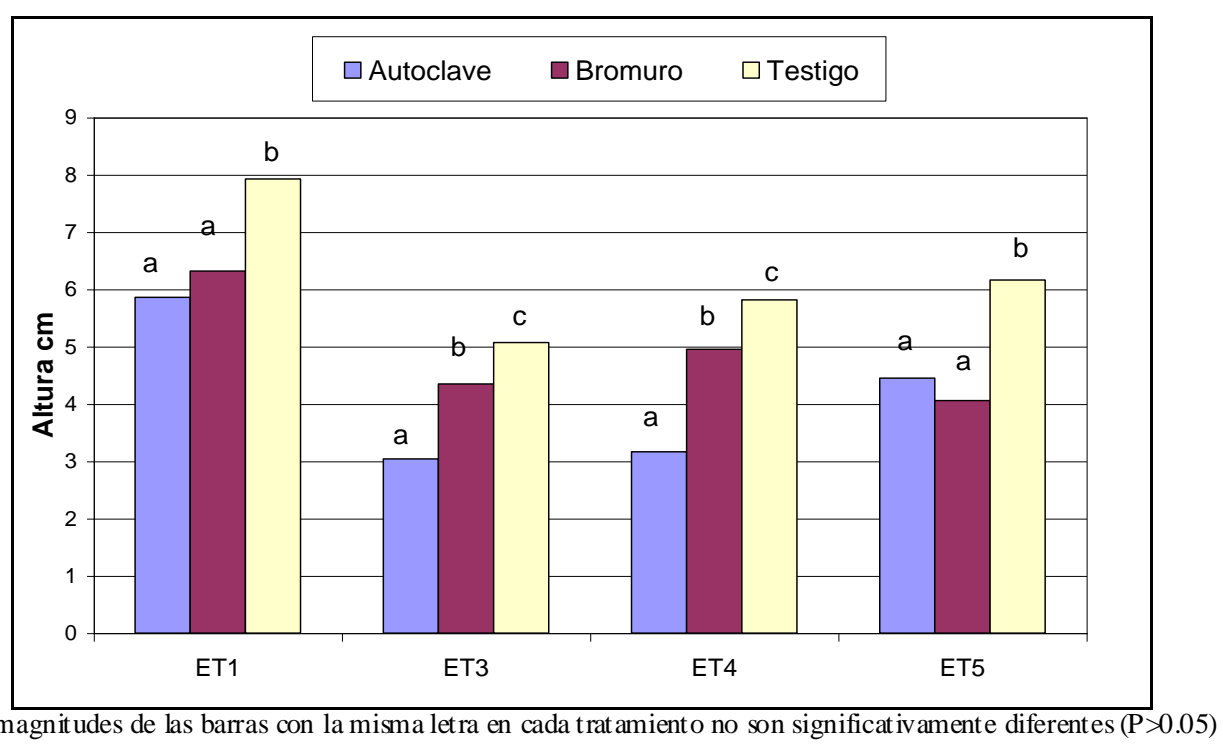

Figura 21. Altura de las plantas de apio sobre fracciones de suelos desinfectados en el laboratorio en autoclave, con bromuro de metilo y no desinfectadas (testigo). Invernadero E 1. Tratamientos ET1: suelo desinfectado con bromuro de metilo; ET3: suelo biosolarizado 1 año; ET4: suelo biosolarizado 2 años; ET5: suelo biosolarizado 3 años.

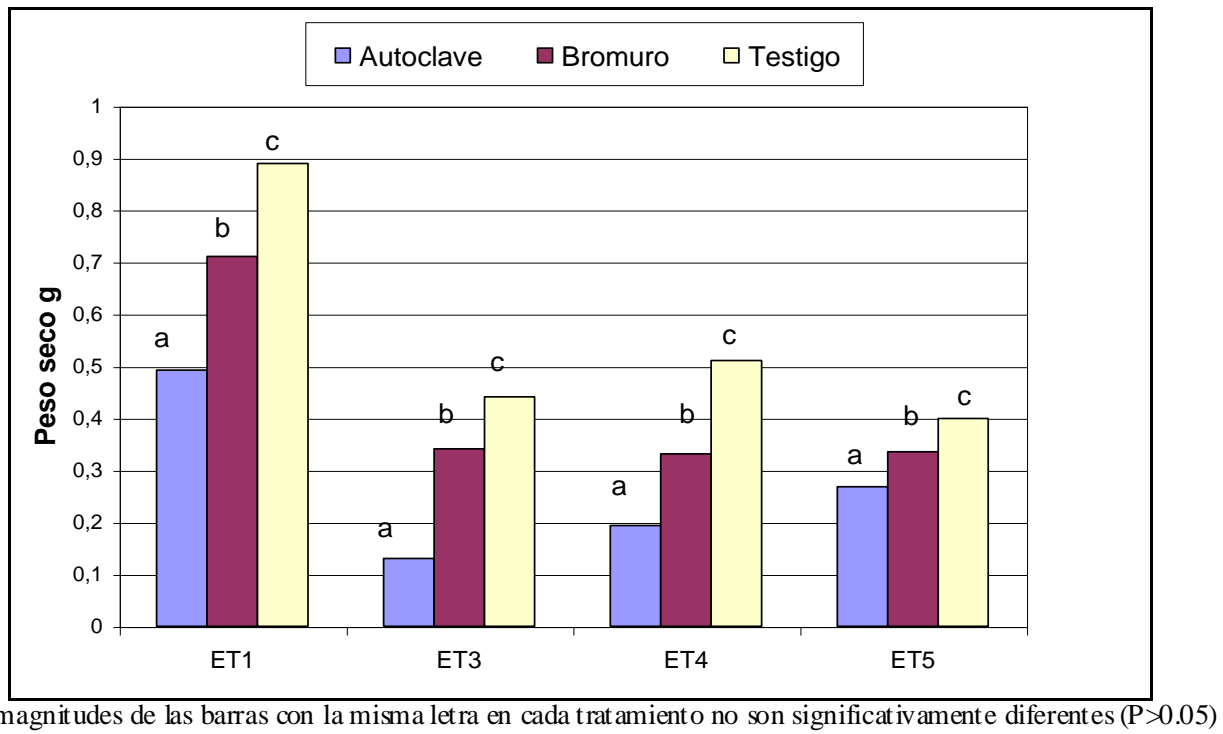

Figura 22. Peso seco de las plantas de apio sobre fracciones de suelos desinfectados en el laboratorio en autoclave, con bromuro de metilo y no desinfectadas (testigo). Invernadero E 1. Tratamientos ET1: suelo desinfectado con bromuro de metilo; ET3: suelo biosolarizado 1 año; ET4: suelo biosolarizado 2 años; ET 5: suelo biosolarizado 3 años.

Tanto la muestra procedente de una parcela desinfectada con bromuro de metilo (ET1), como la que había recibido tratamiento de biosolarización(ET3), con $100 \mathrm{t} \mathrm{ha}^{-1} \mathrm{de}$ materia orgánica poco descompuesta mostraron una respuesta similar a las que se recogieron de los invernaderos de los agricultores (ver Figuras 11, 12 y otras). Las desinfecciones de suelo no favorecen el desarrollo del apio y lo que aquí más importa, la muestra de suelo sin tratar es donde mayor altura y peso seco alcanzan las plantas, 
confirmando la validez del método utilizado y la especificidad de la fatiga. Evidenciando, en consecuencia, que la materia orgánica no parece interferir en la ordenación, pero sí en la magnitud de la respuesta, menor para la materia orgánica.

Cuando se ensayó con los suelos tomados en las parcelas elementales de los tratamientos realizados en el invernadero E 2 los resultados para la altura y el peso seco de las plantas de apio (Figuras 23 y 24), vinieron a corroborar lo encontrado en el ensayo de la campaña precedente en ese mismo invernadero E 1 .

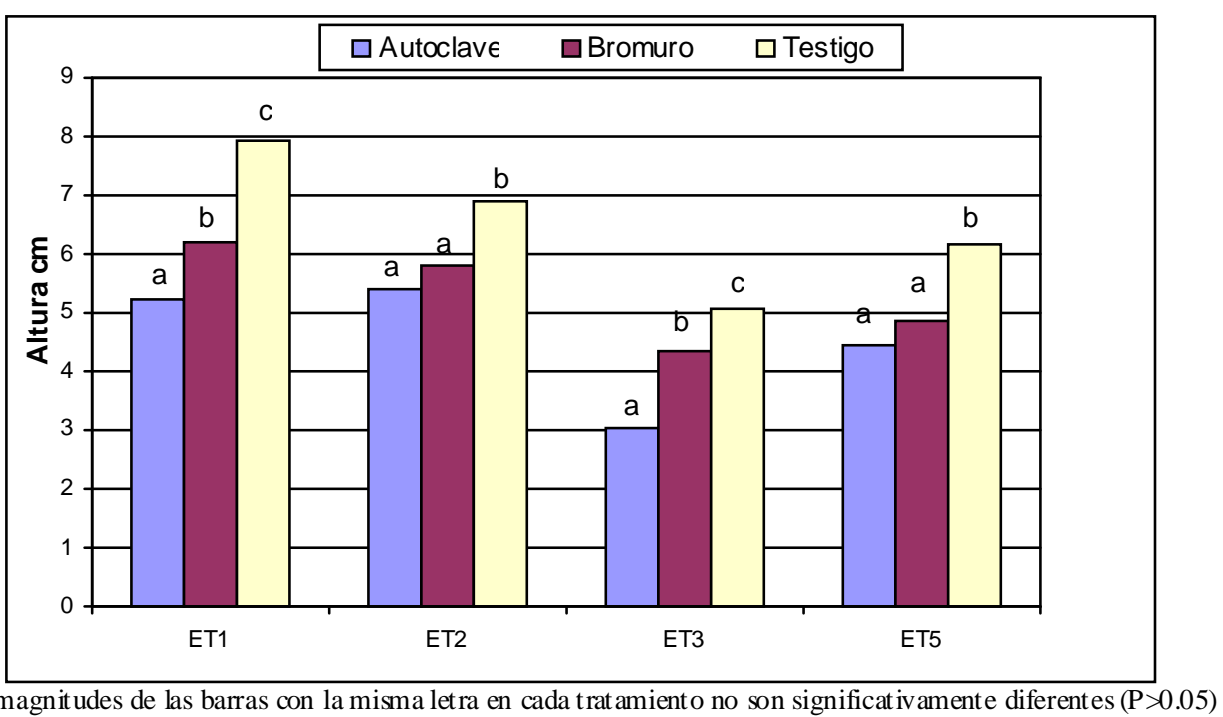

Figura 23. Altura de las plantas de apio sobre fracciones de suelos desinfectados en el laboratorio en autoclave, con bromuro de metilo y no desinfectadas (testigo). Invernadero E 2. Tratamientos ET1: suelo no desinfectado; ET2: suelo desinfectado con bromuro de metilo; ET3: biosolarizado 2 años; ET5: biosolarizado 4 años.

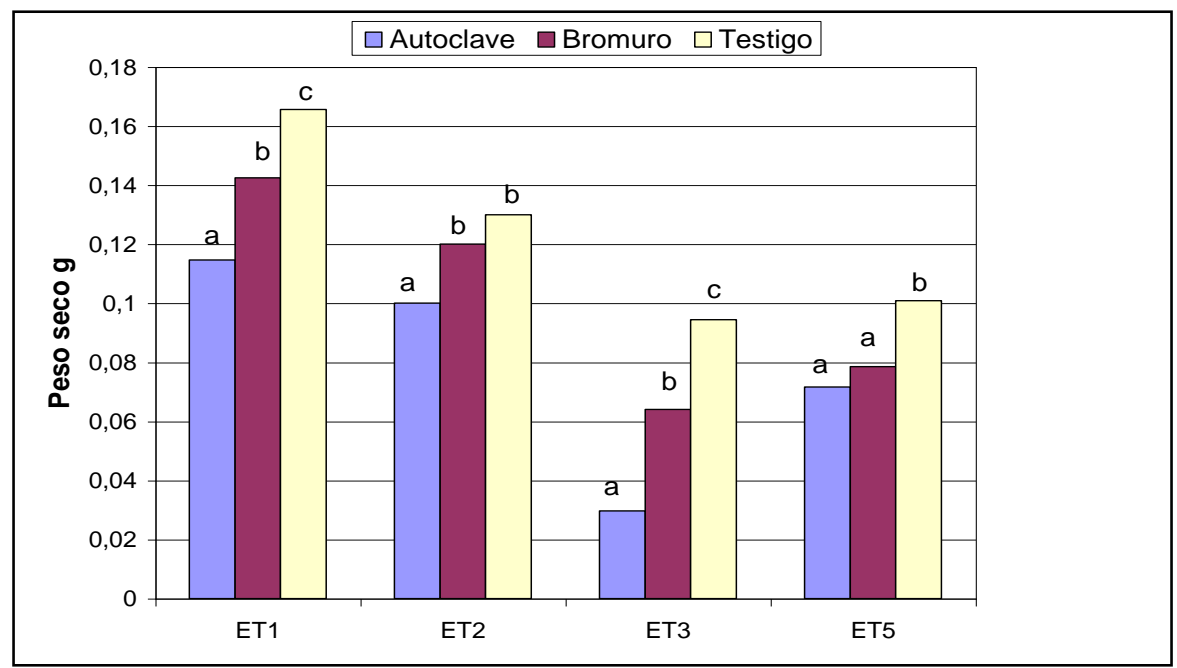

Las magnitudes de las barras con la misma letra en cada trat amiento no son significativamente diferentes $(\mathrm{P}>0.05)$

Figura 24. Peso seco de las plantas de apio sobre fracciones de suelos desinfectados en el laboratorio en autoclave, con bromuro de metilo y no desinfectadas (testigo). Invernadero E 2. Tratamientos ET1: suelo no desinfectado; ET2: suelo desinfectado con bromuro de metilo; ET3: biosolarizado 2 años; ET5: biosolarizado 4 años. 
El suelo no tratado durante las cuatro campañas anteriores (muestra ET1) es el que mejor respuesta da. Se confirma, y esto es lo importante, lo ensayado con los suelos procedentes de los invernaderos comerciales: la especificidad de la fatiga.

Parece paradójico que los suelos desinfectados con biosolarización (ET3 y ET5) den una respuesta peor que los tratados con bromuro de metilo y que los no tratados (ET2 y ET1). Sobre todo si se tiene en cuenta que la "roya de las raíces" del apio causada por Fusarium oxysporum, y considerada un fenómeno de fatiga del suelo, se resuelve mejor con un tratamiento de enmienda a base de materia orgánica que desinfectando con bromuro de metilo (Messiaen et al., 1991).

Si consideramos que cuanto más completa es la fracción biológica del suelo (ET1) mayor es la producción del apio y mayor la fatiga específica para el pimiento, y si suponemos que las desinfecciones ensayadas producen diferentes grados de eliminación de la microbiota telúrica, como indican Martínez et al., (2009), podríamos decir que las plantas de apio estarían indicando que la biosolarización elimina una parte de la microbiota que no elimina el testigo o el tratamiento con bromuro de metilo.

Por otro lado estaría indicando como la biosolarización puede tener un efecto contrario al esperado en lo concerniente al vigor (peso y altura de las plantas) sugiriendo un proceso de desinfección semejante al proporcionado por el bromuro de metilo o el vapor de agua.

En conclusión, las muestras recogidas en el invernadero E 2 corroboran la especificidad de la fatiga para el pimiento, al tiempo que vuelven a confirmar la ausencia en las raíces de cualquier signo de parasitismo.

Los ensayos para evaluar la especificidad de la fatiga del suelo utilizando lechuga y aprovechando las indicaciones dadas por el apio, se realizaron sobre las muestras de suelo del invernadero E 2.

Las Figuras 25, 26 y la Foto 8 resumen los resultados. Resultados que permiten reiterar nuevamente, cómo las muestras no tratadas proporcionan un mejor peso y altura de plantas exceptuando, por igualar los resultados, las desinfectadas con bromuro de metilo, difiriendo así de los resultados obtenidos para los invernaderos de los agricultores (Figuras 13 y 14). Pese a ello, son indicadores válidos para la medición de la especificidad de la fatiga de los suelos. 


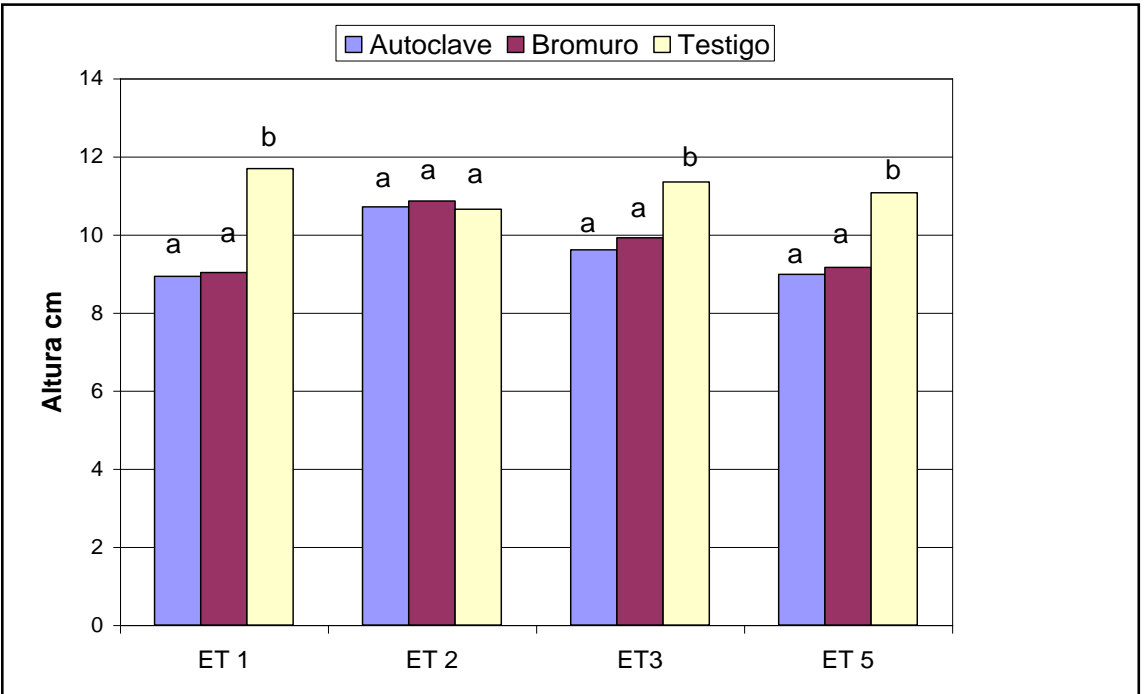

Las magnitudes de las barras con la misma letra en cada trat amiento no son significativamente diferentes $(\mathrm{P}>0.05)$

Figura 25. A ltura de las plantas de lechuga sobre fracciones de suelos desinfectados en laboratorio en autoclave, con bromuro de metilo y no desinfectadas (testigo). Invernadero E 2. Tratamientos ET1: suelo no desinfectado; ET2: suelo desinfectado con bromuro de metilo; ET3: biosolarizado 2 años; ET5: biosolarizado 4 años.

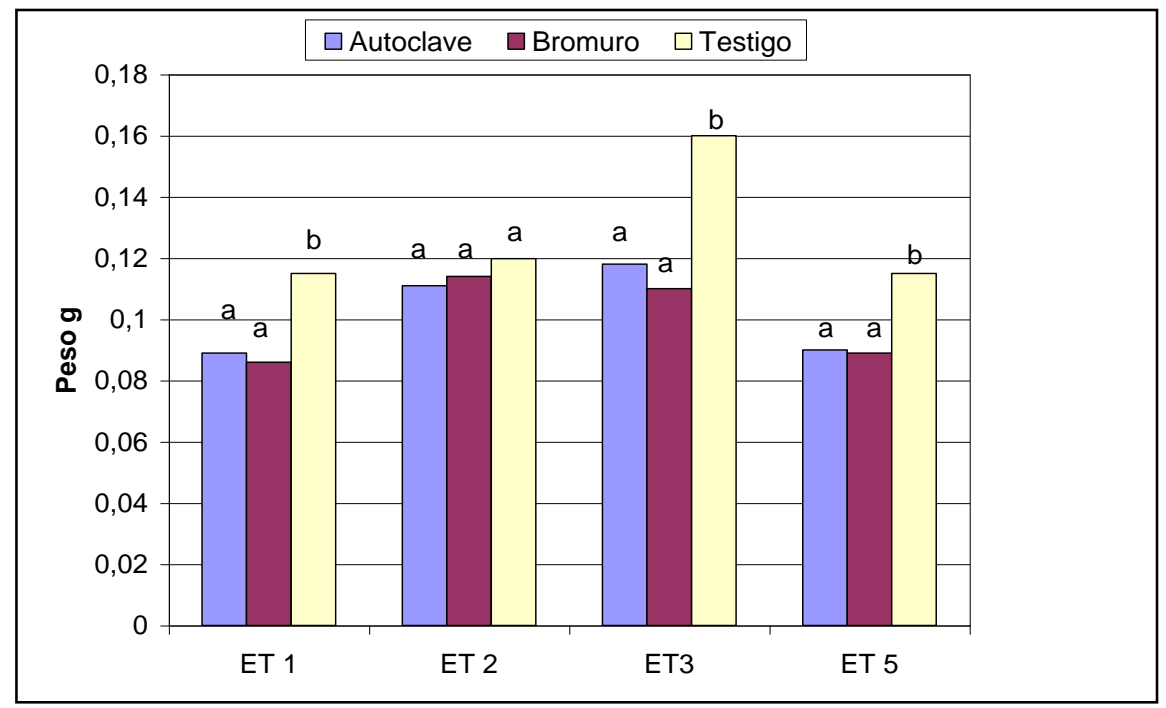

Las magnitudes de las barras con la misma letra en cada trat amiento no son significativamente diferentes $(\mathrm{P}>0.05)$

Figura 26. Peso seco de las plantas de lechuga sobre fracciones de suelos desinfectados en el laboratorio en autoclave, con bromuro de metilo y no desinfectadas (testigo). Invernadero E 2. Tratamientos ET1: suelo no desinfectado; ET2: suelo desinfectado con bromuro de metilo; ET3: biosolarizado 2 años; ET5: biosolarizado 4 años. 


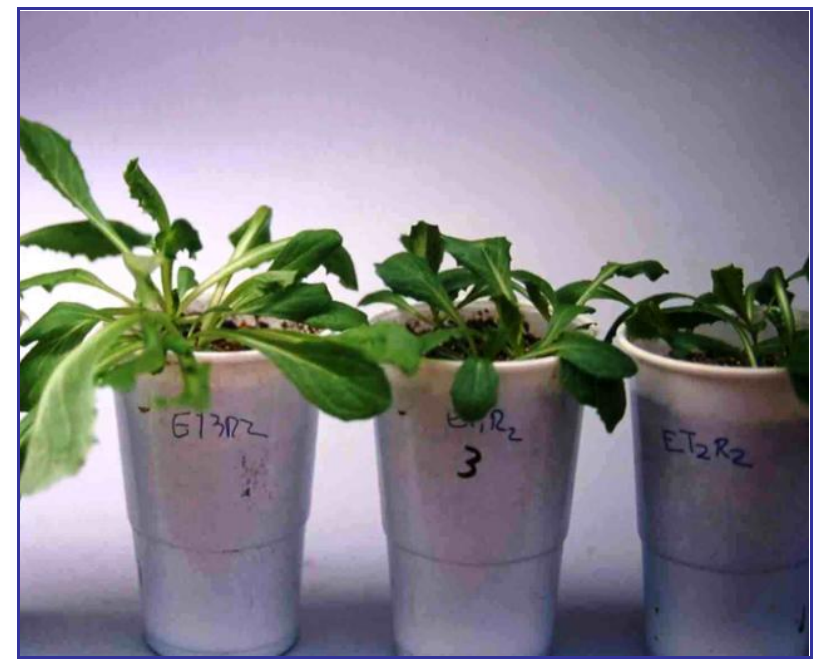

Foto 8. Plantas de lechuga sobre suelo, de izquierda a derecha: sin desinfectar, desinfectado con bromuro de metilo y en autoclave. Invernadero E.

Dos observaciones más parecen pertinentes. Por un lado, como se detectó con los ensayos de fatiga con pimiento y en los ensayos con apio, estos suelos tienen un comportamiento diferente. Observando la muestra ET1 que no había recibido ningún tratamiento de desinfección en los tres años anteriores, vemos que da una respuesta equiparable a los tratados con diferentes procedimientos de desinfección (ET2, ET3 y ET5). Este hecho pone en evidencia, cómo se ha sugerido anteriormente, que el problema de fatiga puede estar supeditado a cada tipo de suelo y a su historia.

La segunda observación es que la planta indicadora puede dar lugar a respuestas diferenciales importantes, influyendo como tal el detectar el fenómeno de fatiga y evaluar su importancia. Comparando visualmente las Figuras 23 y 24 con las Figuras 25 y 26 las disidencias más manifiestas ocurren para las muestras ET3 y ET5. La lechuga se desarrolla más y mejor que el apio y las diferencias son menores entre muestras. Estas observaciones corroboran las presentadas por Bouhot et al. (1979c) que obtienen diferente expresión de la fatiga con apio en comparación con perejil y escarola, especies a las que excluyen de sus experimentaciones.

Esta segunda parte realizada sobre muestras de suelo procedentes de un invernadero experimental con cuatro años de monocultivo de pimiento y con diferentes tratamientos de desinfección, incluyendo la solarización con materia orgánica, sugiere que:

1- La fatiga del suelo existe aunque sea menor la reiteración en el tiempo del monocultivo. El fenómeno se expresa con menor intensidad en el invernadero experimental que en algunos invernaderos de los agricultores. Esto parece sugerir que cada tipo de suelo y el manejo del monocultivo pueden tener una dimensión diferente de la fatiga.

2- La fatiga se manifiesta como específica para el pimiento. La utilización de lechuga y apio como plantas indicadoras pone en evidencia el desarrollo más 
vigoroso de estas especies en muestras de suelos no desinfectados que en las tratadas.

3- La desaparición del efecto fatiga con las desinfecciones practicadas parece sugerir que tiene un origen microbioló gico. Pese a esta evidencia, en los ensayos no se han encontrado signos visuales del parasitismo en las raíces. Sin embargo, no es posible excluir la acción de micotoxinas y este aspecto debería ser investigado en el futuro. Tampoco parece razonable descartar la posible acción de sustancias alelopáticas, emitidas por el propio pimiento, y cuya actividad fuese desnaturalizada por los tratamientos de desinfección ensayados.

4- Los efectos de la fatiga son anulados tanto por la desinfección química (bromuro de metilo) como por la biosolarización (materia orgánica fresca+solarización). No se han encontrado evidencias sobre que la materia orgánica tenga un papel diferente sobre la neutralización de la fatiga que el que se obtiene con la desinfección química. Sin embargo, el cambio de las condiciones físico-químicas del suelo biosolarizado es manifiesto y su valor agronómico deberá ser evaluado.

5- El "método sintético" utilizado para evaluar la fatiga ha tenido una correspondencia con lo que ocurre en el invernadero. Este aspecto tiene un gran interés puesto que uno de los valores de estos trabajos es que se ajusten a la realidad existente en el invernadero.

\subsection{CONCLUSIONES}

- El método experimental utilizado y los parámetros medidos para evaluar el efecto de la fatiga parecen adecuados para los suelos de los invernaderos de pimiento del Campo de Cartagena.

- La componente microbiológica parece ser la responsable de la depresión vegetativa de las plantas y de la reducción de la producción de pimiento observada en la mayor parte de los invernaderos en los que se reitera el monocultivo.

- La mejora de las características físicas del suelo por el aporte de materia orgánica durante el proceso de desinfección por biosolarización podría explicar el efecto de reducción de fatiga en algunos invernaderos.

- La fatiga se muestra específica para el pimiento, por lo que la rotación cultural con otras especies podría paliar sus efectos. 


\subsection{BIBLIOGRAFÍA}

Barnes JP, Putnam AR. 1983. Rye residues contribute to weed suppression in no-tillaje cropping systems. J Chem Ecol 9: 1045-1057.

Barnes JP, Putnam AR. 1987. Role of benzoxazinones in allelopathy by rye (Secale cereale L.). J Chem Ecol 13: 889-906

Bodet JM. 1983. Fatigue des sols et cultures céréalières et fourragères. In: La fatigue des sols. Diagnostic de la fertilité dans les systèmes culturaux. Ed: INRA Paris. 37-43.

Bonnel L, Bouhot D. 1983. Quelques cas de fatigue des sols en culture de céleri. In: La fatigue des sols. Diagnostic de la fertilité dans les systèmes culturaux. Ed: INRA Paris. 83-84.

Bouhot D, Villemin M, Willerval A. 1979a. La fatigue des sols. P. H. M. Revue Horticole 198: 35-39.

Bouhot D, Villemin M, Willerval A. 1979b. La fatigue des sols. P. H. M. Revue Horticole 199: 27-32.

Bouhot D. 1979c Un test biologique à deux niveaux pour l'etude des fatigues du sol. Ann Phytopathol 11: 95-115

Bouhot D. 1983a. La fatigue des sols. Position du probléme et principe du diagnostic. In: La fatigue des sols. Diagnostic de la fertilité dans les systèmes culturaux. Ed: INRA Paris. 9-21.

Bouhot D. 1983b. Étude de la fatigue des sols dans les aspergerais et les pépinières d'asperge. In: La fatigue des sols. Diagnostic de la fertilité dans les systèmes culturaux. Ed: INRA Paris. 61-64.

Bouhot D, Bonnel L. 1983. État actuel des travaux sur la fatigue des sols en culture de fraisier. In: La fatigue des sols. Diagnostic de la fertilité dans les systèmes culturaux. Ed: INRA Paris. 71-75.

Bouhot D, Dumas Y. 1983. Fatigue des sols en culture de tomates de plein champ. In: La fatigue des sols. Diagnostic de la fertilité dans les systèmes culturaux. Ed: INRA Paris. $77-81$.

Cebolla V, Maroto JV. 2004. La desinfección como medio de control de la fatiga del suelo. Comunitat Valenciana Agraria. Revista d'Informació Técnica 26: 21-26.

Chiapusio G, Gallet C, Dobremez JF, Pellissier F. 2004. Compuestos alelopáticos: ¿Herbicidas del futuro? In Biopesticidas de origen vegetal. Ed: Mundi-Prensa. Madrid, 153-171. 
Cuadra C de la, Tello JC, Muzquiz M, Calvo R. 1992. Antifungal effect of quinolizidine alkaloides from Lupinus spp. In: Proc. 1 Conferènce Europèene sur les protegineux, Angers (France), 341-342.

Fernández P, Guerrero M, Ros C, Bello A, García A, Lacasa A. 2004. Efecto de la biofumigación+solarización sobre la características físicas y químicas de los suelos de pimiento del Sureste español. Actas de Horticultura 42: 6-12.

Fernández P, Guerrero MM, Martínez MA, Ros C, Lacasa A, Bello A. 2005. Effects of biofumigation plus solarization on soil fertility. Industrial crops and rural development. Proceedings of Annual Meeting of the Association for the Advancement of industrial crops, 17-21 September, Murcia Spain, 229-236.

Gindrat D, Varady C, Neury G. 1983. Le dépérissement de l'asperge en Suisse romande. In: La fatigue des sols. Diagnostic de la fertilité dans les systèmes culturaux. Ed: INRA Paris. 51-55.

Guerrero MM, Martínez MA, Lacasa A, Martínez MA, Guirao P, Barceló N, Oncina M, Ros C. 2002. Caracterización de la fatiga del suelo de invernaderos de pimiento del sureste peninsular. En XI Congreso Nacional de la Sociedad Española de Fitopatología, Almería, 14-18 octubre. Resúmenes, 131.

Guerrero MM, Lacasa A, Ros C, Martínez MA, López JA, Guirao P, Bello A, Torres J, Martínez MC, González A. 2004. La reiteración de la biofumigación con solarización en la desinfección de suelos de invernaderos de pimiento. En: Lacasa A, Guerrero MM, Oncina M, Mora JA, eds. Desinfección de suelos en invernaderos de pimiento. Publicaciones de la Consejería de Agricultura, Agua y Medio Ambiente. Región de Murcia. Jornadas 16: 239-258.

Guirao P, Guerrero MM, Ros C, Lacasa A, Beltrán C, Martínez MC, Torres J, Oncina M, Contreras J. 2004. La reducción de dosis del bromuro de metilo en el cultivo de pimiento y el calendario de retirada. En: Lacasa A, Guerrero MM, Oncina M, Mora JA, eds. Desinfección de suelos en invernaderos de pimiento. Publicaciones de la Consejería de Agricultura, Agua y Medio Ambiente. Región de Murcia. Jornadas 16: 61-78.

Hoestra H. 1983. La fatigue des sols en Hollande. In: La fatigue des sols. Diagnostic de la fertilité dans les systèmes culturaux. Ed: INRA Paris. 85-90.

Hoffman ML, Buxton IW, Weston LA. 1996. Using subirrigation to maintime soils moisture content in greenhouse experiments. Weed Sci 44:397-401.

Kloepper JW, Schroth M. 1978. Plant growth-promoting rhizobacteria on radishes. In: Proc. Fourth International Conference on Plant Pathogenic Bacteria. Angers (France), 879-882.

Kloepper JW, Schroth M, Miller T.1980. Effects of rhizosphere colonization by plant growth-promoting rhizobacteria on potato plant development and yield. Phytopathology 70: 1078-1082. 
Koitababashi R, Suzuki T, Kawazu T, Sakai A, Kuroiwa H, Kuroiwa T. 1998. 1,8-cineole inhibits root growth and DNA synthesis in the root apical meristem of Brassica campestris L. J Plant Res 110: 1-6.

Lacasa A, Guirao P, Guerrero MM, Ros C, Bello A, Bielza P, López JA. 1999. Alternatives to Methyl Bromide for sweeet pepper cultivation in platichouse in SouthEast Spain. $3^{\text {rd }}$ International Workshop "Alternatives to Methyl Bromide for the Southern European Countries", December, 7-10 Heraclion, Crete, Grecia. Proceedings, 41- 44.

Lacasa A, Guerrero MM, Ros C, Guirao P, Torres J, Bielza P, De Paco T, Contreras J, Molina R Torné M. 2002. Desinfección del suelo de invernadero de pimiento con dicloropropeno+cloropicrina (Telopic EC). Dosis de aplicación y efecto del plástico de sellado. Agrícola Vergel 245:256-266.

Llandó E. 1998. Relaciones químicas: Una revisión a las alelosubstancias vegetales. Ed: Oikos-Tau, Barcelona. 149 pp.

Louvet J. 1979. Maladies et fatigues de sol en cultures légumières. In: Les maladies des plantes. III ${ }^{\text {es }}$ Journées Françaises d'études et d'informations. Ed: ACTA. Paris, 67-73.

Macias FA, Simonet Am, Galindo JCG, Castellano D. 1999. Bioactive phenolis and polar compounds from Melilotus messanensis Phytochem 50:35-46.

Martínez MA, Guerrero MM, Martínez MC, Lacasa A, Barceló N, Yélamos J, Tello J. 2002. Estudios preliminares sobre la componente fúngica de la fatiga de suelos de invernaderos de pimiento. En: Actas del Congreso de la Sociedad Española de Agricultura Ecológica, Gijón 16-21 septiembre. Resúmenes: 134.

Martínez MA, Lacasa A, Tello J. 2009. Ecología de la microbiota fúngica de los suelos de los invernaderos de pimiento y su interés agronómico. Ministerio de Medio Ambiente, Medio Rural y Marino. Madrid, 374 pp.

Martínez MA, Martínez MC, Bielza P, Tello, J, Lacasa A. 2011. Effect of biofumigation wit manure amendments and repeated biosolarization on Fusarium density in pepper crops. Journal Indus trial Microbiology Biotechnology 38: 3-11.

Messiaen CM, Blancard D, Rousell F, Lafon R. 1991. Les maladies des plantes maraîchères. Ed: INRA. Paris.

Meynard JM, Bouhot D. 1983. Confrontation des résultats du diagnostic au champ et du test biologique de fatigue des sols. Cas du blé. In: La fatigue des sols. Diagnostic de la fertilité dans les systèmes culturaux. Ed: INRA Paris. 45-49.

Montoya JR, Gómez JM, Blanco R, Tello J. 2001. Estado sanitario de las semillas de plantas aromáticas cultivadas en Almería Boletín de Sanidad Vegetal Plagas 27:345-354.

Moreau B. 1983. La fatigue des sols dans les aspergerais en France. In: La fatigue des sols. Diagnostic de la fertilité dans les systèmes culturaux. Ed: INRA Paris. 57-60. 
Moreno A, Alférez A, Avilés M, Diánez F., Blanco R, Santos M, Tello JC. 2001. First Report of Fusarium oxysporum fsp. radicis-cucumerinum on cucumber in Spain. Plant Disease 85: 1206.

Richard-Molard M. 1983. La fatigue des terres à betteraves. In: La fatigue des sols. Diagnostic de la fertilité dans les systèmes culturaux. Ed: INRA Paris. 23-28.

Roudeillac P. 1983. Les dépérissements du fraisier et la fatigue de sol. In: La fatigue des sols. Diagnostic de la fertilité dans les systèmes culturaux. Ed: INRA Paris. 65-70.

Scotto La Massesse C. 1983. Mesures susceptibles d'apprécier et de limiter les effets de la fatigue des sols dans le cas de reconstitution des vergers. In: La fatigue des sols. Diagnostic de la fertilité dans les systèmes culturaux. Ed: INRA Paris. 99-111.

Sebillotte M. 1983. Potentialité du milieu et fatigue des sols. In: La fatigue des sols. Diagnostic de la fertilité dans les systèmes culturaux. Ed: INRA Paris, 115-122.

Stengel P, Monnier G. 1983. Critères d'évaluation des composantes physiques de la fertilité des sols; leur adaptation au diagnostic des cas de fatigue des sols. In: La fatigue des sols. Diagnostic de la fertilité dans les systèmes culturaux. Ed: INRA Paris. 121-130.

Tello JC. 1984. Enfermedades criptogámicas en hortalizas. Comunicaciones INIA. Serie Protección Vegetal, n²2, 342 pp.

Tello JC, Lacasa A, Molina R. 1985a. Una nota fitopatológica sobre el "Complejo parasitario" del pie de la judia (Phaseolus vulgaris L.) ITEA 61:57-69

Tello JC, González ML, Lacasa A. 1985b. The "Fusariosis" (Diseases produced by Fusarium spp) of asparagus in Spain. Proc. Sixth Int. Asparagus Symposium. Eucarpia. Vegetable Section, 126-135 pp

Tello JC, Lacasa A, Varés F, Mijares A. 1987. Alteraciones radiculares en pimientos y habas de origen no parasitario. Cuadernos de Fitopatología 10:38-41.

Tello JC, Lacasa A. 1990 Fusarium oxysporum en los cultivos intensivos del litoral mediterráneo de España. Fases parasitaria (Fusariosis vascular del tomate y del clavel) y no parasitaria. Boletín de Sanidad Vegetal Plagas 19: 190 pp.

Tello J, Bello A. 1995. El suelo como ente vivo. La rizosfera, los hongos y los nematodos fitopatógenos en la "memoria del suelo". In: Prácticas ecológicas para una agricultura de calidad. Actas del I Congreso de la Sociedad Española de Agricultura Ecológica (SEAE), 506-510 pp.

Tello JC, Varés F, Notario A, Lacasa A, 1997. Las micorrizas: un potencial a explotar en la lucha contra las enfermedades de las plantas. ITEA 73:40-64.

Tello J, Lacasa A. 2004. Las enfermedades de origen edáfico y su control en los pimentonares del Campo de Cartagena. Una interpretación retrospectiva del sexenio 1979-1985. En: Lacasa A, Guerrero MM, Oncina M, Mora JA, eds. Desinfección de 
suelos en invernaderos de pimiento. Publicaciones de la Consejería de Agricultura, Agua y Medio Ambiente. Región de Murcia. Jornadas 16:11-26.

Walker J. 1975. Patología Vegetal. Ed.: Omega. Barcelona.

Wilhelm S, Paulus AO. 1980. How soils fumigation benefits the California strawberry industry. Plant Disease 64: 265-270.

Yélamos JA, Castillo P, Diánez, F, Villaescusa J, Santos M, Chebâani M, Blanco R, Lacasa A, Tello J. 2002. Efectos del bromuro de metilo y la biosolarización sobre la microbiota fúngica, actinomicética y bacteriana de suelos cultivados con pimiento en Murcia. En: Actas del V Congreso de la SEAE, Gijón 16-21 septiembre. Resúmenes: 1023-1026. 



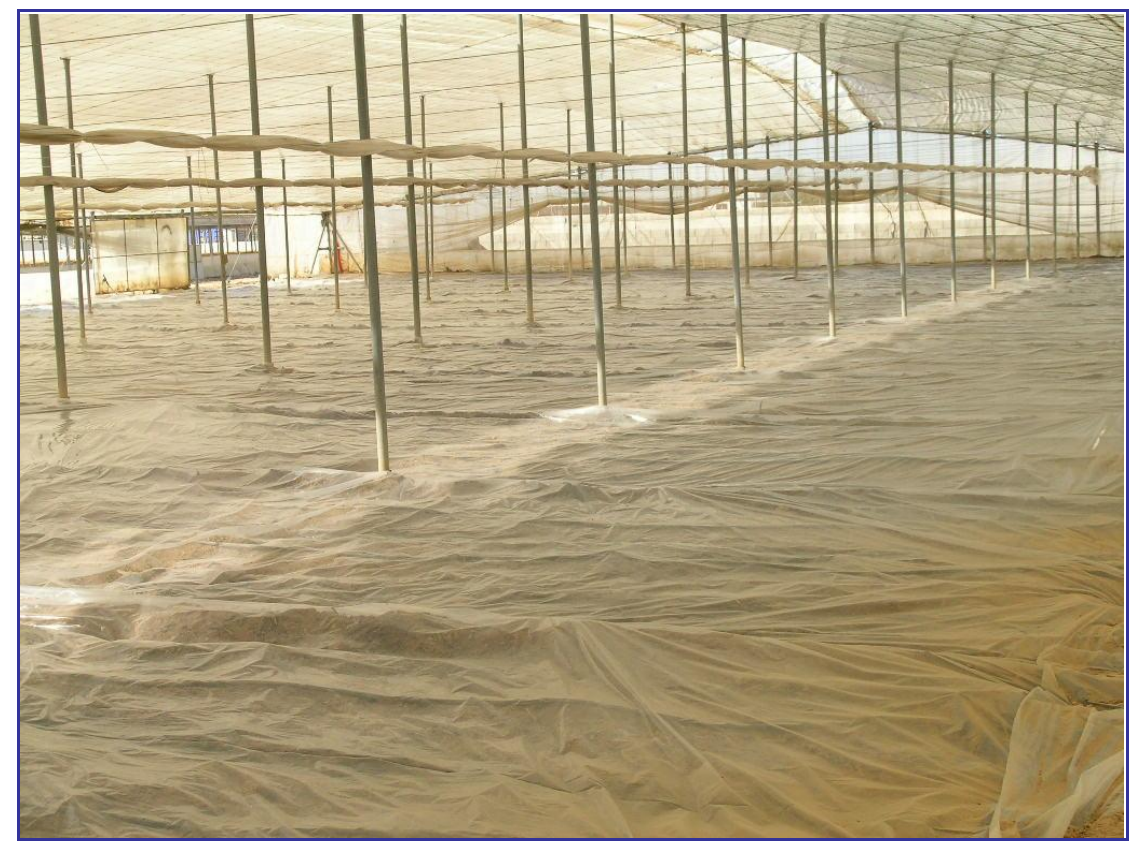

\title{
CAPÍTULO V
}

\author{
BIOSOLARIZACIÓN PARA LA \\ DESINFECCIÓN DE LOS SUELOS DE \\ LOS INVERNADEROS DEL CAMPO DE \\ CARTAGENA
}





\section{BIOSOLARIZACIÓN PARA LA DESINFECCIÓN DE LOS SUELOS DE LOS INVERNADEROS DE PIMIENTO DEL CAMPO DE CART AGENA}

\subsection{ANTECEDENTES E INTRODUCCIÓN}

\subsubsection{Biosolarización, biodesinfección}

La biosolarización se puede definir como la combinación de la biofumigación y la solarización o como la solarización con la adición al suelo de restos orgánicos antes iniciarse el proceso hidrotérmico. En ese contexto ha sido definida y utilizada por Ros et al. (2008) para el control de pató genos del suelo en cultivos de pimiento en invernadero. La biofumigación se basa en los efectos de los gases de la biodescomposición de las enmiendas orgánicas y restos vegetales en el suelo (Bello et al., 1997), sobre los patógenos y fitoparásitos telúricos. Este método de actuación sobre el suelo se denominó, inicialmente, "biological fumigation" (Kirkegaard et al., 1993a) y posteriormente "biofumigation" (Kirkegaard et al., 1993b; Matthiessen y Kirkegaard, 2006; Agnus et al., 1994). Los autores señalaron más tarde que la biofumigación se refiere a la acción de las Brassicaceae, bien en rotación de cultivos o utilizadas como abonos verdes sobre los organismos fitoparásitos y patógenos que colonizan el suelo (Kirkegaard y Sarwar, 1998).

Los compuestos liberados en la descomposición de algunas brasicas tienen efectos insecticidas, fungicidas, nematicidas, bactericidas y herbicidas (Brown y Morra, 1997; Kirkegaard y Sawar, 1998). La eficacia desinfectante depende tanto de la especie de brasica como de las características físicas y químicas del suelo (Kirkegard, 2009) y del estado epidemiológico del organismo o la enfermedad a controlar (Motisi et al., 2010). También se han descrito efectos biofumigantes similares por la descomposición de vegetales de otras familias botánicas, de estiércoles de origen animal o urbano, de coproductos industriales, etc., tanto sólidos como líquidos (Bello et al., 2000, 2004; Piedra-Buena et al., 2007; Santos et al., 2008).

La solarización se define como el proceso hidrotermal que supone el calentamiento del suelo humedecido por la radiación incidente y los efectos que el calentamiento tiene sobre los organismos fitoparásitos y patógenos del suelo (Katan, 1981). El método se muestra muy dependiente de las condiciones climáticas (Chellemi et al., 1994; 1997) y su eficacia depende de la cantidad de radiación incidente y también de las características físicas y químicas del suelo, así como del estado evolutivo del organismo y de la situación epidemiológica de la enfermedad.

La combinación de la solarización con la biofumigación muestra efectos sinérgicos de los dos métodos aplicados por separado (Katan, 2005). Así, el sellado del suelo con el plástico durante el proceso de solarización no solo contribuye a calentar más el suelo sino que retiene los gases de la descomposición de los aportes orgánicos (Gamliel et al., 2000; Oka, 2010). Pero si el humedecimiento del suelo realizado para la solarización alcanza niveles de saturación, en el proceso de descomposición de la enmienda orgánica, además de los gases liberados se produce anaerobiosis que afecta a fitoparásitos y patógenos (Block et al., 2000). 
La anaerobiosis se acetúa cuando se utilizan plásticos impermeables a los gases (Virtually inpermeable film, VIF) para sellar el suelo. A esta forma de desinfección la denominaron Block et al., (2000) como "desinfección biológica de suelos" (biological soil disinfestation, BSD) y en los mismos términos se expresan Goud et al. (2004) y Messiha et al. (2007).

En el suelo sellado, humedecido y con enmiendas orgánicas en descomposición se producen procesos de reducción por lo que algunos autores como Yossen et al., (2008) han denominado al método de desinfección como "esterilización reductiva del suelo" (soil reductive sterilization SRS) o "desinfección reductiva del suelo" (reductive soil disinfestation, RSD) (Katase et al., 2009). Se trata en definitiva de poner un mayor énfasis en las condiciones de anaerobiosis como el mecanismo principal de actuación del método, identificándolo siempre como una forma de desinfección (Butler et al., 2012).

Los mecanismos que intervienen en la biodesinfección no se han puesto claramente de manifiesto, pero se han asociado a la generación de compuestos volátiles (ácidos acético, butírico, propiónico, etc.), a la falta de oxígeno, a la liberación de compuestos tóxicos como el amoníaco o el ácido nitroso (Tenuta y Lazarovits, 2002, 2004, Arriaga et al., 2011).

Coinciden la mayor parte de los autores en que el efecto de la materia orgánica (biofumigación) es mayor si se cubre el suelo con plástico y se humedece el suelo (solarización), y también coinciden en el amplio espectro de acción de este método de desinfección (Chellemi y Rosskopf, 2004; Wang y McSorley, 2008; Wang et al., 2006).

Dado que el efecto de la enmienda orgánica no se limita solo a la generación de compuestos que inciden sobre patógenos fúngicos o nematodos fitoparásitos (similar a otros compuestos químicos de la desinfección química), sino que aporta nutrientes al suelo, que son aprovechados por microorganismos saprofitos y por las plantas, el MBTOC (2007), en el informe del año 2006, propuso denominar "biodesinfección" ("biodisinfestation") a la combinación de la biofumigación y la solarización o a la solarización con enmiendas orgánicas, como método de desinfección del suelo.

Una parte de la microbiota que se ve favorecida por la incorporación de la materia orgánica y que sobrevive a la acción de la biodesinfección, puede actuar como antagonista de los patógenos o parásitos del suelo, favoreciendo la supresividad del suelo para la manifestación de las enfermedades o alteraciones que éstos producen en los cultivos. Bonanomi et al. (2010) recopilan la información sobre los efectos de las enmiendas orgánicas utilizadas como biofumigantes sobre los hongos y Oka (2010) sobre los nematodos, siendo la microbiota la componente principal de la supresividad.

Cualquiera de los términos vienen a reflejar el avance en el conocimiento de los mecanismos que intervienen en el proceso, para explicar los efectos que la integración práctica de los conceptos originarios de la solarización y la biofumigación ejercen sobre los parásitos y patógenos del suelo. Se podría decir que la biosolarización o biodesinfección es el inicio de la integración de métodos o técnicas para el manejo de las enfermedades producidas por organismos del suelo, inicialmente basada en hechos empíricos.

\subsubsection{Biosolarización en invernaderos de pimiento del Campo de Cartagena.}

\section{Ensayos preliminares}

Sobre la base de los estudios sobre solarización realizados en pimiento por Cenis (1986) y Cenis y Fuchs (1988) en el Campo de Cartagena, y la de las experiencias sobre biofumigación realizadas en otros países (Kirkegard et al., 1993 a,b; Agnus et al., 1994; 
Kirkegard y Sarwar, 1998, etc.) o la utilización de enmiendas orgánicas para el control de patógenos edáficos (Kim et al., 1996a, 1996b, etc.), en la campaña agrícola 19971998 se iniciaron los primeros ensayos de biofumigación+solarización en los invernaderos de pimiento del Campo de Cartagena, tratando de aunar las ventajas de ambas fomas de intervención sobre el suelo y de reducir sus deficiencias.

En los primeros ensayos se utilizó estiércol fresco de ovino mezclado con gallinaza (proporción 7:3) como enmienda biofumigante y se orientaron a:

a) Determinar la eficacia en el control de los patógenos principales (Phytophthora spp. y Meloidogyne incognita), de las malas hierbas, los efectos sobre el desarrollo de las plantas y sobre la producción, en diferentes fechas de iniciación de la desinfección (Lacasa et al., 1999, 2002, Bello et al., 2004): última semana de julio, última semana de agosto, primera semana de septiembre, primera semana de octubre y primera semana de noviembre (Guerrero et al., 2004 a)

b) La reducción de la cantidad de enmienda utilizada (desde $10 \mathrm{~kg} \mathrm{~m}^{-2}$ de la mezcla de estiércol fresco de ovino y gallinaza hasta $2,5 \mathrm{~kg} \mathrm{~m}^{-2}$ ) a medida que se reitera su aplicación en suelos con bajos contenidos en materia orgánica para ajustar las dosis a las exigencias medioambientales sobre el uso de estiércoles (Guerrero et $a l .$, 2004b).

c) La sustitución de la gallinaza por otras fuentes de materia orgánica rica en nitrógeno orgánico (harina de soja) o mineral (urea) (Guerrero et al., 2004 a).

d) Evaluar la estabilidad de la eficacia de la desinfección mediante biofumigación con solarización al reiterar su uso de forma continuada (Guerrero et al., 2004c).

e) La combinación de la biosolarización con el uso de microorganismos (control biológico) como diferentes especies de Bacillus (González et al., 2004) o con el injerto del pimiento (Ros et al., 2004).

f) Medir el efecto de la biosolarización sobre las características físicas (Fernández et al., 2004a 2004b, 2005), químicas (Fernández et al., 2004a), enzimáticas (Ros et al., 2008) y microbiológicas (Martínez, 2008; Martínez et al., 2005, 2006a, 2006b, 2009).

\section{a) Fechas de iniciación de la biosolarización}

Independientemente del ciclo de cultivo habitual, los primeros ensayos se plantearon para determinar las fechas más adecuadas, utilizando invernaderos de diferentes antigüedades del monocultivo, con los suelos contaminadas de Phytophthora spp. y/o Meloidogyne incognita.

En los meses de julio y agosto, cuando la temperatura del suelo puede alcanzar o superar $\operatorname{los} 40^{\circ} \mathrm{C}$, se obtienen resultados similares al bromuro de metilo en cuanto a la producción y el desarrollo de la planta (Lacasa et al., 1999), si el proceso se mantiene durante 6 semanas y el humedecimiento de suelo y sellado han sido adecuados. También los niveles de control de Phytophthora sp. son aceptables, al producirse la muerte de las pocas plantas afectadas ya al final del cultivo. Por encima de $40^{\circ} \mathrm{C}$ se produce una merma importante de la supervivencia de $P$. parasitica (Coelho et al., 1999). De igual forma, se reduce la incidencia de Meloidogyne incognita y el inicio de 
las infestaciones se retrasan en el tiempo en relación al testigo no desinfectado, pero el nivel de control no es del mismo orden que para Phytophthora sp. (Guerrero et al., 2004a). En el caso de Phytophthora sp. la densidad de inóculo se reduce tras la desinfección a niveles no detectables; sin embargo al final del cultivo vuelve a estar el hongo a niveles detectables (Guerrero et al., 2004 a).

Si la biosolarización se inicia a partir de la primera decena de septiembre la eficacia desinfectante no resulta satisfactoria, con pérdida de cosecha comercial en relación al bromuro de metilo y la incidencia de Meloidogyne sp. y Phytophthora spp. no son muy distintos al testigo no desinfectado. Por el contrario, si se inicia la desinfección en la primera decena de septiembre la producción comercial es similar a la del bromuro de metilo, aunque las plantas sean más bajas que las del bromuro y los daños del nematodo en las raíces sean menores que los del testigo (Guerrero et al., 2004a).

\section{b) Reducción de la do sis de estiércol y gallinaza y reiteración de la biosolarización}

Los suelos de la mayor parte de los invernaderos del Campo de Cartagena tienen bajos niveles de materia orgánica $(<1,5 \%)$, por lo que la transición de la desinfección química a la biosolarización requiere de la incorporación de cantidades de enmienda orgánica más elevadas de las habitualmente utilizadas por los agricultores en el abonado de fondo, antes de la plantación o antes de la desinfección química.

Los ensayos se plantearon de larga duración con aplicaciones sucesivas en las mismas parcelas elementales del invernadero experimental, iniciando la biosolarización en agosto todos los años y reduciendo la dosis de la mezcla de estiércol fresco de ovino y gallinaza desde $10 \mathrm{~kg} \mathrm{~m}^{-2}$ hasta $2,5 \mathrm{~kg} \mathrm{~m}^{-2}$ a los 3,4 y 5 años. Todos los años se mantuvo la proporción 7:3 entre el estiércol fresco de ovino y la gallinaza en cada dosis de la mezcla. La cantidad de convergencia equivale a la cantidad de nitrógeno autorizada para uso en zonas sensibles a la contaminacción por nitrógeno, como se ha calificado a la comarca del Campo de Cartagena.

El segundo año de reiteración, la eficacia desinfectante de la biosolarización fue similar a la del bromuro de metilo. Aunque el control de $M$. incognita fue inferior al del bromuro, la producción comercial y el desarrollo de las plantas fueron similares a las del desinfectante químico. Ya en el tercer año el nivel de control de $M$. incognita fue similar al del bromuro de metilo; las plantas fueron más altas y la cosecha comercial significativamente mayor (Guerrero et al., 2004b).

Los ensayos de aplicación reiterada en el mismo suelo pusieron de manifiesto que la biosolarización utilizando la mezcla de estiércol fresco de ovino y gallinaza e iniciada en agosto proporcionaba resultados estables, similares al bromuro de metilo, tanto en el control de los patógenos como en el desarrollo de las plantas y en la cosecha comercial (Guerrero et al., 2003, 2005).

\section{c) Enmiendas para la biosolarización}

Se trataba de sustituir la gallinaza como aporte de nitrógeno para conseguir una enmienda con una relación $\mathrm{C} / \mathrm{N}$ entre 8 y 14. Las posibles limitaciones de la gallinaza no valorizada, supondría un posible problema para la viabilidad del método.

La harina de soja, como complemento al estiércol fresco de ovino, proporcionó resultados similares al bromuro de metilo, tanto en el control de Phytophthora spp. y de $M$. incognita como en el desarrollo de las plantas y en la cosecha comercial, y mejores que la gallinaza y la urea (Guerrero et al., 2004 a). La importancia que cobró la harina 
de soja en el mercado internacional de piensos para la alimentación animal, poco después de realizar los ensayos, hizo que la posibilidad de utilización fuera mínima por el precio que alcanzaba la enmienda, pese a utilizarse a $0,5 \mathrm{~kg} \mathrm{~m}^{-2}$.

\section{d) Combinación de la biosolarización con estiércol+gallinaza y agentes de biocontrol}

Varias especies de bacterias del género Bacillus (B. amyloliquefaciens, B. pumilus, B. subtilis, solas o mezcladas) que actúan como promotores del crecimiento de las plantas (Kloepper, 1993) fueron evaluadas en suelos en que se inició la biosolarización con estiércol fresco de ovino en agosto, en invernaderos con diferentes antecedentes de monocultivo y patógenos del suelo.

Las rizobacterias no proporcionaron protección a las plantas inoculadas en la fase de semillero, ni frente a Phytophthora spp. ni frente a Meloidogyne sp., fueron mucho más pequeñas y produjeron mucho menos que las de los suelos desinfectados con bromuro de metilo, no diferenciándose de las del testigo no desinfectado (González et al., 2004).

Cuando las plantas rizobacteriadas se cultivaron en suelos desinfectados mediante biosolarización tardía (inicio posterior a la primera semana de septiembre) no mejoró los efectos de la biosolarización, siendo muy afectadas por Phytophthora spp. y Meloidogyne sp. y fueron tan altas como las del testigo no desinfectado y mucho más pequeñas que las del bromuro de metilo. Cuando las plantas rizobacteriadas se cultivaron en suelo biosolarizado en agosto se redujo la incidencia de Meloidogyne sp. en relación a la biosolarización sola, las plantas fueron tan altas como las cultivadas en suelo desinfectado con bromuro de metilo, pero la producción comercial fue inferior a la del bromuro de metilo (González et al., 2004).

El efecto estimulador del crecimiento por bacterias del género Bacillus, señalado por otros autores (Kloepper y Sehorth, 1978; Bakker y Schipper, 1987) se puso de manifiesto, en el pimiento (González et al., 2004). Sin embargo, no se observó ningún efecto protector frente a las acciones de los patógenos, ( $P$. capsici o M. incognita), como preconizan Nemec et al., (1996) para B. subtilis en pimiento frente a la podredumbre radicular producida por $P$. capsici, u otros autores (Hall et al., 1996; Bohme, 1999; Schipper et al., 1987; K loepper, 1993), en otros cultivos, frente a hongos del suelo y frente a nematodos agalladores. El posible efecto protector no se potenció cuando se combinó la rizobacterización con la biosolarización (González et al., 2004).

\section{e) Combinación de la biosolarización con estiércol+gallinaza y el injerto}

Los ensayos tenían por objetivo, por una parte, el complementar las deficiencias de la biosolarización en el control de Meloidogyne incognita con el injerto de las plantas en porta-injertos portadores de resistencias al nematodo (Ros et al., 2004) y por otra, el evitar el remonte de la resistencia a $M$. incognita que se produce cuando se cultivan de forma continuada plantas injertadas en porta-injertos portadores de determinados genes de resistencia (Ros et al., 2007, 2010).

El cultivo de plantas injertadas sobre porta-injertos portadores de genes de resistencia a $M$. incognita en suelos biosolarizados en agosto o en fechas posteriores, proporcionó un control eficiente del nematodo, y evitó el remonte de la resistencia al repetir la estrategia en el mismo invernadero durante varios años (Ros et al., 2007, 2011). Sin embargo, cuando se combinó el injerto con la solarización la eficacia en el control del nematodo fue muy inferior y los porta-injertos portadores del gen $\mathrm{Me} 7 \mathrm{de}$ resitencia a $M$. incognita se infestaron, al ser remontada la resitencia (Ros et al., 2011). 
La biosolarización redujo las poblaciones de $M$. incognita en preplantación lo suficiente como para preservar la resistencia, manteniendo niveles de producción similares o superiores al de las plantas sin injertar cultivadas en suelo desinfectado con bromuro de metilo.

\section{f) Efecto sobre las características físicas y químicas del suelo}

El aporte de materia orgánica, necesaria para la biosolarización supone una mejora en las características físicas, químicas y biológicas del suelo.

Utilizando una mezcla de estiércol fresco de ovino y gallinaza, en la proporción 7:3, se aumentó la velocidad de infiltración del agua en el suelo y se produjo una disminución de la densidad aparente del suelo en los primeros $10 \mathrm{~cm}$ de profundidad (Fernández et al., 2004a, 2004b). Al reiterar la aplicación de la biosolarización con la misma enmienda que en el caso anterior, la velocidad de infiltración aumentó y la densidad aparente disminuyó hasta una profundidad de $15 \mathrm{~cm}$ (Fernández et al., 2005).

El contenido en materia orgánica aumentó con la biosolarización de forma notable hasta alcanzar niveles de $3 \%$ en el segundo año de reiteración de la desinfección, manteniéndose a ese nivel en los años siguientes, pese al importante aporte. Los niveles de potasio, fosforo, nitrógeno, al igual que algunos micronutrientes como el hierro, zinc, cobre, etc., y la capacidad de intercambio catiónico también aumentaron en las mismas circunstancias de los ensayos en que se midieron los efectos sobre las características físicas (Fernández et al., 2004a, 2005; Pascual et al., 2004), manteniéndose el $\mathrm{pH}$.

Una parte de la actividad enzimática disminuye tras la biosolarización con estiércol fresco de ovino y gallinaza, pero se recupera tras el desarrollo del cultivo, no detectándose efectos fitotóxicos (Ros et al., 2008).

El efecto sobre la microbiota fúngica se evaluó en suelos biosolarizados con estiércol fresco de ovino y gallinaza, tras varios años de reiteración en el mismo invernadero. Los efectos sobre la flora fúngica total y sobre la flora fusárica resultó menos agresiva que la del bromuro de metilo, incluso el quinto año de repetición en el mismo suelo (Martínez et al., 2005, 2006b). La recuperación de las densidades de inóculo en los suelos biosolarizados presentan una dinámica muy diferente a la que se presenta en los suelos desinfectados con bromuro de metilo, de forma que la recolonización del suelo es menos rápida y no se alcanzan niveles tan altos al final del cultivo como en el bromuro de metilo (Martínez 2008; Martínez et al., 2009). La dinámica indicada explica que el efecto de la biosolarización sobre la fatiga del suelo sea similar al del bromuro de metilo, sin embargo, con el transcurso del tiempo y al reiterar la aplicación en el mismo suelo, la reducción de los efectos de la fatiga sobre el desarrollo de las plantas y sobre la producción hace que trasciendan al año siguiente (Martínez 2008; Martínez et al., 2009).

\subsubsection{La metodología del proceso de biosolarización}

No se tenían antecedentes del empleo de la biofumigación y la solarización utilizando estiércoles frescos de origen animal para la desinfección de suelos de invernaderos para cultivo de pimiento, cuando se iniciaron los ensayos en el Campo de Cartagena. Tomando como referencias otros cultivos y enmiendas orgánicas se desarrolló una metodología o protocolo adaptado a las circustancias de los cultivos e insumos de la comarca, con el fin de que sirviera de modelo orientativo para los agricultores a la hora de aplicar la biosolarización en sus invernaderos. El protocolo se 
describe de forma resumida en el trabajo de Guerrero et al. (2004a) y que consta de los siguientes pasos o fases:

\section{Los restos del cultivo precedente y preparación del suelo}

La gestión de los restos del cultivo de pimiento precedente genera no pocos inconvenientes medioambientales a los productores, por lo que es cada vez más frecuente el triturarlos y enterrarlos en el mismo invernadero, tanto si se efectúa desinfección mediante biosolarización como si es por medios químicos.

Después de retirar los hilos y perchas del entutorado y los ramales de riego, y antes de que las plantas se desequen, se trituran las plantas con un pase de fresadora a poca profundidad. Luego se dan pases cruzados de subsolador a una profundidad de 30 $40 \mathrm{~cm}$, para facilitar la percolación del agua en el cultivo siguiente.

\section{Enterrado de la enmienda (estiércol fresco de ovino y gallinaza)}

Sin que el suelo pierda el tempero, se esparce la enmienda orgánica sólida y se entierra con un pase de fresadora a $25-30 \mathrm{~cm}$ de profundidad, procurando que todo quede bien desmenuzado y lo más homogéneo y liso posible en la superficie.

\section{El humedecimiento del suelo y el sellado con plástico}

Si en el inicio el humedecimiento del suelo se realizaba con el riego por goteo, en la actualidad, son muchos los invernaderos que disponen de una instalación fija de riego por aspersión, colocado a la altura de los alambres de sujeción de los hilos para el entutorado de las plantas, a unos $2 \mathrm{~m}$ de altura.

En el caso de utilizar el sistema de riego por goteo, se extienden los ramales a la misma separación que se ponen para hacer el cultivo (1 m entre líneas). Se comprueba que los goteadores funcionan correctamente y se riega en esa postura durante el tiempo necesario (depende del tipo de suelo, de la humedad en el momento de iniciar el riego, de la distancia entre emisores, generalmente $0,40 \mathrm{~m}$, y del caudal de descarga de los goteadores: 3 a 41 hora $^{-1}$ ) para que la humedad del bulbo llegue a unos $30 \mathrm{~cm}$ y se solapen los bulbos en superficie. Luego se cambian de postura los ramales, poniéndolos a $1 \mathrm{~m}$ de separación entre las zonas ya regadas. Algunos invernaderos disponen de una instalación complementaria con igual número de ramales que la utilizada para el cultivo. En ese caso se extienden los ramales colocándolos a 0,50 m de separación, por lo que el riego se realiza al mismo tiempo, y así se puede cubrir antes el suelo con el plástico y realizar la colocación de forma más cómoda.

La forma de colocar el plástico depende de la forma de humedecer el suelo:

a) Si se realiza por aspersión, es preciso colocarlo en los bordes del perímetro del invernadero antes de iniciar la aspersión, enterrándolo y dejándolo plegado durante el humedecimiento. Varias horas después de detener el riego, se extienden los plásticos a lo largo del invernadero y se solapan las láminas en la línea de los postes, plegando los bordes de dos láminas contiguas y grapándolos, después de enroscarlos. Las grapas se deben poner cerca de los postes para evitar el escape de gases, el vapor de agua y el calor, y cogiendo dos o tres puntos entre postes, dependiendo de la distancia entre éstos. 
b) $\mathrm{Si}$ se humede el suelo mediante el riego por goteo con las mangueras a $1 \mathrm{~m}$ de separación, tras el riego en la primera postura, se cambian de postura y luego se extiende el plástico a lo largo del invernadero, se solapan las láminas contiguas y se grapan igual que en el caso anterior. Las láminas de los bordes se entierran en el surco que se habrá abierto antes de iniciar el riego. Después de colocar el plástico, se riega durante el tiempo necesario para que los búlbos se solapen a 25-30 cm de profundidad.

c) Si las mangueras del riego por goteo se colocan a $0,50 \mathrm{~m}$, después de comprobar su funcionamiento se coloca el plástico, que se entierra en los bordes y se grapa en los postes. A continuación se riega y conviene hacerlo en dos días, o bien consecutivos o bien mediando otro entre los dos, para facilitar la dispersión del agua, tanto en profundidad como en horizontal.

Si la enmienda a incorporar al suelo es líquida, se prepara el suelo mediante las labores de subsolador y fresadora, procurando que quede bien desmenuzado, y lisa la superficie, se extienden las mangueras, que han de estar a $0,50 \mathrm{~m}$, se coloca el plástico, se riega un día lo suficiente como para que el líquido a incorporar se pueda difundir con facilidad (aproximadamente la mitad del tiempo necesario para humedecer todo el suelo hasta unos $25-30 \mathrm{~cm}$ de profundidad). Al día siguiente se riega durante 30-60 minutos antes de incorporar la enmienda durante unos 60 a 90 minutos, luego se sigue regando durante el tiempo necesario para que los bulbos se solapen a una profundidad de 25-30 $\mathrm{cm}$.

El film de plástico habitualmente utilizado es de polietileno (PE) transparente de 0,04 o $0,05 \mathrm{~mm}$ de espesor.

\section{Duración de la solarización}

Depende de las condiciones climatológicas en las que se realice con el fin de acumular tiempo a temperaturas elevadas suficientes para afectar a los patógenos. Para fechas de inicio en agosto se recomienda un mínimo de 4 semanas, siendo 6 semanas las más indicadas para que los efectos sean consistentes.

Tras el levantamiento y retirada del plástico se opta, generalmente, por dar una labor de fresadora cuando la humedad del suelo lo permita, con el fin de dejar preparado el suelo para la plantación. Recientemente, se opta por no dar la labor de preparación del terreno después de la desinfección, plantando directamente, con lo que se evita la tarea de recogida de los goteadores y su posterior extensión después de la labor de fresadora, así como la labor de labrado. 

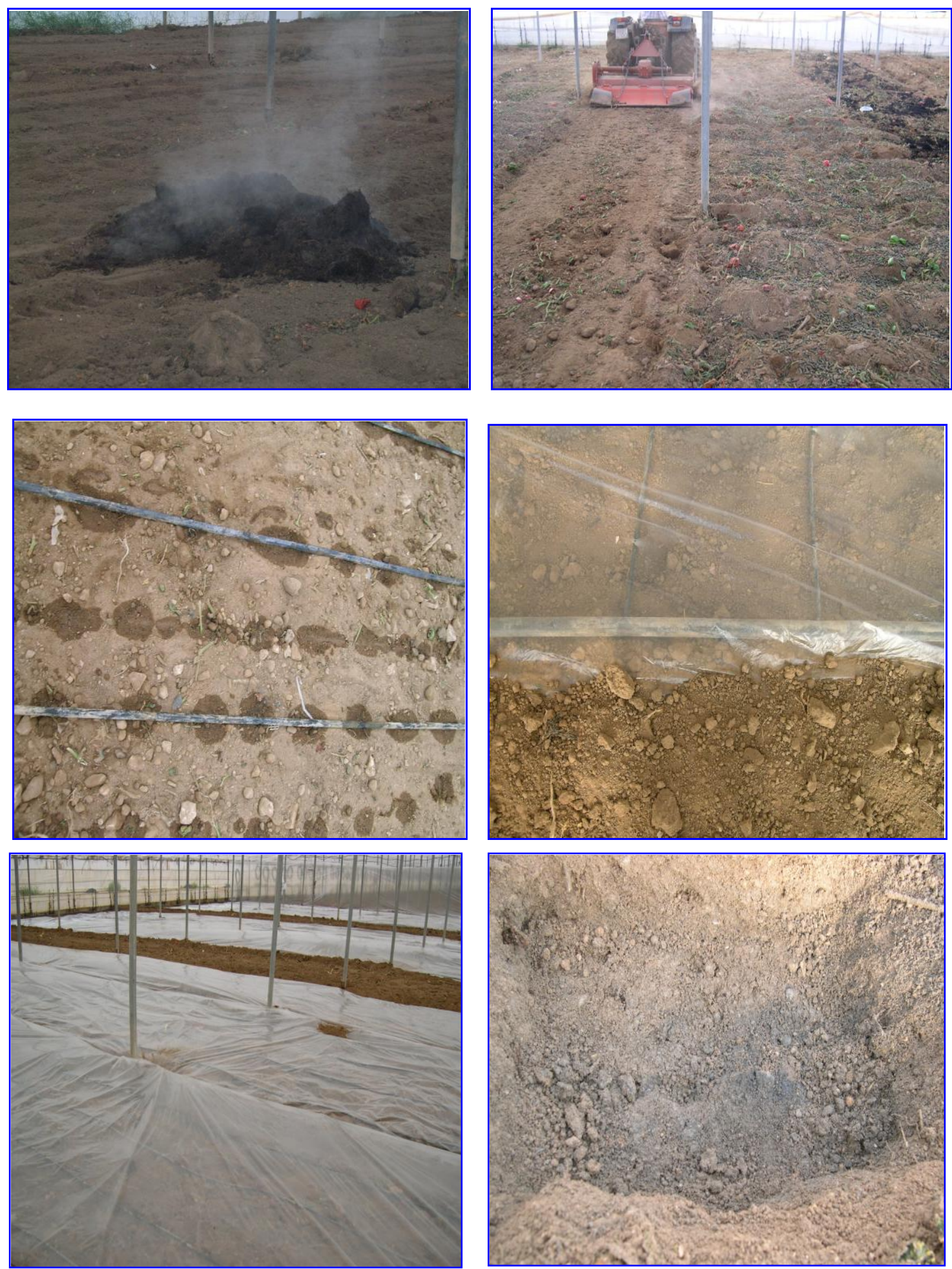

Figura 1. Fases de la realización de la biosolarización de izq. a derecha: Aplicación de materia or gánica, enterrado de enmiendas, comprobación del riego, sellado del plástico, riego, aspecto del suelo después de levantar el plástico. 


\subsection{OBJETIVOS DEL CAPÍTULO}

La biosolarización en las fechas adecuadas (inicio antes de la segunda semana de septiembre) y usando las enmiendas apropiadas (estiércoles frescos, por ejemplo), es un procedimiento eficaz de desinfección de suelos de los invernaderos para el cultivo de pimiento.

Este método fue asumido inicialmente por los agricultores productores de pimiento ecológico en el Campo de Cartagena, como método estable y sostenible, al no haberse detectado impactos negativos en el medio ambiente ni por lixiviados ni por repercusiones en las características físicas y químicas, ni sobre la biodiversidad.

Los productores de pimiento ecológico adaptaron el ciclo de cultivo en los invernaderos y las prácticas culturales para poder realizar la biosolarización en las fechas en que se ha mostrado eficaz.

A los productores convencionales de pimiento de invernadero, el adelanto del final del ciclo habitual del cultivo para iniciar la biosolarización en fechas adecuadas, les supone renunciar a una parte de la cosecha potencial, estimando la pérdida de producción en un $20 \%$, por lo que se han mostrado inicialmente reacios a su aplicación. Sin embargo, las circunstancias que han concurrido en las últimas campañas (bajos precios de la fruta, epidemias precoces de virosis, etc.) han hecho que los planteamientos cambiaran y, en las tres últimas anualidades, se ha experimentado un aumento progresivo de la superficie biosolarizada que alcanza a cerca del $45 \%$ de la superficie total de invernaderos destinados al cultivo de pimiento, una parte de ella en sistemas rotacionales con otras hortalizas.

La implementación de la biosolarización en la comarca del Campo de Cartagena para la desinfección de los suelos de los invernaderos es el objetivo principal de este capítulo, concretándose en:

a) Comprobar la estabilidad de la eficacia al reiterar su aplicación, al tiempo que se reduce la cantidad de la mezcla de estiércol fresco y gallinaza.

b) Elaboración de enmiendas con características específicas para su uso en agricultura ecológica y evaluación de su eficacia.

c) Estudiar la posibilidad de suprimir el plástico en invernaderos ecológicos, evaluando la eficacia de la biofumigación en relación a la biosolarización.

d) Nuevas enmiendas orgánicas que refuercen el efecto de los estiércoles para el control de los patógenos, en especial de Meloidogyne incognita.

e) Enmiendas orgánicas complementarias para aumentar la eficacia de la biosolarización iniciada en fechas compatibles con el ciclo habitual del cultivo, es decir posteriores a la primera decena de septiembre. 


\subsection{BIBLIOGRAFÍA}

Angus JF, Gardner PA, Kirkegaard JA, Desmarchelier JM. 1994. Biofumigation: isothiocyanates released from Brassica roots inhibit growth of the take-all fungus. Plant and Soil 162:107-112.

Arriaga H, Núñez-Zofio Larregla S, Merino P, 2011. Gaseous emissions from soil biodisinfestation by animal manure on a greenhouse pepper crop. Crop Protection 30: 412-419.

Bakker A, Schippers B. 1987. Microbial cyanide production in the rhizosphere in relation to potato yields reduction and Pseudomonas spp-mediated plant growthstimulation. Soil Biol Biochem 19: 451-457.

Bello A, Escuer, M, Sanz R, López-Pérez JA, Guirao P. 1997. Biofumigación, nematodos y bromuro de metilo en el cultivo de pimiento. En: López A, Mora JA, eds. Publicaciones de la Consejería de Medio Ambiente, Agricultura y Agua. Jornadas 11: 67-108.

Bello A, López-Pérez JA, Sanz R, Escuer M, Herrero J. 2000. Biofumigation and organic amendments. Regional Workshop on Methyl Bromide Alternatives for North Africa and Southern European Countries, United Nations Environment Programme (UNEP), Francia, 113-141.

Bello A, López-Pérez JA, García-Alvárez A, Arcos SC, Ros C, Guerrero MM, Guirao P, Lacasa A. 2004. Biofumigación con solarización para el control de los nematodos en cultivo de pimiento. En: Lacasa A, Guerrero MM, Oncina M, Mora JA, eds. Desinfección de suelos en invernaderos de pimiento. Publicaciones de la Consejería de Agricultura, Agua y Medio Ambiente. Región de Murcia. Jornadas 16: 129-207.

Blok WJ, Lamers JG, Termorshuizen AJ, Bollen GJ. 2000. Control of soilborne plant pathogens by incorporating fresh organic amendments followed by tarping. Phytopathol 90: 253-259.

Bohme M.1999. Effects of lactate, humate and Bacillus subtilis on the growth of tomato plants in hydroponic systems. Acta Horticulturae 481:231-239.

Bonanomi G, Antignani V, Capodilupo M, Scala F. 2010. Identifying the characteristics of organic soil amendments that suppress soilborne plant diseases. Soil Biology and Biochemistry 42: 136-144.

Brown PD, Morra MJ. 1997. Control of soil-borne plant pests using glucosinolate containing plants. Advances in Agronomy 61:167-231.

Butler DM, Rosskopf EN, Kokalis N, Burelle N, Albano JP, Muramoto J, and Shennan C. 2012. Exploring warm-season cover crops as carbon sources for anaerobic soil disinfestation (ASD). Plant Soil 335: 149-165. 
Cenis JL. 1986. Desarrollo de un enfoque cuantitativo de la solarización y aplicación al control del nematodo Meloidogyne javanica (Treub) Chit. Tesis doctoral ETSIA. Universidad Politécnica de Madrid, 372 pp.

Cenis JL, Fuchs P. 1988. Efecto comparado de la solarización y el metam sodio en un cultivo de pimiento en invernadero. Itea $75: 21-38$.

Coelho L, Chellemi DO., Mitchell DJ. 1999. Efficacy of soil solarization and cabbage amendment for the control of Phytophthora spp. in North Florida. Plant Disease 83: 293-299.

Chellemi DO, Olson SM, Mitchell DJ. 1994. Effect of soil solarization and fumigation on survival of soilborne pathogens of tomato in Northern Florida. Plant Disease 78: 1167-1172.

Chellemi DO, Olson SM, Mitchell DJ, Secker I, McSorley R. 1997. Adaption of soil solarization to the integrated management of soilborne pests of tomato under humid conditions. Phytopathol 87: 250-258.

Chellemi DO, Rosskopf E.N. 2004. Yield potential and soil quality under alternative crop production practices for fresh market pepper. Renew Agric Food Syst 19: 168-175.

Fernández P, Guirao P, Ros C, Guerrero MM, Quinto V, Lacasa A. 2004a. Efecto de la biofumigación con solarización sobre las características físicas y químicas del suelo. En: Lacasa A, Guerrero MM, Oncina M, Mora JA, eds. Desinfección de suelos en invernaderos de pimiento. Publicaciones de la Consejería de Agricultura, Agua y Medio Ambiente. Región de Murcia. Jornadas 16:259-277.

Fernández P, Guerrero MM, Ros C, Bello A, García A, Lacasa A. 2004b. Efecto de la biofumigación+solarización sobre la características físicas y químicas de los suelos de pimiento del Sureste español. Actas de Horticultura 42: 6-12.

Fernández P, Guerrero MM, Martínez MA, Ros C, Lacasa A, Bello A. 2005. Effects of biofumigation plus solarization on soil fertility. Industrial crops and rural development. Proceedings of Annual Meeting of the Association for the Advancement of industrial crops, 17-21 September, Murcia Spain: 229-236.

Gamliel A, Austerwell M, Kritzman G. 2000. Non-chemical approach to soilborne pest management -organic amendments. Crop Protection 19:847-853.

González A, Rodríguez R, Lacasa A, Ros C, Guerrero MM, Guirao P, Martínez MC, Beltrán C. 2004. La rizobacterización de plantas de pimiento. Comportamiento vegetativo y frente a patógenos del suelo. En: Lacasa A, Guerrero MM, Oncina M, Mora JA, eds. Desinfección de suelos en invernaderos de pimiento. Publicaciones de la Consejería de Agricultura, Agua y Medio Ambiente. Región de Murcia. Jornadas 16: 313-335.

Goud JKC, Termorshuizen AJ, Blok WJ, Van Bruggen AHC. 2004. Long-term effect of biological soil disinfestation on Verticillium wilt. Plant Dis 88:688-694. 
Guerrero MM, Lacasa A, Ros C, Martínez MA, Guirao P, Barceló N, Martínez MC, Bello A, Fernández P, Quinto V. 2003. Eficacia de la biofumigación con solarización reiterada en los suelos de invernaderos para el cultivo ecológico del pimiento. Actas de Horticultura 39: 31-32.

Guerrero MM, Lacasa A, Ros C, Bello A, Martínez M.C, Torres J, Fernández P. 2004a. Efecto de la biofumigación con solarización sobre los hongos del suelo y la producción: fechas de desinfección y enmiendas. En: Lacasa A, Guerrero MM, Oncina M, Mora JA, eds. Desinfección de suelos en invernaderos de pimiento. Publicaciones de la Consejería de Agricultura, Agua y Medio Ambiente. Región de Murcia. Jornadas 16: 209-238.

Guerrero MM, Lacasa A, Ros C, Martínez MA, López JA, Guirao P, Bello A, Torres J, Martínez MC, González A. 2004b. La reiteración de la biofumigación con solarización en la desinfección de suelos de invernaderos de pimiento. En: Lacasa A, Guerrero MM, Oncina M, Mora JA, eds. Desinfección de suelos en invernaderos de pimiento. Publicaciones de la Consejería de Agricultura, Agua y Medio Ambiente. Región de Murcia. Jornadas 16: 239-258.

Guerrero MM, Ros C, Martínez MA, Barceló N, Martínez MC, Guirao P, Bello A, Contreras J, Lacasa A. 2004c. Estabilidad en la eficacia desinfectante de la biofumigación con solarización en cultivos de pimiento. Actas de Horticultura 42: 2024.

Guerrero MM, Ros C, Martínez MA, Martínez MC, Barceló N, Lacasa A. 2005. Biofumigación con solarización. Un método estable de desinfección de suelos de invernadero. Actas Portuguesas de Horticultura 7 (3): 111-115.

Hall JA, Peirson D, Ghosh S, Glick BR. 1996. Root elongation in various agronomic crops by the plant growth promoting rhizobacterium Pseudomonas putida GR12-2. Israel Journal of Plant Sciences 44: 37-42.

Katan J. 1981. Solar heating (solarization) of soil for control of soilborne pests. Ann. Rev. 475 Phytopathol 19: 211-236.

Katan J. 2005. Soil disinfestation: One before Methyl Bromide phase out. Procedures of $\mathrm{VI}^{\text {th }}$ International Symposium on Chemical and Non-chemical Soil and Substrate Disinfestation. Acta Hortoculturae 698: 19-25.

Katase M, Kubo C, Ushio S, Ootsuka E, Takeuchi T, Mizukubo T. 2009. Nematicidal activity of volatile fatty acids generated from wheat bran in reductive soil disinfestation. Nematol Res 39: 53-62.

Kim KD, Nemec S, Musson G. 1996a. Control of Phytophthora stem rot of pepper with compost and soil amendment in the greenhouse. International Research Conference on Methyl Bromide, Alternatives and Emissions Reductions. Methyl Bromide Alternatives Outreach, US Dept.of Agriculture, Florida, US A 100, 1-3.

Kim KD, Nemec S, Musson G. 1996b. Effect of compost and soil amendments on soil microflora and Phytophthora stem rot of pepper. International Research Conference on Methyl Bromide, Alternatives and Emissions Reductions. Methyl Bromide Alternatives 
Outreach, US Dept.of Agriculture, Florida, US A 101, 1-3.

Kirkegaard JA, Gardner J, Desmarchelier JM, Angus JF. 1993a. Biofumigation using Brassica species to control pest and diseases in horticulture and agriculture, in: Wrather, N, Mailes RJ. (eds.), Proceedings of 9th Australian Research Assembly on Brassicas. Wagga Wagga (Australia), 5-7 October. Proceedings: 77-82.

Kirkegaard JA, Angus JF, Gardner PA, Cresswell HP. 1993b. Benefits of brassica break crops in the Southeast wheatbelt, en: 7th Australian Agronomy Conference. Adelaide, 19-24 September. Proceedings: 282-285.

Kirkegaard JA, Sawar M. 1998. Biofumigation potential of brassicas. I. Variation in glucosinolates profiles of diverse field-grown brassicas. Plant and Soil 201: 71-89.

Kirkegaard JA. 2009. Biofumigation for plant disease control - from the fundamentals tothe farming system, en: Walters, D. (Ed.), Disease Control in Crops: Biological and Environmentally Friendly Approaches. Wiley-Blackwell, Oxford (UK), 172-195.

Kloepper J, Schroth M. 1978. Plant growth-promoting rhizobacteria on radishes. In proceedings of the Fourth International Conference on Plant pathogenic Bacteria. Vol. 2. Station de Pathologie Végétale et Phytobactériologie, INRA Angers (Ed.) GilberClarey. Tours: 879-882.

Kloepper JW. 1993. Plant growth-promoting rhizobacteria as biological control agents. In Soil Microbial Ecology. F. Blaine Metting (Ed) NY. 255-274.

Lacasa A, Guirao P, Ros C, López-Pérez JÁ, Bello A, Bielza P. 1999. Alternatives to Methyl Bromide for sweet pepper cultivation in plastic greenhouses in South-east Spain. En Alternatives to Methyl Bromide for the Southern European Countries: 133135.

Lacasa A, Guerrero MM, Guirao P, Ros C. 2002. Alternatives to methyl bromide in sweet pepper crops in Spain. In: (Batchelor T, Bolivar JM, eds). Proceedings of International Conference on Alternatives to MB. The remaining challenges", European Commission, Sevilla, 5-8 marzo. Office for Official Publications of the European Communities, Luxembourg, 187-192.

Martínez MA, Guerrero MM, Ros C, Martínez MC, Lacasa A, Tello J. 2005. Effects of biofumigation plus solarization on crop microbiology. Industrial crops and rural development. Proceedings of Annual Meeting of the Association for the Advancement of industrial crops, 17-21 September, Murcia (Spain), 237-244.

Martínez MA, Lacasa A, Guerrero MM, Ros C, Martínez MC, Bielza P, Tello J. 2006a. Effect of soil disinfectation on fungi greenhouses planted with sweet peppers. Bulletin OILB/Crop 29 (4): 301-306.

Martínez MA, Guerrero MM, Martínez MC, Ros C, Lacasa A, Tello JC. 2006b. Efecto de la biosolarización reiterada sobre la microbiota fúngica en cultivos de pimiento. Actas del VII Congreso de la SEAE, 212: 1-10. 
Martínez M.A. 2008. La microbiota fúngica de los suelos de los invernaderos de pimiento. Tesis doctoral. Universidad Politécnica de Cartagena, 260 pp.

Martínez MA, Lacasa A, Tello J. 2009. Ecología de la microbiota fúngica de los suelos delos invernaderos de pimiento y su interés agronómico. Ministerio de Medio Ambiente, Medio Rural y Marino. Madrid, 374 pp.

Matthiessen JN, Kirkegaard A. 2006. Biofumigation and enhanced biodegradation: opportunity and challenge in soilborne pest and disease management. Critical Reviews in Plant Sciences 25: 235- 265.

MBTOC. 2007. Montreal Protocol on Substances that Deplete the Ozone Layer. 2006. In: Report of the Methyl Bromide Technical Options Committee United Nations Environment Programme. UNEP, 453 pp.

Messiha N, Van Diepeningen A, Wenneker M, Van Beuningen A, Janse J, Coenen T, Termorshuizen A, Van Bruggen A, Blok W. 2007. Biological soil disinfestation (BSD), a new control method for potato brown rot, caused by Ralstonia solanacearum race 3 biovar 2. Eur. J Plant Path 117: 403-415.

Motisi N, Doré T, Lucas P, Montfort F. 2010. Dealing with the variability in biofumigation efficacy through an epidemiological framework. Soil Biology and Biochemistry 42: 2044-2057.

Nemec S, Datnoff LE, Strandberg J. 1996. Efficacy of biocontrol agents in planting mixes to colonize plant root and control root diseases of vegetable and citrus. Crop Protection 15 (8): 735-742.

Oka Y. 2010. Mechanisms of nematode suppression by organic soil amendments: a review. Appl Soil Ecol 44: 101-115.

Pascual JA, Ros M, Fernandez P, Bernal A, Lacasa A. 2004. Future of compost as alternative to chemical compounds in ecological agricultura. In: Warte Management and environment II, (Popov V, Itoch H, Brebia CA and Kungolos S, eds.). WITPRESS, Southanton, Boston ISBN : 1-85312-738-8.

Piedra-Buena A, García-Álvarez A, Díez-Rojo MA, Ros C, Fernández P, Lacasa A, Bello A. 2007. Use of pepper crop residues for the control of root-knot nematodes. Bioresource Technology 98: 2846-2851.

Ros C, Guerrero MM, Martínez MA, Barceló N, Martínez MC, Guirao P, Bello A, Lacasa A. 2004. La combinación injerto y biofumigación en el control de Meloidogyne incognita en pimiento de invernadero. Actas de Horticultura 42:25-31.

Ros C, Martínez MA, Guerrero MM, Torres J, Lacasa CM, Lacasa A, Bello A. 2007. Comportamiento de la resistencia a Phytophthora y Meloidogyne de patrones de pimiento. Actas de Horticultura 48: 534-537.

Ros M, García C, Hernández MT, Lacasa A, Fernández P, Pascual JA. 2008. Effects of biosolarization as methyl bromide alternative for Meloidogyne incognita control on quality of soil under pepper. Biology and Fertility of Soils 45:37-44. 
Ros C, Martínez C, Guerrero MM, Lacasa CM, Martínez V, Cenis JL, Cano A, Bello A, Lacasa A. 2010. Response of rootstocks resistant pepper to Meloidogyne incognita populations in Greenhouses of Southeast Spanish. In Advances in genetics and breeding of Capsicum and Eggplant. (Prohems J and Rodriguez-Borruezo A, eds.). Editorial Universidad Politécnica de Valencia: 199- 209.

Ros C, Martínez C, Sánchez F, Lacasa CM, Guerrero MM, Lacasa A. 2011. Biosolarización and grafting as a way mitigate the selection of virulent populations of Meloidogyne incognita in pepper. IOBC-WPRS Bulletin 71:113-116

Santos M, Diánez F, de Cara M, Tello JC. 2008. Possibilities of the use of vinasses in the control of fungi phytopathogens. Bioresource Technology 99: 9040-9043.

Schippers B, Bakker A, Bakker PA. 1987. Interactions of deleteciones and beneficial rhizosphere microorganisms and the effect of cropping practices. Annu Rev Phytopathology $25: 339-358$.

Tenuta M, Lazarovits G. 2002. Ammonia and nitrous acid from nitrogenous amandements kill the microsclerotia of Verticillium dahliae. Phytopathol 92:255-264.

Tenuta M, Lazarovits G. 2004. Soil properties associated with the variable effectiveness of meat and bone meal to kill microsclerotia of Verticillium dahliae. Applied Soil Ecology 25: 219-236.

Wang K, McSorley R, Kokalis-Burelle N. 2006. Effects of cover cropping, solarization, and soil fumigation on nematode communities. Plant Soil 286: 229-243.

Wang KH, McSorley R. 2008. Exposure time to lethal temperatures for Meloidogyne incognita suppression and its implication for soil solarization. J Nematol40: 7-12.

YossenV, Zumelza G, Gasoni L, Kobayashi K. 2008. Effect of soil reductive sterilization on Fusarium wilt in greenhouse carnation in Cordoba, Argentina. Australasian Plant Pathol 37: 520-522. 


\title{
5.4 IMPLEMENTACIÓN DE LA BIOSOLARIZACIÓN EN PIMIENTO DE INVERNADERO. REITERACIÓN DE LA APLICACIÓN 7 AÑOS, CON REDUCCIÓN DE LA CANTIDAD DE ENMIENDA
}

\author{
EFICACIA DE LA BIOSOLARIZACIÓN COMO DESINFECTANTE DEL SUELO \\ EN INVERNADEROS DE PIMIENTO
}

Published in Actas de Horticutura 48: 451-454. 2007.

\section{Resumen}

La desinfección de los suelos de invernaderos de pimiento en el Campo de Cartagena y el Sur de Alicante se debe a la presencia de los patógenos M. incognita y Phytophthora capsici y a la fatiga del suelo acumulada por la reiteración del monocultivo. Se han planteado ensayos para evaluar la eficacia desinfectante de la biosolarización cuando se reitera en el mismo suelo durante varios años, a medida que se reduce la cantidad de materia orgánica en un invernadero contaminado del nematodo. El control del nematodo mejoró a medida que se reiteró la aplicación, siendo similar al bromuro de metilo a partir del segundo año, aunque los resultados se muestran variables de unos años a otros. Las mejoras también fueron notables en los niveles de producción siendo estables los efectos desinfectantes.

Palabras clave: Meloidogyne incognita, Phytophthora capsici, bromuro de metilo, fatiga del suelo

\section{Introducción}

La biofumigación con solarización (biosolarización (Reyes et al., 2004)) se considera un método de desinfección de suelos. La eficacia en el control de los patógenos presenta variaciones con la enmienda orgánica utilizada, con el patógeno, con la fecha de aplicación y con las características del suelo (Guerrero et al., 2004a).

En la región de Murcia, el pimiento es un monocultivo en más del 95\% de los invernaderos del Campo de Cartagena (Lacasa y Guirao, 1997), siendo Phytophthora y Meloidogyne los principales patógenos. Desde hace unos 20 años los suelos se desinfectan anualmente para el control de los patógenos y para paliar los efectos de la fatiga, producida por la reiteración del monocultivo.

La biosolarización es utilizada en los invernaderos con cultivo ecológico, obteniendo buenos resultados en el control de Phytophthora, cuando se inicia en el mes de agosto (Guerrero et al., 2004a). La eficacia se muestra variable en el control de $M$. incognita (Guerrero et al., 2003 y 2005), cuyos daños llegan a repercutir la producción.

Parece imprescindible conocer la persistencia en la eficacia de este método de desinfección, antes de considerar su uso de forma continuada como una solución a los problemas antes señalados. 


\section{Material y métodos}

En un invernadero experimental, de suelo franco-arcilloso, contaminado de $M$. incognita, donde se cultivaba pimiento desde hacía 5 años, se diseñó, en el verano de 1998, un ensayo de bloques al azar con tres repeticiones por tratamiento, parcelas elementales de $60 \mathrm{~m}^{2}$ (formada por tres filas de plantas al marco de 1,0 x 0,4 m), donde se ha reiterado la biosolarización en las mismas parcelas hasta un máximo de 7 años consecutivos, al tiempo que se reducía la cantidad de enmienda orgánica (una mezcla de estiércol fresco de oveja, EFO, y gallinaza, G), alcanzando un límite máximo en la quinta (Tabla 1). Como referencia se ha teniendo un testigo no desinfectado y suelo desinfectado con bromuro de metilo.

Tabla 1. Tratamientos ensayados en cada campaña y dosis de las enmiendas orgánicas utilizadas.

\begin{tabular}{|l|c|c|c|c|c|c|c|}
\hline Tratamientos & $1998-99$ & $1999-00$ & $2000-01$ & $2001-02$ & $2002-03$ & 2003-04 & 2004-05 \\
\hline BrMe, 30 & sí & sí & sí & sí & sí & sí & sí \\
\hline 1er año, 7+3 & sí & - & sí & - & sí & - & - \\
\hline 1er año, 6+2 & - & sí & - & - & - & - & - \\
\hline $2^{\circ}$ año, 5+2,5 & - & sí & sí & sí & - & sí & - \\
\hline 3er año, 4+2 & - & - & sí & sí & sí & - & sí \\
\hline $4^{\circ}$ año, 3+1,5 & - & - & - & sí & sí & sí & - \\
\hline $5^{\circ}$ año, 2+0,5 & - & - & - & - & sí & sí & sí \\
\hline $6^{\circ}$ año, 2+0,5 & - & - & - & - & - & sí & sí \\
\hline $7^{\circ}$ año, 2+0,5 & - & - & - & - & - & - & sí \\
\hline Testigo & sí & sí & sí & sí & - & sí & sí \\
\hline
\end{tabular}

El bromuro de metilo (98:2, Brom-o-Gas) se aplicó en fumigación en frío a la dosis de $30 \mathrm{~g} \mathrm{~m}^{-2}$ y plástico VIF (Virtually Impermeable Film) de 0,04 mm, en la primera semana de noviembre, todos los años.

En la campaña 1998-99 la biosolarización se inició en la primera semana de septiembre, haciéndolo en la tercera semana de agosto el resto de las campañas. El plástico se levantó en la última semana de octubre, todos los años. Se aplicó siguiendo el procedimiento indicado por Guerrero et al. (2004c).

La primera campaña de plantó la variedad Dallas, Lido la segunda y Ribera las siguientes. Se plantó en la primera semana de enero, todas las campañas, finalizando el cultivo en la primera semana de agosto. Las prácticas culturales fueron las habituales en la zona, para este ciclo de cultivo.

Para la evaluación comparativa se midieron los siguientes parámetros: a) Incidencia de Meloidogyne sp: al final del cultivo se arrancaron, al azar, 10 plantas en cada parcela elemental y se examinaron las raíces, anotando el número de plantas que presentaban nódulos y el índice de nodulación en cada una, de acuerdo a la escala de Bridge y Page (1980). b) La producción comercial y total: en cada recolección se clasificaron los frutos de cada fila según las categorías comerciales y se pesaron por separado.

La comparación entre tesis se ha realizado mediante un análisis de varianza (ANOVA, tratamientos y bloques) y el test LSD al 95\% para la comparación entre 
medias. Se han empleado para ello los datos transformados con $\operatorname{arcsen} \sqrt{x}$, cuando se trataba del porcentaje de plantas afectadas, la transformación $\log _{10}(x+1)$ en el caso del índice medio de nodulación y producciones.

\section{Resultados}

\section{Control de Meloidogyne}

Al final del cultivo de la campaña 1997-98 se detectó la presencia de Meloidogyne en el invernadero. En la primera campaña de reiteración de la biosolarización (99-00) la incidencia fue baja y la biosolarización proporcionó similares niveles de control que el BrMe (Tabla 2). En la siguiente campaña la incidencia del nematodo en la biosolarización reiterada 2 ó 3 años fue similar al BrMe, siendo menor en el caso de la aplicación por primera vez. La situación en el testigo, en el BrMe y en la biosolarización repetida 3 y 4 veces en la campaña 01-02 fue similar a la anterior, pero no para el segundo año de reiteración en que la severidad de los ataques fue mayor que en la homóloga de la campaña anterior. En las tres campañas siguientes (Tabla 3) la biosolarización reiterada mantuvo los niveles de control de las campañas precedentes en las parcelas de $3^{\circ}, 4^{\circ}, 5^{\circ}, 6^{\circ}$ y $7^{\circ}$ año, situándose en límites aceptables, aunque en algunas reiteraciones los niveles fueron superiores a los del bromuro BrMe. Los resultados parecen indicar que la tendencia es a disminuir la incidencia del nematodo con la reiteración, si bien se presentan resultados aleatorios en algunas campañas.

Tabla 2. Incidencia de Meloidogyne en los dife rentes tratamientos realizados en las tres campañas primeras, 1999-00 a 2001-02.

\begin{tabular}{|c|c|c|c|c|c|c|}
\hline \multirow[b]{2}{*}{ Tratamiento } & \multicolumn{2}{|c|}{ 1999-00 } & \multicolumn{2}{|c|}{ 2000-01 } & \multicolumn{2}{|c|}{ 2001-02 } \\
\hline & $\begin{array}{l}\text { Índice } \\
\text { medio }{ }^{\mathrm{a}}\end{array}$ & $\begin{array}{c}\text { Plantas con } \\
\text { nódulos }{ }^{\mathrm{b}}(\%)\end{array}$ & $\begin{array}{l}\text { Índice } \\
\text { med io }^{a}\end{array}$ & $\begin{array}{c}\text { Plantas con } \\
\text { nódulos }{ }^{b}(\%)\end{array}$ & $\begin{array}{l}\text { Índice } \\
\text { medio }{ }^{a}\end{array}$ & $\begin{array}{c}\text { Plantas con } \\
\text { nódulos }{ }^{\mathrm{b}}(\%)\end{array}$ \\
\hline Testigo & $1,16 \mathrm{~b}$ & $50,0 \mathrm{~b}$ & $6,78 \mathrm{c}$ & $100,0 \mathrm{~b}$ & $7,2 \mathrm{c}$ & $100 \mathrm{c}$ \\
\hline BrMe & $0,00 \mathrm{a}$ & $0,0 \mathrm{a}$ & $1,48 \mathrm{a}$ & $36,7 \mathrm{a}$ & $1,3 \mathrm{a}$ & $54,2 \mathrm{ab}$ \\
\hline Bios. 1er año & $0,28 \mathrm{a}$ & $11,1 \mathrm{ab}$ & $4,53 \mathrm{~b}$ & $90,0 \mathrm{~b}$ & -- & -- \\
\hline Bios. $2^{\circ}$ año & $0,18 \mathrm{a}$ & $12,8 \mathrm{ab}$ & $1,77 \mathrm{a}$ & $43,3 \mathrm{a}$ & $4,3 \mathrm{~b}$ & $87,5 b c$ \\
\hline Bios. 3er año & -- & -- & $1,30 \mathrm{a}$ & $40,0 \mathrm{a}$ & $1,4 \mathrm{a}$ & $33,3 a$ \\
\hline Bios. $4^{\circ}$ año & -- & -- & -- & -- & $1,6 \mathrm{a}$ & $54,2 \mathrm{ab}$ \\
\hline
\end{tabular}

${ }^{a}$ Test LSD al 95\% con datos transformados mediante Log10 $(x+1) .{ }^{b}$ Test LSD al 95\% con datos transformados mediante Arcsen $\sqrt{x}$. Las cifras con la misma letra en una misma columna no son diferentes $(P<0,05)$

\section{Efecto sobre la producción comercial}

Desde el segundo año de reiteración, la producción comercial final en los tratamientos de biosolarización fue similar o mayor que la del BrMe (Tablas 4 ) y mucho mayor que las del testigo. Los rendimientos productivos no aumentan a partir de la tercera campaña de reiteración de la biosolarización en el mismo suelo, como no lo hace, tampoco, cuando se desinfecta con bromuro de metilo en invernaderos comerciales. 
Tabla 3. Incidencia de Meloidogyne en los dife rentes tratamientos realizados en las tres últimas campañas 2002-03 a 2004-05.

\begin{tabular}{|c|c|c|c|c|c|c|}
\hline \multirow[b]{2}{*}{ Tratamiento } & \multicolumn{2}{|c|}{$2002-03$} & \multicolumn{2}{|c|}{ 2003-04 } & \multicolumn{2}{|c|}{ 2004-05 } \\
\hline & $\begin{array}{l}\text { Índice } \\
\text { med io }^{a}\end{array}$ & $\begin{array}{c}\text { Plantas con } \\
\text { nódulos }^{\mathrm{b}}(\%)\end{array}$ & $\begin{array}{l}\text { Índice } \\
\text { med io }{ }^{a}\end{array}$ & $\begin{array}{c}\text { Plantas con } \\
\text { nódulos }^{\mathrm{b}}(\%)\end{array}$ & $\begin{array}{l}\text { Índice } \\
\text { med io }^{a}\end{array}$ & $\begin{array}{l}\text { Plantas con } \\
\text { nódulos }^{\mathrm{b}}(\%)\end{array}$ \\
\hline Testigo & ne & ne & $3,8 \mathrm{c}$ & $66,7 \mathrm{c}$ & $3,97 \mathrm{~d}$ & $83,33 c$ \\
\hline $\mathrm{BrMe}$ & $0,00 \mathrm{a}$ & $0,00 \mathrm{a}$ & $0,0 \mathrm{a}$ & $0,0 \mathrm{a}$ & $0,20 \mathrm{a}$ & $6,60 \mathrm{a}$ \\
\hline Bios. 1er año & $2,40 b$ & $53,3 b$ & & & & \\
\hline Bios. $2^{\circ}$ año & & & $2,7 \mathrm{c}$ & $53,3 \mathrm{bc}$ & & \\
\hline Bios. 3er año & $1,93 b$ & $53,3 b$ & & & $2,33 \mathrm{c}$ & $73,33 \mathrm{c}$ \\
\hline Bios. $4^{\circ}$ año & $2,67 \mathrm{~b}$ & $66,6 \mathrm{~b}$ & $0,7 \mathrm{ab}$ & $20,0 \mathrm{~b}$ & & \\
\hline Bios. $5^{\circ}$ año & $1,80 \mathrm{~b}$ & $40,0 \mathrm{ab}$ & $1,0 \mathrm{~b}$ & $33,3 b$ & $0,67 a b$ & $13,33 a$ \\
\hline Bios. $6^{\circ}$ año & & & $0,3 \mathrm{a}$ & $13,3 \mathrm{ab}$ & $1,67 \mathrm{~b}$ & $40,00 \mathrm{~b}$ \\
\hline Bios. $7^{\circ}$ año & & & & & $0,13 a$ & $6,67 \mathrm{a}$ \\
\hline
\end{tabular}

${ }^{a}$ Test LSD al 95\% con datos transformados mediante $\log 10(\mathrm{x}+1) .{ }^{\mathrm{b}}$ Test LSD al 95\% con datos transformados mediante arcsen $\sqrt{x}_{\mathrm{x}}$. Las cifras con la misma letra en una misma columna no son diferentes $(\mathrm{P}<0,05)$.

Tabla 4. Producciones comerciales $\left(\mathrm{kg} \mathrm{m}^{-2}\right)$ en los tratamientos evaluados cada campaña.

\begin{tabular}{|c|c|c|c|c|c|c|}
\hline Tratamientos & $99-00$ & $00-01$ & $01-02$ & $02-03$ & 03-04 & $04-05$ \\
\hline Testigo & $7,7 \mathrm{~b}$ & $9,6 \mathrm{~b}$ & $7,0 \mathrm{c}$ & $8,6 \mathrm{~b}$ & $7,4 \mathrm{~b}$ & $6,3 \mathrm{~b}$ \\
\hline$\overline{\mathrm{BrMe}}$ & $9,1 \mathrm{a}$ & $11,0 \mathrm{a}$ & $8,2 \mathrm{~b}$ & $8,1 \mathrm{~b}$ & $8,7 \mathrm{a}$ & 5 \\
\hline Bios. 1er año & $8,3 \mathrm{a}$ & $10,0 \mathrm{~b}$ & ----- & $10,6 \mathrm{a}$ & $\begin{array}{l}---- \\
\end{array}$ & ----- \\
\hline Bios. $2^{\circ}$ año & $8,0 \mathrm{ab}$ & $11,1 \mathrm{a}$ & $10,1 \mathrm{a}$ & ----- & $8,7 \mathrm{a}$ & $\overline{-----}$ \\
\hline Bios. 3er año & & $11,1 \mathrm{a}$ & $9,3 \mathrm{a}$ & $10,4 \mathrm{a}$ & ----- & $8,7 \mathrm{a}$ \\
\hline Bios. $4^{\circ}$ año & & & $9,2 \mathrm{a}$ & $10,1 \mathrm{a}$ & $8,4 \mathrm{a}$ & --- \\
\hline Bios. $5^{\circ}$ año & & & & $10,6 \mathrm{a}$ & $9,2 \mathrm{a}$ & $9,2 \mathrm{a}$ \\
\hline${\text { Bios. } 6^{\circ} \text { año }}$ & & & & & $9,2 \mathrm{a}$ & $8,4 \mathrm{a}$ \\
\hline Bios. $7^{\circ}$ año & & & & & & $8,5 \mathrm{a}$ \\
\hline
\end{tabular}

Test LSD al 95\% con datos transformados mediante $\log _{10}(x+1)$. Las cifras con la misma letra en una misma columna no son diferentes $(\mathrm{P}<0,05)$.

\section{Conclusiones}

La eficacia de la biosolarización en el control de Meloidogyne incognita se mantiene a niveles aceptables al reiterar la aplicación en el mismo suelo. Aunque presenta algunas deficiencias en relación al bromuro de metilo, la tendencia es a la estabilidad con el tiempo. La biosolarización proporciona similares niveles de producción que el bromuro de metilo al reiterar la aplicación, sin que la reducción de la dosis de enmienda orgánica suponga pérdidas de eficacia desinfectante o de capacidad productiva.

En definitiva, la biosolarización se muestra como un método eficaz y estable de desinfección de los suelos de invernaderos de pimiento, que requeriría de su integración con otros métodos para cubrir sus deficiencias en el control de nematodos. 


\section{Agradecimientos}

Trabajo financiado INIA, proyectos: SC97-003-C05-03 y OT03-006-C07-04, así como del Programa de Colaboración de la Federación de Cooperativas Agrarias de Murcia y la Consejería de Agricultura y Agua de la Región de Murcia.

\section{Bibliografía}

Bridge J, Page SJ. 1980. Estimation of root-knot nematodes infestation levels on roots using a rating chart. Tropical Pest Management 26:296-298.

Guerrero MM, Lacasa A, Ros C, Martínez MA, Guirao P, Barceló N, Martínez MC, Bello A, Fernández P, Quinto V. 2003. Eficacia de la biofumigación con solarización reiterada en los suelos de invernaderos para cultivo ecológico de pimiento. Actas de Horticultura 39: 33-35.

Guerrero MM, Lacasa A, Ros C, Bello A, Martínez MC, Torres J, Fernández P. 2004a. Efecto de la biofumigación con solarización sobre los hongos del suelo y la producción: fechas de desinfección y enmiendas. En: Lacasa A, Guerrero MM, Oncina M, Mora JA, eds. Desinfección de suelos en invernaderos de pimiento. Publicaciones de la Consejería de Agricultura, Agua y Medio Ambiente. Región de Murcia. Jornadas 16: 209-238.

Guerrero MM, Ros C, Martínez MA, Barceló N, Martínez MC, Guirao P, Bello A, Contreras J, Lacasa A. 2004b. Estabilidad en la eficacia desinfectante de la biofumigación con solarización en cultivos de pimiento. Actas de Horticultura 42: 2024.

Guerrero MM, Ros C, Guirao P, Martínez MA, Martínez MC, Barceló N, Bello A, Lacasa A, López JA. 2004c. Biofumigation plus solarization efficacy for soil desinfection in sweet pepper greenhouses in the Southeast of Spain. Acta Horticulturae 698: 293-297.

Guerrero MM, Ros C, Martínez MA, Martínez MC, Barceló N, Lacasa A. 2005. Biofumigación con solarización. Un método estable de desinfección de suelos de invernadero. Actas Portuguesas de Horticultura 7 (3): 111-115.

Lacasa A, Guirao P. 1997. Investigaciones actuales sobre alternativas al uso del bromuro de metilo en pimiento de invernadero. En: López A, Mora JA, eds. Publicaciones de la Consejería de Medio Ambiente, Agricultura y Agua. Jornadas 11: 47-50.

Reyes JM, De Cara M, Diámez F, Santos M, Segura JM, Blanco R, Sánchez JA, Tello J. 2004. Efecto de la solarización, biofumigación y biosolarización sobre la población de la microbiota fúngica del suelo del olivo. VI Congreso SEAE, Almería, 27 septiembre. 4 octubre. Resúmenes, 96. 


\title{
5.5 ENMIENDAS PARA CULTIVOS ECOLÓGICOS
}

\author{
PELLETS DE BRASICAS COMO ENMIENDAS PARA BIOSOLARIZACIÓN DE \\ INVERNADEROS DE PIMIENTO
}

Published in Actas de Horticulutra 54: 424-429. 2009

\section{Resumen}

En la desinfección del suelo de invernaderos del Campo de Cartagena (Murcia) para el cultivo de pimiento mediante biosolarización se utiliza estiércol en diferentes estados de descomposición. Este método de desinfección se muestra eficaz para el control de Phytophthora sp. cuando se reitera en años consecutivos, presentando deficiencias en el control de nematodos del género Meloidogyne. Ante posibles limitaciones en el empleo de estiércoles para estos usos se ensayan nuevas enmiendas orgánicas como biosolarizantes. En un invernadero experimental y en dos comerciales se ha evaluado el efecto desinfectante de pellets comerciales de brasicas, tanto sobre el control de los patógenos como sobre el desarrollo de las plantas y la producción, cuando se inició la biosolarización en el mes de agosto. En el invernadero experimental la mezcla de los pellets con estiércol proporcionó niveles de control de nematodos similares (13,3\% de planta infestadas y 0,5 de índice de nodulación medio) al bromuro de metilo (ninguna planta infestada) y mejores producciones $\left(15,6 \mathrm{~kg} \mathrm{~m}^{-2}\right.$ frente a 12,8 $\mathrm{kg} \mathrm{m}^{-2}$ en el bromuro de metilo) mientras los pellets solos mostraron deficiencias en el control de Meloidogyne incognita (46,7\% de plantas infestadas y 2,3 de índice de nodulación medio) que no influyeron en el desarrollo de las plantas ni en la producción $\left(14,8 \mathrm{~kg} \mathrm{~m}^{-2}\right)$. En los invernaderos comerciales no se encontraron las diferencias que en el invernadero experimental, ni cuando los pellets se utilizaron a dosis de $0,3 \mathrm{~kg} \mathrm{~m}^{-2} \mathrm{ni}$ cuando se aplicaron a $0,15 \mathrm{~kg} \mathrm{~m}^{-2}$.

Palabras clave: Nematodos, Meloidogyne, Phytophthora, estiércol, bromuro de metilo, patógenos del suelo.

\section{Introducción}

La desinfección de los suelos es una práctica habitual en el cultivo de pimiento de los invernaderos del Campo de Cartagena (Murcia), para el control de los patógenos (Phytophthora spp. y Meloidogyne incognita son los principales) y para paliar los efectos de la fatiga del suelo debida a la reiteración del monocultivo (Guerrero et al., 2006; Martínez, 2008) de forma ininterrumpida desde hace más de 20 años.

El bromuro de metilo ha sido el desinfectante empleado en las más de 1.700 ha de invernaderos todos los años hasta 2005 (Guirao et al., 2004; Lacasa et al., 2007) y en una parte de la superficie hasta 2008.

Por el amplio espectro de acción, la mezcla emulsionable de 1,3-dicloropropeno y cloropicrina aplicada en el agua de riego, se considera el método más asequible para sustituir al bromuro de metilo (Guerrero et al., 2004; 2007).

Cerca del 20\% de la superficie de invernaderos se desinfectó, en 2007, mediante biosolarización utilizando estiércol de ovino en diferentes grados de descomposición o compostaje. Este método de desinfección se muestra eficaz para el control de 
Phytophthora cuando se reitera en años consecutivos (Guerrero et al., 2004, 2006), presentando deficiencias en el control de nematodos del género Meloidogyne (Guerrero et al., 2008). Ante posibles limitaciones en el empleo de estiércoles para estos usos se ensayan nuevas enmiendas orgánicas como biosolarizantes.

\section{Material y métodos}

Se ensayaron pellets de una mezcla de brasicas (Biofence), solos o mezclados con estiércol fresco de ovino, tomando como referencia el suelo desinfectado con bromuro de metilo, suelo no desinfectado y suelo biosolarizado con una enmienda compuesta por estiércol fresco de ovino (70\%), estiércol de vacuno (10\%), gallinaza $(10 \%)$ y restos de la industria cítrica $(10 \%)$ o con estiércol de ovino semicompostado a $75^{\circ} \mathrm{C}$ (Tabla 1).

Tabla 1. Tratamientos ensayados en los tres invernaderos.

\begin{tabular}{|l|c|c|c|}
\hline Tratamiento & Inver. E & Inver. R6 & Inver. Y \\
\hline Testigo no desinfectado & Sin en mienda & --- & --- \\
\hline Bromuro de metilo 98:2 & $30 \mathrm{~g} \mathrm{~m}^{-2}$ & --- & $7 \mathrm{~kg} \mathrm{~m}^{-2}$ \\
\hline $\begin{array}{l}\text { Biosolarización estiércol fresco } \\
\text { de ovino }\end{array}$ & & $7 \mathrm{~kg} \mathrm{~m}^{-2}$ & $7 \mathrm{~kg} \mathrm{~m}^{-2}$ \\
\hline $\begin{array}{l}\text { Biosolarización es tiércol } \\
\text { semico mpostado de ovino }\end{array}$ & $2,5 \mathrm{~kg} \mathrm{~m}^{-2}$ & --- & $7 \mathrm{~kg} \mathrm{~m}^{-2}$ \\
\hline $\begin{array}{l}\text { Biosolarización en mienda de } \\
\text { cítricos }\end{array}$ & $2,5 \mathrm{~kg} \mathrm{~m}^{-2}$ & $7 \mathrm{~kg} \mathrm{~m}^{-2}$ & $7 \mathrm{~kg} \mathrm{~m}^{-2}+0,3 \mathrm{~kg} \mathrm{~m}^{-2}$ \\
\hline $\begin{array}{l}\text { Biosolarización estiércol fresco } \\
\text { de ovino y pellets de brasicas }\end{array}$ & $2,5 \mathrm{~kg} \mathrm{~m}^{-2}+0,3 \mathrm{~kg} \mathrm{~m}^{-2}$ & $7 \mathrm{~kg} \mathrm{~m}^{-2}+0,3 \mathrm{~kg} \mathrm{~m}^{-2}$ & $7 \mathrm{~kg} \mathrm{~m}^{-2}+0,15 \mathrm{~kg} \mathrm{~m}^{-2}$ \\
\hline $\begin{array}{l}\text { Biosolarización estiércol fresco } \\
\text { de ovino y pellets de brasicas } \\
\text { dosis mitad }\end{array}$ & & --- & \\
\hline $\begin{array}{l}\text { Biosolarización con pellets de } \\
\text { brasicas }\end{array}$ & $0,3 \mathrm{~kg} \mathrm{~m}^{-2}$ & $0,3 \mathrm{~kg} \mathrm{~m}^{-2}$ & \\
\hline
\end{tabular}

Los ensayos se realizaron en la campaña 2007-08 en un invernadero experimental (inv E de $1.000 \mathrm{~m}^{2}$ ) y en dos invernaderos comerciales (R6 de $2.100 \mathrm{~m}^{2} \mathrm{e}$ $\mathrm{Y}$ de $3.000 \mathrm{~m}^{2}$ ), calificados como ecológicos, ubicados en los términos de Dolores de Pacheco, El Mirador-San Javier y San Pedro del Pinatar, respectivamente. Los suelos son franco arcillosos con contenidos en materia orgánica inferior al $1 \%$ (Y) y próximo al $3 \%$ en los otros dos. En los tres se viene haciendo monocultivo de pimiento desde hace 18 años (R6) desde hace 12 (E) y 6 años (Y). El diseño experimental fue de bloques al azar con tres repeticiones por tratamiento y parcelas elementales de $52 \mathrm{~m}^{2}$ en el E, de $75 \mathrm{~m}^{2}$ en el Y, y de $50 \mathrm{~m}^{2}$ en el R6, con tres filas de plantas por parcela en el E (40 plantas por fila, al marco de $1 \times 0,4 \mathrm{~m}$ ) y en el Y (75 plantas por fila, al marco de $1 \times 0,4 \mathrm{~m}$ ) y con dos en el R6 (60 plantas por fila, al marco de 1,12x0,4 m). En los tres el suelo estaba contaminado de Meloidogyne incognita y en la campaña precedente se habían desinfectado mediante biosolarización.

La biosolarización se realizó entre el 9/08/07 y el 17/10/07 en el invernadero E, entre el 14/08/07 y el 26/10/07 en el Y, y entre el 10/08/07 y el 29/10/07 en el R6. El procedimiento seguido fue el descrito por Guerrero et al. (2004). Al finalizar el cultivo precedente se extrajeron los restos de plantas, se subsoló, se extendieron las enmiendas e inmediatamente se enterraron mediante labor de fresadora, cada parcela por separado. 
Se extendieron los ramales de goteros (de $31 \mathrm{~h}^{-1}$, dispuestos a $0,40 \mathrm{~m}$ ) separados $1 \mathrm{~m}$ (inv E e Y) y 1,12 m en el R6. Se regó 3 horas un día y 3-4 horas al día siguiente. Se cambiaron de posición los ramales, se cubrió con plástico transparente de PE de 0,05 mm cada parcela y se regó, en esta nueva postura de los ramales, 3 horas un día y 3-4 horas al día siguiente. El bromuro de metilo en el invernadero E se aplicó el 6/11/07, levantando el plástico (VIF de 0,04 mm) el 13/11/07.

Cuando el suelo estuvo en condiciones, se subsoló cada parcela por separado y se preparó para plantar mediante labor de fresadora. Se plantó la variedad "Coyote", el 29/12/07 en el invernadero R6 y el 23/01/08 en el Y, y la variedad "Somontano" el 4/01/08 en el invernadero E. Las prácticas culturales fueron las habituales en la zona para cultivos ecológicos en los invernaderos R6 e Y, y las habituales para cultivos en producción integrada en el E.

Cada 3 semanas, a partir de la plantación, se midieron 5 plantas en cada una de las dos filas control de las parcelas elementales, hasta finales de junio en que resulta difícil mantener erguidas las plantas con el sistema de entutorado empleado. En cada recolección se clasificaron los frutos de cada línea según las categorías comerciales oficiales, pesándolos por separado. En el invernadero E se recolectaron los frutos con color verde y en los otros dos se hizo la primera recolección de frutos de color verde y las restantes de frutos de color rojo.

Al finalizar el cultivo (5/08/08 en el invernadero E; 29/08/08 en el R6 y el 12/08/08 en el Y), se arrancaron 5 plantas tomadas al azar en cada fila control, se limpiaron las raíces y se anotó el número de plantas con nódulos y el índice de nodulación según la escala (0-10) descrita por Bridge y Page (1980).

Se realizó el análisis de la varianza de los datos (tratamientos y bloques) transformando la altura mediante la expresión $\log _{10}(\mathrm{x})$, las producciones y el índice de nodulación mediante $\log _{10}(\mathrm{x}+1)$ y la proporción de plantas infestadas mediante arcsen $\sqrt{x}$. La comparación de las medias se realizó mediante el test MDS al95\%.

\section{Resultados y discusión}

\section{Efecto sobre los nematodos}

En el invernadero Y el control de los nematodos fue total, no encontrándose nódulos en las raíces de ninguna de las plantas examinadas. Los niveles de infestación y de daños en el invernadero R6 fueron muy reducidos (Tabla 2), no encontrándose diferencias entre los tratamientos. Por el contrario, en el invernadero E el efecto desinfectante se puso de manifiesto en la incidencia de Meloidogyne al final del cultivo. La biosolarización con estiércol fresco de ovino y pellets resultó tan eficaz como el bromuro de metilo y como la enmienda con restos de cítricos (Tabla 2); sin embargo, la biosolarización con pellets solos presentó deficiencias en el control del nematodo en relación a los anteriores tratamiento, proporcionando índices de nodulación y niveles de infestación menores que el estiércol semicompos tado y que el testigo no desinfectado. 
Tabla 2. Incidencia de Meloidogyne incognita. Índice medio de nodulación (IN) y porcentaje de plantas infestadas (PI) en los dos invernaderos E y R6 (no hubo infestación en el invernadero Y).

\begin{tabular}{|l|c|c|c|c|}
\hline \multirow{2}{*}{ Tratamientos } & \multicolumn{2}{|c|}{ Invernadero E } & \multicolumn{2}{c|}{ Invernadero R6 } \\
\cline { 2 - 5 } & $\mathrm{IN}^{\mathrm{a}}$ & $\% \mathrm{PI}^{\mathrm{b}}$ & $\mathrm{IN}^{\mathrm{a}}$ & \% $^{\mathrm{b}}$ \\
\hline Testigo no desinfectado & $5,0 \mathrm{~d}$ & $100,0 \mathrm{c}$ & ----- & ----- \\
\hline Bromuro de metilo $98: 2$ & $0,0 \mathrm{a}$ & $0,0 \mathrm{a}$ & ----- & ----- \\
\hline Biosol. estiércol fresco de ovino & ----- & ----- & $0,2 \mathrm{a}$ & $6,7 \mathrm{a}$ \\
\hline Biosol. estiércol semicom. de ovino & $4,1 \mathrm{~d}$ & $86,7 \mathrm{c}$ & & \\
\hline Biosol. enmienda de cítricos & $0,9 \mathrm{~b}$ & $20,0 \mathrm{ab}$ & $0,0 \mathrm{a}$ & $0,0 \mathrm{a}$ \\
\hline $\begin{array}{l}\text { Biosol. con estiércol fresco de ovino y } \\
\text { pellets de brasicas }\end{array}$ & $0,5 \mathrm{ab}$ & $13,3 \mathrm{a}$ & $0,1 \mathrm{a}$ & $3,3 \mathrm{a}$ \\
\hline Biosol. con pellets de brasicas & $2,3 \mathrm{c}$ & $46,7 \mathrm{~b}$ & $0,1 \mathrm{a}$ & $6,7 \mathrm{a}$ \\
\hline
\end{tabular}

a Test LSD al 95\% con datos transformados mediante $\log _{10}(\mathrm{x}+1) .{ }^{\mathrm{b}}$ Test LSD al $95 \%$ con datos transformados mediante $\operatorname{arcsen} \sqrt{\mathrm{x}}$. Las cifras con la misma letra en una columna no son significativamente diferentes $(\mathrm{P}<0.05 \%)$.

Efectos de las enmiendas sobre el desarrollo de las plantas

En todos los invernaderos se encontraron diferencias en la altura de las plantas al final del periodo de controles (Tabla 3) y también en la evolución del desarrollo de plantas. En el invernadero E el grado de infestación por nematodos al final del cultivo pudo influir sobre el desarrollo de las plantas, siendo las del testigo no desinfectado las más pequeñas y las de los tratamientos con pellets más altas que las del bromuro de metilo y las del estiércol semicompostado. En el invernadero R6 las más pequeñas fueron las del estiércol fresco de ovino, no habiendo diferencias entre las de la enmienda con restos de cítricos y las de los pellets. Por el contrario, en el invernadero Y solo se encontraron diferencias entre el estiércol fresco mezclado o no con pellets de brasicas con el estiércol semicompostado (Tabla 3).

Tabla 3. Altura media de las plantas (cm) a principios de julio.

\begin{tabular}{|l|c|c|c|}
\hline Tratamientos & Inver. E & Inver. R6 & Inver. Y \\
\hline Testigo no desinfectado & $140,2 \mathrm{c}$ & ---- & ---- \\
\hline Bromuro de metilo 98:2 & $153,1 \mathrm{~b}$ & ---- & ---- \\
\hline Biosol. estiércol fresco de ovino & ---- & $127,2 \mathrm{~b}$ & $120,0 \mathrm{a}$ \\
\hline Biosol. estiércol semicompostado de ovino & $151,6 \mathrm{~b}$ & ------ & $112,4 \mathrm{~b}$ \\
\hline Biosol. enmienda de cítricos & $154,0 \mathrm{ab}$ & $135,8 \mathrm{a}$ & $115,8 \mathrm{ab}$ \\
\hline $\begin{array}{l}\text { Biosol. con estiércol fresco de ovino y pellets de } \\
\text { brasicas }\end{array}$ & $159,2 \mathrm{a}$ & $134,8 \mathrm{a}$ & $119,9 \mathrm{a}$ \\
\hline $\begin{array}{l}\text { Biosol. estiércol fresco de ovino y pellets de } \\
\text { brasicas dosis mitad }\end{array}$ & ----- & ---- & $115,7 \mathrm{ab}$ \\
\hline Biosol. con pellets de brasicas & $158,1 \mathrm{a}$ & $141,3 \mathrm{a}$ & ---- \\
\hline
\end{tabular}

Las cifras con la mis ma letra en una colu mna no son significativamente diferentes $(\mathrm{P}<0.05 \%)$ 


\section{Efecto sobre las producciones}

En los invernaderos comerciales no se encontraron diferencias entre tratamientos en la producción comercial final (Tabla 4), ni tampoco se encontraron entre las enmiendas utilizadas para realizar la biosolarización en el invernadero experimental $\mathrm{E}$. Con los pellets de brasicas, solos o mezclados con el estiércol fresco de ovino la producción comercial fue superior a la del bromuro de metilo y a la del testigo no desinfectado; el estiércol semicompostado y la enmienda con restos de cítricos proporcionaron producciones similares a las de los pellets y a las del bromuro de metilo, y superiores a las del testigo no desinfectado.

La eficacia desinfectante en cuanto al control de los nematodos y de los hongos que actúan como patógenos subclínicos (Tello y Lacasa, 1997), implicados en los fenómenos de fatiga del suelo (Martínez et al., 2006, Martínez, 2008), pudiera estar compensada por el efecto de las enmiendas orgánicas aportadas en las parcelas biosolarizadas, que no se aportaron en las desinfectadas con bromuro de metilo o en las no desinfectadas. Índices de nodulación medios superiores a 5 provocan amarilleos en la copa de las plantas que suponen una reducción en el desarrollo de las plantas y en la producción (Guerrero et al., 2006, 2008). En los ensayos realizados solo se apreciaron estos síntomas en las parcelas no desinfectadas del invernadero E.

Los pellets de brasicas pueden mejorar la eficacia de la biosolarización realizada con estiércoles frescos y semicompostados en el control de Meloidogyne incognita, utilizando cantidades reducidas de enmienda.

Tabla 4. Producciones comerciales finales medias $\left(\mathrm{kg} \mathrm{m}^{-2}\right)$.

\begin{tabular}{|l|c|c|c|}
\hline Tratamientos & Inver. E & Inver. R6 & Inver. Y \\
\hline Testigo no desinfectado & $12,6 \mathrm{c}$ & ---- & ---- \\
\hline Bromuro de metilo 98:2 & $12,8 \mathrm{bc}$ & ---- & ---- \\
\hline Biosol. estiércol fresco de ovino & ---- & $13,8 \mathrm{a}$ & $8,7 \mathrm{a}$ \\
\hline Biosol. estiércol semicompostado de ovino & $14,5 \mathrm{ab}$ & ---- & $8,6 \mathrm{a}$ \\
\hline Biosol. enmienda de cítricos & $14,1 \mathrm{ab}$ & $13,6 \mathrm{a}$ & $8,2 \mathrm{a}$ \\
\hline $\begin{array}{l}\text { Biosol. con estiércol fresco de ovino y pellets } \\
\text { de brasicas }\end{array}$ & $15,6 \mathrm{a}$ & $13,9 \mathrm{a}$ & $8,6 \mathrm{a}$ \\
\hline $\begin{array}{l}\text { Biosol. estiércol fresco de ovino y pellets de } \\
\text { brasicas dosis mitad }\end{array}$ & ----- & ---- & $8,5 \mathrm{a}$ \\
\hline Biosol. con pellets de brassicas. & $14,8 \mathrm{a}$ & $14,4 \mathrm{a}$ & ---- \\
\hline
\end{tabular}

Las cifras con la mis ma letra en una colu mna no son significativamente diferentes $(\mathrm{P}<0.05 \%)$

\section{Agradecimientos}

Los trabajos se encuadran en las actividades del proyecto INIA AT2006-0006C08-03. Nuestro agradecimiento a los agricultores Ramón Robles González y Eloy López Pardo que prestaron sus invernaderos para la realización de los ensayos y al Programa de Colaboración entre la Federación de Cooperativas Agrarias de Murcia y la Consejería de Agricultura y Agua de la Región de Murcia 


\section{Bibliografía}

Bridge J, Page J. 1980. Estimation of root-knot nematodes infestation levels on roots using a rating chart. Tropical Pest Management 26: 296-298.

Guerrero M M, Lacasa A, Ros C, Bello A, Martínez M C, Torres J, Fenández P. 2004. Efecto de la biofumigación con solarización sobre los hongos del suelo y la producción: fechas de desinfección y enmiendas. En: Lacasa A, Guerrero MM, Oncina M, Mora JA, eds. Desinfección de suelos en invernaderos de pimiento. Publicaciones de la Consejería de Agricultura, Agua y Medio Ambiente. Región de Murcia. Jornadas 16: 209-238.

Guerrero MM, Ros C, Martínez MA, Martínez MC, Bello A, Lacasa A. 2006. Biofumigation vs biofumigation plus solarization to control Meloidogyne incognita in sweet pepper. Bulletin OILB/Crop 29 (4): 313-318.

Guerrero MM, Martínez MA, Ros C, Bello A, Fernández P, Martínez MC, Lacasa A. 2007. Eficacia de la biosolarización como desinfectante del suelo en invernaderos de pimiento. Actas de Horticultura 48: 451-454.

Guerrero MM, Ros C, Lacasa CM, Martínez V, Fernández P, Bello A, Lacasa A. 2008. Control de nematodos en invernaderos de pimiento mediante biosolarización con enmiendas orgánicas. Actas del VIII Congreso SEAE, S4, p. 210.

Guirao P, Guerrero MM, Ros C, Lacasa A, Beltrán C, Martínez MC, Torres J, Oncina M, Contreras J. 2004. La reducción de dosis del bromuro de metilo en el cultivo de pimiento y el calendario de retirada. En: Lacasa A, Guerrero MM, Oncina M, Mora JA, eds. Desinfección de suelos en invernaderos de pimiento. Publicaciones de la Consejería de Agricultura, Agua y Medio Ambiente. Región de Murcia. Jornadas 16: 61-78.

Lacasa A, Martínez MA, Guerrero MM, Torres J, Beltrán C, Ros C. 2007. Determinación de la dosis de aplicación de la cloropicrina para la desinfección de suelos de pimiento. Actas de Horticultura 48: 538-541.

Martínez MA, Lacasa A, Guerrero MM, Ros C, Martínez MC, Bielza P y Tello J. 2006. Effect of soil disinfectation on fungi greenhouses planted with sweet peppers. Bulletin OILB/Crop 29 (4): 301-306.

Martínez MA. 2008. La microbiota fúngica de los suelos de los invernaderos de pimiento. Universidad Politécnica de Cartagena, E.T.S. Ingeniería Agronómica, 260 pp.

Tello J, Lacasa A. 1997. Problemática fitosanitaria del suelo en cultivos de pimiento en el Campo de Cartagena. En: López A, y Mora JA, eds. Posibilidades de alternativas viables al bromuro de metilo en pimiento en invernadero. Publicaciones de la Consejería Medio Ambiente, Agricultura y Agua. Región de Murcia. Jornadas 11: 1117. 


\title{
5.6 ENMIENDAS ESPECÍFICAS PARA BIOSOLARIZACIÓN DE INVERNADEROS ECOLÓGICOS
}

\author{
CONTROL DE NEMATODOS EN INVERNADEROS DE PIMIENTO MEDIANTE \\ BIOSOLARIZACIÓN CON ENMIENDAS ORGÁNICAS
}

Publicado en Actas del VIII Congreso SEAE, S4, p. 210. 2008

\section{Resumen}

Para reducir la incidencia de los principales patógenos del suelo (Phytophthora $s p$. y Meloidogyne sp.) y la fatiga en cultivos ecológicos de pimiento realizados en los invernaderos de Murcia, se viene aplicando la biosolarización utilizando estiércoles frescos como biofumigantes. Con el objeto de mejorar la eficacia desinfectante de los estiércoles y de reducir los riesgos para la seguridad alimentaria de su uso, se han elaborado enmiendas con estiércoles frescos y restos de cosecha (brócoli) o subproductos industriales (de cítricos) o se ha semicompostado el estiércol. En un invernadero contaminado de Meloidogyne incognita se ha evaluado la eficacia frente al nematodo de cuatro enmiendas (estiércol+ restos de brócoli (E+B), estiércol+ restos de cítricos $(\mathrm{E}+\mathrm{C})$, estiércol semicompostado a $75^{\circ} \mathrm{C}$ (ES) y restos de brócoli (RB) comparándolas con un testigo no desinfectado y otro desinfectado con bromuro de metilo (BM). No se encontraron diferencias entre las enmiendas, ni entre éstas y el bromuro de metilo, ni en el porcentaje de plantas infestadas $(6,6 \%$ para el bromuro, $0 \%$ para $\mathrm{E}+\mathrm{C}, 16,7 \%$ para $\mathrm{E}+\mathrm{B}, 3,3 \%$ para $\mathrm{ES}$ y $13,3 \%$ para $\mathrm{RB}$ ) ni en el índice de nodulación $(0,2 \mathrm{BM}, 0,0 \mathrm{E}+\mathrm{C}, 0,6 \mathrm{E}+\mathrm{B}, 0,1 \mathrm{ES}$ y $0,4 \mathrm{RB})$, pero sí con el testigo no desinfectado (100\% plantas afectadas y 5,9 de índice de nodulación). Tampoco se encontraron diferencias entre enmiendas ni entre éstas y el bromuro de metilo en la producción comercial final.

Palabras clave: Meloidogyne, restos de brócoli, restos cítricos, semi-compostado, estiércol

\section{Introducción}

En los invernaderos de la Región de Murcia, Phytophthora capsici y Meloidogyne incognita son los principales patógenos del suelo (Tello y Lacasa, 1997; Bello et al., 2004). El monocultivo reiterado desde hace más de 20 años ha dado lugar a la aparición de fenómenos de fatiga del suelo específica del pimiento (Lacasa et al., 2002; Guerrero et al., 2004), asociada a determinados microorganismos (Martínez et al., 2006).

Tradicionalmente, para el control de los patógenos y para paliar los efectos de la fatiga, se ha venido desinfectando el suelo con bromuro de metilo (Lacasa y Guirao, 1997). En los invernaderos con cultivos ecológicos se ha aplicado la biosolarización utilizando estiércoles frescos como biofumigantes (Guerrero et al., 2004 y 2006).

Mezclas de estiércoles, residuos urbanos, residuos verdes, composts, turbas, etc. se han evaluado tanto en sistemas de producción convencional como ecológica, para 
mejorar la estructura y la fertilidad del suelo y para el control de los patógenos edáficos en numerosos cultivos (Bonanomi et al., 2007), incluido el pimiento (Chellemi, 2006).

Como objetivo del presente trabajo, nos propusimos evaluar el efecto sobre los nematodos del género Meloidogyne de enmiendas orgánicas, especialmente elaboradas para mejorar la eficacia desinfectante de los estiércoles frescos hasta ahora estudiados (Guerrero et al., 2004; 2006; 2007) y para garantizar la seguridad alimentaria de su uso.

\section{Material y métodos}

En un invernadero experimental de $1.000 \mathrm{~m}^{2}$ se evaluaron 4 enmiendas (Cuadro 1). El suelo es franco arcillosos con un 3\% de materia orgánica, en el que se tenía constancia de la presencia de poblaciones medias de Meloidogyne incognita. Desde 1992 se ha cultivado ininterrumpidamente de pimiento. El diseño experimental fue de bloques al azar, teniendo como referencia suelo desinfectado con bromuro de metilo (98:2 a $30 \mathrm{~g} \mathrm{~m}^{-2}$, sellado con plástico VIF de 0,04 mm) y suelo no desinfectado, siendo las elementales de $50 \mathrm{~m}^{2}$, que albergaban tres filas de 40 plantas, al marco de 1,0 x 0,40 $\mathrm{m}$, utilizando para los controles solo las dos filas centrales. En la campaña precedente las parcelas de bromuro se desinfectaron con el mismo producto y las restante mediante biosolarización utilizando $2,5 \mathrm{~kg} \mathrm{~m}^{-2}$ de estiércol fresco de oveja como biofumigante, salvo las del testigo que no se desinfectaron.

\section{Cuadro 1. Composición porcentual, en volumen, de las enmiendas y dosis de aplicación.}

\begin{tabular}{|l|l|c|}
\hline \multicolumn{1}{|c|}{ Enmienda } & \multicolumn{1}{|c|}{ Composición } & Dosis $\left(\mathrm{kg} \mathrm{m}^{-2}\right)$ \\
\hline Enmienda cítricos & $\begin{array}{l}\text { Estiércol fresco de oveja 70\% } \\
\text { Estiércol de vacuno 10\% } \\
\text { Gallinaza 10\% } \\
\text { Restos ind ustria cítrica 10\% }\end{array}$ & 2,5 \\
\hline Enmienda brócoli & $\begin{array}{l}\text { Estiércol fresco de oveja 65\% } \\
\text { Gallinaza 10\% } \\
\text { Restos cosecha brócoli 25\% }\end{array}$ & 2,5 \\
\hline Estiércol semi-compostado & Estiércol de oveja semicompostado a 75 ${ }^{\circ} \mathrm{C}$ & 2,5 \\
\hline Restos cultivo brócoli & $\begin{array}{l}\text { Restos frescos del cultivo después de la } \\
\text { cosecha }\end{array}$ & 5 plantas $\mathrm{m}^{-2}$ \\
\hline
\end{tabular}

Las enmiendas con estiércol se prepararon, dos días antes de la aplicación, en una planta de elaboración de abonos orgánicos, realizando las mezclas después de triturar o desmenuzar los componentes.

La biosolarización se inició el 28/07/06, permaneciendo el plástico hasta el 16/10/06. El procedimiento seguido fue el descrito por Guerrero et al. (2004). Al finalizar el cultivo precedente se extrajeron los restos de plantas, se subsoló, se extendieron las enmiendas e inmediatamente se enterraron mediante labor de fresadora, cada parcela por separado. Se instalaron sondas de temperatura a 10, 20 y $30 \mathrm{~cm}$ de profundidad en la parcela central de cada tratamiento. Se extendieron los ramales de goteros (de $31 \mathrm{~h}^{-1}$, dispuestos a $0,40 \mathrm{~m}$ ) separados $0,5 \mathrm{~m}$, se cubrió con plástico transparente de PE de 0,05 mm cada parcela y se regó 3 horas un día y 3-4 horas al día siguiente. 
El bromuro de metilo se aplicó el 16/11/06 en fumigación en frío, utilizando un dosificador volumétrico de precisión. El suelo se selló con plástico VIF de 0,04 mm, levantándose el plástico a los 10 días de la aplicación.

Cuando el suelo estuvo en condiciones, se subsoló cada parcela por separado y se preparó para plantar mediante labor de fresadora. Se plantó la variedad 'Somontano', el 19/12/06. Las prácticas culturales fueron las habituales en la zona, no realizando tratamientos al suelo. El control de las plagas se hizo por medios biológicos y el de las enfermedades aéreas mediante sublimadores de azufre. El ensayo se dio por finalizado el 02/08/07.

Cada 3 semanas, a partir de la plantación, se midieron 5 plantas en cada fila control de las parcelas elementales, hasta finales de junio en que resulta difícil mantener erguidas las plantas con el sistema de entutorado empleado. En cada recolección se clasificaron los frutos de cada línea según las categorías comerciales oficiales, pesándolos por separado.

Cada semana se examinaron todas las plantas de cada fila control. Cuando se encontraron alteraciones se analizaron para determinar la causa. Al final del cultivo (02/08/07) se arrancaron 10 plantas de cada parcela elemental (5 de cada fila) y se examinaron las raíces anotando el número de las que presentaban nódulos y el índice de nodulación según la escala (0 a 10) de Bridge y Page (1980).

Se realizó el análisis de la varianza de los datos (tratamientos y bloques) transformando: el porcentaje de plantas infestadas por nematodos mediante arcsen $\sqrt{x}$; el índice de nodulación transformados mediante $\log _{10}(x+1)$; la altura mediante la expresión $\log _{10}(\mathrm{x})$ y las producciones mediante $\log _{10}(\mathrm{x}+1)$. La comparación de las medias se realizó mediante el test MDS al $95 \%$.

\section{Resultados y discusión}

\section{Control del nematodo}

Con las cuatro enmiendas se obtuvieron niveles de control del nematodo similares a los del bromuro (Cuadro 2), tanto para la proporción de plantas infestadas como para el índice de nodulación. La incidencia en las parcelas no desinfectadas fue elevada, presentándose síntomas de amarilleos en el ápice de las plantas a partir de principios de mayo, con reducción en el desarrollo y disminución de la cosecha.

Cuadro 2. Incidencia media de los nematodos. Valoración realizada el 02/08/07.

\begin{tabular}{|c|c|c|}
\hline Tratamiento & $\begin{array}{c}\text { Indice medio de } \\
\text { nodulación } \mathrm{n}^{\mathrm{a}}\end{array}$ & $\begin{array}{c}\text { Plantas con } \\
\text { nódulos }{ }^{\mathrm{b}}(\%)\end{array}$ \\
\hline Testigo no desinfectado & $5,9 \mathrm{c}$ & $100,0 \mathrm{~b}$ \\
\hline BrMe 98:2, 30 $\mathrm{g} \mathrm{m}^{-2}$ & $0,2 \mathrm{ab}$ & $6,6 \mathrm{a}$ \\
\hline Biosol. enmienda cítricos & $0,0 \mathrm{a}$ & $0,0 \mathrm{a}$ \\
\hline Biosol. enmienda brócoli & $0,4 \mathrm{ab}$ & $13,3 \mathrm{a}$ \\
\hline Biosol. estiércol de oveja semicompostado & $0,1 \mathrm{ab}$ & $3,3 \mathrm{a}$ \\
\hline Biosol. con restos brócoli & $0,6 \mathrm{~b}$ & $16,7 \mathrm{a}$ \\
\hline
\end{tabular}

transformados mediante Arcsen $\sqrt{ } \mathrm{x}$. 
En el suelo desinfectado con bromuro las plantas crecieron más que en los otros tratamientos y que en el testigo no desinfectado (Figura 1). A partir de principios de marzo, las plantas del suelo no desinfectado fueron más pequeñas que las de los suelos desinfectados, acentuándose las diferencias con el transcurso del cultivo. Desde principios de mayo se encontraron diferencias entre tipos de enmiendas, siendo la elaborada con restos de brócoli y estiércol la que proporcionó las plantas más altas, sobre todo en relación a las del estiércol de oveja semicompostado y a la enmienda que contenía restos de cítricos, llegando a igualar a las del bromuro de metilo a partir de mediados de mayo. En invernaderos con cultivos ecoló gicos y sin patógenos en el suelo, se observaron diferencias entre enmiendas al final del cultivo, siendo la enmienda con restos de brócoli y el estiércol semicompostado las que proporcionaron las plantas más altas (Guerrero et al., 2008).

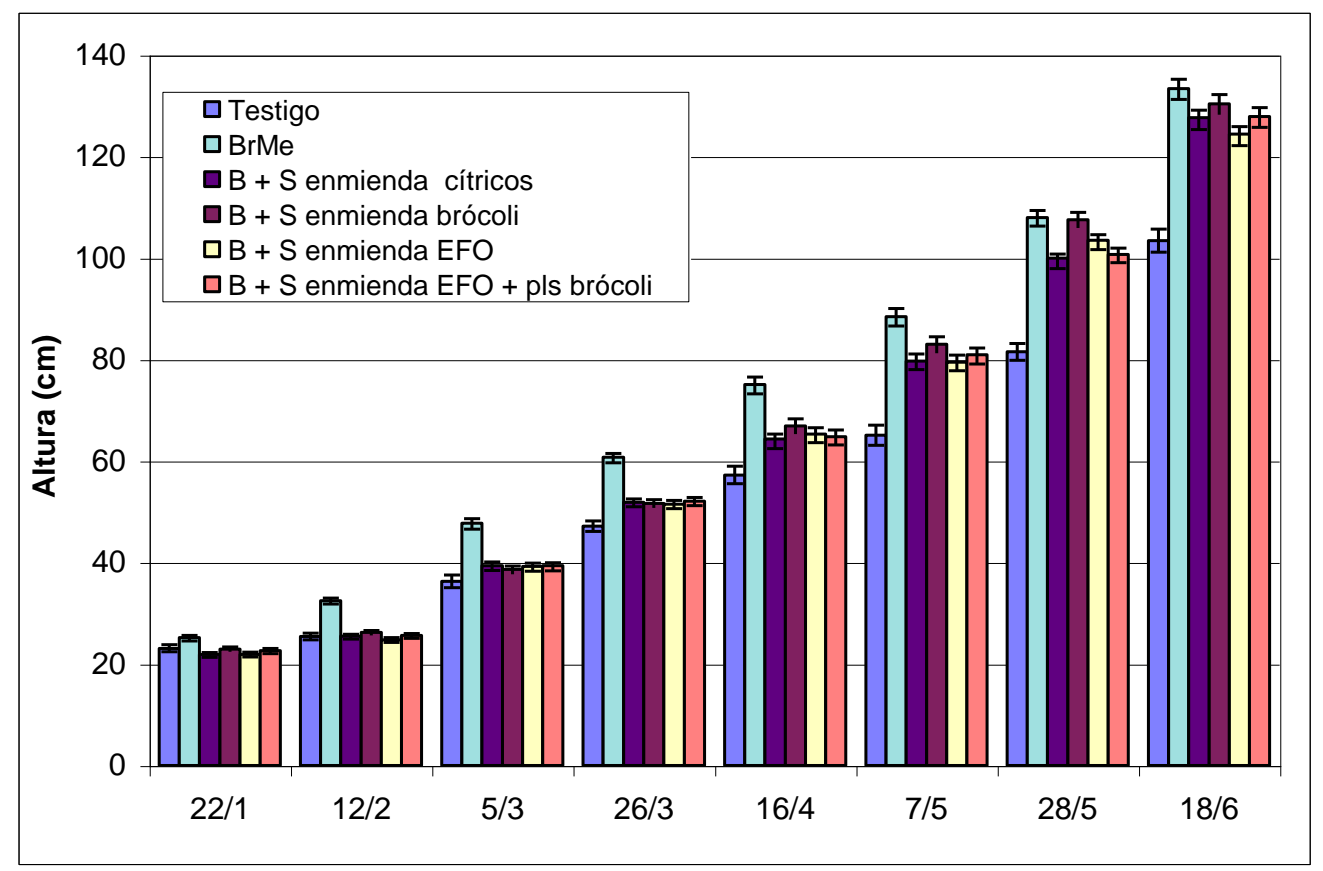

Intervalos LSD al $95 \%$ con los datos transformados con $\log _{10}(\mathrm{x})$.

Figura 1. Evolución de la altura media de las plantas.

\section{Efecto sobre las producciones}

No se encontraron diferencias ni entre enmiendas ni entre éstas y el bromuro de metilo en la producción comercial final (Figura 2). Tampoco entre el bromuro de metilo y el testigo no desinfectado, ni entre éste y la enmienda con restos de cítricos, siendo la produc ción comercial en el resto de las enmiendas superiores a las del testigo.

Con las enmiendas se obtuvieron mayores cantidades de frutos de tercera categoría que en el bromuro de metilo, pero no del resto de las categorías comerciales, siendo el testigo no desinfectado el que menor cantidad de frutos de primera produjo (Figura 2).

En la primera recolección la producción comercial en el bromuro de metilo fue superior a la de las enmiendas (Figura 3), manteniéndose tal diferencia en relación a la enmienda con cítricos en la siguiente recolección, pero no con el resto de las enmiendas. 
A partir de mediados de mayo no se encontraron diferencias entre los tratamientos de desinfección. Similares resultados se han obtenido al ensayar estas enmiendas en invernaderos exentos de hongos nematodos y cultivados bajo normas de agricultura ecológica. Algunas variaciones en la influencia de las calidades de la cosecha se observaron entre la enmienda con restos de cítricos y las restantes enmiendas (Guerrero et al., 2008).

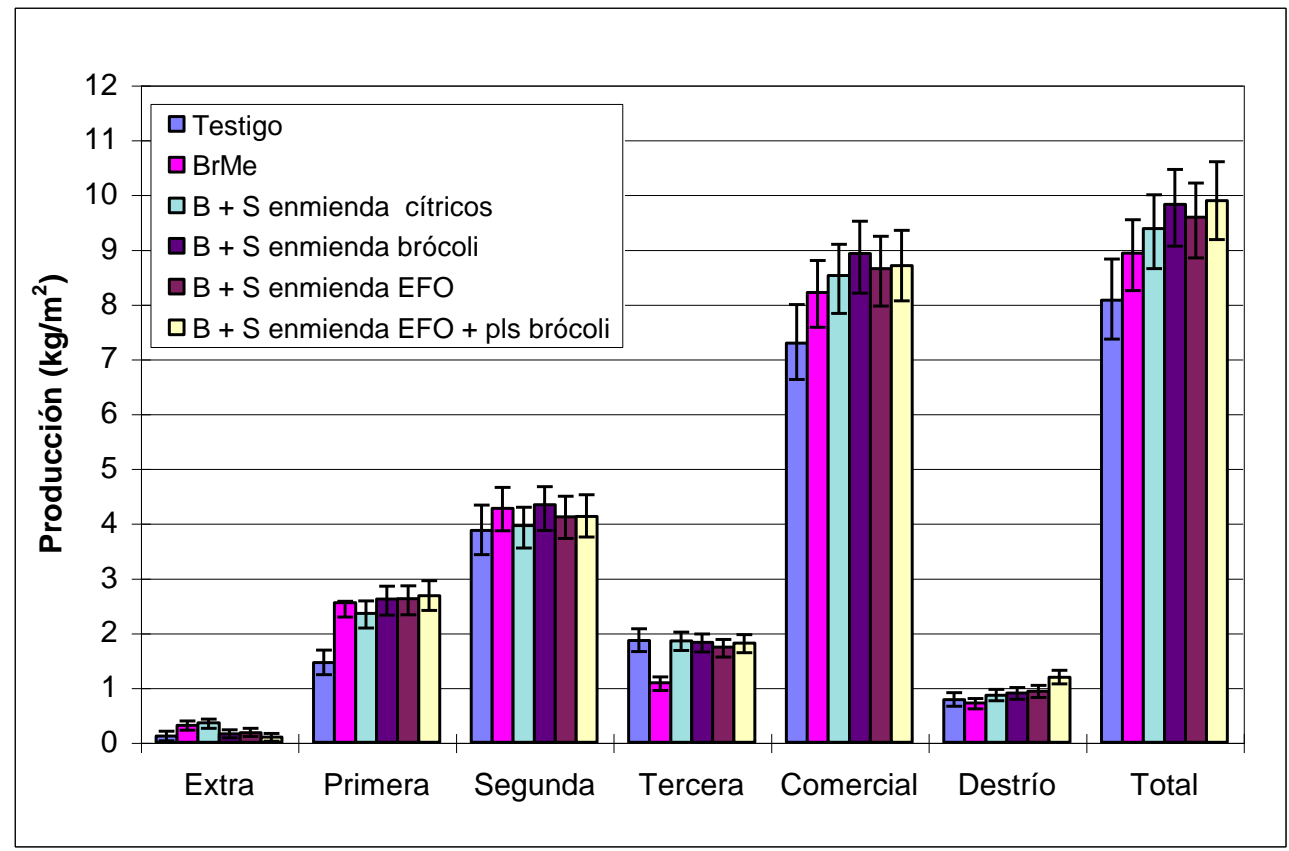

Intervalos LSD al $95 \%$ con los datos transformados con $\log _{10}(\mathrm{x}+1)$.

Figura 2. Producción final media por categorías comerciales.

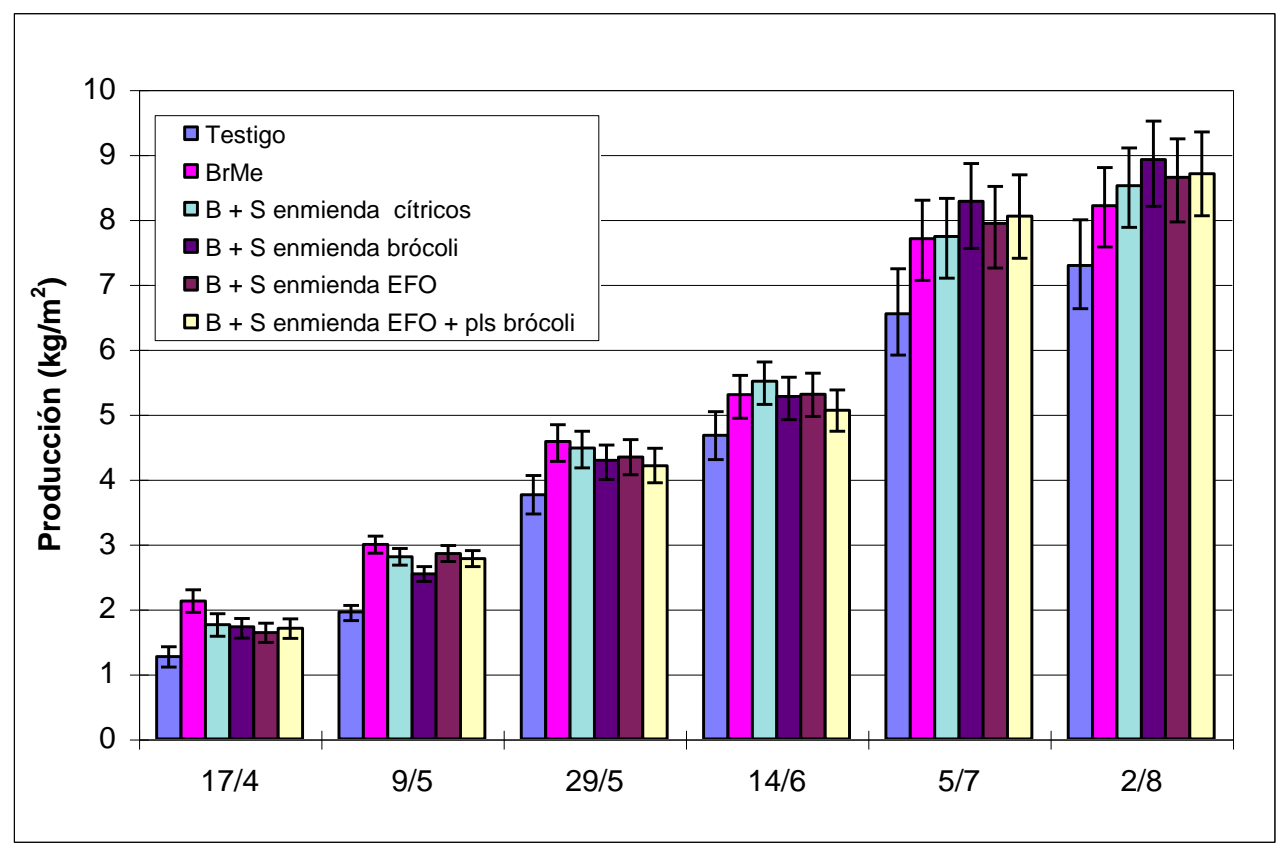

Intervalos LSD al $95 \%$ con los datos transformados con $\log _{10}(x+1)$.

Figura 3. Evolución de la producción comercial media acumulada. 


\section{Otros efectos}

El análisis microbiológico de los suelos después de la biosolarización puso de manifiesto la ausencia de bacterias coliformes y bacterias fecales, igual que en el estiércol de oveja semicompostado en el momento de aplicarlo. Se podría interpretar que el proceso de biosolarización supone el compostaje de la enmienda utilizada. La temperatura del suelo se mantuvo próxima a $33^{\circ} \mathrm{C}$ a $30 \mathrm{~cm}$ de profundidad, a $36^{\circ} \mathrm{C}$ a 20 $\mathrm{cm}$ y a $42^{\circ} \mathrm{C}$ a $10 \mathrm{~cm}$, durante todo el tiempo, no encontrándose diferencias entre enmiendas en los niveles térmicos obtenidos.

El control de las malas hierbas con las enmiendas (densidades medias de 0,33 a $0,12)$ fue similar al del bromuro de metilo $(0,09)$ y muy inferior al del testigo no desinfectado $(1,45)$.

\section{Agradecimientos}

El trabajo ha sido financiado por el INIA, proyecto AT2006-006-C08-04 y el Programa de Colaboración FECOAM-Consejería de Agricultura y Agua. Nuestro agradecimiento a Jerónimo Torres por su asistencia técnica. A la empresa Abonos Orgánicos Pedrín que elaboró las enmiendas utilizadas.

\section{Bibliografía}

Bello A, López-Pérez J A, García A, Arcos S C, Ros C, Guerrero MM, Guirao P, Lacasa A. 2004. Biofumigación con solarización para el control de nematodos en cultivo de pimiento. En: Lacasa A, Guerrero MM, Oncina M, Mora JA, eds. Desinfección de suelos en invernaderos de pimiento. Publicaciones de la Consejería de Agricultura, Agua y Medio Ambiente. Región de Murcia. Jornadas 16: 129-208.

Bridge J, Page SJ. 1980. Estimation of root-knot nematodes infestation levels on roots using a rating chart. Tropical Pest Management 26:296-298.

Bonanomi G, Antignani V, Pane C, Scala F. 2007. Suppression of soilborne diseases with organic amendments. Journal Plant Pathology 89 (3): 311-324.

Chellemi DO. 2006. Effect of urban debris and soil management practices on plant parasitic nematodos, Phytophthora bligth and Pythium root knot of bell pepper. Crop Protection 25: 1109-1116.

Guerrero MM, Lacasa A, Ros C, Bello A, Martínez MC, Torres J, Fenández P. 2004. Efecto de la biofumigación con solarización sobre los hongos del suelo y la producción: fechas de desinfección y enmiendas. En: Lacasa A, Guerrero MM, Oncina M, Mora JA, eds. Desinfección de suelos en invernaderos de pimiento. Publicaciones de la Consejería de Agricultura, Agua y Medio Ambiente. Región de Murcia. Jornadas 16: 209-238.

Guerrero MM, Ros C, Martínez MA, Martínez MC, Bello A, Lacasa A. 2006. Biofumigation vs biofumigation plus solarization to control Meloidogyne incognita in sweet pepper. Bulletin OILB/Crop 29 (4): 313-318. 
Guerrero MM, Martínez MA, Ros C, Bello A, Fernández P, Martínez MC, Lacasa, A. 2007. Eficacia de la biosolarización como desinfectante del suelo en invernaderos de pimiento. Actas de Horticultura 48:451-454.

Guerrero MM, Lacasa CM, Ros C, Martínez V, López MA, Martínez MA, Beltrán C, Monserrat A, Fernández P. 2008. Enmiendas orgánicas para biosolarización de suelos de invernaderos de pimiento. Actas de Horticultura 50: 83-88.

Lacasa A, Guirao P. 1997. Investigaciones actuales sobre alternativas al uso del bromuro de metilo en pimiento en invernaderos del campo de Cartagena. En: López A, Mora JA, eds. Publicaciones de la Consejería de Medio Ambiente, Agricultura y Agua. Jornadas $11: 21-36$.

Lacasa A, Guerrero MM, Guirao P, Ros C. 2002. Alternatives to Methyl Bromide in sweet pepper crops in Spain. Proceedings of International Conference on Alternatives to Methyl Bromide. T. Batchelor and J. M. Bolivar Ed. European Comisión, 172-177.

Martínez MA, Lacasa A, Guerrero MM, Ros C, Martínez MC, Bielza P, yTello J. 2006. Effect of soil disinfectation on fungi greenhouses planted with sweet peppers. Bulletin OILB/Crop 29 (4): 301-306.

Tello J, Lacasa A. 1997. Problemática fitosanitaria del suelo en cultivos de pimiento en el Campo de Cartagena. En: López A, Mora JA, eds. Publicaciones de la Consejería de Medio Ambiente, Agricultura y Agua. Jornadas 11: 11- 17. 


\title{
5.7 LA BIOSOLARIZACIÓN MÁS EFICAZ QUE LA BIOFUMIGACIÓN
}

\author{
BIOFUMIGATION VS BIOFUMIGATION PLUS SOLARIZATION TO CONTROL \\ MELOIDOGYNE INCOGNITA IN SWEET-PEPPER
}

Published in Bulletin OILB/Crop 29(4): 313-318. 2006

\begin{abstract}
Abstrac
In Region of Murcia (Spain), Meloidogyne incognita is one of the main phytopathological problems in soils where sweet pepper is grown under greenhouse conditions. Biofumigation efficacy when local amend ments are used has been compared with biofumigation plus solarization, which is considered as an alternative to methyl bromide in soil disinfestation. When biofumigation plus solarization is repeated in the same soil, $M$. incognita control levels and marketable yield are similar to methyl bromide. Biofumigation alone was not efficient to control the nematode. If this method is repeated one time, marketable yield is better when it is compared with untreated soil but this improvement is not sustainable along the next growing seasons.
\end{abstract}

Keywords : Biofumigation, solarization, Meloidogyne, pepper crops, greenhouses.

\section{Introducción}

Meloidogyne incognita, a root-knot nematode, infests Spanish Mediterranean soils with high consequences in more than 1,600 ha of sweet pepper monoculture crop which is grown under greenhouse conditions in Region of Murcia (Tello and Lacasa, 1997; Bello et al., 1997) and other places in the world (Brito et al., 2004).

Chemical disinfestation of soil has been the usual way of control (Lacasa et al., 2002). Since the restriction of methyl bromide as soil disinfectant, biofumigation plus solarization (using local organic amendments) is successfully applied in more than 45 ha (Guerrero et al., 2005; Lacasa et al., 2002). Both Organic Agriculture and Integrated Crop Production are progressively increasing the use of this method. The most common cropping season goes from November-January to August-October in Region of Murcia, which is a disadvantage for the practice of the process of biofumigation plus solarization.

The effect of biofumigation alone (without plastic film) and biofumigation plus solarization (with plastic film) to nematode control and its consequence in marketable yield has been studied with the objective of decreasing the use of inputs such as plastic which needs to be recycled.

\section{Material y methods}

The experimental site was located in the middle of Campo de Cartagena, so it takes part from a great area of several crops where sweet pepper crops occupy about 2,100 ha. The assay was carried out in one greenhouse at IMIDA Torreblanca experimental station with a clay-loam soil, with a $1.8 \%$ of organic matter and infested by 
Meloidogyne incognita. Sweet pepper crops have been a monoculture in this greenhouse since 2000. A complete block design with three replicates was used (plots of $60 \mathrm{~m}^{2}$ ) (Table 1). Along three consecutive growing seasons, treatments were repeated in the same place at the same time and amounts of organic amendments were progressively reduced.

Table 1. Treatments, rates of application and organic amendment and type of plastic film used.

\begin{tabular}{|c|c|c|c|}
\hline Treatments & $2002-03$ & $2003-04$ & $2004-05$ \\
\hline $\begin{array}{c}\text { Methyl Bromide } \\
98: 2\end{array}$ & \multicolumn{2}{|c|}{$30 \mathrm{~g} \mathrm{~m}^{-2}, \mathrm{VIF} 0.04 \mathrm{~mm}$} \\
\hline $\begin{array}{c}\text { Biofumigation }+ \\
\text { solarization }\end{array}$ & $\begin{array}{c}(7 \mathrm{FSM}+2.5 \mathrm{CM}) \mathrm{kg} \mathrm{m}^{-2}, \\
\mathrm{PE} 0.05 \mathrm{~mm}\end{array}$ & $\begin{array}{c}(5 \mathrm{FSM}+2.0 \mathrm{CM}) \mathrm{kg} \mathrm{m}^{-2}, \\
\mathrm{PE} 0.05 \mathrm{~mm}\end{array}$ & $\begin{array}{c}(4 \mathrm{FSM}+1.5 \mathrm{CM}) \mathrm{kg} \mathrm{m} \mathrm{m}^{-2}, \\
\mathrm{PE} 0.05 \mathrm{~mm}\end{array}$ \\
\hline Biofumigation & $(7 \mathrm{FSM}+2.5 \mathrm{CM}) \mathrm{kg} \mathrm{m}^{-2}$ & $(5 \mathrm{FSM}+2.0 \mathrm{CM}) \mathrm{kg} \mathrm{m}^{-2}$ & $(4 \mathrm{FSM}+1.5 \mathrm{CM}) \mathrm{kg} \mathrm{m}^{-2}$ \\
\hline Untreated & - & Non tested & - \\
\hline
\end{tabular}

FSM= Fresh Sheep Manure; CM= Chicken Manure; VIF= Virtually Impermeable Film; PE= Polyethylene.

Almuden cultivar (Syngenta Seeds) was planted the first week of January every year at 1.0 x $0.40 \mathrm{~m}\left(25,000\right.$ plants $\left.\mathrm{ha}^{-1}\right)$. Crop was finished the first week of August. Watering and fertilisation were made following suggestions from Rincon et al. (2006) according to crop extractions and environmental conditions. No phytosanitary treatments were made and biological control of pests was done, which is usually practiced in sweet pepper greenhouses of Campo de Cartagena.

Biofumigation and biofumigation plus solarization treatments were carried out the third week of August every year, and plastic film was removed the last week of October. When the previous crop was finished, soil was prepared and the mixture of fresh sheep manure (FSM) and chicken manure (CM) was incorporated through an Ltype cultivator. Soil was watered through a drip irrigation system $\left(3 \mathrm{l} \mathrm{h}^{-1}\right)$ following indications suggested by Guerrero et al. (2004a) for Region of Murcia. After seven days, the biofumigated plot was watered. Methyl bromide $(98 \%$ methyl bromide $+2 \%$ chloropicrin) was applied in cold fumigation under VIF (Virtually Impermeable Film) plastic (0.04 mm thick) the first week of November. Total marketable yield $\left(\mathrm{kg} \mathrm{m}^{-2}\right)$ and $M$. incognita incidence were measured. At the end of the crop, ten plants of each plot were removed from the soil in a randomized way and root system was observed. Damage caused by $M$. incognita was measured according to Bridge and Page scale (1980) checked by Bello et al. (1997). Percentage of infested plant and the root-knot index were transformed into arc $\sin \sqrt{\mathrm{x}}$ and $\log _{10}(\mathrm{x}+1)$ prior to analysis of variance (ANOVA) ( $\mathrm{P}>0.05)$. Marketable yield categories and total yield were transformed into $\log _{10}(\mathrm{x}+1)$ and analysed through ANOVA. In both significant differences among treatments were compared with the LSD test $(\mathrm{P}>0.05)$. 


\section{Results and discussion}

\section{M. incognita incidence}

No differences were found among treatments in relation to percentage of plants infested by $M$. incognita the first year, but there were differences in root-knot index (Table 2). Roots damage severity was lower with methyl bromide, but there were no differences among biofumigation alone, biofumigation plus solarization and untreated soil. The last two years, biofumigation plus solarization was as effective as methyl bromide (Table 2), but biofumigation alone had the same efficiency than the untreated soil, with the same percentage of infested plants and damage severity.

From the second year onwards, biofumigation plus solarization give $M$. incognita similar control levels to methyl bromide (Guerrero et al., 2004a). Biofumigation plus solarization is shown as an effective and stable method for soil disinfestation in South East Spanish greenhouses (Guerrero et al., 2004b and 2005).

Table 2. Percentage of plants infested by Meloidogyne incognita and root-knot index (0-10).

\begin{tabular}{|c|c|c|c|c|c|c|}
\hline \multirow{2}{*}{ Treatments } & \multicolumn{2}{|c|}{$2002-03$} & \multicolumn{2}{c|}{$2003-04$} & \multicolumn{2}{c|}{$2004-05$} \\
\cline { 2 - 7 } & $\begin{array}{c}\% \\
\text { infested } \\
\text { plants }^{\mathrm{a}}\end{array}$ & $\begin{array}{c}\text { Root-knot } \\
\text { index }\end{array}$ & $\begin{array}{c}\% \\
\text { infested } \\
\text { plants }^{\mathrm{a}}\end{array}$ & $\begin{array}{c}\text { Root-knot } \\
\text { index }\end{array}$ & $\begin{array}{c}\% \\
\text { infested } \\
\text { plants }^{\mathrm{a}}\end{array}$ & $\begin{array}{c}\text { Root-knot } \\
\text { index }^{\mathrm{b}}\end{array}$ \\
\hline MB 98:2 VIF & $80.0 \mathrm{a}$ & $4.3 \mathrm{~b}$ & $40.0 \mathrm{~b}$ & $1.2 \mathrm{~b}$ & $20.0 \mathrm{~b}$ & $0.8 \mathrm{~b}$ \\
\hline $\begin{array}{c}\text { Biofumigation } \\
\text { + solarization }\end{array}$ & $93.3 \mathrm{a}$ & $5.9 \mathrm{a}$ & $40.0 \mathrm{~b}$ & $1.7 \mathrm{~b}$ & $33.3 \mathrm{~b}$ & $2.8 \mathrm{~b}$ \\
\hline Biofumigation & $100.0 \mathrm{a}$ & $7.2 \mathrm{a}$ & $100.0 \mathrm{a}$ & $7.3 \mathrm{a}$ & $98.3 \mathrm{a}$ & $6.5 \mathrm{a}$ \\
\hline Untreated & $100.0 \mathrm{a}$ & $6.9 \mathrm{a}$ & - & - & $100.0 \mathrm{a}$ & $6.3 \mathrm{a}$ \\
\hline
\end{tabular}

Means in the same column followed by the same letter are not significantly different $(\mathrm{P}>0.05)$. ANOVA $(\mathrm{a}=$ Test LSD $y=\operatorname{arcsen} \sqrt{x} ; b=$ Test LSD $\left.y=\log _{10}(x+1)\right)$.

After biofumigation plus solarization disinfestation, root-knot nematode populations go down significantly while saprophytic nematode populations go up, improving biodiversity (Bello et al., 2001). The effect of biofumigation plus solarization tends to be higher than biofumigation and solarization (Gamliel et al., 2001).

\section{Marketable yield}

In the first cropping season, significantly differences on marketable yield were found among treatments tested (Table 3 ) but there was no relation between quality and yield level with severity of nematode damage. Biofumigation plus solarization gave similar yield than methyl bromide in the first cropping season although the following years, results obtained were better than the first one (Table 3 and 4). Biofumigation alone gave similar marketable yield than methyl bromide during two growing seasons (Table 3 and 4), but did not happen the same on the third year which was lower and similar to the untreated soil (Table 5). 
Table 3. Marketable yield $\left(\mathrm{kg} \mathrm{m}^{-2}\right)$ according to marketable categories. Growing season 2002/2003.

\begin{tabular}{|c|c|c|c|c|c|c|}
\hline Treatments & Extra & First & Second & Third & Marketable & Total \\
\hline MB 98:2 VIF & $0.26 \mathrm{a}$ & $3.84 \mathrm{a}$ & $4.28 \mathrm{ab}$ & $0.91 \mathrm{a}$ & $9.30 \mathrm{a}$ & $9.79 \mathrm{a}$ \\
\hline $\begin{array}{c}\text { Biofumigation } \\
+ \text { solarization }\end{array}$ & $0.62 \mathrm{a}$ & $4.54 \mathrm{a}$ & $4.33 \mathrm{a}$ & $0.58 \mathrm{a}$ & $10.08 \mathrm{a}$ & $10.53 \mathrm{a}$ \\
\hline Biofumigation & $0.27 \mathrm{a}$ & $2.84 \mathrm{~b}$ & $3.36 \mathrm{bc}$ & $0.91 \mathrm{a}$ & $7.39 \mathrm{~b}$ & $7.53 \mathrm{~b}$ \\
\hline Untreated & $0.11 \mathrm{a}$ & $1.87 \mathrm{c}$ & $2.80 \mathrm{c}$ & $0.71 \mathrm{a}$ & $5.50 \mathrm{c}$ & $5.65 \mathrm{c}$ \\
\hline
\end{tabular}

Data in the same column followed by the same letter are not significantly different $(\mathrm{P}>0.05)$. ANOVA $\log _{10}(\mathrm{x}+1)$, LSD Test.

Table 4. Marketable yield $\left(\mathrm{kg} \mathrm{m}^{-2}\right)$ according to marketable categories. Growing season 2003/2004.

\begin{tabular}{|c|c|c|c|c|c|c|}
\hline Treatments & Extra & First & Second & Third & Marketable & Total \\
\hline MB 98:2 VIF & $0.01 \mathrm{a}$ & $3.45 \mathrm{~b}$ & $5.52 \mathrm{a}$ & $1.30 \mathrm{a}$ & $10.29 \mathrm{~b}$ & $11.08 \mathrm{ab}$ \\
\hline $\begin{array}{c}\text { Biofumigation }+ \\
\text { solarization }\end{array}$ & $0.19 \mathrm{a}$ & $4.59 \mathrm{a}$ & $5.84 \mathrm{a}$ & $1.34 \mathrm{a}$ & $11.97 \mathrm{a}$ & $12.35 \mathrm{a}$ \\
\hline Biofumigation & $0.08 \mathrm{a}$ & $3.10 \mathrm{~b}$ & $5.50 \mathrm{a}$ & $0.96 \mathrm{a}$ & $9.65 \mathrm{~b}$ & $9.92 \mathrm{~b}$ \\
\hline
\end{tabular}

Data in the same column followed by the same letter are not significantly different $(\mathrm{P}>0.05)$. ANOVA $\log _{10}(\mathrm{x}+1)$, LSD Test.

Table 5. Marketable yield $\left(\mathrm{kg} \mathrm{m}^{-2}\right)$ according to marketable categories. Growing season 2004/2005.

\begin{tabular}{|c|c|c|c|c|c|c|}
\hline Treatments & Extra & First & Second & Third & Marketable & Total \\
\hline MB 98:2 VIF & 0 & $2.04 \mathrm{a}$ & $3.40 \mathrm{a}$ & $1.75 \mathrm{ab}$ & $7.20 \mathrm{ab}$ & $7.97 \mathrm{ab}$ \\
\hline $\begin{array}{c}\text { Biofumigation }+ \\
\text { solarization }\end{array}$ & 0 & $2.05 \mathrm{a}$ & $3.84 \mathrm{a}$ & $2.05 \mathrm{a}$ & $7.95 \mathrm{a}$ & $8.93 \mathrm{a}$ \\
\hline Biofumigation & 0 & $2.13 \mathrm{a}$ & $3.01 \mathrm{a}$ & $1.46 \mathrm{~b}$ & $6.61 \mathrm{~b}$ & $7.32 \mathrm{~b}$ \\
\hline Untreated & 0 & $2.20 \mathrm{a}$ & $3.14 \mathrm{a}$ & $1.62 \mathrm{~b}$ & $6.97 \mathrm{ab}$ & $7.76 \mathrm{~b}$ \\
\hline
\end{tabular}

Data in the same column followed by the same letter are not significantly different $(\mathrm{P}>0.05)$. ANOVA $\log _{10}(\mathrm{x}+1)$, LSD Test.

The increment of marketable yield with biofumigation plus solarization was shown since the first year in comparison to methyl bromide. The effect also took place in other greenhouses (Guerrero et al., 2004b and 2005) and it seems to be related with the improvement of physical and chemical soil properties (Fernández et al., 2004 and 2005) and with effect over pathogens (Guerrero et al., 2004a). Similar results were obtained by Harvey and Sams (2001) when they used Brassica species for tomato crops. With biofumigation alone, the increase of yield which happened the first year in relation to 
methyl bromide was as a result of the improvement of soil properties, but the following years did not keep because of the severity of nematode damages.

In short, to obtain acceptable disinfection levels in Spanish South East greenhouses with non chemical ways it could be necessary to complement the use of biofumigation with solarization.

\section{References}

Bello A, Escuer M, Sanz R, López JA, Guirao P. 1997. Biofumigación, nematodos y bromuro de metilo en el cultivo de pimiento. En: Posibilidad de alternativas viables al bromuro de metilo en pimiento de invernadero. López A, Mora JA eds. Publicaciones de la Consejería de Medio Ambiente, Agricultura y Agua. Jornadas 11:67-108.

Bello A, López JA, Arias M, Lacasa A, Ros C, Guerrero MM, Fernández P. 2001. Biofumigation and grafting in pepper as alternative to methyl bromide. Annual Internacional Research Conference on Methyl Bromide Alternatives and Emissions Reductions. San Diego (USA), 5-9 November, 31, 1-2.

Bridge J, Page SJ. 1980. Estimation of root-knot nematodes infestation levels on roots using a rating chart. Tropical Pest Management 26:296-298.

Brito J, Santley J, Retintas R Di Vito M, Thies J, Dickson DW. 2004. Meloidogyne mayaguensis reproduction on resistant tomato and pepper. Annual International Research Conference on Methyl Bromide Alternatives and Emissions Reductions. Orlando (USA), November, 77, 1-5.

Fernández P, Guerrero MM, Ros C, Bello A, García A, Lacasa A. 2004. Efecto de la biofumigación+solarización sobre la características físicas y químicas de los suelos de pimiento del Sureste español. Actas de Horticultura 42: 6-12.

Fernández P, Guerrero MM, Martínez MA, Ros C, Lacasa A, Bello A. 2005. Effects of biofumigation plus solarization on soil fertility. Industrial crops and rural development. Proceedings of Annual Meeting of the Association for the Advancement of Industrial Crops, 17-21 September, Murcia Spain, 229-236.

Gamliel A, Skantelsky Y, Pérez Y, Becker E. 2001. Soil solarization using sprayable plastic polymers to control soilborne pathogens in field crops. Annual Internacional Research Conference on Methyl Bromide Alternatives and Emissions Reductions. San Diego (USA), 5-9 November, 10, 1-3.

Guerrero MM, Ros C, Martínez MA, Barceló N, Martínez MC, Guirao P, Bello A, Contreras J, Lacasa A. 2004a. Estabilidad en la eficacia desinfectante de la biofumigación con solarización en cultivos de pimiento. Actas de Horticultura 42: 2024.

Guerrero MM, Ros C, Guirao P, Martínez MA, Martínez MC, Barceló N, Bello A, Lacasa A, López JA. 2004b. Biofumigation plus solarization efficacy for soil disinfection in sweet pepper greenhouses in the Southeast of Spain. Acta Horticulturae 698: 293-297. 
Guerrero MM, Ros C, Martínez MA, Martínez MC, Barceló N, Lacasa A. 2005. Biofumigación con solarización. Un método estable de desinfección de suelos de invernadero. Actas Portuguesas de Horticultura 7 (3): 111-115.

Harvey SG, Sams CE. 2001. Brassica biofumigation increases marketable tomato yield. Annual International Research Conference on Methyl Bromide Alternatives and Emissions Reductions. San Diego (USA), 5-9 November 97: 1-2.

Lacasa A, Guerrero MM, Guirao P, Ros C. 2002a. Alternatives to methyl bromide in ve getable crops and strawberry crops in Spain. En: T.A. Batchelor, J.M. Bolívar (Edits). Proceedings of the International Conference on Alternatives to Methyl Bromide. The Remaining Challenges. Seville, Spain, 5-8 March. European Commission, Brussels, Belgium, 172-177.

Rincón L, Pérez A, Abadía A, Sáez J, Pellicer C. 2006. Fertirrigación localizada en un cultivo de pimiento grueso de invernadero en producción integrada. I Respuesta productiva y balance del agua de riego. Agrícola Vergel 286:488-493.

Tello J, Lacasa A. 1997. Problemática fitosanitaria del suelo en el cultivo del pimiento en el Campo de Cartagena. En: López A, Mora JA, eds. Publicaciones de la Consejería de Medio Ambiente, Agricultura y Agua. Jornadas 11: 11-18. 


\title{
5.8 PELLETS DE BRASSICA CARINATA ENMIENDA DE BIOSOLARIZACIÓN PARA EL CONTROL DE PATÓGENOS
}

\author{
EFFECT OF BIOSOLARIZATION USING PELLETS OF BRASSICA CARINATA ON \\ SOIL-BORNE PATHOGENS IN PROTECTED PEPPER CROPS
}

Published in Acta Horticulturae 381: 337-344. 2010

\begin{abstract}
Abstrac
Phytophthora spp. and Meloidogyne incognita are the main soil-borne pathogens of greenhouse pepper crops in Southeast Spain. Between 1985 and 2005, soils were disinfested every year with methyl bromide (MB). Nowadays, among the different alternatives to MB, biosolarization with fresh sheep manure (FSM) is applied at 450 ha, using 1.3-dicholoropropene+chloropicrin in the rest of surface (1,500 ha). Disinfestant efficacy of biosolarization with Brassica carinata pellets at $300 \mathrm{~g} \mathrm{~m}^{-2}$ alone or mixed with FSM in different dates of application has been evaluated at experimental and commercial greenhouses. When biosolarization was carried out in August, the survival of $P$. capsici oospores was as low as MB and the incidence of Meloidogyne was similar to $\mathrm{MB}$ (Nodulation Index $\mathrm{NI}=0.0$; percentage of infested plantas $\mathrm{IP}=0 \%$ ). Results showed that when pellets were mixed with FSM $(\mathrm{NI}=0.5 ; \mathrm{IP}=13 \%)$ although incidence using pellets alone $(\mathrm{NI}=2.3 ; \mathrm{IP}=47 \%)$ was inferior to $\mathrm{FSM}$ alone $(\mathrm{NI}=4.1 ; \mathrm{IP}=87 \%)$ that improved the control $(\mathrm{NI}=5.6 ; \mathrm{IP}=100 \%)$. When biosolarization was initiated in October, disinfestant efficacy decreased, since the incidence of Meloidogyne and the survival of $P$. capsici inoculum increased using either pellets alone or mixed with manure.
\end{abstract}

Keywords: Phytophthora capsici, Meloidogyne incognita, greenhouses, soil disinfestation, organics amendments.

\section{Introduction}

Phytophthora spp. (P. capsici and P. parasitica) and Meloidogyne incognita are the main soil-borne pathogens in protected pepper crops in Southeastern Spain (Tello J, Lacasa A, 1997; Bello et al., 2004).

Soils used to be disinfested with methyl bromide (MB) every year in that area (Guirao et al., 2004) from 1985 to 2005, when this method was banned. MB was replaced by the mixture of 1.3-dichloropropene and chloropicrin as other chemical alternative which was used in 1,500 ha in 2008. Due to environmental concerns, its future availability is under suspicion.

Biosolarization (BS, biofumigation + solarization) with fresh sheep manure (FSM) showed its efficacy for pathogen control if it was carried out in August or at the beginning of September (Guerrero et al., 2004a; Ros et al., 2008) as well as if it was repeated for two or three consecutive years (Guerrero et al., 2004b, 2005, 2006, 2007; Candido et al., 2005). In 2008, BS was applied in more than 450 ha in Campo de Cartagena (Murcia) (Guerrero et al., 2009). The use of Brassica crops in rotations or as green manure has been related with reduction of soil diseases incidence caused by fungi 
and nematodes (Smoliska et al., 2003; Larkin and Griffin, 2008). Besides, benefits in the control of pathogens and weeds have been shown (Palmieri, 2005; Sachi et al., 2005; Lazzeri and Manici, 2000) when using organic amendments obtained as byproduct from seeds oil extraction. In this study, the effect of biosolarization using pellets of $B$. carinata on soil-borne pathogens of pepper greenhouses has been evaluated, with the objective of reducing amount of manure and improving the effectiveness of biosolarization when it is carried out in October, a more compatible period with pepper crop cycle in the area.

\section{Material and methods}

\section{Trials characteristics}

Trials were performed during 2007-2008 and 2008-2009 in a greenhouse of IMIDA Experimental Station, located at Campo de Cartagena (Murcia), with 1,000 $\mathrm{m}^{2}$ and 12 years of monoculture. Soil type was clay-loam, with $3 \%$ of organic matter content and it was infected by Meloidogyne incognita.

Treatments were randomized in a complete block design with three replicates. Non disinfested soil and methyl bromide were considered as reference treatments. The last one was applied by fumigation in October. Treatments are shown in Table 1. Plots had $52 \mathrm{~m}^{2}$ (120 plants plot $\left.^{-1}\right)$. Pepper cv. 'Somontano' was grown in 2007-2008 and cv. 'Pedrosa' in 2008-2009.

\section{Table 1. Treatments assayed.}

\begin{tabular}{|l|c|c|}
\hline Treatment $^{1}$ & $2007-08$ & $2008-09$ \\
\hline MB 98:2, VIF 0.04 mm, October & $30 \mathrm{~g} \mathrm{~m}^{-2}$ & $30 \mathrm{~g} \mathrm{~m}^{-2}$ \\
\hline BS Fresh Sheep Manure (FSM), August & $2.5 \mathrm{~kg} \mathrm{~m}^{-2}$ & $2.5 \mathrm{~kg} \mathrm{~m}^{-2}$ \\
\hline BS pellets B. carinata, August & $0.3 \mathrm{~kg} \mathrm{~m}^{-2}$ & $0.3 \mathrm{~kg} \mathrm{~m}^{-2}$ \\
\hline BS FSM + pellets B. carinata, August & $2.5+0.3 \mathrm{~kg} \mathrm{~m}^{-2}$ & --- \\
\hline BS pellets B. carinata, October & --- & $0.3 \mathrm{~kg} \mathrm{~m}^{-2}$ \\
\hline BS FSM + pellets B. carinata, October & --- & $2.5+0.3 \mathrm{~kg} \mathrm{~m}^{-2}$ \\
\hline Non- disinfested & $\mathrm{X}$ & $\mathrm{X}$ \\
\hline
\end{tabular}

${ }^{1}$ MB: Methyl Bromide; VIF: Virtually Impermeable Film; BS: Bio solarization; FSM: Fresh Sheep Manure

In growing season 2007-2008, biosolarization was initiated at the beginning of August, keeping the film for ten weeks. In growing season 2008-2009, it was initiated at the beginning of August and in the first week of October, keeping the film (PE transparent of $0.05 \mathrm{~mm}$ ) for six weeks in the two dates. The methodology was made according to Guerrero et al. (2004a). The applied manure had the following characteristics: $\mathrm{pH} 8.2$ and EC $5.0 \mathrm{dS} \mathrm{m}{ }^{-1}$, organic C: $400 \mathrm{~g} \mathrm{~kg}^{-1}$, total $\mathrm{N}: 25.0 \mathrm{~g} \mathrm{~kg}^{-1}$, total P: $5.5 \mathrm{~g} \mathrm{~kg}^{-1}$ and total $\mathrm{K}: 26.1 \mathrm{~g} \mathrm{~kg}^{-1}$. Pellets of Brassica carinata (Biofence, Triumph Italia SPA, Cerealetoscana Group) had: $6 \%$ of total N; $7 \%$ of total P; $2.4 \%$ of total $\mathrm{K}$ and $84.2 \%$ of organic matter). The amendments were added to soil using a rototiller and soil was immediately sealed with the film. A drip-irrigation system was set up and soil was moistened during three hours (using $31 \mathrm{~h}^{-1}$ emitters spaced $0.40 \mathrm{~m}$ apart in the same row, with $0.50 \mathrm{~m}$ between drip rows), watering the following day 3-4 hours again. 
In treatments with pellets alone, with MB or in non-disinfested, before pepper plantation, it was incorporated the same amount of mature sheep manure $\left(2.5 \mathrm{~kg} \mathrm{~m}^{-2}\right)$ than in biosolarised treatment with fresh sheep manure.

Crop management was the same that it is commonly used in the area of Campo de Cartagena, with integrated pest management and without soil treatments during the growing season.

\section{Parameters studied}

Ambient and soil (at 15 and $30 \mathrm{~cm}$ depth) temperatures were monitored with thermistor probes attached to a $32 \mathrm{~K}$ Hobo $\mathrm{H} 8-4$ datalogger during biosolarization experiments.

Oospores were produced by crossing Spanish isolates of $P$. capsici obtained from pepper of the A1 compatibility type (Neiker 02-206, 00-004, 06-1303) with reference isolates of $P$. capsici of the A2 compatibility type (CBS111336, CBS 370772).

Nylon meshes $(25 \mu \mathrm{m})$ containing embedded oospores of $P$. capsici were placed into the soil at 15 and $30 \mathrm{~cm}$ depth in three points of each experimental plot and were retrieved at 2, 4 and 6 (10 in case of growing season 2007-2008) weeks since the beginning of the biosolarization, in BS treatments and non-disinfested one, and one week after soil disinfestation with MB. Viability of oospores was determined by the plasmolysis method described by Jiang and Erwin (1990).

For the infectivity bioassay, oospores of $P$. capsici were added to moist sterilized soil $(10,000$ oospores in $100 \mathrm{ml}$ soil) from every treatment plot and then wrapped in a museline to form a small bag which was buried at 15 and $30 \mathrm{~cm}$ soil depth in four points of each experimental plot. The soil bags were sampled at the end of disinfestation process. After that period soil from each bag was put into a pot with one pepper plant cv. 'Derio' (sensitive to $P$. capsici) in the phenological stage of two true leaves. Pots were grown under controlled conditions in a growth chamber at $25^{\circ} \mathrm{C}$ with a 10:14 photoperiod, during 12 weeks, registering the number of plants with symptoms every week.

The effect on Meloidogyne was determined at the end of the growing season, pulling up ten plants, in a randomized way, for each elemental plot. Roots were examined and the nodulation index (NI) (0-10 according to Bridge and Page (1980)) and the percentage of infested plants (\% IP) was noted.

Height of 10 plants, in a randomized way from each elemental plot, was measured every three weeks. The marketable yield, according to official commercial categories, was weighed in each harvest moment for each elemental plot, expressed as $\mathrm{kg} \mathrm{m}^{-2}$.

The data obtained were subjected to statistical analysis using ANOVA, comparing the means of the treatments with the LSD Test at $95 \%(P<0.05)$. The $\log _{10}$ (x) transformation was used to normalise the data for plant height, the $\log _{10}(x+1)$ for yield and root nodulation index and $\arcsin \sqrt{\mathrm{x}}$ for percentage of infested plants by nematodes and for percentage of viable oospores. 


\section{Results and discussion}

\section{Effect on Phytophthora inoculum}

The viability of oospores at $15 \mathrm{~cm}$ of soil depth was reduced when biosolarised treatments were performed in August (Table 2), with the same efficacy as methyl bromide, for both growing seasons studied, whereas at $30 \mathrm{~cm}$ of soil depth, the reduction at $\mathrm{BS}$ treatments was inferior to $\mathrm{MB}$. The proportion of infested plants by surviving inoculum (infectivity) was higher with BS with pellets than with FSM and $\mathrm{MB}$ at $30 \mathrm{~cm}$, but there was not infection with buried inoculum at $15 \mathrm{~cm}$. When BS was made in October, infectivity at $15 \mathrm{~cm}$ was higher with pellets of $B$. carinata alone than with the mixture of FSM+pellets, but the contrary fact took place at $30 \mathrm{~cm}$. The proportion of died plants by the surviving inoculum in October was higher in BS treatments than in non disinfested soil, probably because soil in last treatment had a lower water content (non plastic tarped soil).

Table 2. Viability (\% of surviving oospores) and infectivity (\% of died plants) of Phytophthora capsici oos pores buried at 15 and $30 \mathrm{~cm}$ following disinfes tation process.

\begin{tabular}{|l|c|c|c|c|c|c|c|}
\hline \multirow{2}{*}{ Treatment } & \multicolumn{2}{|c|}{$2007-08$} & \multicolumn{4}{|c|}{$2008-09$} \\
\cline { 2 - 7 } & Viab. $^{2}$ & Viab. & Viab. & Infect $^{2}$ & Viab. & Infect. \\
\cline { 2 - 7 } & $15 \mathrm{~cm}$ & $30 \mathrm{~cm}$ & \multicolumn{2}{|c|}{$15 \mathrm{~cm}$} & \multicolumn{2}{|c|}{$30 \mathrm{~cm}$} \\
\hline MB 98:2, VIF, October & $0.3 \mathrm{~b}^{3}$ & $0.0 \mathrm{~b}$ & $4.3 \mathrm{c}$ & $0.0 \mathrm{c}$ & $3.4 \mathrm{c}$ & $8.3 \mathrm{~d}$ \\
\hline BS FSM, August & $0.0 \mathrm{c}$ & $0.0 \mathrm{~b}$ & $4.6 \mathrm{c}$ & $0.0 \mathrm{c}$ & $18.2 \mathrm{ab}$ & $0.0 \mathrm{~d}$ \\
\hline BS pellets, August & $0.0 \mathrm{c}$ & $0.0 \mathrm{~b}$ & $3.2 \mathrm{c}$ & $0.0 \mathrm{c}$ & $16.1 \mathrm{ab}$ & $16.7 \mathrm{~cd}$ \\
\hline BS FSM + pellets, August & ----- & ----- & ----- & ----- & ------ & ------ \\
\hline Non- disinfested, August & $0.0 \mathrm{c}$ & $0.0 \mathrm{~b}$ & $14.9 \mathrm{ab}$ & $83.3 \mathrm{a}$ & $24.9 \mathrm{a}$ & $100.0 \mathrm{a}$ \\
\hline BS pellets, October & ------ & ----- & $15.2 \mathrm{ab}$ & $58.3 \mathrm{ab}$ & $23.2 \mathrm{ab}$ & $41.7 \mathrm{bc}$ \\
\hline BS FSM + pellets, October & ----- & ----- & $24.1 \mathrm{a}$ & $41.7 \mathrm{~b}$ & $28.0 \mathrm{a}$ & $50.0 \mathrm{~b}$ \\
\hline Non- disinfested, October & $0.6 \mathrm{a}$ & $1.7 \mathrm{a}$ & $8.2 \mathrm{abc}$ & $25.0 \mathrm{bc}$ & $10.7 \mathrm{bc}$ & $16.7 \mathrm{~d}$ \\
\hline
\end{tabular}

${ }^{1}$ MB: Methyl Bromide; VIF: Virtually Impermeable Film; BS: Biosolarization; FSM: Fresh Sheep Manure.

${ }^{2}$ Viab.: Viability, Infec.: Infectiv ity.

${ }^{3}$ Mean values of the same colu mn, followed by the same letter do not differ significantly, according to the LSD Test $(P<0.05)$. The arcsin $\sqrt{ } \mathrm{x}$ transformation was used to normalise data.

In conclusion, when BS is made in October it shows some deficiencies in the reduction of Phytophthora inoculum (Figures 3 and 4), respect to make it in August. Oospores viability decreases along time, emphasizing at $15 \mathrm{~cm}$ four weeks later (Figure 1). The inactivity at $30 \mathrm{~cm}$ is the same for all treatments until the sixth week (Figure 2).

According to the data, the high soil temperature achieved could be the main factor to inactivate Phytophthora inoculum when BS is carried out in August. 


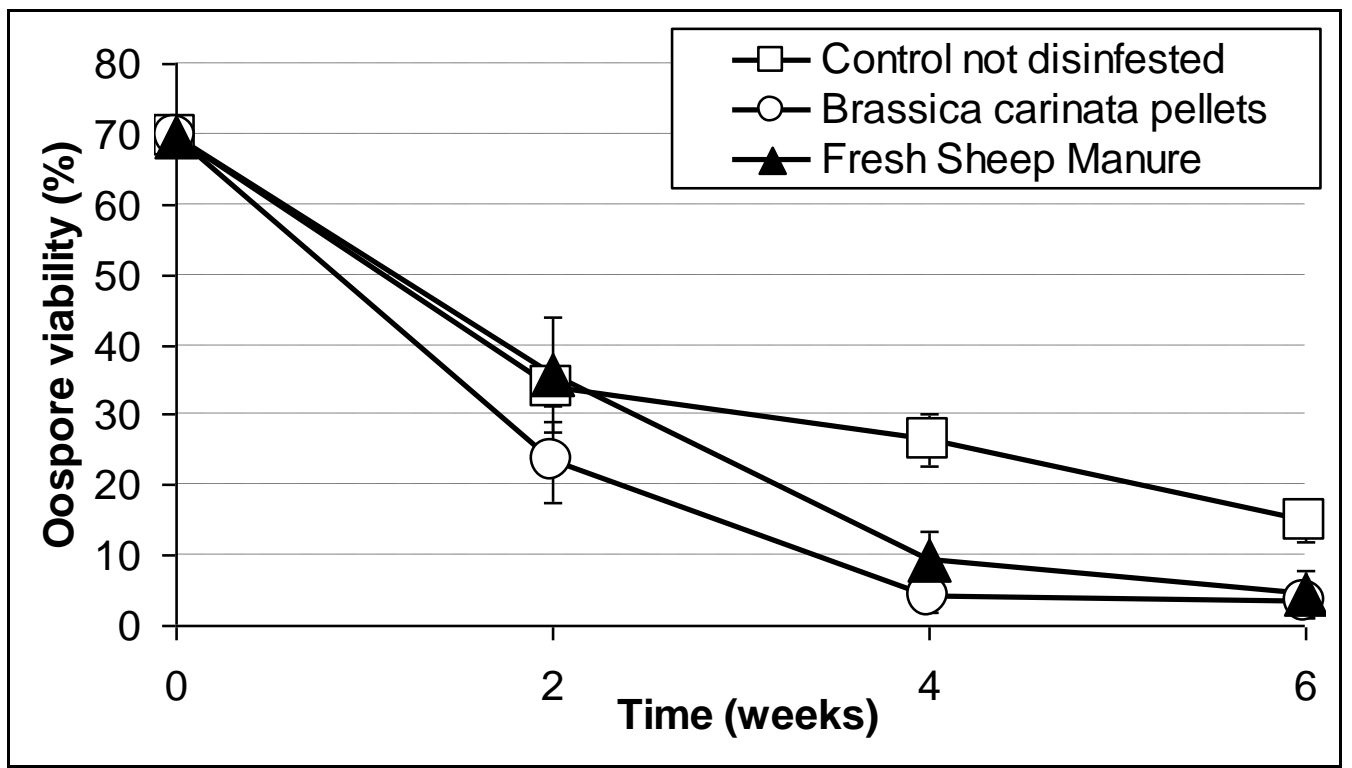

Figure 1. Effect of BS with different organic amend ments during August 2008 on the oospore viability buried at $15 \mathrm{~cm}$ depth.

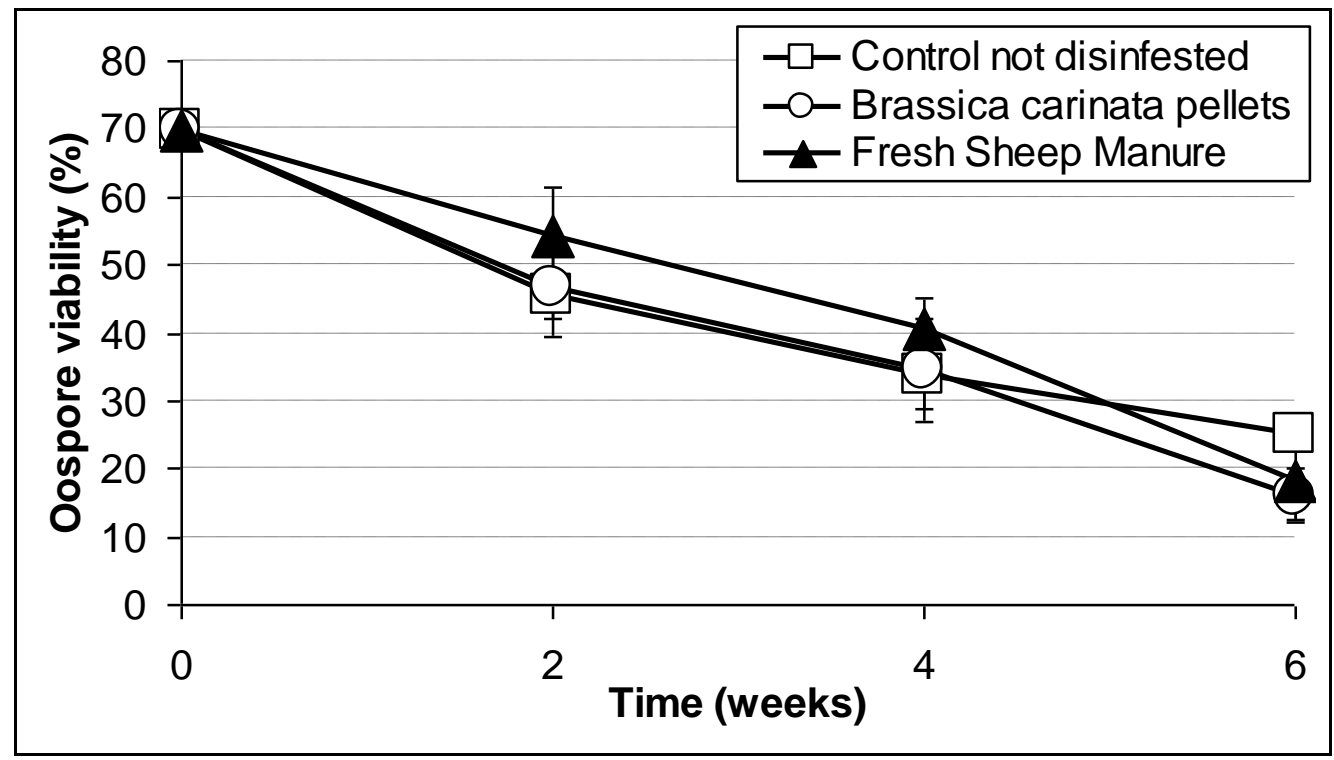

Figure 2. Effect of BS with different organic amend ments during August 2008 on the oospore viability buried at $30 \mathrm{~cm}$ depth. 


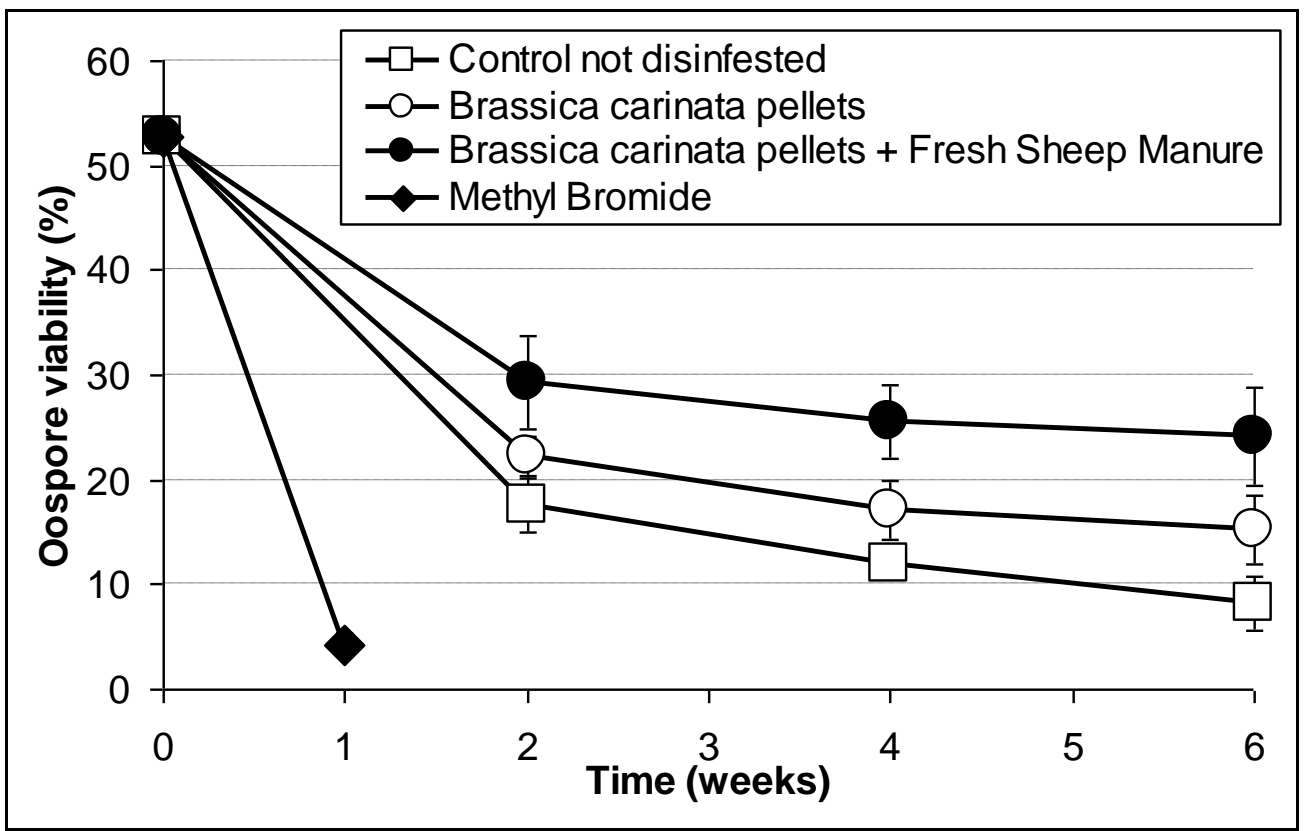

Figure 3. Effect of BS with different organic a mend ments during October 2008 on the oospore viability buried at $15 \mathrm{~cm}$ depth.

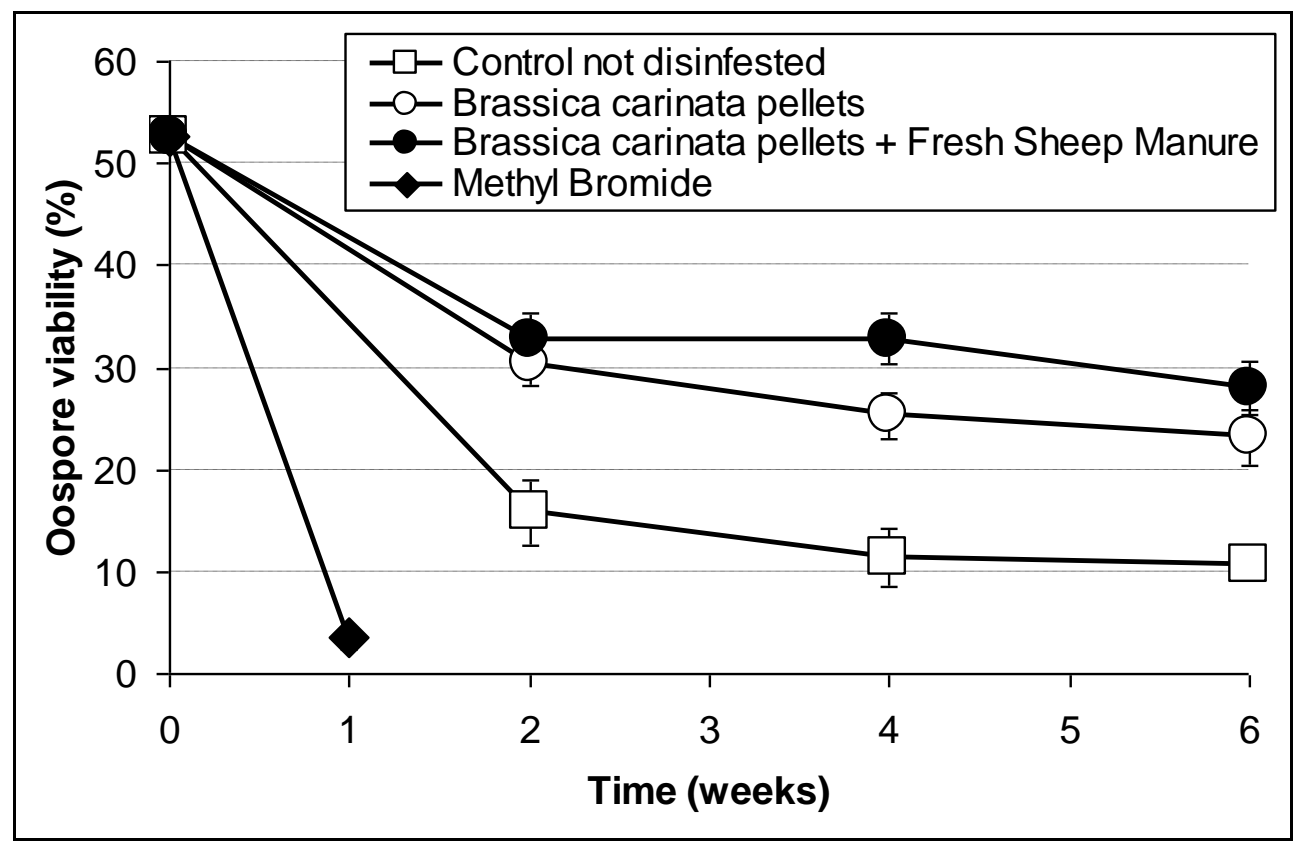

Figure 4. Effect of BS with different organic amend ments during October 2008 on the oo spore viability buried at $30 \mathrm{~cm}$ depth.

\section{Effect on nematodes}

Pellets of $B$. carinata improved the efficacy of BS with fresh sheep manure (FSM) with similar results to MB (Table 3). In 2008-2009, pellets of B. carinata gave better results than FSM. BS made in October was not effective, since there were not significant differences among BS treatments. Neither BS treatments made in October nor BS treatments made in August with FSM showed significant differences, although results obtained were better than non-disinfested soil. 
Table 3. Nodulation Index (NI) and percentage of infes ted plants by Meloidogyne (\% IP).

\begin{tabular}{|c|c|c|c|c|}
\hline \multirow{2}{*}{ Treatment $^{1}$} & \multicolumn{2}{|c|}{$2007-08$} & \multicolumn{2}{|c|}{$2007-08$} \\
\hline & NI & $\% \mathrm{IP}$ & NI & $\% \mathrm{IP}$ \\
\hline MB 98:2, VIF, October & $0.0 \mathrm{a}^{2}$ & $0.0 \mathrm{a}^{2}$ & $0.1 \mathrm{a}^{3}$ & $6.6 \mathrm{a}^{3}$ \\
\hline BS FSM, August & $4.1 \mathrm{c}$ & $86.7 \mathrm{c}$ & $4.9 \mathrm{c}$ & $100.0 \mathrm{~b}$ \\
\hline BS pellets, August & $2.2 \mathrm{~b}$ & $46.7 \mathrm{~b}$ & $3.8 \mathrm{~b}$ & $93.3 \mathrm{~b}$ \\
\hline BS FSM $+0,3 \mathrm{~kg} \mathrm{~m}^{-2}$ pellets, August & $0.5 \mathrm{a}$ & $13.3 \mathrm{a}$ & --- & --- \\
\hline BS pellets, October & --- & ---- & $4.1 \mathrm{bc}$ & $93.3 \mathrm{~b}$ \\
\hline BS FSM + pellets, October & --- & --- & $4.6 \mathrm{bc}$ & $93.3 \mathrm{~b}$ \\
\hline Non- disinfested & $5.6 \mathrm{~d}$ & $100.0 \mathrm{c}$ & $5.7 \mathrm{~d}$ & $100.0 \mathrm{~b}$ \\
\hline
\end{tabular}

'MB: Methyl Bromide; VIF: Virtually Impermeable Film; B S: B iosolarization; FSM: Fresh Sheep M anure.

${ }^{2}$ Mean values of the same column, followed by the same letter do not differ significantly, according to the LSD Test $(P<0.05)$. The $\log _{10}(\mathrm{x}+1)$ transformation was performed to normalised data of root nodulation index.

${ }^{3}$ Mean values of the same column, followed by the same letter do not differ significantly, according to the LSD Test $(P<0.05)$. The arcsin $\sqrt{\mathrm{x}}$ transformation was performed to normalised data of percentage of infested plants.

\section{Effect on plant growth and yield}

Biosolarization in August using pellets of $B$. carinata, allowed getting plants taller than MB or BS with FSM alone (Table 4) at the end of growing season. There were not significant differences among BS treatments made in October which had taller plants than in non-disinfested soil. Plant height with BS treatments of FSM alone made in August was similar than BS treatments of FSM+pellets made in October. On the other hand, the use of pellets of B. carinata alone or mixed with FSM in October had plants as tall as carrying out BS with FSM alone in August.

Total marketable yield obtained in BS treatments made in August was superior to MB and non-disinfested soil (Table 4) for both growing seasons. There were not significant differences among organic amendments. When BS was made in October, total yield was lower than in August, but was similar to MB and non-disinfested soil. Results shown than the mixture of pellets of $B$. carinata with FSM improved the marketable yield of BS with FSM.

Table 4. Plant height $(\mathrm{cm})$ and total marketable yield $\left(\mathrm{kg} \mathrm{m}^{-2}\right)$ at the end of growing season.

\begin{tabular}{|c|c|c|c|c|}
\hline \multirow[t]{2}{*}{ Treatment $^{1}$} & \multicolumn{2}{|c|}{$\begin{array}{l}\text { Plant height } \\
(\mathrm{cm})\end{array}$} & \multicolumn{2}{|c|}{$\begin{array}{l}\text { Total marketable yield } \\
\qquad\left(\mathrm{kg} \mathrm{m}^{-2}\right)\end{array}$} \\
\hline & $2007-08$ & 2008-09 & $2007-08$ & $2008-09$ \\
\hline MB 98:2, VIF October & $153.1 \mathrm{~b}^{2}$ & $148.7 \mathrm{a}^{2}$ & $12.8 \mathrm{c}^{3}$ & $11.1 \mathrm{~b}^{3}$ \\
\hline BS FSM, August & $151.6 \mathrm{~b}$ & $135.4 \mathrm{~b}$ & $14.5 \mathrm{ab}$ & $12.7 \mathrm{a}$ \\
\hline BS pellets, August & $158.1 \mathrm{a}$ & $151.9 \mathrm{a}$ & $14.8 \mathrm{ab}$ & $12.6 \mathrm{a}$ \\
\hline BS FSM $+0.3 \mathrm{~kg} \mathrm{~m}^{-2}$ pellets, August & $159.2 \mathrm{a}$ & ---- & $15.6 \mathrm{a}$ & --- \\
\hline BS pellets, October & --- & $138.2 \mathrm{~b}$ & --- & $10.9 \mathrm{~b}$ \\
\hline BS FSM + pellets, October & --- & $137.9 \mathrm{~b}$ & --- & $10.9 \mathrm{~b}$ \\
\hline Non-disinfested & $140.2 \mathrm{c}$ & $128.3 \mathrm{c}$ & $12.5 \mathrm{c}$ & $10.7 \mathrm{~b}$ \\
\hline
\end{tabular}

MB: Methyl Bromide; VIF: Virtually Impermeable Film; BS: Biosolarization; FSM: Fresh Sheep Manure. ${ }^{2}$ Mean values of the same column, followed by the same letter do not differ significantly, according to the LSD Test $(P<0.05)$. The $\log _{10}(\mathrm{x})$ transformation was performed to normalised data of plant height. ${ }^{3}$ Mean values of the same column, followed by the same letter do not differ significantly, according to the LSD Test $(P<0.05)$. The $\log _{10}(\mathrm{x}+1)$ transformation was performed to normalised data of yield. 


\section{Lite ratured cited}

Bridge J, Page SJ. 1980. Estimation of root-knot nematodes infestation levels on roots using a rating chart. Trop Pest Manag 26: 296-298.

Bello A, López-Pérez JA, García-Álvarez A, Arcos SC, Ros C, Guerrero MM, Guirao P, Lacasa A. 2004. Biofumigación con solarización para el control de nematodos en cultivo de pimiento. In: Lacasa A, Guerrero MM, Oncina M, Mora JA, eds. Desinfección de suelos en invernaderos de pimiento. Publicaciones de la Consejería de Agricultura, Agua y Medio Ambiente. Región de Murcia. Jornadas 16: 129-208.

Candido V, Miccolis V, Basile M, D’Addabbo T, Gatta G. 2005. Soil solarization for the control of Meloidogyne javanica on eggplant in Southern Italy. Acta Hort 698: 195199.

Guerrero MM, Lacasa A, Ros C, Bello A, Martínez MC, Torres J, Fernández P. 2004a. Efecto de la biofumigación con solarización sobre los hongos del suelo y la producción: fechas de desinfección y enmiendas. En: Lacasa A, Guerrero MM, Oncina M, Mora JA, eds. Desinfección de suelos en invernaderos de pimiento. Publicaciones de la Consejería de Agricultura, Agua y Medio Ambiente. Región de Murcia. Jornadas 16: 209-238.

Guerrero MM, Ros C, Martínez MA, Barceló N, Martínez MC, Guirao P, Bello A, Contreras J, Lacasa A. 2004b. Estabilidad en la eficacia desinfectante de la biofumigación con solarización en cultivos de pimiento. Actas Hort 42: 20-24.

Guerrero MM, Ros C, Guirao P, Martínez MA, Martínez MC, Barceló N, Bello A, Lacasa A, López JA. 2005. Biofumigation plus solarization efficacy for soil disinfestation in sweet pepper greenhouses in the Southeast of Spain. Acta Hort 698: 293-297.

Guerrero MM, Ros C, Martínez MA, Martínez MC, Bello A, Lacasa A. 2006. Biofumigation vs biofumigation plus solarization to control Meloidogyne incognita in sweet pepper. Bulletin OILB/Crop 29 (4):313-318.

Guerrero MM, Martínez MA, Ros C, Bello A, Fernández P, Martínez MC, Lacasa A. 2007. Eficacia de la biosolarización como desinfectante del suelo en invernaderos de pimiento. Actas de Horticultura 48: 451-454.

Guerrero MM, Lacasa CM, Ros C, Martínez V, Fenoll J, Torres J, Beltrán C, Fernández P, Bello A, Lacasa A. 2009. Pellets de brasicas como enmiendas para biosolarización de invernaderos de pimiento. Actas de Horticultura 54:424: 429.

Guirao P, Guerrero MM, Ros C, Lacasa A, Beltrán C, Martínez MC, Torres J, Oncina M, Contreras J. 2004. La reducción de dosis del bromuro de metilo en el cultivo de pimiento y el calendario de retirada. En: Lacasa A, Guerrero MM, Oncina M, Mora JA, eds. Desinfección de suelos en invernaderos de pimiento. Publicaciones de la Consejería de Agricultura, Agua y Medio Ambiente. Región de Murcia. Jornadas 16: 61-77.

Jiang J, Erwin DC. 1990. Morphology, plasmolysis and tetrazolium bromide stain as criteria for determining viability of Phytophthora oospores. Mycol 82 (1):107-113 
Larkin RP, Griffin TS. 2008. Control of soil potato diseases using Brassica green manure. Crop Protection 26: 1067-1077.

Lazzeri L, Manici LM. 2000. The glucosinolate- myrosinase system: a natural and practical tool for biofumigation. Acta Hort 532: 89-95.

Palmieri S. 2005. Biofumigation: a new technology based on the use of sulphurcontaining metabolites in Brassica plants. Proc. of Annual Meeting of the Association for the Advancement of industrial crops. Murcia, Spain, 17-21 September, p. 201-213.

Ros M, García C, Hernández MT, Lacasa A, Fernández P, Pascual JA. 2008. Effects of biosolarization as methyl bromide alternative for Meloidogyne incognita control on quality of soil under pepper. Biol Fertil Soils 45: 37-44.

Sachi S, Odorizzi S, Lazzeri L, Marciano P. 2005. Effect of Brassica carinata seed meal treatment on the Trichoderma harzianum T39 Sclerotinia species interation. Acta Hort 698: 289-292.

Smoliska U, Morra MJ, Kanudsen GR, James RL. 2003. Isothiocyanate produced by Brassicaceae species as inhibitors of Fusarium oxysporum. Plant Dis 87: 407-412.

Tello J, Lacasa A. 2004. Las enfermedades de origen edáfico y su control en los pimentonares del Campo de Cartagena. En: Lacasa A, Guerrero MM, Oncina M, Mora JA, eds. Desinfección de suelos en invernaderos de pimiento. Publicaciones de la Consejería de Agricultura, Agua y Medio Ambiente. Región de Murcia. Jornadas 16: 11-26. 


\title{
5.9 EVALUATION OF REPEATED BIODISINFESTATION USING BRASSICA CARINATA PELLETS TO CONTROL MELOIDOGYNE INCOGNITA IN PROTECTED PEPPER CROPS
}

\begin{abstract}
The nematode Meloidogyne incognita is responsible for substantial losses in greenhouse-grown peppers in south-eastern Spain. This study evaluates the use of biodisinfestation (organic amendment+solarisation) as an alternative to using methyl bromide (MB) over three consecutive years to control the nematode in greenhouse conditions. Brassica carinata (BP) pellets or B. carinata (BP)+fresh sheep manure (M) were evaluated in treatments which began on two different dates (August and October) and the results were compared with MB disinfested and untreated controls. During the third year, the gall index for $\mathrm{BP}$ was lower than that obtained for $\mathrm{BP}+\mathrm{M}$ and in the August treatment than in the October treatment. The commercial crop of pepper fruit obtained with the biodisinfestation treatments begun in August was similar to or higher than that obtained with $\mathrm{MB}$, and higher than that obtained with both October biodisinfestation treatments. The yield of the October biodisinfestation treatments was higher than that of the untreated. In August of all the years studied, the accumulated exposure times were greater than the thresholds required to kill $M$. incognita populations at $15 \mathrm{~cm}$ depth. The incidence of the nematode did not correspond to the reduction achieved during solarisation, and seemed to increase during the crop cycle. Further studies should look at why high temperatures do not produce a sustained reduction in the populations of Meloidogyne incognita.
\end{abstract}

Key words: Soil, nematode, organic amendments, greenhouses.

\section{Resumen}

Meloidogyne incognita es causante de importantes pérdidas en cultivos de pimiento en invernadero del Sureste de España. Por este motivo se planteó un ensayo para evaluar la biodesinfección (enmiendas orgánicas+solarización) como alternativa al bromuro de metilo (BM), en un invernadero naturalmente infectado por el nematodo, durante tres años consecutivos. El diseño experimental fue de bloques al azar y se evaluaron pellets de Brassica carinata y pellets de B. carinata (PB)+estiércol fresco de oveja (M), en dos fechas de inicio de la solarización (agosto y octubre). Como controles se utilizaron un testigo no desinfectado y otro desinfectado con BM. El tercer año los índices de agallas en $\mathrm{PB}$ fueron menores que en $\mathrm{BP}+\mathrm{M}$ y los de agosto menores que los de octubre. La producción comercial de los tratamientos de BS de agosto fueron similares o superiores a las del BM y mayores que las de BS octubre, para las dos enmiendas. Las producciones de BS octubre fueron mayores que las del testigo. En agosto se acumularon tiempos de exposición que sobrepasaron los umbrales requeridos para matar las poblaciones de $M$. incognita a $15 \mathrm{~cm}$ todos los años. La incidencia del nematodo no corresponde al grado de reducción de las poblaciones durante la biodesinfección, que pudieron incrementarse a lo largo del ciclo de cultivo. Deben investigarse los motivos 
por los que las altas temperaturas no provocan un efecto sostenido en la reducción de las poblaciones.

Abbreviations used: BS: biodisinfestation, MB: methyl bromide, VIF: Virtually Impermeable Film, BP: Brassica carinata pellets; M: fresh sheep manure, GI: galling index

\section{Introduction}

In the province of Murcia (south-eastern Spain) pepper is a crop that occupies more than $90 \%$ of the area dedicated to greenhouse crops and has been a monoculture for the last 20 years (Lacasa and Guirao, 1997). The normal crop cycle lasts 9-10 months (November-December to September-October). Phytophthora spp. (P. capsici and $P$. parasitica) and Meloidogyne incognita are recurring and persistent problems and, together, cause substantial crop spoilage (Tello and Lacasa, 1997; Bello et al., 2004).

Until 2005, methyl bromide (MB) was use to disinfect soils to control both pathogens and to lessen the effects of fatigue caused by repeated monocultures (Martínez et al., 2011). Since that time, MB has been replaced by a mixture of 1,3dichloropropene and chloropicrin, but these, too, will shortly be banned by EU legislation. To this forthcoming ban must be added the growth in demand for ecological foods produced by sustainable agricultural practices, meaning that non-chemical methods must be sought for controlling soilborne plant pathogens and plant parasite nematodes adapted for use in intensive horticulture.

In recent years numerous alternatives to chemical disinfection have been studied, and of these, those based on organic amendments alone or in combination with solarisation seem to be the most promising. This method involves incorporating decomposable organic matter into the soil and subsequent humidification, covering with plastic for 2-15 weeks. Decomposition of the source of carbon in the humid or wet soil by anaerobic microorganisms reduces the oxygen content below the plastic (Messiha et al., 2007) in a process that has been called "biological disinfestation" (Blok et al., 2000), "reductive soil disinfestation" (Katasse et al., 2009) or "soil reductive sterilization" (Yossen et al., 2008). The anaerobic conditions increase the activities of the microorganisms in the soil, which have a suppressive effect on pathogens and parasites (Gamliel et al., 2000, Bonanomi et al., 2007; Oka et al., 2010, Kleim et al., 2011).

The combined action of organic amendment and solarisation has demonstrated its effectiveness in the control of Phytophthora capsici in pepper crops. The process of soil disinfection was called "biodisinfestation" by Núñez-Zofio et al. (2011). In these processes, the effects of anaerobiosis and suppression are added to the effect of temperature and of the gases released during decomposition of the organic matter, such as ammonia and nitrous acid (Lazarovits et al., 2001, Tenuta and Lazarovits, 2001, Arriaga et al., 2011). Although the characteristics of the OM are regarded as critical elements for the control of pathogens in general, the same characteristics do not seem to have a great impact on the control of some pathogens produced in anaerobic conditions (Bonanomi et al., 2007, 2010).

The use of Brassicaceae in crop rotations or as green manure amendments in biofumigation treatments (Staplenton and Bolaños, 2009) has been seen to reduce the incidence of some soilborne pathogens and plant parasites, including nematodes (Smolika et al., 2003, Larking and Griffin, 2008) through their release of 
isothiocyanates. For example, improved pathogen and weed control has been achieved by using amendments obtained from by-products produced during the extraction of oil from Brassica carinata and Sinapis alba seeds (Palmieri, 2005, Sachi et al., 2005, Lazzeri and Manici, 2000, Cohen et al., 2005, Lazzeri et al., 2004).

Biodisinfestation (BS) using fresh sheep manure (M) as amendment in August was seen to provide similar results to those obtained using MB to control Phytophthora spp. in pepper crops (Guerrero et al., 2004a). Production increased when the application was repeated more than two years (Guerrero et al., 2004b, 2006; Candido et al., 2005), but it seemed to have little effect when applied after the beginning of September (Guerrero et al., 2010).

Some growers are reluctant to use biodisinfestation (BS) because they would have to be able shorten the regular cycle by one or two months, which implies a substantial reduction in the crop yield (20-30\%). The implementation of biodisinfestation (BS) is one of the drawbacks of the method because biodisinfestation (BS) must begin in August (Guerrero et al., 2004 a).

The objective of the present study was to evaluate the effect of biodisinfestation (BS) using Brassica carinata pellets (BP) alone or combined with fresh sheep manure, when applied in August or October for the control of Meloidogyne incognita as well as marketable yield in greenhouse grown pepper crops in a mild-warm climate. The experiment was carried out over three consecutive years and the treatments were repeated in the same plots.

\section{Material and Methods}

\section{Experimental design}

The trials were carried out in a greenhouse located in Campo de Cartagena (Murcia, southeast Spain) over three consecutive crop seasons.

The soil was naturally contaminated by Meloidogyne incognita (race 2, biovar pepper according to Robertson et al., (2006). The experiment treatments were arranged in a completed randomized block design with three replicates, and a plot size of $52 \mathrm{~m}^{2}$. The soil was a clay loam with an organic matter content of $2 \%$, a total nitrogen content of $1.5 \mathrm{~g} \mathrm{~kg}^{-1}, \mathrm{pH}=7.8$, a $\mathrm{C} / \mathrm{N}$ ratio of 10.3 and electrical conductivity of $14.4 \mathrm{dS} \mathrm{m}^{-1}$.

Two treatments were studied: (i) BP: solarisation + Brassica carinata pellets $\left(0.3 \mathrm{~kg} \mathrm{~m}^{-2}\right.$ as organic amendment; (ii) $\mathrm{BP}+\mathrm{M}$ : solarization+a mixture of seed mail Brassica carinata pellets $\left(0.3 \mathrm{~kg} \mathrm{~m}^{-2}\right)$ and fresh sheep manure $\left(2.5 \mathrm{~kg} \mathrm{~m}^{-2}\right)$. Treatments were carried out for 6 weeks in both August and October (August and October treatments were performed in different experimental plots). Untreated (neither solarisation nor organic amendment) and MB-treated plots were included as reference controls.

Organic amendments were buried using a rotary tiller and a drip irrigation system $\left(31 \mathrm{~h}^{-1}\right.$ emitters spaced $0.40 \mathrm{~m}$ apart in the same rows) was installed. Then, a transparent plastic (PE, $0.05 \mathrm{~mm}$ ) was spread over the biodisinfestation treatments plots and the soil was watered for three hours a day on two consecutives days. The Brassica carinata pellets (BP) (Biofence Triumph Italia SPA) contained 6\% N, 7\% P, $2.4 \mathrm{~K}$ $84.2 \%$ organic matter. The glucosinolate sinigrin constituted the Brassica carinata seed mail as well as the derived isothiocyanate, these are efficacy to Meloidogyne nematodes (Lazzeri et al., 2010). The applied manure had the following characteristics: $\mathrm{pH} 8.2$ and EC $5.0 \mathrm{dS} \mathrm{m}^{-1}$, organic C: $400 \mathrm{~g} \mathrm{~kg}^{-1}$, total $\mathrm{N}: 25.0 \mathrm{~g} \mathrm{~kg}^{-1}$, total P: $5.5 \mathrm{~g} \mathrm{~kg}^{-1}$ and total $\mathrm{K}$ : $26.1 \mathrm{~g} \mathrm{~kg}^{-1}$.

In the treatments not including $\mathrm{M}$, composted manure was added at $2.5 \mathrm{~kg} \mathrm{~m}^{-2}$ before planting. Methyl bromide (MB)(98\% a.i., $2 \%$ chlorpicrin) was applied at a dosage 
of $30 \mathrm{~g} \mathrm{~m}^{-2}$ as a cold fumigation, using a volumetric dispenser after the soil was covered with virtually impermeable film (VIF, $0.04 \mathrm{~mm}$ thick) and maintained for one week.

In January, pepper plants (Capsicum annuum L) were planted with a crop density of 25,000 plants $\mathrm{ha}^{-1}$ corresponding to 3 rows of 45 plants per row. The crop season ended in the first week of August. Pests were controlled using biological control.

\section{Parameters studied}

Soil temperature (at 15 and $30 \mathrm{~cm}$ depth) was monitored using sensors connected to a data-logger (Hobo Weather Station, Onset Computer Corporation, US, H8-4 32K) with continuous data recording and reading every $15 \mathrm{~min}$.

Pepper fruits were harvested throughout the crop season and final marketable yield $(\mathrm{kg}$ $\mathrm{m}^{-2}$ ) was determined.

The incidence of Meloidogyne incognita was evaluated at the end of the crop season. Ten pepper plants of each experimental plot were pulled up in order to determine a) the percentage of galled plants and $b$ ) the galling index according to Bridge and Page (1980) on a scale of 0-10.

\section{Statistical analyses}

The data were studied using ANOVA. Differences among treatments were tested using the LSD test al $95 \%(\mathrm{P}<0.05)$. The data were transformed to achieve homocedasticity and normality using the following transformations: $\log (\mathrm{x}+1)$ for the crop yield and nodulation index, and the formula arcsine $\sqrt{ }(\mathrm{x})$ for the percentage of galled plants.

\section{Results}

\section{Incidence of $M$. incognita}

In the first year the galling index (GI) of BS was less than in the untreated control and the date of beginning the treatment or amendment had no influence. In the second year the GI of the August BS treatments was lower than that of the October BS treatments finding no differences between amendments in August, but in October there were differences.

In the third year there were differences in the GI between dates (August and October) and between both amendments. The GI of the October BP+M did not differ from that of the untreated control. The incidence was lower in the BP treatments than in the $\mathrm{BP}+\mathrm{M}$ in both dates. The GI values of the August treatments were more similar to those of MB than those of the October treatments. The BS treatments beginning in August reduced the incidence of Meloidogyne in the third year of application (GI was 3.8 in the first year, and 2.6 in the third year), the reduction being more pronounced in the treatment with $\mathrm{BP}(31.58 \%)$ than with $\mathrm{BP}+\mathrm{M}(14.6 \%)$. In the October treatments the incidence of $M$. incognita increased (50\% in $\mathrm{BP}+\mathrm{M}$ and $31 \%$ in $\mathrm{BP}$ ), and also in the non-treated control $(20 \%)$ and MB $(150 \%)$.

The percentage of infested plants varied very little between the BS treatments and the non-treated control in all three years. However, this proportion increased in MB in the last year. In the August BS treatments there was a (non-significant) tendency for the percentage of infested plants to fall as time passed. In the plots with GI values below 
4 no symptoms of yellowing, reduced growth, etc, were evident in the aerial part of the plants.

\section{Effect on pepper crop yield}

In the first year, differences were observed between BS dates but not between amendments, within a same date, being higher in August than in October (Table 2). Yield for the October treatments were similar to those obtained with MB but higher than those obtained in the non-treated control and lower than in the August BS treatments. In the second year there were no differences between dates or between both amendments (August and October) (Table 2), the production obtained with BS treatments being similar to that obtained with MB and higher than in the control.

In the third year, there were differences between dates but not between amendments (Table 2). The production obtained in October was lower than that obtained with MB, which was similar to that obtained in August. The production obtained with BS at any date was higher than that obtained with the control, as in the other years.

The August BS treatments provided similar levels of production or higher than MB every year, while the October BS treatments yields were no different from MB in two of the three years and always higher than the non-treated control.

\section{Soil Temperatures}

In general, the daily evolution of the maximum, mean and minimum temperatures was similar for the same depth $(15$ and $30 \mathrm{~cm}$ ) and treatment date (August and October). Differences between depths and also between dates for the same treatment were observed and between the treatments and the untreated control. Tables 3, 4 and 5 depict the percentage of the total biodisinfestation time that the soil temperatures were in given ranges above $30^{\circ} \mathrm{C}$. Above $38^{\circ} \mathrm{C}$ the values are represented at $1^{\circ} \mathrm{C}$ intervals, as suggested by Wang and McSorely (2008).

In the August treatments the temperature at $15 \mathrm{~cm}$ always were above $25^{\circ} \mathrm{C}$ the first year, above $30^{\circ} \mathrm{C}$ the second year and above $32^{\circ} \mathrm{C}$ the third, while at $30 \mathrm{~cm}$ the corresponding minimum temperatures were $28^{\circ} \mathrm{C}, 32^{\circ} \mathrm{C}$ and $34^{\circ} \mathrm{C}$, respectively. In the first year the percentage of time that the soil at $15 \mathrm{~cm}$ was above $42^{\circ} \mathrm{C}$ was higher for $\mathrm{BP}+\mathrm{M}(24.44 \%)$ than for $\mathrm{BP}(0.3 \%)$, while at $30 \mathrm{~cm}$ the differences between the amendments were slight ( $0.6 \%$ for $\mathrm{BP}$ and $0.10 \%$ for $\mathrm{BP}+\mathrm{M})$. In the second year the \% differences between soils with temperatures above $42^{\circ} \mathrm{C}$ were very small at $15 \mathrm{~cm}(1.12 \%$ for $\mathrm{BP}$ and $3.70 \%$ for $\mathrm{BP}+\mathrm{M})$, while at $30 \mathrm{~cm}$ the temperatures did not exceed $42^{\circ} \mathrm{C}$ in either amendment. In the third year the soil temperature frequently exceeded $42^{\circ} \mathrm{C}$ at $15 \mathrm{~cm}$ with both treatments $(18.70 \%$ for $\mathrm{BP}, 23.28 \%$ for $\mathrm{BP}+\mathrm{M})$ while at $30 \mathrm{~cm}$ the corresponding times were $\mathrm{BP}+\mathrm{M}(22.41 \%)$ and $\mathrm{BP}(1.65 \%)$.

The first year in October treatments the temperature was always lower than $38^{\circ} \mathrm{C}$ at both depths analysed and for both amendments except the second year at $15 \mathrm{~cm}$ for $\mathrm{BP}$, where the soil was above this temperature for $8.9 \%$ of the time. The percentage of time when the soil was above $35^{\circ} \mathrm{C}$ was greater for $\mathrm{BP}+\mathrm{M}$ than for $\mathrm{BP}$ at both depths the first year $(17.07 \%$ and $3.5 \%$, respectively, at $15 \mathrm{~cm}$ and $21.2 \%$ and $6.8 \%$, respectively, at $30 \mathrm{~cm})$. In the second year, the time with temperatures above $35^{\circ} \mathrm{C}$ was similar for both amendments at $15 \mathrm{~cm}(16.6 \%$ for BP+FSM and $25.3 \%$ for BP) at $30 \mathrm{~cm}(16.39 \%$ for $\mathrm{BP}+\mathrm{M}$ and $23.58 \%$ for $\mathrm{BP})$. In the third year, only the soils in $\mathrm{BP}+\mathrm{M}$ at $15 \mathrm{~cm}$ exceeded $35^{\circ} \mathrm{C}(4.40 \%$ of the time). 
In the untreated control the temperature was lower than for both treatments at both depths and dates during the three years of the experiment. Only in August of the first year did the soil temperature rise above $38^{\circ} \mathrm{C}(1.93 \%$ of the time $)$.

\section{Discussion}

In previous studies, we showed that biodisinfestation with fresh sheep or poultry manure provided acceptable levels of $M$. incognita control (Guerrero et al., 2004a; 2006) which improved as the treatments were prolonged over 3 to 7 years (Guerrero et al., 2007). The results of the present study show that biodisinfestation with seed mail Brassica carinata pellets, alone or in combination with fresh sheep manure, when begun in August provides effective control of $M$. incognita and ensures similar production levels to those obtained using MB. However when this treatment is beginning in October was not effective.

Many species of the family Brassicaceae contain glucosinolates, which upon decomposition, give rise to isothiocyanates (Kirkegard and Sarwar, 1998; Smolinka et al., 1997), which reduce the incidence of pathogens in the soil, whether buried as green manure (Larkin and Griffin, 2008; Pikerton et al., 2000) or whether in the form of by products of oil extract on from seeds (Palmieri, 2005; Sachi et al., 2005; Lazzeri, et al., 2004). The biofumigation effect of organic amendments on pathogens is due to, among other factors, toxic volatile compounds, anaerobic conditions and the increasing suppressive capacity of the soil (Everts et al., 2006; Katasse et al., 2009; Tenuta et al., 2002; Nuñez-Zofio et al., 2011; Arriaga et al., 2011; Oka, 2010; Bonanomi et al., 2007). The sinigrin glucosinolate of seed mail B. carinata pellets showed activity to Meloidogyne nematodes (Lazzeri et al., 2010), but not alls Brassicaceus pellets are effectives to the nematode control, which must be taken into account when selecting the amendment to the management of Meloidogyne (Zasada et al., 2009). The hydrothermal effect of solarization (Katan, 1981) has a direct effect on pathogens (Wang et al., 2006; Gamliel, et al., 2004; Katan, 2005) and an indirect effect since it speeds up the decomposition of the organic amendment applied. Combining soil solarization with sorghum green manure reduced the nematodes populations more that the untarped sorghum but the combination of solarisation with broccoli residues did no reduced nematodes populations compared with untarped broccoli (Zasada et al., 2010).

In our case, the volatile compounds were not measured during the biodisinfestation process but they may have been involved in reducing the incidence of $M$. incognita when compared with the reduction obtained in October with BP and $\mathrm{BP}+\mathrm{M}$ each year and with the same treatment in August in the third year. However, no such effect was observed in the second and third years with $\mathrm{BP}+\mathrm{M}$ since the GI in October was similar to that of the control. Neither was nematode control improved when BP were mixed with $\mathrm{M}$ on both dates. An additive or synergic effect might have been expected between both amendments since $\mathrm{M}$ provided good control of $M$. incognita in pepper (Guerrero et al., 2007; Ros et al., 2008) as did the pellets alone (Guerrero et al., 2009). However, the interaction seems to be negative. In our conditions and soils with a $\mathrm{pH}>8.0$, decomposition of the amendments generates $\mathrm{NH}_{3}$, whose effect on fungi and nematodes, as described by Everts et al., (2006) and Riegel and Noe, (2000), would explain the extent to which these pathogens are controlled by biosdisinfestation in similar conditions. The organic carbon may negatively influence the toxicity of glucosinolate-hydrolysis products (Morra, 2004). It seems that the organic matters of fresh sheep manure are not adequately to address the complex relationships than occur when using plant tissues as a source for pesticidal compounds. 
It seems that the intrinsic water content of Brassicaceus tissues is insufficient to allow maximum hydrolysis of glucosinolates to isothiocyanates (Matthiessen, 2004). The addition of water performs the dual functions of boosts this process and serving to carry the isothiocyanates so formed into the soil. In our case the water absorption by fresh manure (M) could reduce the available water below the needs for hydrolysis of glucosinolates in pellets of $B$. carinata $(\mathrm{BP})$. This might explain the lower efficiency of $\mathrm{BP}+\mathrm{M}$ to $\mathrm{BP}$ in reducing the incidence of Meloidogyne.

Differences were observed in the soil oxygen content between the treatments (Guerrero, data not shown). The accumulated number of hours with oxygen levels below 5 or $1 \%$ was greater in $\mathrm{BP}+\mathrm{M}$ than in the $\mathrm{BP}$ treatments and greater in August than in October for the same treatment. In the BP treatments the effect on the decrease of oxygen content disappeared after 3-4 weeks, while in BP+M it remained until the end of the solarization process. Anaerobios is mechanisms may explain the differences in the incidence of $M$. incognita observed between the treatments and the control but not between BP and BP+M. Nuñez-Zofío et al. (2011) observed differences between Brassica carinata pellets (BP)+Sinapis alba green manure and fresh manure (M) biodisinfestation treatments for the control of Phytophthora sp. in pepper, but in the opposite direction as we observed for M. incognita. Nuñez-Zofío et al. (2011 and 2012) found greater numbers of bacteria, actinomycetes and Pseudomonas spp. in soils containing pepper crops biodisinfected with Brassica carinata pellets (BP)+Sinapis alba green manure than in soils disinfected with $\mathrm{M}$ or semi-composted sheep manure and the control, finding a positive correlation between total microbiota and the suppressive capacity of the soil after biodisinfectation accompanied by a similar incidence of Phyptophthora sp. in the crop. We did not measure the micobiota but the effects on the incidence of the pathogen (M. incognita) differed between BP and BP+M the third year, which suggests that the possible effect in soil suppressiveness was not the main factor acting in the biodisinfestation action mechanism.

Soil temperature seems to have been the main component of the effect of biodisinfestation effect on $M$. incognita. In the August treatments of the third year more than 150 accumulated hours of temperatures above $42^{\circ} \mathrm{C}$ were recorded in $\mathrm{BP}$ at $15 \mathrm{~cm}$ depth and in $\mathrm{BP}+\mathrm{M}$ at 15 and $30 \mathrm{~cm}$; at this last depth the figure was $12.5 \mathrm{~h}$ for $\mathrm{BP}$. Wang and McSorley (2008) found the accumulated exposure of more than $15 \mathrm{~h}$ to temperatures of $42^{\circ} \mathrm{C}$ were lethal for the eggs and juveniles 2 of $M$. incognita. In our case, this lethal exposure time was obtained for all the treatments and at both soil depths in the third year, at $15 \mathrm{~cm}$ the second year and at both depths the first year. However, the GI differed between treatments the second and third year. The time with temperatures above $38^{\circ} \mathrm{C}$ exceeded $400 \mathrm{~h}$ the second year at $30 \mathrm{~cm}$ in $\mathrm{BP}$ and at 15 and $30 \mathrm{~cm}$ in $\mathrm{BP}+\mathrm{FSM}$ and only at $15 \mathrm{~cm}$ in BP the third year. Although Wang and McSorley (2008) suggested that $390 \mathrm{~h}$ at $38^{\circ} \mathrm{C}$ were necessary to kill all $\mathrm{J} 2$, this would still not explain the differences in GI between the treatments. Exposure of J2 and eggs to sublethal periods ( $<13$ hours) of temperatures above $42.5^{\circ} \mathrm{C}$ may have an accumulative effect (Heald and Robinson, 1987), while temperatures that vary between22 and $42^{\circ} \mathrm{C}$ considerably reduce $M$. incognita $\mathrm{J} 2$ populations and eggs (Wang and Mcsorley, 2008). However, a reduction in the populations as a result of solarization is not always reflected in the adequate control of the damage caused to crops, which, according to Wang and McSorley (2008) would be related to low temperatures at greater depths of the soil. Populations remaining in the deep soil would recolonized and infest the damaged roots (Hewlett and Dickson, 1991), as occurred in the untreated control of long term crops (Chellemi et al., 1993). In our case, the 7 month crop cycle would have facilitated the multiplication of $M$. incognita and reinfestation of the plants, 
particularly in the autumn treatments, when the temperature never exceeded $38{ }^{\circ} \mathrm{C}$ at either depth in any of the years.

Despite the fact that solarization only has a short term impact on nematode populations (Wang and McSorley, 2008) such an effect can be improved in conjunction with organic amendments, both in warmer and cooler periods of the year. The action of the volatile compounds released during the decomposition of biodisinfestation amendments, the possible increase in the microbial community, and the concomitant suppressive effect of the soil and the reduction of the soil oxygen content, together, would explain the damage caused to nematodes by the August treatment. This reduced incidence of $M$. incognita enabled yields of pepper fruit similar to those obtained by MB. While in Autumn biodisinfestation of greenhouse soils used for growing pepper in south-eastern Spain cannot necessarily be recommended for the total control of $M$. incognita, such treatment can be used to alleviate the effect of soil fatigue due to microbiological causes (Martínez et al., 2011). The use of cultivars or plants grafted on rootstock that carry genes resistant to $M$. incognita may be considered as a complement to biodisinfestation for the control of soil pathogens (Guerrero et al., 2012).

\section{Acknowledgments}

This research was financially supported by the National Institute for Agricultural and Food Research and Technology (INIA) of the Spanish Ministry of Science and Inno vation (projects RTA 2008-00058-C03 and RTA 2011-00005-C03).

\section{References}

Arriaga H, Núñez-Zofío M, Larregla S, Merino P. 2011. Gaseous emissions from soil biodisinfestation by animal manure on a greenhouse pepper crop. Crop Protection 30: 412-419.

Bello A, López-Pérez JA, García-Álvarez A, Arcos SC, Ros C, Guerrero MM, Guirao P. and Lacasa, A. 2004. Biofumigación con solarización para el control de nematodos en cultivo de pimiento. En: Lacasa A, Guerrero MM, Oncina M, Mora JA, eds. Desinfección de suelos en invernaderos de pimiento. Publicaciones de la Consejería de Agricultura, Agua y Medio Ambiente. Región de Murcia. Jornadas 16: 105-129.

Blok WJ, Lamers JG, Termorshuizen AJ, Bollen GJ. 2000. Control of soilborne plant pathogens by incorporating fresh organic amendments followed by tarping. Phytopathology 90: 253-259.

Bonanomi G, Antignani V, Pane C, Scala F. 2007. Suppression of soilborne fungal diseases with organic amendments. J. Plant Pathol 89:311-324.

Bonanomi G, Antignani V, Capodilupo M, Scala F. 2010. Identifying the characteristics of organic soil amendments that suppress soil-borne plant diseases. Soil Biol Biochem 42: 136-144.

Bridge J, Page SLJ. 1980. Estimation of root-knot infestation levels in roots using a rating chart. Trop Pest Manag 26: 296-298. 
Candido V, Miccolis V, Basile M, D’Addabbo T, Gatta G. 2005. Soil solarization for the control of Meloidogyne javanica on eggplant in Southern Italy. Acta Hort 698: 195199.

Chellemi DO, Olson SM, Scott JW, Mitchell DJ, McSorley R. 1993. Reduction of phytoparasitic nematodes on tomato by solarization and genotype. Supplement to Journal of Nematology 25: 800-805.

Cohen MF, Yamasaki H, Mazzola M. 2005. Brassica napus seed meal soil amendment modifies microbial community structure, nitric oxide production and incidence of Rhizoctonia root rot. Soil Biol Biochem 37: 1215-1227.

Everts KL, Sardanelli S, Kratochvil RJ, Armentrout DK, Gallagher LE. 2006. Root-knot and root-lesion nematode suppression by cover crops, poultry litter, and poultry litter compost. Plant Dis 90: 487-492.

Gamliel A, Austerweil M, Kritzman G. 2000. Non-chemical approach to soilborne pest management-organic amend ments. Crop Protection 19:847-853.

Gamliel A, Gadkar V, Zilberg V, Beniches M, Rabinowich E, Manor H, Wininger S, Kapulnik Y. 2004. Effect of solarization intensity on the control of pink root of chives, and the response of the crop to AM fungal application. Symbiosis 37:233-247.

Guerrero MM, Lacasa A, Ros C, Bello A, Martínez MC, Torres J, Fernández, P. 2004a. Efecto de la biofumigación con solarización sobre los hongos del suelo y la producción: fechas de desinfección y enmiendas. En: Lacasa A, Guerrero MM, Oncina M, Mora JA, eds. Desinfección de suelos en invernaderos de pimiento. Publicaciones de la Consejería de Agricultura, Agua y Medio Ambiente. Región de Murcia. Jornadas 16: 208-238.

Guerrero MM, Ros C, Martínez MA, Barceló N, Martínez MC, Guirao P, Bello A, Contreras J, Lacasa A. 2004b. Estabilidad en la eficacia desinfectante de la biofumigación con solarización en cultivos de pimiento. Actas Hort 42: 20-24.

Guerrero MM, Ros C, Martínez MA, Martínez MC, Bello A, Lacasa A. 2006. Biofumigation vs biofumigation plus solarization to control Meloidogyne incognita in sweet pepper. Bulletin OILB/Crop 29 (4): 313-318.

Guerrero MM, Martínez MA, Ros C, Bello A, Fernández P, Martínez MC, Lacasa A. 2007. Eficacia de la biosolarización como desinfectante del suelo en invernaderos de pimiento. Actas Hort 48: 451-454.

Guerrero MM, Lacasa CM, Ros C, Martínez V, Fenoll J, Torres J, Beltrán C, Fernández P, Bello A, Lacasa A. 2009. Pellets de brasicas como enmiendas para biosolarización de invernaderos de pimiento. Actas de Hort 54: 424:429.

Guerrero MM, Ros C, Lacasa C, Martínez V, Lacasa A, Fernández P, Martínez MA, Núñez M, Larregla S, Díez-Rojo MA, Bello A. 2010. Effect of biosolarization using pellets of Brassica carinata on soil-borne pathogens in protected pepper crops. Acta Horticulturae 381: 337-344. 
Guerrero MM, Lacasa CM, Hernández A, Martínez V, Martínez MA, Ros C. 2012 Biosolarización e injerto para el manejo integrado de los patógenos del suelo en cultivos de pimiento en invernadero. Actas de Hort 60: 321-326.

Heald CD, Robinson AF. 1987. Effect of soil solarization on Rotylenchuslus reniformis in the lower Rio Grande Valley of Texas. Journal of Nematology 19: 93-103.

Hewlet TE, Dikson DW. 1991. Population dynamics of Meloidogyne arenaria race 1 in peanut. Journal of Nematology $25: 532-533$.

Katan J. 1981. Solar heating (solarization) of soil control of soilborne pets. Annual Review of Phytopathology 19:211-236.

Katan J. 2005. Soil disinfestation: One before Methyl Bromide phase out. Procedures of $\mathrm{VI}^{\text {th }}$ International Symposium on Chemical and Non-chemical Soil and SubstrateDisinfestation. Acta Horticulturae 698: 19-25.

Katase M, Kubo C, Ushio S, Ootsuka E, Takeuchi T, Mizukubo T. 2009. Nematicidal activity of volatile fatty acids generated from wheat bran in reductive soil disinfestation. Nematol Res 39: 53-62.

Kirkegaard JA, Sarwar M. 1998. Biofumigation potential of brassicas. Variation in glucosinolate profiles of diverse field-grown brassicas. Plant and Soil 201:71-89.

Klein E, Katan J, Gamliel A. 2011. Soil suppressiveness to Fusarium dissease following organic amendments and solarization. Plant Dis 95:1116-1123.

Lacasa A, Guirao P. 1997. Investigaciones actuales sobre alternativas al uso del bromuro de metilo en pimiento en invernaderos del campo de Cartagena. En: López A, Mora JA, eds. Publicaciones de la Consejería de Medio Ambiente, Agricultura y Agua. Jornadas 11:21-36.

Larkin RP, Griffin TS. 2008. Control of soil potato diseases using Brassica green manure. Crop Protection 26: 1067-1077.

Lazzeri L, Manici LM. 2000. The glucosinolate- myrosinase system: a natural and practical tool for biofumigation. Acta Hort 532: 89-95.

Lazzeri L, Leoni O, Manici LM. 2004. Biocidal plant dried pellets for biofumigation. Industrial Crops and Products 20:59-65.

Lazzeri L, Leoni O, Mancini L, Palmieri S, Patalano G. 2010. Use of seed flour as soil pesticide. Patent number US7749549B2.

Lazarovits G. 2001. Management of soil-borne plant pathogens with organic soil amendments: a disease control strategy salvaged from the past. Can J Plant Pathol 23: 17. 
Martínez MA, Martínez MC, Bielza P, Tello J, Lacasa A. 2011. Effect of biofumigation with manure amendments and repeated biosolarization on Fusarium density in pepper crops. Journal Ind us trial Microbiology Biotechnology 38 (10): 3-11.

Messiha N, Van Diepeningen A, Wenneker M, Van Beuningen A, Janse J, Coehen T, Termorshuizen A, Van Bruggen A, Blok W.2007. Biological soil disinfestation (BSD), a new control method for potato brown rot, caused by Ralstonia solanacearum race 3 biovar 2. Eur. J Plant Path 117: 403-415.

Matthiessen J. 2004. The importance of plant maceration and water in achieving high ITC levels in soil. pp 13. In Proceedings of the First International Symposium "Biofumigation: a possible alternative to methylbromide? A way for optimising potential for an integrate management of soil-borne pests and diseases.” In: Lazzeri L, Matthiessen J, Morra M J, Palmieri S, Rollin P. eds. Italian Ministry of Agricultural and Forestry Politics and Italian Ministry of Environmental and Territory. 94 pp.

Morra MJ. 2004. Controlling soil-borne plant pests using glucosinolate containing tissues. Pp 7 In Proceedings of the First International Symposium "Biofumigation: a possible alternative to methylbromide? A way for optimising potential for an integrate management of soil-borne pests and diseases." In: Lazzeri L, Matthiessen J, Morra MJ, Palmieri S, Rollin P. Eds. Italian Ministry of Agricultural and Forestry Politics and Italian Ministry of Environmental and Territory. 94 pp.

Núñez-Zofío, Larregla S, Garbisu C. 2011. Application of organic amendments followed by soil plastic mulching reduces the incidence of Phytophthora capsici in pepper crops under temperate climate. Crop Protection 30: 1563-1572.

Oka Y. 2010. Mechanisms of nematode suppression by organic soil amendments: a review. Appl Soil Ecol 44: 101-115.

Palmieri S. 2005. Biofumigation: a new technology based on the use of sulphurcontaining metabolites in Brassica plants. Proc. of Annual Meeting of the Association for the Advancement of ind ustrial crops. Murcia, Spain, 17-21 September, pp. 201-213.

Pikerton JN, Ivors KL, Miller ML, Moore LW. 2000. Effect of soil solarization and cover crops on populations of selected soilborne plant pathogens in Western Oregon. Plant Diseases 84:952-960.

Riegel C, Noe JP, 2000. Chicken litter soil amendment effects on soilborne microbes and Meloidogyne incognita on cotton. Plant Dis 84: 1275-1281.

Robertson L, López-Pérez JA, Bello A, Díez-Rojo MA, Escuer M, Piedra-Buena A, Ros C, Martínez C. 2006. Characterization of Meloidogyne incognita, M. arenaria and $M$. hapla populations from Spain and Uruguay parasitizing pepper (Capsicum annuum). Crop Protection 25: 440-445.

Sachi S, Odorizzi S, Lazzeri L and Marciano P. 2005. Effect of Brassica carinata seed meal treatment on the Trichoderma harzianum T39-Sclerotinia species interaction. Acta Hort. 698: 289-292. 
Smolinska U, Morra MJ, Kanudsen GR, James RL. 2003. Isothiocyanate produced by Brassicaceae species as inhibitors of Fusarium oxysporum. Plant Dis 87: 407-412.

Smolinska U, Morra MJ, Kundsen GR, Brown PD. 1997. Toxicity of glucosinolate degradation products from Brassica napus seed meal toward Aphanomyces euteiches $\mathrm{f}$. sp. pisi. Phytopathology 87: 77-82.

Stapleton J, Bañuelos GS. 2009. Biomass crops can be used for biological disinfestation and remediation of soil and water. California Agriculture 63: 41-46.

Tello J, Lacasa A. 1997. Problemática fitosanitaria del suelo en cultivos de pimiento en el Campo de Cartagena. En: López A, Mora JA, eds. Publicaciones de la Consejería de Medio Ambiente, Agricultura y Agua. Jornadas 11: 11-17.

Tenuta M, Lazarovits G. 2002. Ammonia and nitrous acid from nitrogenous amendments kill the microsclerotia of Verticillium dahliae. Phytopathol 92:255-264.

Tenuta M, Kenneth LC, Lazarovits G. 2002. Volatile fatty in liquid swine manure can kill microsclerotia of Verticillium dahliae. Phytopathology 92:548-552.

Wang KH, McSorley R. 2008. Exposure time to lethal temperatures for Meloidogyne incogita suppression and its implication for soil solarisation. Journal of Nematology 40 (1): 7-12.

Wang KH, McSorley R, Kokalis-Burelle N. 2006. Effects of cover cropping solarization, and soil fumigation on nematode comunities. Plant and soil 286: 299-243.

Yossen V, Zumelza G, Gasoni L, Kobayashi K. 2008. Effect of soil reductive sterilization on Fusarium wilt in greenhouse carnation in Cordoba, Argentina. Australasian Plant Pathology 37: 520-522.

Zasada I, Meyer SLF, Morra MJ. 2009. Brassicaceous seed meals as soil Amendments to suppress the plant-parasitic nematodes Pratylenchus penetrans and Meloidogyne incognita. Journal of Nematology 41 (3): 221-227.

Zasada IA, Halbrent JM, Kokalis-Burelle N, La Mondia J, McKerny MV, Noling JW. 2010. Menaging nematodes witout methyl bromide. Annu Rev Phytopathol 48: 311328. 
Table 1. Incidence of Meloidogyne incognita (GI and \% of galled plants).

\begin{tabular}{|l|l|l|l|l|l|l|}
\hline & \multicolumn{2}{|l|}{ First crop seas on } & \multicolumn{2}{l|}{ Second crop seas on } & \multicolumn{2}{l|}{ Third crop season } \\
\hline Treatement & GI & $\begin{array}{c}\text { \% of galled } \\
\text { plants }\end{array}$ & GI & $\begin{array}{c}\text { \% of galled } \\
\text { plants }\end{array}$ & GI & $\begin{array}{c}\text { of galled } \\
\text { plants }\end{array}$ \\
\hline Untreated & $5.7 \pm 0.96 \mathrm{~d}$ & $100.0 \pm 0 \mathrm{~b}$ & $6.3 \pm 0.79 \mathrm{~cd}$ & $100.0 \pm 0 \mathrm{~b}$ & $7.3 \pm 1.0 \mathrm{e}$ & $100.0 \pm 0 \mathrm{~b}$ \\
\hline MB & $0.1 \pm 0.51 \mathrm{a}$ & $6.6 \pm 0.11 \mathrm{a}$ & $0.2 \pm 0.77 \mathrm{a}$ & $6.6 \pm 1.54 \mathrm{a}$ & $1.5 \pm 0.70 \mathrm{a}$ & $43.3 \pm 37.85 \mathrm{a}$ \\
\hline BP+M august & $4.1 \pm 0.88 \mathrm{~b}$ & $100.0 \pm 0 \mathrm{~b}$ & $3.7 \pm 1.64 \mathrm{~b}$ & $93.3 \pm 1.54 \mathrm{~b}$ & $3.5 \pm 1.87 \mathrm{c}$ & $96.7 \pm 5.7 \mathrm{~b}$ \\
\hline BP august & $3.8 \pm 1.69 \mathrm{~b}$ & $93.3 \pm 0.11 \mathrm{~b}$ & $4.3 \pm 2.19 \mathrm{~b}$ & $86.6 \pm 23.09 \mathrm{~b}$ & $2.6 \pm 1.54 \mathrm{~b}$ & $86.7 \pm 15.27 \mathrm{~b}$ \\
\hline BP+M october & $4.6 \pm 1.76 \mathrm{~b}$ & $93.3 \pm 0.11 \mathrm{~b}$ & $6.8 \pm 1.14 \mathrm{~d}$ & $100.0 \pm 0 \mathrm{~b}$ & $6.9 \pm 2.42 \mathrm{e}$ & $100.0 \pm 0 \mathrm{~b}$ \\
\hline BP october & $4.1 \pm 1.12 \mathrm{~b}$ & $100.0 \pm 0 \mathrm{~b}$ & $5.4 \pm 0.98 \mathrm{c}$ & $100.0 \pm 0 \mathrm{~b}$ & $5.4 \pm 2.42 \mathrm{~d}$ & $100.0 \pm 0 \mathrm{~b}$ \\
\hline
\end{tabular}

Mean values $(n=30) \pm$ standard errors. For each parameter, values followed by the same letter are not significantly different according to Test LSD. GI: galling index; MB: Methyl bromide-treated plots to 30 g. $\mathrm{m}^{-2} ; \mathrm{BP}+\mathrm{M}$ : biodisinfestation with Brassica carinata pellets +fresh sheep manure; BP: biodisinfestation with Brassica carinata pellets.

\section{Table 2. Pepper crop yield $\left(\mathrm{kg} \mathrm{m}^{-2}\right)$.}

\begin{tabular}{|l|c|c|c|}
\hline Crop yield $\left(\mathrm{kg} \mathrm{m}^{-2}\right)$ & First seas on & Second season & Third season \\
\hline Untreated & $9.8 \mathrm{c}$ & $10.3 \mathrm{~b}$ & $9.7 \mathrm{~d}$ \\
\hline MB & $11.1 \mathrm{~b}$ & $11.9 \mathrm{a}$ & $12.0 \mathrm{~b}$ \\
\hline BP+M august & $12.7 \mathrm{a}$ & $11.6 \mathrm{a}$ & $12.1 \mathrm{ab}$ \\
\hline BP august & $12.6 \mathrm{a}$ & $12.2 \mathrm{a}$ & $12.7 \mathrm{a}$ \\
\hline BP+M october & $10.9 \mathrm{~b}$ & $11.8 \mathrm{a}$ & $11.7 \mathrm{c}$ \\
\hline BP october & $10.9 \mathrm{~b}$ & $12.1 \mathrm{a}$ & $11.1 \mathrm{c}$ \\
\hline
\end{tabular}

MB: Methyl bromide-treated plots to $30 \mathrm{~g} \cdot \mathrm{m}^{-2}$; BP+M: biodisinfestation with Brassica carinata pellets +fresh sheep manure; BP: biodisinfestation with Brassica carinata pellets. Values followed by diffe rent upper case are different at significance level $\mathrm{p}<0.05$. 
Table 3. Percentage of hours accumulated for each range of soil temperatures at 15 and $30 \mathrm{~cm}$ depth in each treatment for 27 days in August and 40 days in October. First season.

\begin{tabular}{|c|c|c|c|c|c|c|c|c|c|c|c|c|}
\hline \multirow{2}{*}{$\begin{array}{l}\text { Temperature } \\
\left({ }^{\circ} \mathrm{C}\right)\end{array}$} & \multicolumn{6}{|c|}{$15 \mathrm{~cm}$ depth } & \multicolumn{6}{|c|}{$30 \mathrm{~cm}$ depth } \\
\hline & $\begin{array}{c}\text { Untreated } \\
\text { august }\end{array}$ & $\begin{array}{c}\text { Untreated } \\
\text { october }\end{array}$ & $\begin{array}{c}\text { BP } \\
\text { august }\end{array}$ & $\begin{array}{c}\text { BP } \\
\text { october }\end{array}$ & $\begin{array}{l}\mathrm{BP}+\mathrm{M} \\
\text { august }\end{array}$ & $\begin{array}{l}\mathrm{BP}+\mathrm{M} \\
\text { october }\end{array}$ & $\begin{array}{c}\text { Untreated } \\
\text { august }\end{array}$ & $\begin{array}{l}\text { Untreated } \\
\text { october }\end{array}$ & $\begin{array}{c}\text { BP } \\
\text { august }\end{array}$ & $\begin{array}{c}\mathrm{BP} \\
\text { october }\end{array}$ & $\begin{array}{l}\mathrm{BP}+\mathrm{M} \\
\text { august }\end{array}$ & $\begin{array}{l}\mathrm{BP}+\mathrm{M} \\
\text { october }\end{array}$ \\
\hline$<30$ & 11.31 & 81.6 & & 68.3 & & 11.93 & 86.7 & 56.71 & 25.6 & 71.8 & 4.7 & 5.2 \\
\hline $30.1-35$ & 54.58 & 18.4 & & 28.2 & 32.93 & 71.0 & 12.75 & 43.29 & 14.98 & 21.4 & 26.11 & 73.6 \\
\hline $35.1-38$ & 32.18 & & 57.36 & 3.5 & 34.82 & 17.07 & 0.55 & & 20.2 & 6.8 & 41.9 & 21.2 \\
\hline $38.1-39$ & 0.53 & & 26.2 & & 6.42 & & & & 21.66 & & 27.29 & \\
\hline $39.1-40$ & 1.4 & & 12.14 & & 0.46 & & & & 12.97 & & 6.67 & \\
\hline $40.1-41$ & & & 3.02 & & 0.76 & & & & 2.39 & & 0.56 & \\
\hline $41.1-42$ & & & 0.98 & & 0.17 & & & & 1.6 & & 0.52 & \\
\hline $42.1-43$ & & & 0.3 & & 7.38 & & & & 0.6 & & 0.10 & \\
\hline $43-44$ & & & & & 15.6 & & & & & & & \\
\hline $44-45$ & & & & & 1.46 & & & & & & & \\
\hline
\end{tabular}

MB: Methyl bro mide-treated plots to $30 \mathrm{~g} \cdot \mathrm{m}^{-2}$; $\mathrm{BP}+\mathrm{M}$ : biodisinfestation with Brassica carinata pellets+fresh sheep manure; BP: biodisinfestation with Brassica carinata pellets. 
Table 4. Percentage of hours accumulated number in each range of soil tempe ratures at 15 and $30 \mathrm{~cm}$ depth in each treatment for 30 days in August and 41 October. Second season.

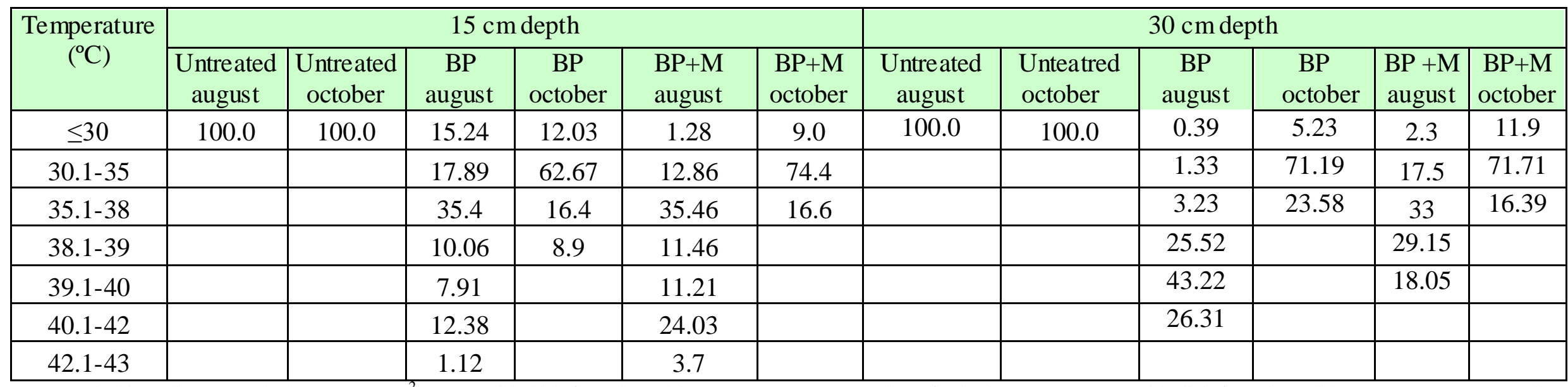

MB: Methyl bro mide-treated plots to $30 \mathrm{~g} \cdot \mathrm{m}^{-2}$; BP+M: biodisinfestation with Brassica carinata pellets+fresh sheep manure; BP: biodisinfestation with Brassica carinata pellets 
Table 5. Percentage of number of hours accumulated in each range of soil temperatures at 15 and $30 \mathrm{~cm}$ depth in each treatment for 44 days in August and 41 October. Third season.

\begin{tabular}{|c|c|c|c|c|c|c|c|c|c|c|c|c|}
\hline \multirow[b]{2}{*}{$\begin{array}{l}\text { Temperature } \\
{ }^{\circ} \mathrm{C}\end{array}$} & \multicolumn{6}{|c|}{$15 \mathrm{~cm}$} & \multicolumn{6}{|c|}{$30 \mathrm{~cm}$} \\
\hline & $\begin{array}{c}\text { Untreated } \\
\text { august }\end{array}$ & $\begin{array}{l}\text { Untreated } \\
\text { october }\end{array}$ & $\begin{array}{c}\mathrm{BP} \\
\text { august }\end{array}$ & $\begin{array}{c}\text { BP } \\
\text { october }\end{array}$ & $\begin{array}{l}\mathrm{BP}+\mathrm{M} \\
\text { august }\end{array}$ & $\begin{array}{l}\mathrm{BP}+\mathrm{M} \\
\text { october }\end{array}$ & $\begin{array}{c}\text { Untreated } \\
\text { august }\end{array}$ & $\begin{array}{l}\text { Unteatred } \\
\text { october }\end{array}$ & $\begin{array}{c}\text { BP } \\
\text { augut }\end{array}$ & $\begin{array}{c}\mathrm{BP} \\
\text { october }\end{array}$ & $\begin{array}{l}\mathrm{BP}+\mathrm{M} \\
\text { august }\end{array}$ & $\begin{array}{c}\mathrm{BP}+\mathrm{M} \\
\text { october }\end{array}$ \\
\hline$<30$ & 89.03 & 100.0 & & 87.05 & & 75.56 & 4.06 & 100.0 & & 98.98 & & 97.7 \\
\hline $30.1-35$ & 10.97 & & 7.4 & 12.95 & & 20.04 & 62.82 & & & 1.02 & & 2.3 \\
\hline $35.1-38$ & & & 40.31 & & 30.65 & 4.4 & 33.12 & & 37.21 & & 31.28 & \\
\hline $38.1-39$ & & & 9.53 & & 25.41 & & & & 36.7 & & 15.71 & \\
\hline $39.1-40$ & & & 9.22 & & 7.8 & & & & 16.31 & & 14.47 & \\
\hline $40.1-41$ & & & 7.94 & & 6.4 & & & & 3.5 & & 10.45 & \\
\hline $41.1-42$ & & & 6.9 & & 6.46 & & & & 4.36 & & 5.68 & \\
\hline $42.1-43$ & & & 6.19 & & 6.05 & & & & 1.65 & & 4.22 & \\
\hline $43.1-44$ & & & 5.15 & & 4.6 & & & & & & 5.2 & \\
\hline $44.1-45$ & & & 4.39 & & 4.5 & & & & & & 3.54 & \\
\hline $45.1-46$ & & & 2.27 & & 4.1 & & & & & & 9.45 & \\
\hline $46.1-47$ & & & 0.7 & & 4.03 & & & & & & & \\
\hline
\end{tabular}

MB: Methyl bro mide-treated plots to $30 \mathrm{~g} . \mathrm{m}^{-2}$; BP+M: biodisinfestation with Brassica carinata pellets+fresh sheep manure; BP: biodisinfestation with Brassica carinata Pellets. 


\subsection{CONCLUSIONES DE BIOSOLARIZACIÓN}

\section{A. Reiteración de la aplicación 7 años, con reducción de la cantidad de enmienda}

La eficacia de la biosolarización con estiércol fresco de ovino y gallinaza para el control de Meloidogyne incognita se mantiene a niveles aceptables al reiterar la aplicación en el mismo suelo. Aunque presenta algunas deficiencias puntuales, la tendencia es a estabilizarse en el tiempo.

Se puede reducir la dosis de enmienda orgánica sin que haya pérdida de eficacia desinfectante, manteniendo niveles de cosecha similares al bromuro de metilo, por lo que se puede considerar como un método eficaz de desinfección del suelo.

\section{B. Enmiendas para cultivos ecológicos}

Los pellets de Brassica carinata mejoran la eficacia de la biosolarización en el control de Meloidogyne incognita cuando se mezclan con estiércol fresco de ovino, proporcionando producciones comerciales superiores al bromuro de metilo, siendo una forma eficiente de desinfección de suelos de invernaderos ecológicos.

\section{Enmiendas específicas para biosolarización de invernaderos ecológicos}

Enmiendas elaboradas para biosolarizar invernaderos ecológicos con estiércoles y restos de industrias cítricas, restos del procesado del brócoli y de restos de cultivos de brócoli, proporcionaron buenos niveles de control de Meloidogyne incognita y de malas hierbas y producciones similares al bromuro de metilo.

\section{La biosolarización más eficaz que la biofumigación}

La biofumigación con mezcla de estiércol fresco de ovino y gallinaza se mostró ineficaz para el control de Meloidogyne incognita, aunque se repitiera en tres campañas en el mismo suelo, y proporcionó cosechas similares a las del suelo no desinfectado.

La biosolarización mejoró el control del nematodo con el tie mpo a niveles similares al bromuro de metilo y las cosechas fueron similares o mayores que las del bromuro de metilo.

\section{E. Pellets de Brassica carinata enmienda de biosolarización para el control de patógenos}

Los pellets de Brassica carinata solos o mezclados con estiércol fresco de ovino utilizados como enmienda orgánica en la biosolarización se muestran tan eficaces como el bromuro de metilo en la destrucción del inóculo de Phytophthora capsici si se inicia el proceso en agosto, no diferenciándose del testigo no desinfectado si se inicia en octubre.

La mezcla de pellets de Brassica carinata y estiércol fresco de ovino se mostró tan eficaz como el bromuro en el control de Meloidogyne incognita al iniciar la biosolarización en agosto, mejorando la eficacia de los pellets solos y la del estiércol solo. En octubre la biosolarización no fue eficaz con los pellets solos o mezclados con estiércol. 
La biosolarización en agosto proporcionó mayor cosecha comercial que el bromuro de metilo, siendo similar al testigo no desinfectado cuando se inició en octubre.

\section{F. Pellets de Brassica carinata para el control de nematodos mediante biosolarización repetida}

La biosolarización iniciada en octubre cuando finaliza el ciclo habitual del cultivo de pimiento en los invernaderos del Campo de Cartagena no proporciona aceptables niveles de control de Meloidogyne incognita utilizando pellets de Brassica carinata solos o con estiércol fresco de ovino, aunque se reitere su aplicación tres años consecutivos, reduciéndose significativamente la cosecha comercial.

Por el contrario si se inicia en agosto las producciones son iguales o mayores que las del bromuro de metilo y el control del nematodo mejora a medida que se repite la biosolarización.

La temperatura del suelo alcanzada en el periodo de biosolarización parece ser determinante de la eficacia desinfectante, siendo reducido el efecto de la enmienda. 

CONCLUSIONES DE LA TESIS 



\section{CONCLUSIONES DE LA TESIS}

\section{CARACTERIZACIÓN DE LAS POBLACIONES DE PHYTOPHTHORA SP. DE LOS INVERNADEROS DE PIMIENTO DEL CAMPO DE CARTAGENA}

De los 70 aislados de Phytophthora sp. obtenidos de plantas de pimiento en los invernaderos del Campo de Cartagena 69 se identificaron como Phytophthora parasitica.

Coexisten aislados de los dos tipos de compatibilidad genética en la proporción $83 \%$ del tipo A1 y $17 \%$ del tipo A2. ni a $35^{\circ} \mathrm{C}$.

En general los aislados no crecen a $5^{\circ} \mathrm{C}$ ni a $40^{\circ} \mathrm{C}$ y algunos no lo hacen a $10^{\circ} \mathrm{C}$

En condiciones controladas pocos se comportan como patógenos para pimiento al inocularlos por riego al sustrato y son más los que manifiestan una agresividad moderada al inocularlos por decapitación, lo que no ayuda a explicar la muerte de plantas con síntomas de "tristeza" en los invernaderos.

La presencia mayoritaria de $P$. parasitica en los invernaderos del Campo de Cartagena en la actualidad contrasta con los resultados de estudios precedentes en los que solo se encontró $P$. capsici.

\section{CARACTERÍSTICAS DE LA FATIGA DEL SUELO EN LOS INVERNADEROS DE PIMIENTO DEL CAMPO DE CARTAGENA (MURCIA)}

La fatiga de los suelos de los invernaderos con monocultivo de pimiento se muestra específica para el pimiento.

La componente microbiológica parece que es la responsable de la depresión vegetativa de las plantas de pimiento, ya que la fatiga desaparece al desinfectar el suelo con bromuro de metilo o con vapor de agua.

La rotación de cultivos podría paliar los efectos de la fatiga, lo mismo que el aporte de materia orgánica al suelo que se realiza para la biosolarización, actuando como mejoradora de las características físicas del suelo.

\section{BIOSOLARIZACIÓN PARA LA DESINFECCIÓN DE LOS SUELOS DE LOS INVERNADEROS DEL CAMPO DE CARTAGENA}

\section{A. Reiteración de la aplicación 7 años, con reducción de la cantidad de enmienda}

La eficacia de la biosolarización con estiércol fresco de ovino y gallinaza para el control de Meloidogyne incognita se mantiene a niveles aceptables al reiterar la aplicación en el mismo suelo. Aunque presenta algunas deficiencias puntuales, la tendencia es a estabilizarse en el tiempo. 
Se puede reducir la dosis de enmienda orgánica sin que haya pérdida de eficacia desinfectante, manteniendo niveles de cosecha similares al bromuro de metilo, por lo que se puede considerar como un método eficaz de desinfección del suelo.

\section{B. Enmiendas para cultivos ecológicos}

Los pellets de Brassica carinata mejoran la eficacia de la biosolarización en el control de Meloidogyne incognita cuando se mezclan con estiércol fresco de ovino, proporcionando producciones comerciales superiores al bromuro de metilo, siendo una forma de desinfección de suelos de invernaderos ecológicos.

\section{Enmiendas específicas para biosolarización de invernaderos ecológicos}

Enmiendas elaboradas para biosolarizar invernaderos ecológicos con estiércoles y restos de industrias cítricas, restos del procesado del brócoli y de restos de cultivo de brócoli, proporcionaron buenos niveles de control de Meloidogyne incognita y de malas hierbas y producciones similares al bromuro de metilo.

\section{La biosolarización más eficaz que la biofumigación}

La biofumigación con mezcla de estiércol fresco de ovino y gallinaza se mostró ineficaz para el control de Meloidogyne incognita, aunque se repitiera en tres campañas en el mismo suelo, y proporcionó cosechas similares a las del suelo no desinfectado.

La biosolarización mejoró el control del nematodo con el tiempo a niveles similares al bromuro de metilo y las cosechas fueron similares o mayores que las obtenidas en éste.

\section{E. Pellets de Brassica carinata enmienda de biosolarización para el control de patógenos}

Los pellets de Brassica carinata solos o mezclados con estiércol fresco de ovino utilizados como enmienda orgánica en la biosolarización se muestran tan eficaces como el bromuro de metilo en la destrucción del inóculo de Phytophthora capsici si se inicia el proceso en agosto, no diferenciándose del testigo no desinfectado si se inicia en octubre.

La mezcla de pellets de Brassica carinata y estiércol fresco de ovino se mostró tan eficaz como el bromuro en el control de Meloidogyne incognita al iniciar la biosolarización en agosto, mejorando la eficacia de los pellets solos y la del estiércol solo. En octubre la biosolarización no fue eficaz con los pellets solos o mezclados con estiércol.

La biosolarización en agosto proporcionó mayor cosecha comercial que el bromuro de metilo, siendo similar al testigo no desinfectado cuando se inició en octubre. 


\section{F. Pellets de Brassica carinata para el control de nematodos mediante biosolarización repetida}

La biosolarización iniciada en octubre cuando finaliza el ciclo habitual del cultivo de pimiento en los invernaderos del Campo de Cartagena no proporciona aceptables niveles de control de Meloidogyne incognita utilizando pellets de Brassica carinata solos o con estiércol fresco de ovino, aunque se reitere su aplicación tres años consecutivos, reduciéndose significativamente la cosecha comercial.

Por el contrario si se inicia en agosto las producciones son iguales o mayores que las del bromuro de metilo y el control del nematodo mejora a medida que se repite la biosolarización.

La temperatura del suelo alcanzada en el periodo de biosolarización parece ser determinante de la eficacia desinfectante, siendo reducido el efecto de la enmienda. 